ANATÁLIA LARA SILVA

MOAGEM SEMIAUTÓGENA PILOTO DO MINÉRIO DE OURO DA RIO PARACATU MINERAÇÃO 
ANATÁLIA LARA SILVA

\title{
MOAGEM SEMIAUTÓGENA PILOTO DO MINÉRIO DE OURO DA RIO PARACATU MINERAÇÃO
}

\author{
Dissertação apresentada à Escola \\ Politécnica da Universidade de São Paulo \\ para Obtenção do Título de Mestre em \\ Engenharia
}


ANATÁLIA LARA SILVA

\title{
MOAGEM SEMIAUTÓGENA PILOTO DO MINÉRIO DE OURO DA RIO PARACATU MINERAÇÃO
}

\author{
Dissertação apresentada à Escola \\ Politécnica da Universidade de São Paulo \\ para Obtenção do Título de Mestre em \\ Engenharia \\ Área de Concentração: \\ Engenharia Mineral \\ Orientador: \\ Prof. Dr. Homero Delboni Jr.
}


Este exemplar foi revisado e alterado em relação à versão original, sob responsabilidade única do autor e com a anuência de seu orientador.

São Paulo, de agosto de 2012.

Assinatura do autor

Assinatura do orientador

FICHA CATALOGRÁFICA

Silva, Anatália Lara Moagem semiautógena piloto do minério de ouro da Rio

Paracatu Mineração / A.L. Silva. -- ed.rev. -- São Paulo, 2012.

154 p.

Dissertação (Mestrado) - Escola Politécnica da Universidade

de São Paulo. Departamento de Engenharia de Minas e de Petróleo.

1. Cominuição 2. Moagem 3. Planta piloto 4. Ouro Paracatu 
Dedico este trabalho aos meus pais, Odilon e Helena, exemplos de amor e simplicidade, pela compreensão, carinho $e$ incentivo em todos os momentos da minha vida. 


\section{AGRADECIMENTOS}

Ao Professor Doutor Homero Delboni Jr., pela preciosa orientação, pela atenção e pela paciência nos momentos difíceis.

À Rio Paracatu Mineração S/A (Kinross Gold Corporation) e ao Engenheiro Luis Albano Tondo, pela oportunidade de desenvolver este trabalho.

Ao meu irmão Leonardo, companheiro de todas as horas.

A Deus, por ter me dado força e persistência ao longo deste caminho.

A todos aqueles cuja contribuição, direta ou indireta, foi fundamental para a realização deste trabalho. 
"Da mesma forma que a flor tira da terra seu perfume e sua vida, assim a alma tira, da matéria imperfeita e fraca, força e sabedoria".

Gibran Khalil Gibran (Uma lágrima e um sorriso) 


\section{RESUMO}

As moagens autógena ( $A G$ ) e semiautógena ( $S A G)$ mostram-se como opções cada vez mais consideradas na seleção de novos circuitos de cominução. A flexibilidade de operação, assim como a combinação de grandes capacidades de processamento e altas relações de redução obtidas, são algumas das vantagens destes circuitos. Este trabalho procurou descrever o método utilizado na condução de ensaios de moagem semiautógena em escala piloto e de caracterização tecnológica, empregando o minério de ouro da Rio Paracatu Mineração S/A (RPM). A moagem semiautógena foi investigada considerando diferentes condições de operação e às especificidades do minério da RPM. Foram conduzidos 69 ensaios em planta piloto que permitiram o estudo do efeito das variáveis de operação sobre parâmetros de moagem SAG, como taxa de processamento, consumo energético específico, qualidade do produto, entre outros. As informações obtidas na campanha de ensaios em planta piloto e nos trabalhos de caracterização das amostras mostraram-se consistentes e fundamentaram o dimensionamento e projeto do circuito de Expansão da RPM, com capacidade de processamento adicional de $41 \mathrm{Mtpa}$.

Palavras-chave: Cominuição. Moagem. Moagem Semiautógena. Planta Piloto. 


\begin{abstract}
The autogenous (AG) and semi-autogenous (SAG) mills have increasingly been considered options in the selection of new comminution circuits. The flexibility of the operation, as well as the combination of high processing capacity and high reduction rates obtained, are some of the advantages of these circuits. This study sought to describe the method used in conducting semi-autogenous grinding pilot plant and technological characterization, using the gold ore from the Rio Paracatu Mineração S/A (RPM) mine. The semi-autogenous grinding was investigated considering different operating conditions and specific characteristics of the ore from the Rio Paracatu Mineração mine. Were conducted 69 tests in a pilot plant that enabled the study of the effects of the operating variables of the SAG grinding parameters such as processing rates, specific energy consumption, product quality, among others. Information obtained in the test campaign of the pilot plant and the characterization work of the samples were consistent and supported the design and project of the circuit of the expansion of the Rio Paracatu Mineração mine, with additional processing capacity of 41 Mtpy.
\end{abstract}

Key Words: Comminution. Grinding. Semi-autogenous grinding. Pilot plant. 


\section{LISTA DE ILUSTRAÇÕES}

Figura 3.1 Mecanismos de fragmentação

Figura 3.2 Forças que atuam sobre um corpo moedor no interior de um moinho de carga cadente

Figura 3.3 Forças que atuam sobre um corpo moedor no interior de um moinho de carga cadente

Figura 3.4 Moinho de bolas com descarga por diafragma

Figura 3.5 Regime de catarata (a); Regime de cascata (b) 34

Figura 3.6 Diagrama de um circuito fechado normal de moagem 36

Figura 3.7 Moinho de aspecto alto 38

Figura 3.8 Representação esquemática de um moinho semiautógeno

Figura 3.9 Circuito de moagem autógena ou semiautógena em estágio único

Figura 3.10 Circuito de moagem autógena seguida de moagem de pebbles

Figura 3.11 Circuito de moagem autógena seguida de moagem de bolas

Figura 3.12 Circuito de moagem semiautógena seguida de moagem de bolas

Figura 3.13 Circuito de moagem semiautógena com britagem de pebbles e seguida de moagem de bolas

Figura 3.14 Foto do moinho SAG de $34 \times 17,5$ pés da MMIC operado em configuração SABC

Figura 3.15 Dispositivo para a realização do teste de abrasão de Bond

Figura 3.16 Moinho utilizado para ensaios de WI na RPM

Figura 3.17 Dispositivo para realização de ensaio DWT do Laboratório da ALS AMMTEC, Perth - Austrália

Figura 3.18 Representação da relação energia / fragmentação obtida a partir de ensaios para amostras de minérios

Figura 3.19 Correlações entre os parâmetros $A * b, t_{a}$ e WI

Figura 4.1 Localização geográfica da Mina Morro do Ouro (Paracatu - MG)

Figura 4.2 Secção geológica conceitual do depósito de Paracatu .....

Figura 4.3 Grãos de ouro associados à arsenopirita em amostra de minério da RPM

Figura 4.4 Operação em frente de lavra da RPM 
Figura 4.5 Fluxograma simplificado do processo de beneficiamento da RPM ........... 70

Figura 4.6 Vista do moinho de bolas de 16,5 x 25 pés da RPM ............................... 71

Figura 4.7 Fluxograma das etapas de moagem, jigagem e flotação da RPM ............. 73

Figura 4.8 Gráfico de variação do WI e alimentação da RPM no período de 2000 a 2006

Figura 5.1 Peneiramento das amostras de minério: carregamento do "caminhãopeneira"

Figura 5.2 Peneiramento das amostras de minério: separação manual na malha ......

Figura 5.3 Peneiramento das amostras de minério: frações obtidas dispostas em baias

Figura 5.4 Fluxograma de preparação das amostras para os ensaios em planta piloto

Figura 5.5 Parte dos testemunhos de sondagem referentes à amostra tipo 7/8

Figura 5.6 Fração $-153+75 \mathrm{~mm}$, obtida após etapa de preparação da amostra tipo $7 / 8$

Figura 5.7 Uma das configurações da grelha do moinho SAG utilizadas nos ensaios

Figura 5.8 Pesagem de um dos incrementos de minério

Figura 5.9 Introdução do incremento de minério no circuito através da correia transportadora

Figura 5.10 Peneira vibratória utilizada nos ensaios piloto

Figura 5.11 (a) Célula de carga instalada na plataforma do moinho SAG e (b) monitor de leitura do valor da célula de carga instalado em frente à plataforma de alimentação do circuito

Figura 5.12 Gráfico com dados de monitoramento de valores das células de carga e potência para um dos ensaios de moagem SAG conduzidos

Figura 5.13 Distância "d" entre a superfície da carga e o eixo do moinho

Figura 5.14 Monitoramento de potência em vazio do moinho SAG com 70,0\% $\mathrm{n}_{\mathrm{c}}$

Figura 5.15 Prony Brake utilizado nos ensaios

Figura 5.16 Comparação entre potência bruta e total para o ensaio de Prony Brake $78,5 \% \mathrm{n}_{\mathrm{c}}$

Figura 5.17 Fluxograma típico dos ensaios piloto

Figura 5.18 Pontos de amostragem e de adição de água nos ensaios piloto

Figura 5.19 Carga remanescente típica do moinho SAG 
Figura 6.1 Distribuição granulométrica das amostras de minérios utilizadas

Figura 6.2 Correlação entre WI e DWT para amostras de minério da RPM ............... 112

Figura 6.3 Correlação entre PLT e BWI para amostras de minério da RPM .............. 113

Figura 6.4 Vazão de alimentação do circuito SAG para a sequência de ensaios conduzidos

Figura 6.5 Consumo energético específico para a sequência de ensaios conduzidos

Figura 6.6 Resultados de potência líquida, em kW, para a sequência de ensaios conduzidos

Figura 6.7 Resultados de $T_{80}$, em $\mu \mathrm{m}$, para a sequência de ensaios conduzidos ...... 124

Figura 6.8 Consumo energético específico para blendagens de minérios tipos 1 e 5

Figura 6.9 Vazão de alimentação em função do WI da alimentação 128

Figura 6.10 Consumo energético específico em função do WI da alimentação

Figura 6.11 Resultados de $\mathrm{T}_{80}$, em $\mu \mathrm{m}$, para diferentes distribuições e volumes de carga de bolas

Figura 6.12 Consumo energético específico para diferentes cargas de bolas

Figura 6.13 Consumo energético específico para diferentes velocidades de rotação ..

Figura 6.14 $\mathrm{T}_{80}$ para diferentes velocidades de rotação

Figura 6.15 Consumo energético específico e $T_{80}$ para diferentes velocidades de rotação

Figura 6.16 Consumo energético específico e $T_{80}$ para diferentes configurações de circuito

Figura A.1 Esquema do dispositivo de Prony Brake utilizado 


\section{LISTA DE TABELAS}

Tabela 3.1 Classificação da resistência ao impacto como função do parâmetro A * b 56

Tabela 3.2 Classificação da resistência à abrasão como função do parâmetro $t_{a} \ldots . . . . . . . . . .57$

Tabela 5.1 Informações da reserva da RPM no ano de 2002 .................................... 77

Tabela 5.2 Classificação das reservas da RPM em 2002 ......................................... 78

Tabela 5.3 Características gerais dos minérios da RPM selecionados para os ensaios piloto ................................................................................ 78

Tabela 5.4 Blendagens dos minérios da RPM utilizadas nos ensaios piloto ............... 79

Tabela 5.5 Distribuição de carga de bolas tipo 1 utilizada nos ensaios de moagem SAG .......................................................................................... 90

Tabela 5.6 Distribuição de carga de bolas tipo 2 utilizada nos ensaios de moagem SAG

Tabela 5.7 Distribuição granulométrica do material alimentado nos ensaios ............. 92

Tabela 5.8 Distribuição granulométrica do material alimentado nos ensaios .............. 99

Tabela 6.1 Resultados de WI para as faixas granulométricas obtidas na preparação 107

Tabela 6.2 Resultados de WI ponderado e de $F_{80}$ para as amostras ensaiadas ......... 108

Tabela 6.3 Resultados de WI, DWT $\left(A^{*} b\right)$ e $t_{a}$ para as amostras ensaiadas em planta piloto

Tabela 6.4 Resultados de PLT, WI, DWT (A*b) e $t_{a}$ para amostras de minério da RPM

Tabela 6.5 Classificação de amostras da RPM quanto à resistência ao impacto e à abrasão

Tabela 6.6 Resumo dos ensaios em planta piloto conduzidos com minérios da RPM

Tabela 6.7 Classificação dos ensaios piloto, segundo configuração de grelhas do moinho SAG

Tabela 6.8 Classificação dos ensaios piloto, segundo percentual de sólidos na descarga do moinho SAG

Tabela 6.9 Classificação dos ensaios piloto, segundo distribuição e carga de bolas do moinho SAG

Tabela 6.10 Classificação dos ensaios piloto, segundo carga total ocupada do moinho SAG

Tabela 6.11 Classificação dos ensaios piloto, segundo velocidade de rotação do moinho SAG 
Tabela 6.12 Classificação dos ensaios piloto, segundo tipo de configuração do moinho SAG

Tabela 6.13 Sumário das condições operacionais dos ensaios piloto de moagem SAG

Tabela 6.14 Sumário dos tipos e proporções de minérios utilizados nos ensaios piloto de moagem SAG

Tabela 6.15 Comparação entre amostragens realizadas em um mesmo ensaio de moagem SAG

Tabela 6.16 Estatística de alguns parâmetros de moagem SAG, nos 69 ensaios

Tabela 6.17 Resultados de alguns parâmetros de moagem SAG

Tabela 6.18 Valores médios do consumo energético específico para diferentes cargas de bolas

Tabela 6.19 Valores médios de parâmetros de moagem em função da velocidade de rotação

Tabela 6.20 Valores médios de parâmetros de moagem em função da configuração do circuito 


\section{LISTA DE ABREVIATURAS E DE SÍMBOLOS}

A ampère (unidade padrão no sistema internacional para medida de intensidade de corrente)

$\mathrm{Ai} \quad$ índice de abrasão de Bond

ABNT Associação Brasileira de Normas Técnicas

AG moinho(s) autógeno(s)

As arsênio

AVR acidificação, volatilização e reneutralização

CEET2® comminution economic evaluation toll

CETEC Fundação Centro Tecnológico de Minas Gerais

CETEM Centro de Tecnologia Mineral

$\mathrm{CIL} \quad$ carbon in leach

CV cavalo-vapor (unidade de medida de potência)

DWT drop weight test (ensaio de carga cadente)

DWT-S drop weight test simplificado (ensaio de carga cadente simplificado)

Ecs energia específica aplicada (ou consumo energético específico)

EGL effective grinding length

FAB circuito moinho autógeno + moinho de bolas

FAP circuito moinho autógeno + moinho de pebbles

IQ índice de quebra

ISRM International Society for Rock Mechanics

JKRMC Julius Kruttschnitt Mineral Research Center

km quilômetro(s)

$\mathrm{kWh} / \mathrm{t} \quad$ quilowatt-hora por tonelada

Kinross Kinross Gold Corporation

LSC-EPUSP Laboratório de Simulação e Controle da Escola Politécnica da Universidade de São Paulo 


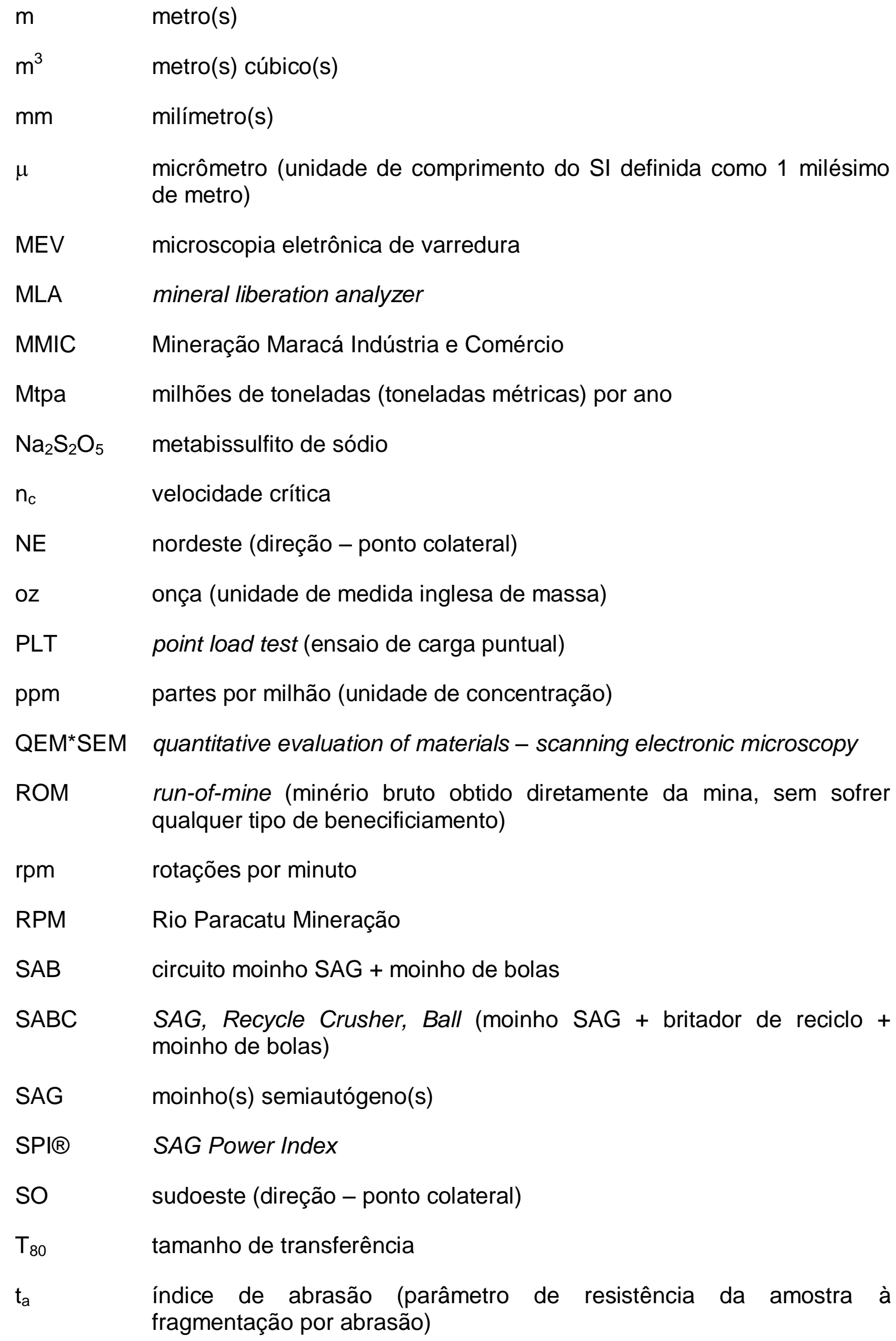


tonelada métrica $(1 \mathrm{ton}=1000 \mathrm{~kg})$

$\mathrm{t} / \mathrm{h}$

tonelada(s) por hora - toneladas métricas por hora

UCS

unconfined compressive strength (resistência à compressão uniaxial)

USP

Universidade de São Paulo

V

volt (unidade de tensão elétrica do sistema internacional de unidades)

vi

volume interno do moinho

WI

work index de Bond (índice de trabalho de Bond) 


\section{SUMÁRIO}

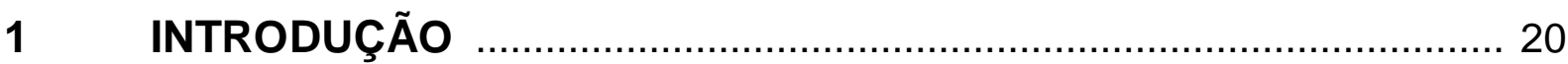

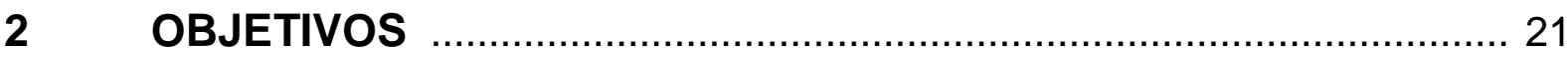

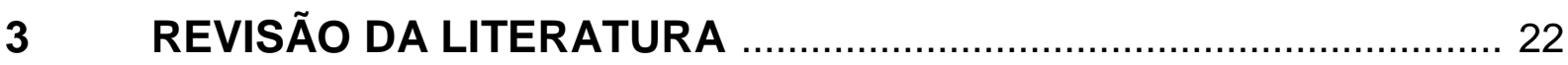

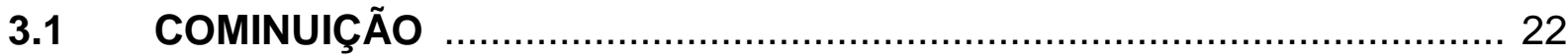

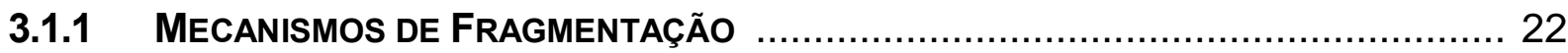

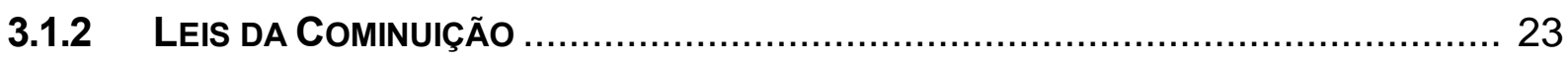

3.1.3 MODELOS DE PROCESSO DE CoMINUIÇÃo ………................................. 25

3.1.3.1 Modelos Fundamentais e Modelos Fenomenológicos .............................. 26

3.1.3.2 Cinética no Processo de Cominuição ................................................... 26

3.1.3.3 Modelo de Balanço Populacional ........................................................ 27

3.1.3.4 Modelo de Misturador Perfeito ........................................................... 28

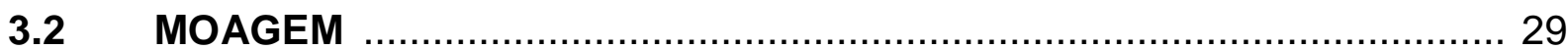

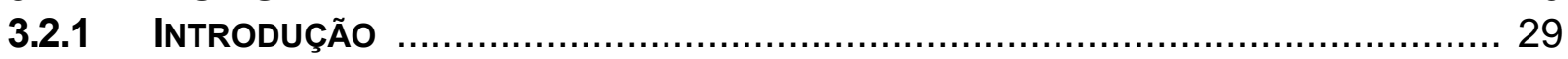

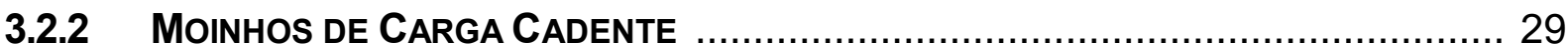

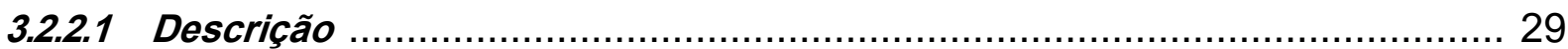

3.2.2.2 Características Construtivas dos Moinhos .............................................. 31

3.2.2.3 Regimes de Operação dos Moinhos .................................................... 33

3.2.2.4 Operação de Circuitos de Moagem ……............................................ 34

3.3 MOAGEM AUTÓGENA E MOAGEM SEMIAUTÓGENA …...................... 37

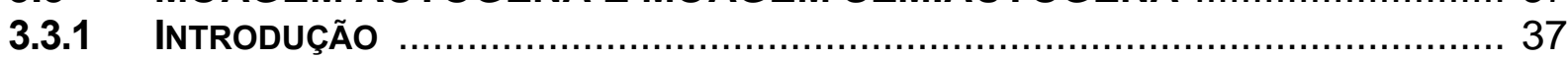

3.3.2 MoINHOS AUtógeNOS E SEMIAUTÓGENOS …............................................ 37

3.3.3 CaRACTERÍSTICAS GERAIS DoS EQUIPAMENTOS ...................................... 39

3.3.4 Configuração de Circuitos de Moagem Autógena e Semiautógena ....... 42

3.3.4.1 Circuito em Estágio Único ................................................................. 42

3.3.4.2 Circuito Moinho Autógeno + Moinho de Pebbles (FAP) .......................... 43

3.3.4.3 Circuito Moinho Autógeno + Moinho de Bolas (FAB) ............................... 44

3.3.4.4 Circuito Moinho SAG + Moinho de Bolas (SAB) .................................. 45

3.3.4.5 Circuito Moinho SAG + Britador de Reciclo + Moinho de Bolas (SABC) ...... 46

3.3.5 Operação de Circuitos de Moagem Autógena e Semiautógena ............... 48

3.4 ENSAIOS E CARACTERIZAÇÃO DO MINÉRIO QUANTO À

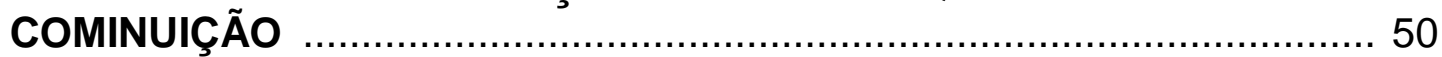

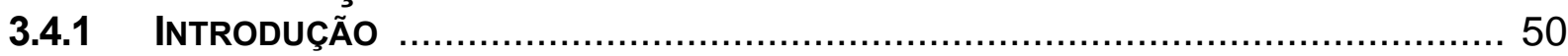

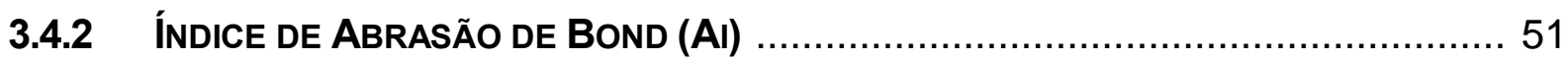

3.4.3 ENSAIO DE BOND PARA MOINHO DE BOLAS (WI) …................................ 52

3.4.4 ENSAIOS DE CARGA CADENTE OU DROP WEIGHT TEST (DWT) ...................... 53

3.4.4.1 Ensaio Drop Weight Test Simplificado (DWT-S) ..................................... 56

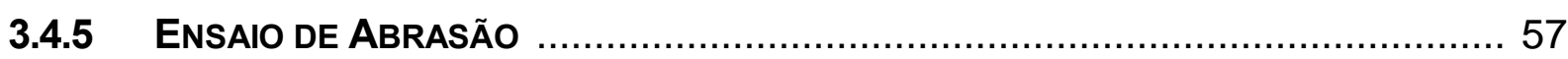

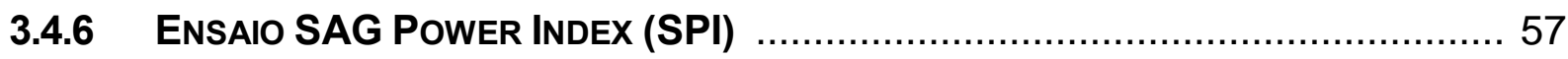

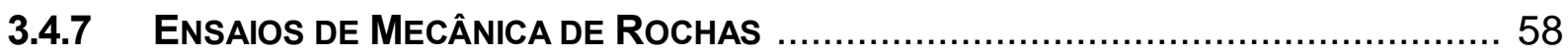




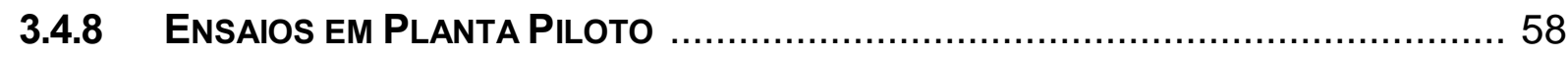

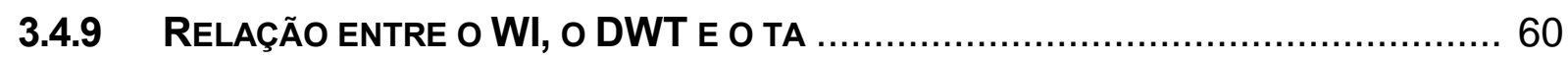

3.5 FATORES QUE INFLUENCIAM A SELEÇÃO E O DIMENSIONAMENTO DE CIRCUITOS DE COMINUIÇÃO ....................... 60

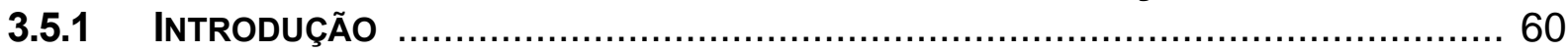

3.5.2 INTERPRETAÇÃo GEOLÓGICA E REQUISITOS DE AMOSTRAGEM .......................61 61

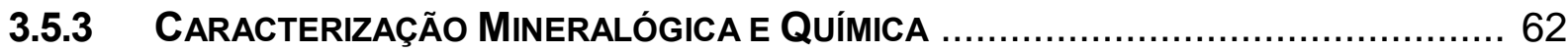

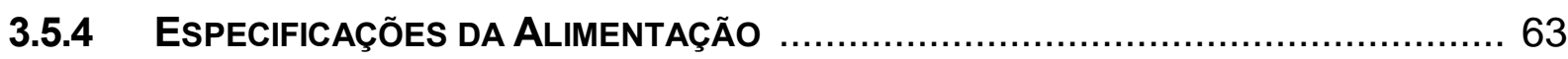

3.5.5 InfluênCIA do CIRCUITO de Cominuição nos Processos MetalúRgicos .... 63

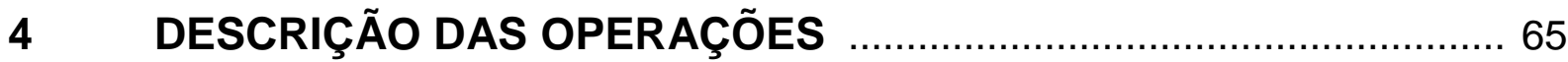

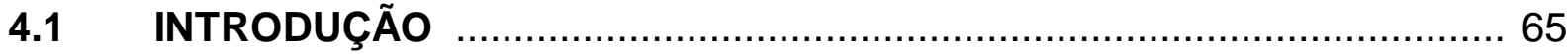

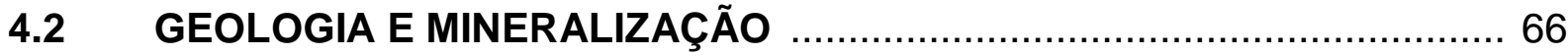

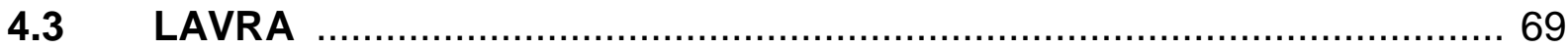

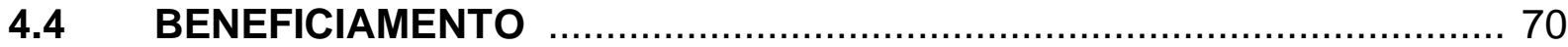

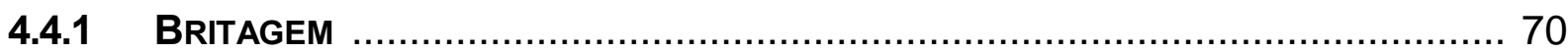

4.4.2 MOAGEM, CLASSIFICAÇÃO, FLotAÇÃo E JIGAGEM ................................... 71

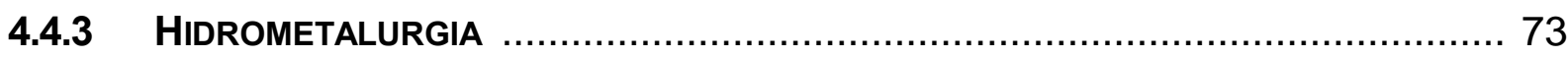

4.4.4 TRATAMENTO E DISPOSIÇÃo DE REJEITO ………..................................... 74

4.5 MOTIVAÇÕES PARA O ESTUDO ………....................................... 75

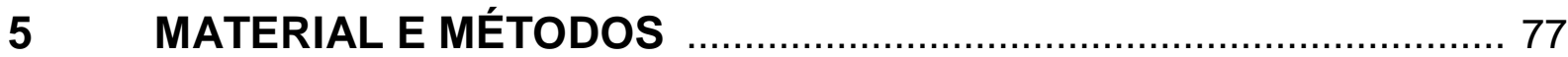

5.1 OBJETIVOS DOS ENSAIOS EM PLANTA PILOTO E DE
CARACTERIZAÇÃO DAS AMOSTRAS .......................................... 77

5.2 MINÉRIOS EMPREGADOS NOS ENSAIOS ....................................... 77

5.3 PREPARAÇÃO DAS AMOSTRAS DE MINÉRIOS PARA OS ENSAIOS EM PLANTA PILOTO ……........................................................... 79

5.3.1 PREPARAÇÃo de AMOSTRAS de SUPERFíCIE ……................................ 79

5.3.2 PreparaÇÃo de Amostras de Testemunhos de SondAGEM ..................... 82

5.4 CARACTERIZAÇÃO DAS AMOSTRAS DE MINÉRIOS UTILIZADAS

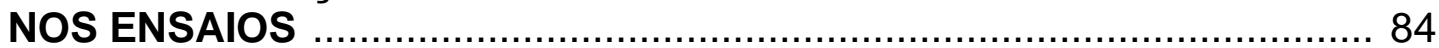

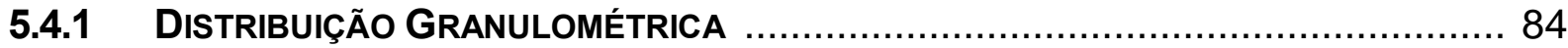

5.4.2 ENSAIO DE BOND PARA MOINHO DE BOLAS (WI) …................................. 85

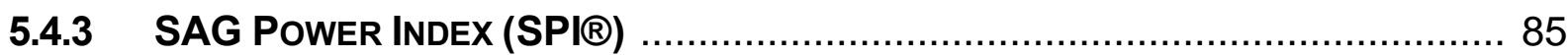

5.4.4 DROP WEIGHT TEST (DWT) E POINT LOAD TEST (PLT) .............................. 85

5.4.5 DESCRIÇÃO DAS AMOSTRAS DE SONDAGEM ............................................ 86

5.5 ENSAIOS DE MOAGEM SEMIAUTÓGENA EM PLANTA PILOTO ..........8 86

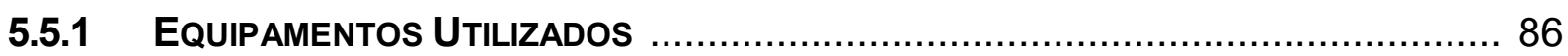

5.5.2 INSTRUMENTAÇÃO E SISTEMAS DE MONITORAMENTO ................................. 87

5.5.3 MATERIAL E EQUIPAMENTOS COMPLEMENTARES UTILIZADO NOS ENSAIOS ....... 88

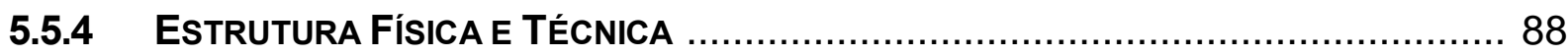

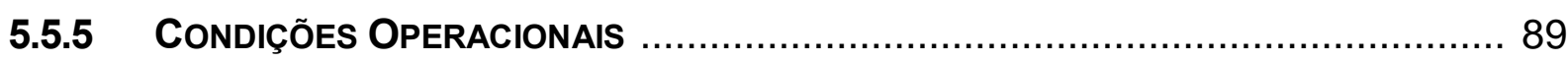




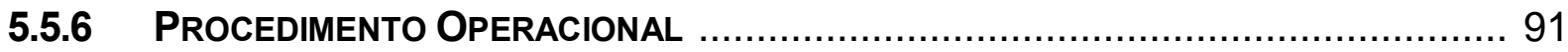

5.5.6.1 Condução dos Ensaios ............................................................. 91

5.5.6.2 Controle do Percentual de Sólidos na Descarga do Moinho SAG .............. 95

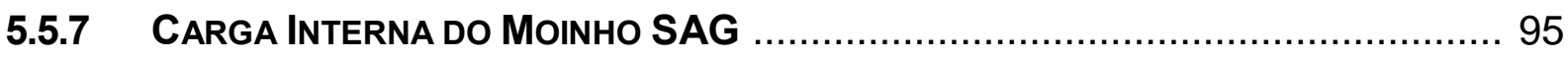

5.5.7.1 Sistema de Pesagem da Carga do Moinho SAG .................................... 95

5.5.7.2 Medições do Volume da Carga Interna .............................................. 96

5.5.7.3 Retirada da Carga Interna do Moinho SAG ......................................... 98

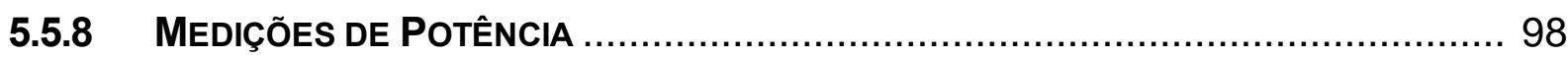

5.5.8.1 Medição de Potência Durante os Ensaios ................................................ 98

5.5.8.2 Medição de Potência em Vazio .......................................................... 99

5.5.8.3 Ensaio de Prony Brake ................................................................ 100

5.5.9 AMOSTRAGEM Do CIRCUITo PILOTO ..................................................... 102

5.5.9.1 Amostragem dos Fluxos ............................................................ 102

5.5.9.2 Medições de Vazão de Sólidos e de Polpa ........................................... 103

5.5.10 Processamento e Caracterização das Amostras Obtidas nos

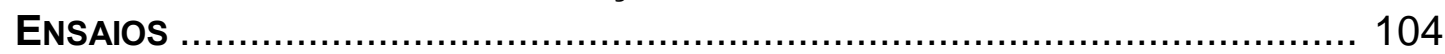

5.5.10.1 Classificação da Carga Interna ......................................................... 104

5.5.10.2 Determinações Granulométricas ...................................................... 105

5.5.10.3 Determinação do Índice de Moabilidade para o Produto de Moagem ......... 106

5.5.10.4 Análises Químicas ....................................................................... 106

5.5.10.5 Determinação do Percentual de Sólidos .............................................. 106

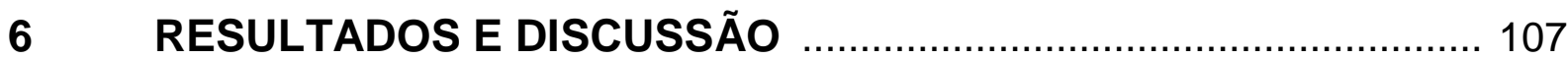

6.1 CARACTERIZAÇÃO DAS AMOSTRAS DE MINÉRIOS UTILIZADAS

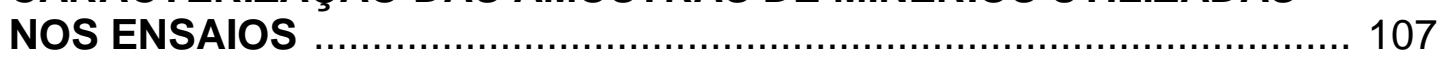

6.1.1 DiSTRIBUIÇÃo GRANULOMÉTRICA E BOND WORK INDEX (WI) ..................... 107

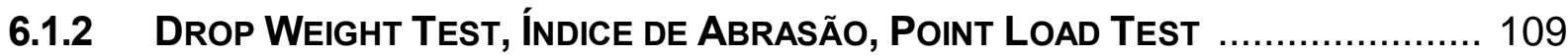

6.2 ENSAIOS EM PLANTA PILOTO ................................................... 113

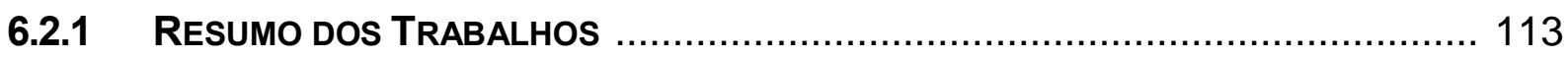

6.2.2 Protocolo de Amostragem e EstabilizaÇÃo da OPeração ................... 121

6.2.3 RESULTADOS DOS ENSAIOS: ASPECTOS GERAIS ................................... 122

6.2.4 RESULTADOS DOS ENSAIOS: ASPECTOS ESPECÍFICOS .............................. 127

6.24.1 Efeito da Blendagem e Tipos de Minérios ............................................ 127

6.24.2 Efeito da Tenacidade da Alimentação de Minérios .................................. 128

6.24.3 Efeito da Distribuição de Carga de Bolas ............................................. 129

6.24.4 Efeito da Carga de Bolas ............................................................... 130

6.24.5 Efeito da Velocidade de Rotação do Moinho SAG ................................. 131

6.24.6 Efeito do Tipo de Circuito de Moagem SAG ....................................... 133

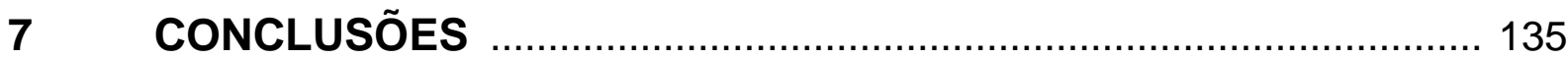

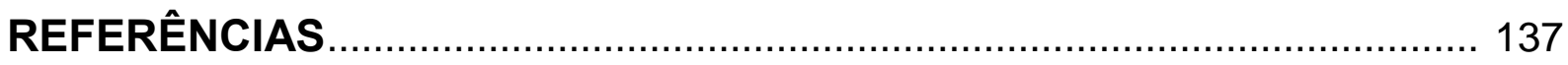

APÊNDICE A - Utilização do Freio Prony …....................................... 141

APÊNDICE B - Exemplo: Informações Referentes à um Ensaio Piloto 144

APÊNDICE C - Sumário dos Resultados Obtidos nos Ensaios Piloto . 147 


\section{INTRODUÇÃO}

A busca por empreendimentos cada vez mais eficientes - tanto do ponto de vista técnico quanto no que concerne aos aspectos econômicos - tem marcado todos os setores produtivos desde as últimas décadas do século XX. No setor mineral, essa busca tem sido traduzida no desenvolvimento de plantas de tratamento de minério com elevada capacidade de processamento.

Nesse cenário, cujo principal objetivo é a economia de escala, os novos circuitos - ou a expansão dos circuitos existentes - caracterizam-se predominantemente pela utilização de equipamentos de grande porte. Os projetos devem apresentar confiabilidade e baixos custos de operação, além de adequação às normas de segurança e de impacto ambiental.

Os moinhos autógenos (AG) e semiautógenos (SAG), de dimensões e potência cada vez maiores e elevada capacidade de processamento - possibilitando alimentação de material mais grosseiro e geração de produto para alimentação de moagem secundária ou de produto final em circuitos de estágio único de moagem estão presentes em muitos dos grandes projetos de mineração. A flexibilidade, que abrange o tratamento de vários tipos de minérios - inclusive os friáveis-, constitui uma vantagem adicional para a moagem semiautógena.

Além disso, o processo de desenvolvimento e escolha do melhor circuito de cominuição para um determinado empreendimento mineiro não é simples, pois contempla etapas como interpretação de dados geológicos, caracterizações físicas e químicas, ensaios em escala de bancada e ensaios em planta piloto.

Essas são apenas algumas das razões que justificam o estudo dos processos de moagem autógena e semiautógena como alternativas de cominuição para diferentes tipos de minérios. 


\section{OBJETIVOS}

Com base na constatação apresentada ao final da seção anterior, o objetivo geral do presente trabalho foi estabelecer um método para analisar a viabilidade técnica de utilização da moagem semiautógena de minério na Rio Paracatu Mineração (RPM). Mas, para efetivamente subsidiar o projeto de expansão do circuito industrial de moagem da RPM - de 18 milhões de toneladas métricas por ano (Mtpa) processadas para uma capacidade nominal de 61 Mtpa -, esse método deve ser suficientemente robusto para gerar dados e informações consistentes.

Assim sendo, as propriedades singulares do minério da RPM foram objetos de ensaios de caracterização específicos. Os resultados serviram de base para determinar a configuração de circuito que permitisse processar taxas elevadas de alimentação em equipamentos de grande porte.

No contexto desse objetivo geral, incluem-se os objetivos específicos a seguir elencados:

- Apresentar o método adotado para o estudo da moagem semiautógena em planta piloto do minério da Rio Paracatu Mineração. No cenário brasileiro, marcado pela escassez de investigações sobre esse método e pela profusão de projetos novos e de expansão das operações existentes, tal descrição poderá ser utilizada como referência para futuros estudos.

- Possibilitar melhor entendimento das características de fragmentação do minério da Rio Paracatu Mineração.

- Produzir informações que apresentem solidez para a avaliação e o dimensionamento do circuito de moagem semiautógena voltada ao aumento da capacidade de processamento da RPM.

- Analisar o efeito dos diferentes tipos de variáveis sobre os parâmetros da moagem semiautógena. 


\section{REVISÃO DA LITERATURA}

Neste capítulo é apresentada uma revisão da literatura e dos conceitos referentes à cominuição com ênfase à moagem, e em especial, à moagem autógena e semiautógena. Os ensaios de caracterização para circuitos de cominuição e os fatores que influenciam esses tipos de circuito serão também descritos.

\subsection{COMINUIÇÃO}

Originária do latim - comminuere -, a palavra cominuição" significa "fazer menor". A cominuição é uma atividade que acompanha o homem desde a sua préhistória englobando, na área de mineração, as operações unitárias de britagem, moagem e classificação (NAPIER-MUNN et al., 1999).

Cominuição pode ser definida como o conjunto de operações de redução de tamanho de partículas minerais, executado de forma controlada e de modo a atingir um objetivo pré-determinado, controlando o tamanho máximo dos produtos e a geração de quantidades excessivas de finos.

Etapa determinante no processamento de minérios, a cominuição absorve a maior parte da energia consumida por uma usina de tratamento de minérios, e também é responsável pela maior parte dos custos operacionais desse setor de atividade.

\subsubsection{MeCANismos de FragmentaÇão}

Os métodos de cominuição podem ser classificados de acordo com a granulometria do minério e com os mecanismos de fragmentação envolvidos. A britagem, utilizada em etapas nas quais o minério encontra-se em maior granulometria, reduz o tamanho das partículas por mecanismos de compressão e impacto. Já na moagem, o principal mecanismo de fragmentação é a abrasão, e o produto obtido é da ordem de centenas ou dezenas de micrômetros.

1 Cominuição: 1 Ato ou efeito de cominuir; fragmentação; trituração; pulverização. 2 Diminuição gradual pela remoção sucessiva de pequenas partículas; desgaste. $3 \mathrm{Med}$ Fratura em vários pequenos pedaços (de um osso, $p$ ex) (FERREIRA, 1999). 
Os principais mecanismos de fragmentação envolvidos na cominuição são sumarizados a seguir (BERALDO, 1987) e ilustrados na Figura 3.1.

- IMPACtO: quando a força é aplicada de forma rápida e com intensidade bem superior à resistência da partícula.

- COMPRESSÃo: a força é aplicada de forma lenta, promovendo a propagação de fraturas que aliviam os esforços.

- ATRIÇÃO / ABRASÃO: a concentração localizada de esforços provoca o surgimento de pequenas fraturas superficiais, com pequena diminuição de tamanho da partícula original e geração de partículas finas.

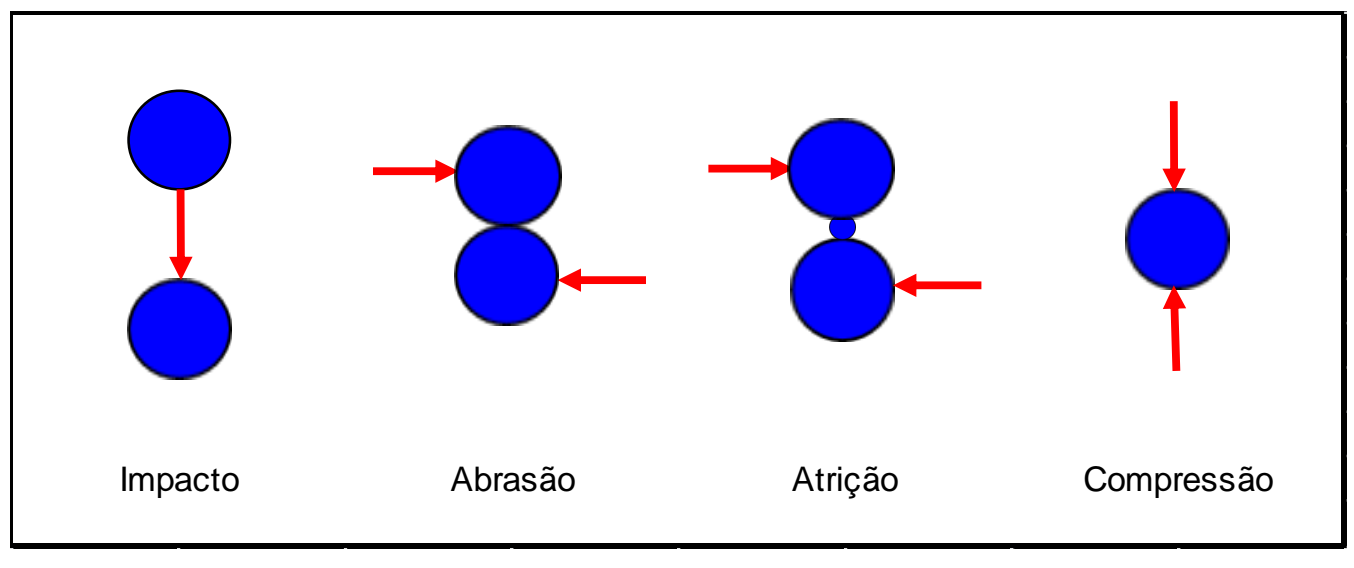

Adaptado de Delboni Jr. e Morrel (2002)

Figura 3.1 - Mecanismos de fragmentação.

\subsection{LEIS DA COMINUIÇÃO}

Em 1937, Walker (apud JANKOVIK; DUNDAR; MEHTA, 2010) propôs uma equação para relacionar, de forma geral, a fragmentação e a energia consumida com o tamanho da partícula.

$d E=-k \frac{d x}{x^{n}}$

onde:

$\mathrm{dE}=\quad$ incremento de energia aplicada a uma massa unitária de minério;

$\mathrm{X}=\quad$ tamanho das partículas;

$\mathrm{dx}=\quad$ incremento na diminuição de tamanho das partículas;

$\mathrm{ke} n=$ constantes do minério 
Substituindo-se - na Equação (1) - o valor da constante $\underline{n}$ pelos valores 2, 1 e 1,5 e calculando a integral dessa equação, obtêm-se as relações de Rittinger, Kick e Bond, respectivamente.

\section{LEI DE RITTINGER}

A primeira lei de cominuição, apresentada por P. Ritter Von Rittinger em 1867, considera que "a energia específica consumida na redução de tamanho de um sólido é diretamente proporcional à nova superfície específica gerada". Essa relação, que estabelece que a área da nova superfície, produzida pela fragmentação, é diretamente proporcional ao trabalho útil consumido, é expressa por:

$$
E=k\left(\frac{1}{x_{P}}-\frac{1}{x_{A}}\right)
$$

onde:

$E=\quad$ energia consumida;

$\mathrm{k}=\quad$ parâmetro característico do minério;

$x_{p}=$ tamanho das partículas depois da cominuição - produto;

$\mathrm{x}_{\mathrm{a}}=\quad$ tamanho das partículas antes da cominuição - alimentação

LEI DE KICK

Kirpichev, em 1874, e posteriormente Kick, em 1885, propuseram independentemente - uma segunda teoria. Essa segunda lei de cominuição, conhecida com Lei de Kick, estabelece que "a energia requerida na cominuição é proporcional ao volume das partículas envolvidas" e é expressa na seguinte relação:

$$
E=k \times \ln \left(\frac{x_{A}}{x_{P}}\right)
$$

onde:

$\mathrm{k}=\quad$ parâmetro característico do minério;

$X_{p}=$ tamanho das partículas depois da cominuição - produto;

$\mathrm{X}_{\mathrm{a}}=\quad$ tamanho das partículas antes da cominuição - alimentação 


\section{LEI DE BOND}

Com base em trabalhos experimentais e na análise de processos industriais, em 1952 F. C. Bond apresentou a terceira lei da cominuição, que estabelece que "a energia requerida por tonelada de minério é proporcional ao diâmetro das partículas" e é expressa por:

$$
E=k\left[\left(\frac{1}{\sqrt{x_{P}}}\right)-\left(\frac{1}{\sqrt{x_{A}}}\right)\right]
$$

onde:

$\mathrm{k}=\quad$ parâmetro característico do minério;

$\mathrm{X}_{\mathrm{P}}=\quad$ tamanho das partículas depois da cominuição - produto;

$\mathrm{X}_{\mathrm{a}}=$ tamanho das partículas antes da cominuição - alimentação

O parâmetro característico do material $(k)$ é conhecido como índice de trabalho (work index - WI) e determinado por meio de um ensaio padronizado em laboratório, segundo a Norma Técnica MB 3253 (Associação Brasileira de Normas Técnicas - ABNT, 1990).

Austin considerou novas aproximações contemplando as aplicações e restrições de cada uma das expressões. Autores como Klimpel e Broadbent, entre outros, também estudaram expressões e relações matemáticas para a cominuição.

As aplicações das leis de Bond (1952) e Rittinger (1867) em diferentes tipos de minérios têm sido investigadas por outros autores. Exemplo disso é o trabalho de Jankovic, Dundard e Mehta (2010), que avaliaram a relação entre a energia e a distribuição de tamanho do produto da cominuição em minério de magnetita. Nesse estudo, a equação de Rittinger representou bem os dados experimentais, enquanto a equação de Bond não se mostrou adequada.

\subsubsection{Modelos de Processos de Cominuição}

A modelagem de processos de cominuição objetiva a compreensão dos fenômenos envolvidos nessa etapa. Os dois tipos de modelos que têm sido aplicados na indústria mineral são os modelos fundamentais e os modelos fenomenológicos: 


\subsubsection{Modelos Fundamentais e Modelos Fenomenológicos}

Os modelos fundamentais consideram todos os elementos inerentes ao processo e os detalhes envolvidos nos eventos de fragmentação. Alicerçados na mecânica newtoniana, os modelos fundamentais consideram diretamente as interações entre as partículas minerais e os elementos do equipamento. Assim sendo, esses modelos possibilitam a avaliação detalhada da interação do moinho com o minério e os corpos moedores, além da estimativa do consumo energético.

Denominados Black Box Models, os modelos fenomenológicos permitem prever a distribuição granulométrica do produto a partir da distribuição granulométrica da alimentação, da caracterização da fragmentação e de experiências anteriores com equipamentos similares. Os Black Box Models - que consideram o equipamento de cominuição como um elemento de transformação da distribuição da granulometria da alimentação (FOGGIATTO, 2009) - podem ser expressos pela seguinte equação (NAPIER-MUNN, 1999).

$$
p=F(a, b, m, s, C)
$$

onde:

p e $\mathrm{a}=$ distribuição do produto e da alimentação, respectivamente;

$\mathrm{b}=\quad$ matriz ou vetor normalizado de quebra;

$\mathrm{m}=$ fator relacionado ao equipamento;

$\mathrm{S}=\quad$ condições de operação, incluindo a vazão de alimentação;

$\mathrm{C}=$ conjunto de parâmetros experimentais derivados de outros equipamentos.

As partículas no equipamento podem ser consideradas perfeitamente misturadas (Modelo do Misturador Perfeito - Perfect Mixing Model) ou com movimentos diferenciais (Modelo Cinético).

\subsubsection{Cinética no Processo de Cominuição}

Esses modelos apresentam similaridade quanto aos conceitos da cinética do processo de cominuição, e apresentam as três funções descritas a seguir:

- FUNÇÃO SELEÇÃO: representa a probabilidade que uma partícula tem de sofrer o processo de cominição, sendo expressa pela relação entre a massa que foi cominuída e a massa inicial de material em uma dada faixa granulométrica. A 
Função Seleção ou Velocidade de Quebra é função do material e das condições de moagem, em especial da energia do moinho (BERALDO, 1987).

- FUNÇão QUEBRA (Appearance Function ${ }^{2}$ ): é definida como a distribuição granulométrica das partículas proveniente da quebra primária de uma partícula maior. Essa função, que se constitui em uma característica do minério, é usualmente determinada em laboratório, por meio de ensaios em um moinho padrão ou por retrocálculo.

- FUNÇÃO CLASSIFICAÇÃO: depois de uma série de eventos de quebra, cada fração é submetida a um processo de classificação antes de ser submetida ao próximo estágio de quebra. Com isso, as partículas mais grossas são retidas e impedidas de passar para o próximo estágio de quebra. Essa função, pouco importante no moinho de bolas, é essencial no moinho de barras, no qual ocorre uma acentuada quebra de partículas grossas em virtude da classificação do material efetuada pelas barras (BERALDO, 1987).

Outra premissa importante na avaliação da cinética de processos de cominuição é o tempo de residência, também denominado tempo de permanência. Essa variável considera que as partículas da alimentação não mantêm exatamente a mesma velocidade ao longo do moinho, havendo sempre uma mistura na direção do eixo.

\subsubsection{Modelo de Balanço Populacional}

O modelo de Balanço Populacional (Population Balance Model), introduzido por Epstein em 1947 (apud NAPIER-MUNN et al., 1999), descreve o processo de moagem em sucessivos eventos de quebra das partículas. Esse modelo é um modelo de taxa de primeira ordem, de vez que assume que a produção de material cominuído em um intervalo de tempo depende da massa da fração granulométrica considerada. Cada fração granulométrica corresponde a uma constante que caracteriza a taxa de desaparecimento, denominada taxa de quebra e expressa por:

Massa Moída $=k_{i} \times s_{i}$

onde:

$\mathrm{k}_{\mathrm{i}}=\quad$ taxa de quebra da i-ésima fração granulométrica da carga do moinho, $\min ^{-1}$;

$s_{i}=\quad$ massa da i-ésima fração granulométrica da carga do moinho, $\mathrm{kg}$.

2 Tradução literal: função aparecimento. 
A premissa de quebra de primeira ordem apresenta como vantagem a simplificação do modelo, mas sua aplicação em faixas granulométricas muito amplas apresenta limitações. Por assumir que o número de impactos em cada intervalo de energia se mantém aproximadamente constante, ela não é válida quando a quantidade de partículas é muito superior ou inferior ao número de impactos.

\subsubsection{Modelo de Misturador Perfeito}

Desenvolvido por Whiten em 1976 (apud NAPIER-MUNN et al., 1996), o Modelo de Misturador Perfeito considera o conteúdo do moinho como perfeitamente misturado o que implica que, para cada faixa granulométrica, a carga desse equipamento está relacionada com o produto através de uma taxa de descarga.

$$
p_{i}=d_{i} \times s_{i}
$$

onde:

$\mathrm{p}_{\mathrm{i}}=\quad$ vazão de sólidos do produto do equipamento correspondente à i-ésima faixa granulométrica;

$\mathrm{d}_{\mathrm{i}}=\quad$ descarga correspondente a i-ésima faixa granulométrica;

$s_{i}=\quad$ massa da carga do moinho correspondente à i-ésima faixa granulométrica.

O Modelo do Misturador Perfeito também se baseia no balanço de massa para as faixas granulométricas, descrito pela seguinte equação:

$$
f_{i}+\sum_{j=1}^{i}\left[\frac{a_{i j} r_{j} p_{j}}{d_{j}}\right]=p_{i}+\frac{r_{i} p_{i}}{d_{i}}
$$

O parâmetro principal do modelo, a razão $\mathrm{r} / \mathrm{d}$, pode ser retrocalculada por meio de amostragens e estimativas das distribuições granulométricas da alimentação e do produto do moinho.

A normalização do parâmetro r/d é conduzida para corrigir as variações no tempo de residência médio das partículas no interior do moinho. A normalização do parâmetro r/d é representada pela equação:

$\frac{r_{i}}{d_{i}}=\frac{r_{i}}{d_{i}^{*}} \times\left(\frac{D^{2} L}{4 Q}\right)$ 
onde:

$\mathrm{D}=\quad$ diâmetro interno do moinho, em m;

$\mathrm{L}=\quad$ comprimento interno do moinho, em $\mathrm{m}$;

$\mathrm{Q}=\quad$ vazão volumétrica da alimentação do moinho, em $\mathrm{m}^{3} / \mathrm{h}$.

O parâmetro $\mathrm{r} / \mathrm{d}^{*}$ representa as características do equipamento e da interação entre o equipamento e o minério.

\subsection{MOAGEM}

\subsubsection{INTRODUÇÃO}

Os métodos de cominuição são classificados, de acordo com a granulometria do minério e os mecanismos de fragmentação, em britagem e moagem.

A britagem é utilizada nos estágios em que o minério é mais grosseiro. As partículas são reduzidas a tamanhos da ordem de centímetros pelas forças de compressão e de impacto.

Caracterizada por se valer da abrasão como principal mecanismo de fragmentação para a geração de partículas finas - da ordem de centenas ou dezenas de micrômetros -, a moagem é a etapa que requer maior gasto operacional de energia elétrica e revestimentos. O desempenho da moagem é determinante nos processos de concentração subsequentes. Se for insuficiente, resultando em produto relativamente mais grosso - muitas vezes com liberação insuficiente do mineral útil ou de ganga -, a recuperação metalúrgica pode sofrer efeito deletério. Já a geração de finos em excesso não só prejudica a recuperação metalúrgica nas etapas de concentração, como eleva os custos da própria moagem.

\subsubsection{Moinhos de Carga Cadente}

\subsection{Descrição}

Os moinhos de carga cadente são constituídos por uma carcaça cilíndrica de aço revestida internamente com placas de aço ou borracha, parcialmente preenchida com corpos moedores - que consistem de barras, bolas, seixos, o próprio minério, 
entre outros -, que gira sobre mancais (CHAVES; PERES, 2006). Esses moinhos são, portanto, cilindros rotativos que realizam o trabalho de cominuição pela ação dinâmica dos corpos moedores - carga - que se encontram em seu interior.

O movimento da carcaça eleva os corpos moedores até uma altura prédeterminada, de onde caem. O movimento de queda da carga pode ser classificado como em cascata ou catarata. No primeiro tipo, ao atingirem o ponto mais alto os corpos moedores rolam sobre a própria carga. No movimento de catarata, os corpos moedores desprendem-se e são lançados segundo uma trajetória parabólica.

Os corpos moedores acompanham o movimento da carcaça percorrendo uma trajetória circular, na qual permanecem enquanto a componente centrífuga for maior que a componente força da gravidade. Em um determinado momento, quando a componente força da gravidade se torna maior que a centrífuga, os corpos moedores abandonam o movimento circular e passam a seguir a trajetória parabólica. As forças que atuam sobre um corpo moedor no interior de um moinho são apresentadas, sob a forma de diagrama, na Figura 3.2.

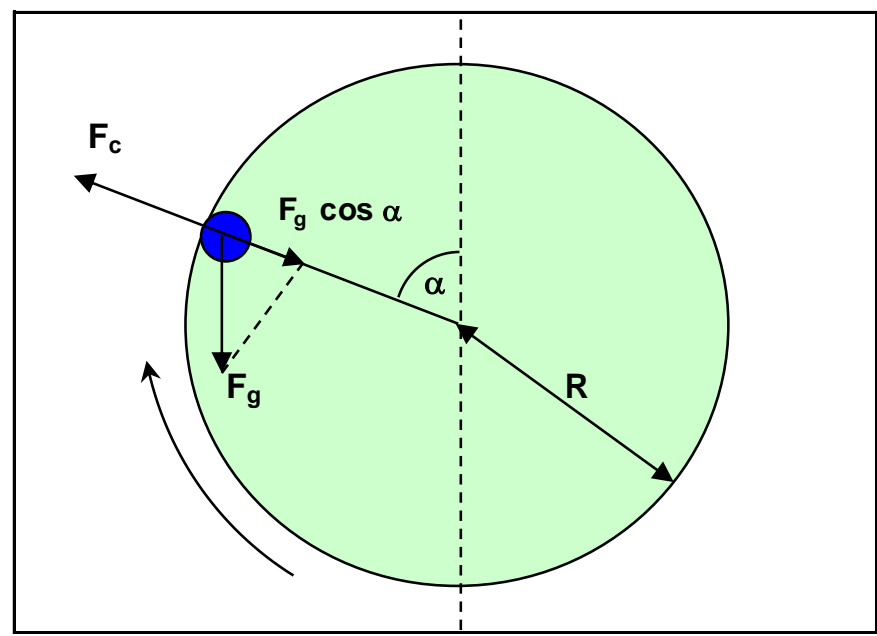

Figura 3.2 - Forças que atuam sobre um corpo moedor no interior de um moinho de carga cadente.

Com o aumento da velocidade do moinho, tem-se um instante em que o corpo moedor fica preso à carcaça, pela ação da força centrífuga, durante a volta completa do cilindro. Nesse instante, as forças peso e centrífuga se igualam, conforme apresentado na Figura 3.3. 


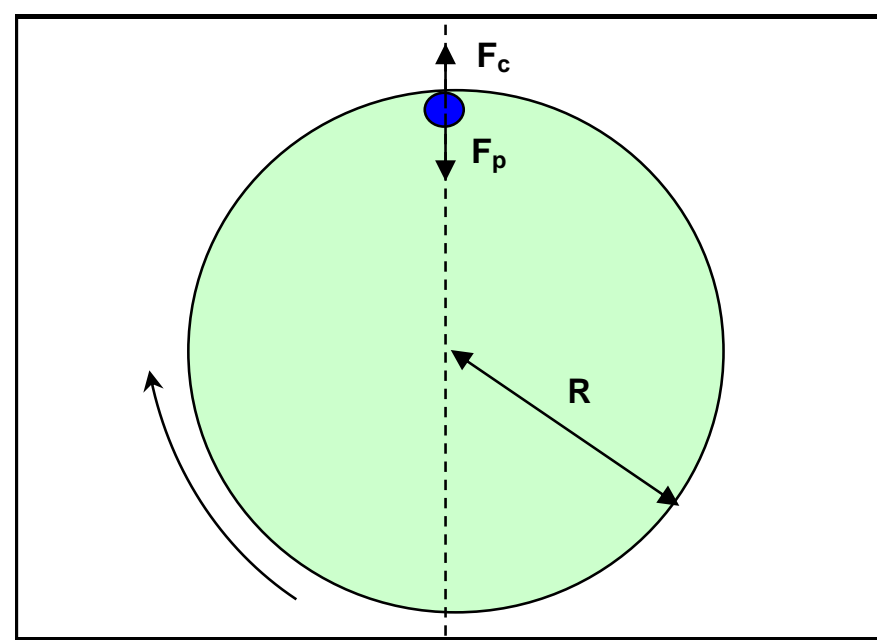

Figura 3.3 - Forças que atuam sobre um corpo moedor no interior de um moinho de carga cadente.

A velocidade em que as forças peso e centrífuga se igualam, denominada velocidade crítica $\left(\mathrm{n}_{\mathrm{c}}\right.$ em rpm), é calculada conforme expressões deduzidas na sequência. O percentual da velocidade crítica é utilizado para referenciar a operação dos moinhos (LUZ; SAMPAIO; ALMEIDA, 2004).

$F_{c}=F_{p}$

$\frac{m v^{2}}{r}=m g$

$v^{2}=m g$

$v=2 \pi r n$

$(2 \pi r n)^{2}=r g$

$n=\frac{1}{2 \pi} \sqrt{\frac{g}{r}}$

ou $n_{c}=\frac{42,3}{\sqrt{2 r}}$, quando $r$ é dado em $\mathrm{m}$ e $\mathrm{n}_{\mathrm{c}} \mathrm{em} \mathrm{m} / \mathrm{s}$

\section{Características Construtivas dos Moinhos}

Os moinhos de carga cadente têm o seu tamanho expresso pelo diâmetro e comprimento da carcaça. No caso do diâmetro, as dimensões são expressas em termos de valores interno à carcaça ou interno ao revestimento. No caso do 
comprimento utilizam-se também, além desses dois termos, as dimensões flange-aflange e effective grinding length (EGL).

Construídas para suportar o impacto das cargas, as carcaças dos moinhos são usualmente fabricadas em chapas de aço-carbono, calandradas e soldadas. As cabeceiras ou tampas são fabricadas em aço fundido ou ferro fundido nodular em uma só peça, e ligadas ao cilindro por meio de flanges aparafusados (BERALDO, 1987). A Figura 3.4 apresenta o desenho de um moinho de bolas.

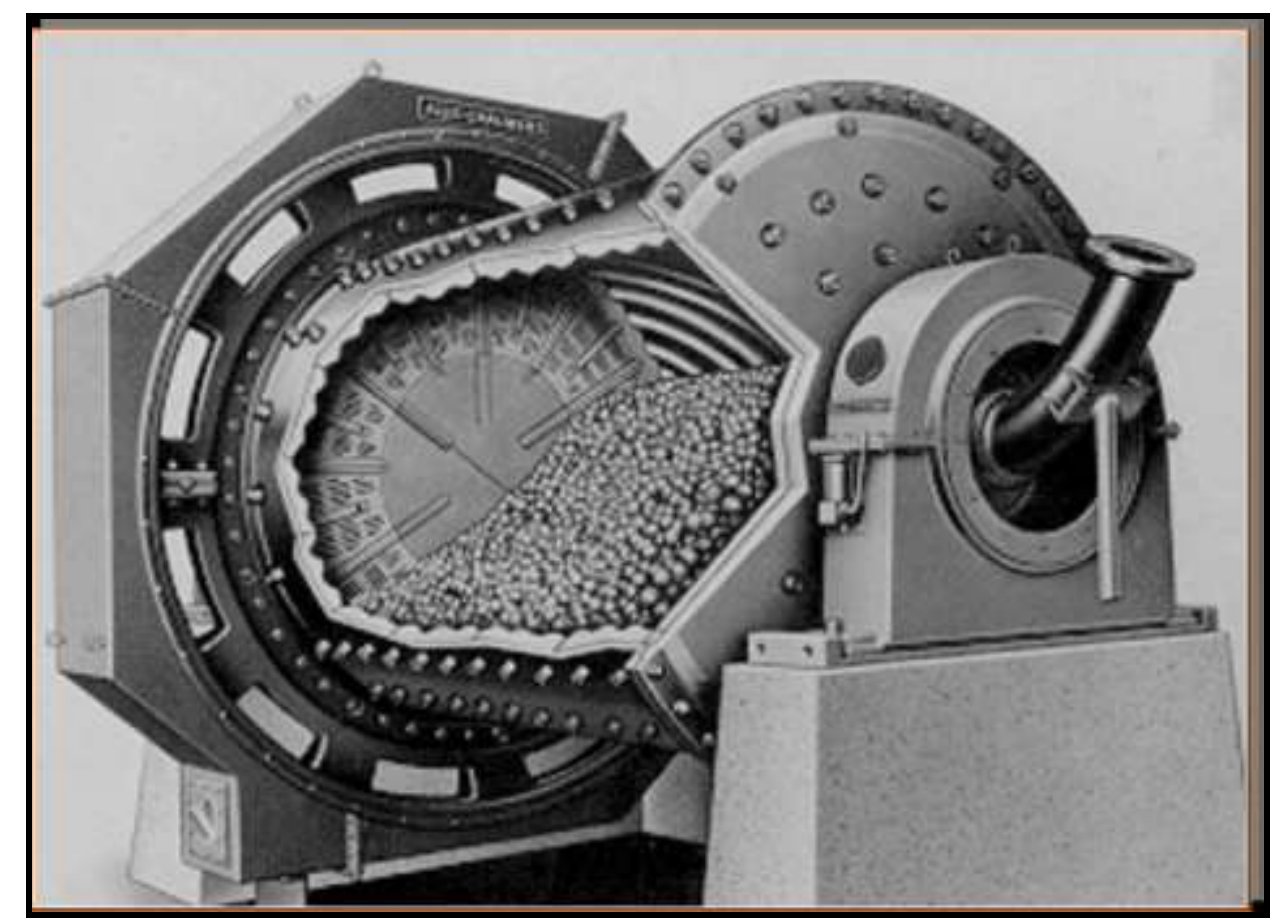

Fonte: Rowland Jr e Kjos (1980, p. 241)

Figura 3.4 - Moinho de bolas com descarga por diafragma.

A utilização de revestimentos tem por objetivo proteger a carcaça contra o desgaste, bem como reduzir o deslizamento da carga moedora dentro do cilindro. Os revestimentos são fabricados com diferentes ligas metálicas, borracha ou alguns tipos de cerâmica. Geralmente existem furos na carcaça para que o revestimento seja aparafusado no cilindro. Vários são os tipos de revestimento, e a escolha do mais adequado baseia-se na condição de operação do moinho.

Também os sistemas de alimentação contemplam diferentes arranjos, em função do tipo de circuito. Os moinhos que operam a seco são usualmente providos por algum tipo de alimentador vibratório. Já nos moinhos a úmido são usados spout feeder, scoop feeder e drum feeder. O sistema mais simples de alimentação é o 
spout feeder, composto por um duto cilíndrico ou elíptico independente do moinho e que conduz a polpa de alimentação ao interior deste.

Os dois tipos de descarga mais frequentemente presentes nos moinhos de bolas são o transbordo (overflow) e o diafragma (grelha - grate). Já os tipos de descarga dos moinhos de barras são o transbordo, a descarga periférica central e a descarga periférica terminal. Alimentados em uma das extremidades, os moinhos dotados de descarga periférica terminal descarregam o produto moído através de aberturas periféricas existentes na própria carcaça.

O acionamento dos moinhos é usualmente realizado através de transmissão por coroa e pinhão. Conjuntos de acionamento constituídos por motor assíncrono com redutor ou motor síncrono de baixa velocidade são usuais nos moinhos. Motores como rotor (de polos salientes) fixado à carcaça do moinho (gearless motor ou wrap around motor) são atualmente utilizados em moinhos de grandes dimensões.

\section{Regimes de Operação dos Moinhos}

Os regimes de operação dos moinhos de bolas, cascata e catarata são determinados por fatores como velocidade e grau de enchimento. A moagem em catarata (Figura 3.5a) - na qual as bolas são carregadas até uma posição relativamente elevada e caem sobre as outras e sobre a polpa, promovendo a fragmentação por impacto - é adequada para a fragmentação de material mais grosso, e evita a produção de finos. Esse efeito pode ser aumentado com o uso de bolas de maior tamanho e baixo fator de enchimento.

O regime de cascata (Figura 3.5b) - no qual a baixa velocidade do moinho e o alto fator de enchimento fazem com que as bolas rolem sobre as outras ao alcançarem certa altura, acionando mecanismos de abrasão e atrição - é adequado para a obtenção de produto mais fino, resultado que é potencializado quando são utilizadas bolas de menor diâmetro. 


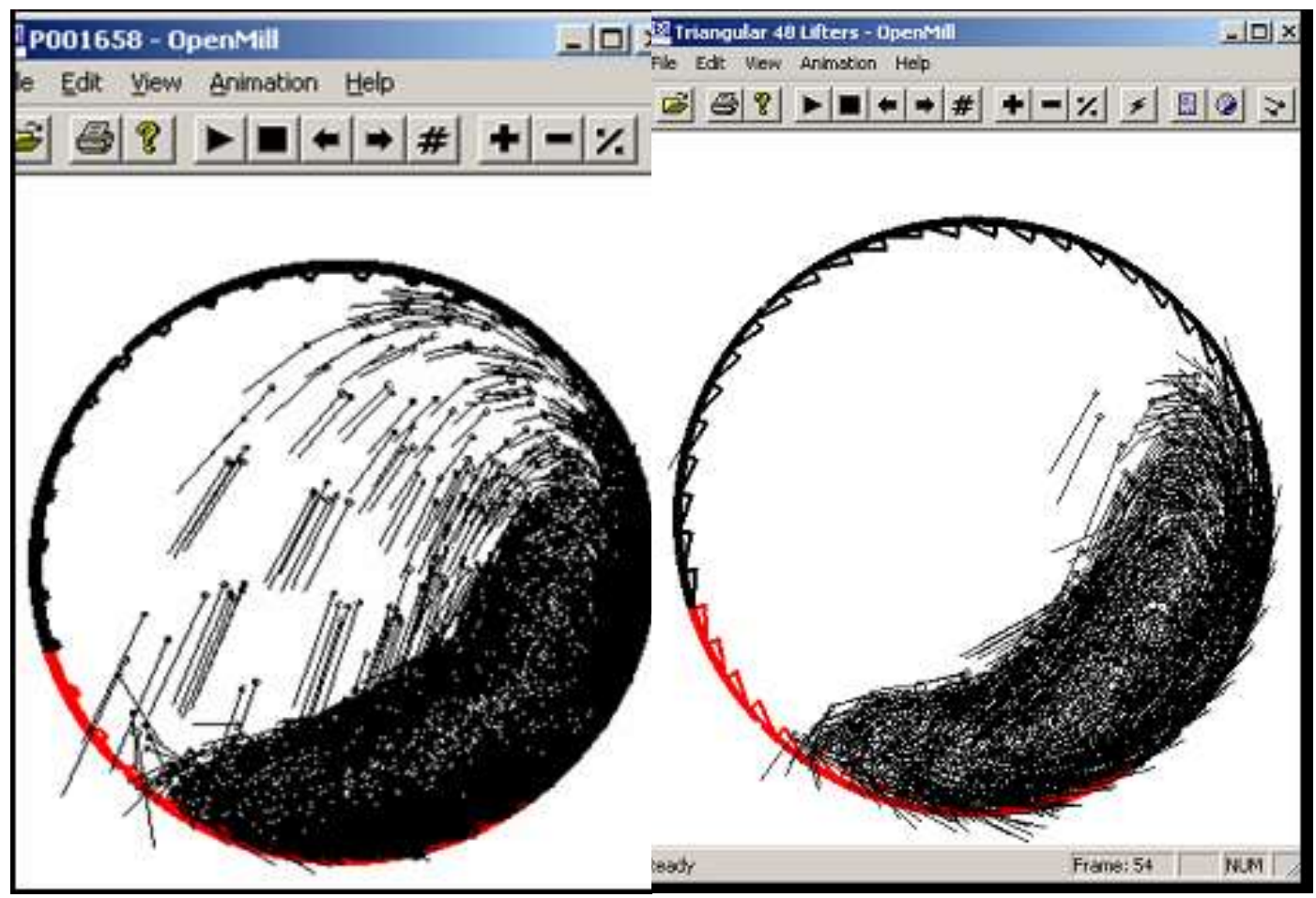

(a)

(b)

Fonte: Seminário Moly-Cop (2006)

Figura 3.5 - Regime de catarata (a); Regime de cascata (b).

\section{Operação de Circuitos de Moagem}

Apenas parte da energia consumida pelos moinhos é utilizada na cominuição de partículas. Os principais responsáveis pelo consumo de energia desses equipamentos são a velocidade de operação, a fração de volume da câmara de moagem ocupada pela carga moedora - grau de enchimento -, a porcentagem de sólidos na polpa, o tamanho dos corpos moedores e a viscosidade da polpa.

A literatura e os catálogos de fornecedores indicam as velocidades de operação mais adequadas para os moinhos de carga cadente. De forma geral, a fração de velocidade crítica dos moinhos diminui com o aumento do diâmetro destes.

A fração ou a porcentagem do volume da câmara de moagem preenchida pela carga, incluindo os espaços vazios entre os corpos moedores, é denominada grau de enchimento, que pode ser aproximado pela seguinte relação:

$$
V=113-126\left(\frac{H_{c}}{D_{m}}\right)
$$


onde:

$\mathrm{V}=\quad$ volume ocupado pela carga (grau de enchimento), em fração;

$\mathrm{H}_{\mathrm{c}}=$ distância entre o topo da carga - em repouso - ao topo da carcaça interna, considerando-se o revestimento, em m;

$D_{m}=$ diâmetro interno do moinho, em $m$

A moagem pode ser realizada a seco ou a úmido, dependendo do tipo de processo subsequente e da natureza do material a ser moído. O percentual de sólidos da polpa alimentada ao moinho é um fator importante na operação desse equipamento, influenciando aspectos como a velocidade de passagem das partículas no interior do moinho, a viscosidade e a densidade da polpa e, por consequência, a ação mecânica dos corpos moedores.

A moagem a seco é geralmente utilizada quando há exigências em relação às condições químicas e/ou físicas, ou seja, quando o material a ser processado reage com a água, ou quando há limitações quanto ao consumo de água. $A$ moagem a úmido é mais comumente utilizada no tratamento de minérios, e apresenta as seguintes vantagens:

- menor consumo de energia, em kWh/t, do que a moagem a seco;

- maior capacidade por unidade de volume do moinho;

- possibilidade de realizar peneiramento e classificação a úmido, para controle do produto;

- $\quad$ eliminação da geração de poeira;

- possibilidade de uso de operações de transporte simples como bombeamentos, calhas e tubulações.

- dissipação do calor gerado no processo de cominuição.

A desvantagem da moagem a úmido é o maior desgaste dos revestimentos e dos corpos moedores. Esse desgaste é decorrente de processos eletroquímicos que ocasionam a corrosão das partes metálicas expostas.

A operação de moagem pode ser realizada em circuito fechado ou aberto. No circuito aberto, o material passa uma única vez pelo moinho. No circuito fechado, a fração grossa contida no produto retorna para o moinho constituindo a carga circulante, geralmente expressa em porcentagem da alimentação nova. Há dois tipos de circuitos fechados: circuito fechado normal, no qual a alimentação nova é 
introduzida pelo moinho; circuito fechado reverso, no qual a alimentação nova é introduzida pelo equipamento de classificação.

A Figura 3.6 constitui-se no diagrama representativo de um circuito fechado normal de moagem. As expressões para cálculo da carga circulante são apresentadas a seguir.

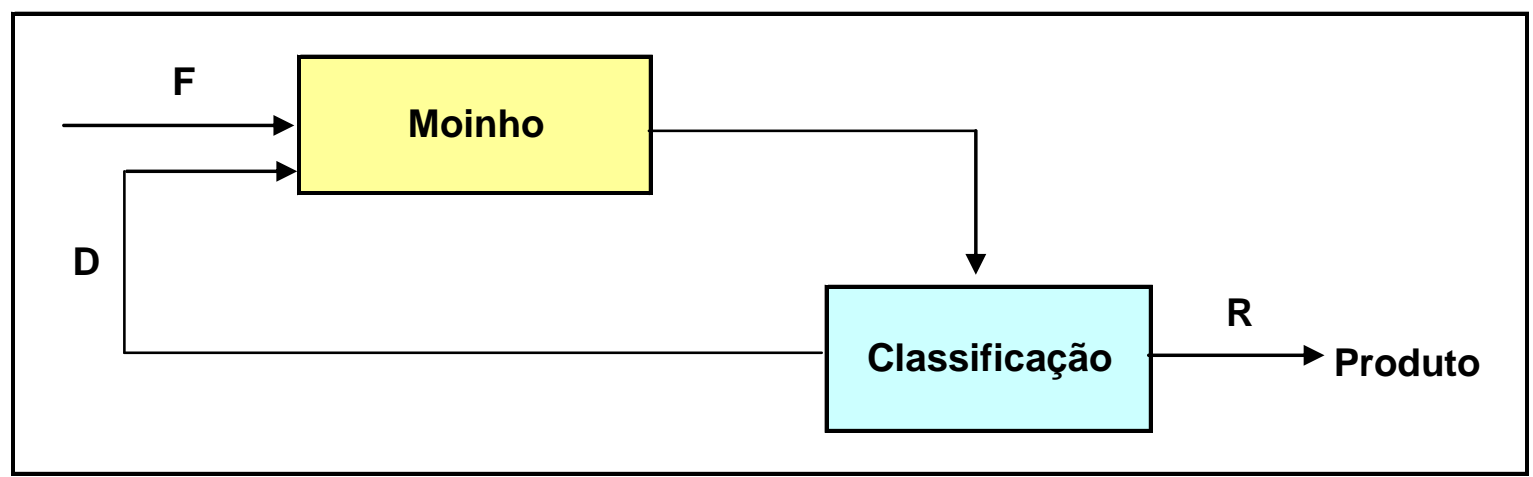

Figura 3.6 - Diagrama de um circuito fechado normal de moagem.

$C C=\frac{D}{F} \times 100$

ou

$C C=\frac{D}{R} \times 100$, quando o moinho está em regime

onde:

$\mathrm{CC}=$ carga circulante, $\%$;

$\mathrm{F}=\quad$ alimentação, $\mathrm{t} / \mathrm{h}$;

$\mathrm{R}=$ produto, $\mathrm{t} / \mathrm{h}$;

D = fração do classificador que retorna ao moinho

De acordo com Chaves e Peres (2006), os principais objetivos da carga circulante são

- garantir o tamanho máximo do produto da moagem;

- diminuir a geração de finos dentro do moinho: a carga circulante age como um amortecedor da moagem de partículas da alimentação nova, dissipando a energia mecânica aplicada sobre essas partículas e diminuindo a geração de finos. 


\subsection{MOAGEM AUTÓGENA E MOAGEM SEMIAUTÓGENA}

\subsubsection{INTRODUÇÃO}

Etimologicamente, o termo autógeno é derivado da palavra grega “autogenes" que significa próprio (autos); gerado, nascido ou produzido (genos). No tratamento de minérios, contudo, a expressão moagem autógena designa genericamente as ações de moagem de uma determinada rocha por fragmentos dessa mesma rocha (DELBONI Jr., 1999). Assim, na moagem autógena a cominuição é realizada por fragmentos de minério bruto (run of mine - ROM) ou por fragmentos de minério submetidos somente a britagem primária.

Embora conhecida e empregada há bastante tempo, a utilização rotineira da moagem autógena em alguns setores da indústria mineral teve início somente na década de 1960. Já a partir da década de 1970, a moagem semiautógena passou a ser a tecnologia mais utilizada na indústria de minérios. De aplicação inicialmente limitada à mineração de ouro, as moagens autógena e semiautógena especialmente esta última - são largamente empregadas no processamento de diferentes tipos de minérios na atualidade.

A crescente utilização desses circuitos fez com que os equipamentos que os compõem adquirissem dimensões cada vez maiores. Se os moinhos autógenos utilizados comercialmente em 1959 tinham 18 pés de diâmetro $(5,5 \mathrm{~m})$ e potência instalada de $450 \mathrm{~kW}$, em 2010 - projeto Conga de cobre e ouro (Peru) - foi instalado o primeiro moinho de 42 pés de diâmetro $(12,8 \mathrm{~m})$ e potência de $28.000 \mathrm{~kW}$-. Naquele mesmo ano, foram contabilizados quinze moinhos de 40 pés $(12,2 \mathrm{~m})$ de diâmetro, e quinze equipamentos de 38 pés $(11,6 \mathrm{~m})$ de diâmetro, o que demonstra o desenvolvimento dessa tecnologia (JONES Jr.; FRESKO, 2011).

\subsubsection{Moinhos Autógenos e Semiautógenos}

Conceitualmente, os moinhos autógenos ou semiautógenos consistem de uma câmara cilíndrica rotatória: enquanto uma das extremidades dessa câmara recebe alimentação continuamente - com o auxílio de um alimentador, a outra extremidade descarrega o material moído. 
Jones Jr. (2006) descreve os moinhos autógenos e semiautógenos da maneira que segue:

- MOINHO AUTÓGENO: moinho que utiliza o próprio minério como corpo moedor;

- MOINHO SEMIAUTÓGENO: moinho autógeno que utiliza bolas de aço, em adição ao próprio minério, como corpos moedores. A adição de bolas de 100, 125 ou 150 $\mathrm{mm}$ de diâmetro na proporção de 6 a 12\% do volume - modelo típico - melhora o desempenho de moinhos autógenos no tratamento de minérios resistentes à moagem, e quando a quantidade de corpos moedores naturais é insuficiente.

Os moinhos AG e SAG são usualmente classificados pelo aspecto - relação entre diâmetro e comprimento. Na configuração norte-americana, a relação diâmetro:comprimento é maior que 1, tipicamente 2:1, configurando moinhos de aspecto alto. Já nas configurações europeia e sul-africana são encontradas relações de diâmetro:comprimento da ordem de 1:1 ou menor, ou seja, moinhos de aspecto baixo. Um moinho de aspecto alto e as principais definições das dimensões de um moinho são apresentados na Figura 3.7.

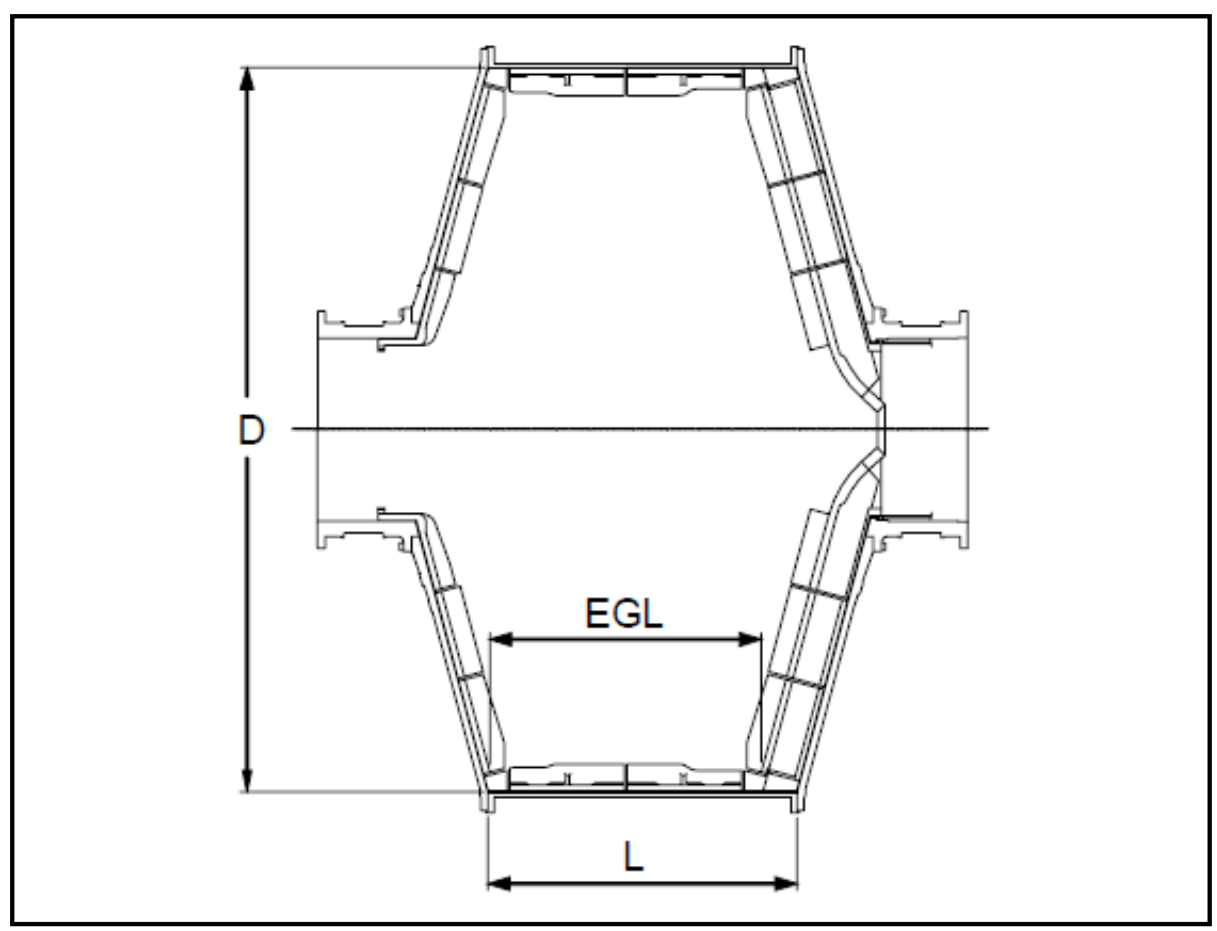

Fonte: Jones Jr. (2006)

Figura 3.7 - Moinho de aspecto alto.

Um conceito importante para o estudo da moagem autógena é o tamanho crítico, que pode ser definido como a classe de fragmentos - faixa granulométrica que, além de ter tamanho muito grande para ser cominuída por atrição e/ou impacto, 
apresenta formato arredondado, o que resulta em taxa relativamente baixa de quebra por abrasão. Para evitar e/ou minimizar a formação dessa fração - que tende a se acumular no interior do moinho, diminuindo o desempenho deste -, recomendase a moagem semiautógena e, algumas vezes, a instalação de aberturas maiores de descarga - as denominadas pebble ports -, que permitem a retirada desses fragmentos. Na maior parte das vezes, a fração descarregada é classificada, o material retido é encaminhado para um britador de reciclo - pebble crusher -, e o produto da britagem retorna ao moinho.

Ao contrário da moagem autógena, a moagem semiautógena tem a flexibilidade de tratar vários tipos de minérios, e é um processo de cominuição adequado aos minérios que apresentam baixo índice de competência para gerar corpos moedores (SAMPAIO et al., 2002).

\subsubsection{Características Gerais dos Equipamentos}

As câmaras de moagem dos moinhos semiautógenos são protegidas internamente por placas de revestimentos substituídas periodicamente. Esses revestimentos são fundamentais para o desempenho do processo de moagem pois, além de fornecer proteção contra desgastes e danos estruturais, transferem energia à carga do moinho. Por terem a função de levantar a carga, as regiões elevadas das placas de revestimentos dos moinhos são denominadas levantadores de carga (charge lifters).

As grelhas e os descarregadores de polpa (pulp lifters) controlam a descarga dos moinhos. As grelhas têm a função de reter os corpos moedores e classificar o produto da moagem, determinando assim o tamanho máximo do material que deixará a câmara de moagem e o tamanho do material que permanecerá retido no interior desta. Assim sendo, e com o objetivo de otimizar a operação dos moinhos 
semiautógenos - reduzindo fenômenos como o slurry pool ${ }^{3}$-, especialistas têm investigado as variações na área aberta e no tamanho dos pebble ports das grelhas dos moinhos, como Burger et al. (2006) - que alteraram o tamanho das grelhas (de 25 e $60 \mathrm{~mm}$ para 80 e $60 \mathrm{~mm}$ ) e vedaram os furos das grelhas localizadas fora do material para impedir o retorno deste ao moinho -; Coleman, Nugroho e Neale (2001) - que, depois de compararem grelha cuja área aberta correspondia a $12 \%$ de seu tamanho, concluíram que a área aberta da grelha e o descarregador de polpa são os fatores que mais impactam a capacidade do moinho -; Sherman (2006) - que reitera a importância de eleger a grelha que melhor se adéque às características e às finalidades do moinho -; e Villouta (2001), que propõe o aumento da área aberta da grelha e do descarregador de polpa para melhorar a descarga.

O sistema de acionamento do moinho semiautógeno compreende um ou até dois motores elétricos, dispositivos de redução de velocidade e dispositivos de transmissão, geralmente pinhão/engrenagem. Existem, contudo, limitações técnicas e econômicas que ditam o sistema de acionamento mais apropriado para cada instalação. As opções de acionamento dos moinhos são sistemas com um único pinhão, sistemas com dois pinhões e sistemas com dispositivos de acionamento sem engrenagens (gearless). A utilização de sistemas gearless em moinhos semiautógenos ocorreu a partir da década de 1980.

Na Figura 3.8, observa-se o interior de um moinho semiautógeno.

3 O slurry pool [(acumulação de polpa no moinho)] ocorre quando o volume de polpa a ser descarregado moinho é maior que a capacidade de descarga do descarregador de polpa (BERGERMAN, 2009, p. 95). 


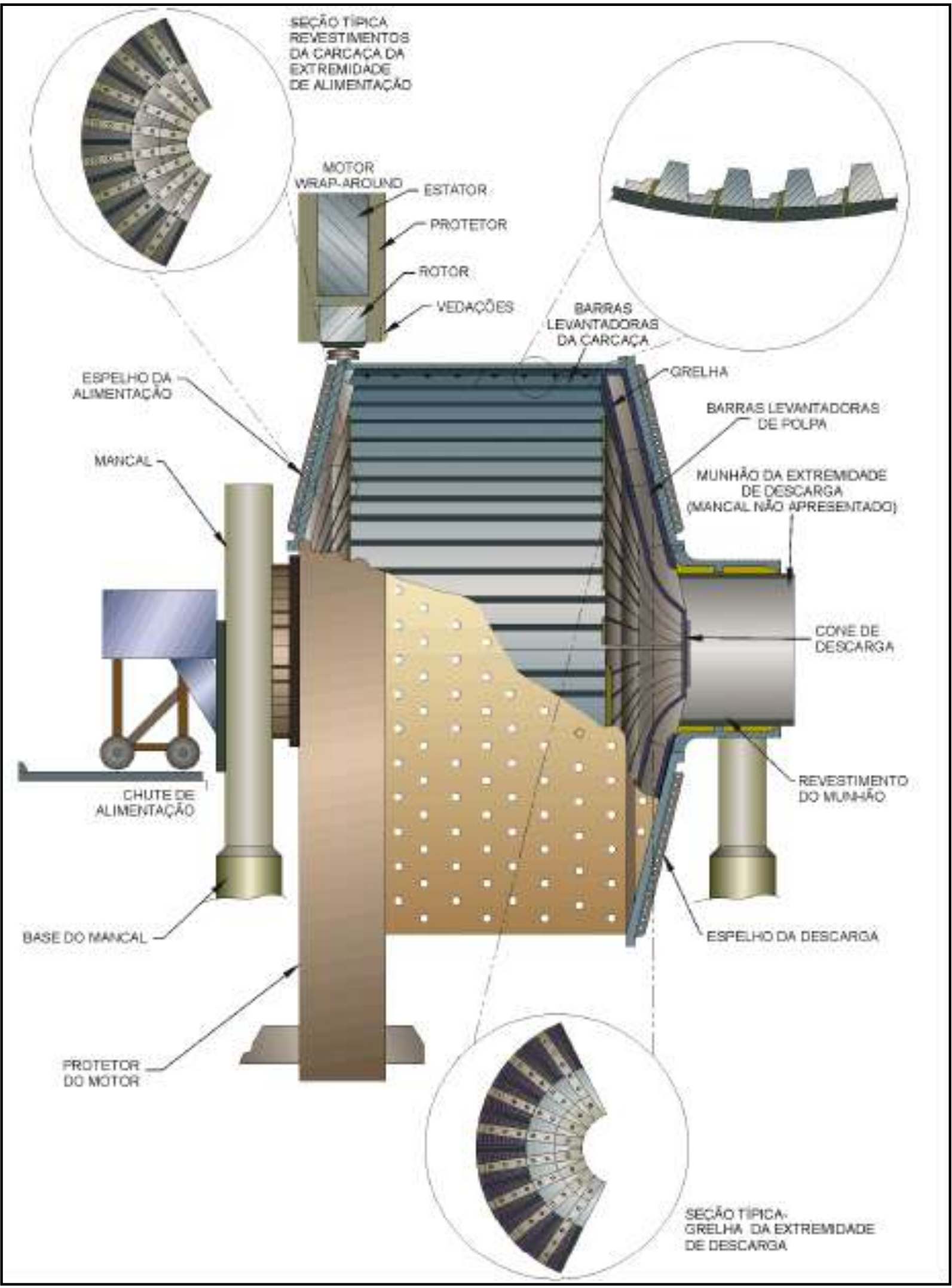

Fonte: Vale (2003) apud Bergerman (2009, p.91)

Figura 3.8 - Representação esquemática de um moinho semiautógeno. 


\subsubsection{Configuração de Circuitos de Moagem Autógena e Semiautógena}

Como a aplicação de moagem AG ou SAG atualmente contempla uma ampla gama de tipos de minérios e alimentações, várias são as configurações de circuito existentes, das quais Delboni Jr. (2007) descreve as cinco básicas:

\subsubsection{Circuito em Estágio Único}

A configuração de moagem em estágio único, que inclui tanto operações com moinhos AG quanto operações com moinhos SAG, apresenta riscos relacionados principalmente à falta de conhecimento das características do minério e/ou à dificuldade de operação conjunta entre a mina e a usina de tratamento dos minérios. É importante que o minério e/ou a blendagem ${ }^{4}$ tenham granulometria e competências constantes, para garantir que as capacidades e as condições de processo objetivadas sejam alcançadas.

A configuração de moagem em estágio único, ilustrada de forma esquemática na Figura 3.9, tem como vantagens os baixos custos de investimento capital - e operacionais.

4 Blendagem: composição (mistura), em proporções definidas, de minérios de características diferentes, com o objetivo de se obter uma massa com características específicas e conhecidas. 


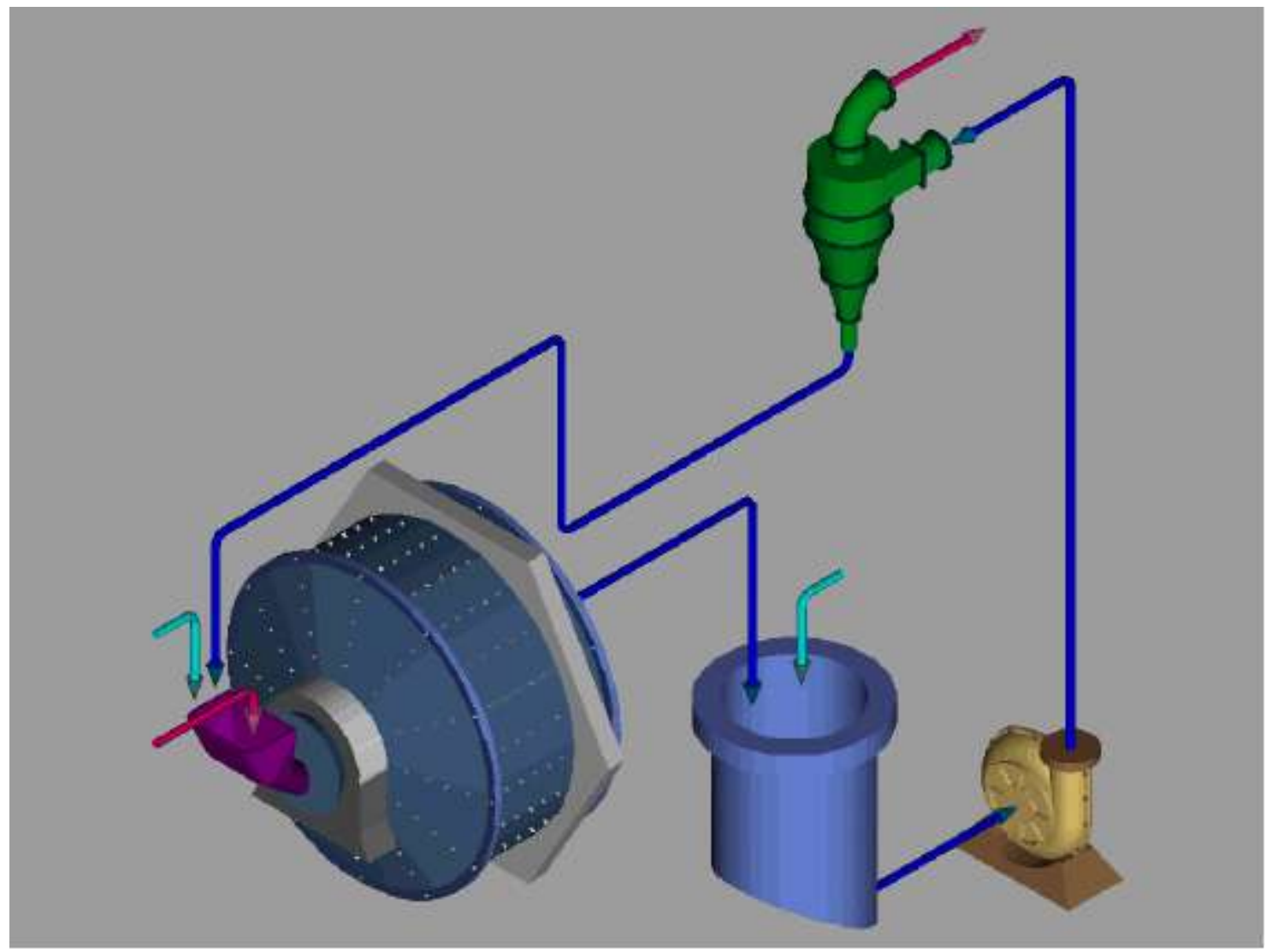

Fonte: Delboni Jr. (2007, p. 113)

Figura 3.9 - Circuito de moagem autógena ou semiautógena em estágio único.

\subsection{Circuito Moinho Autógeno + Moinho de Pebbles (FAP)}

Esse circuito combina duas etapas de moagem: a moagem autógena primária e a moagem secundária dos pebbles ${ }^{5}$, obtidos no estágio anterior (moinho de pebbles). Tal configuração constitui-se em alternativa para circuitos em estágio único que apresentam alta geração de pebbles, já que as oscilações de vazão do circuito primário podem ser absorvidas pela moagem secundária, por meio do ajuste da carga no estágio secundário.

O investimento para esse circuito - ilustrado na Figura 3.10 - é um pouco maior do que o necessário para circuitos de moagem autógena acompanhados de moinho de bolas. Mas, embora o investimento para um moinho de pebbles seja

Pebbles: fragmentos de rocha gerados em processos de britagem ou moagem, em geral entre 35 e $70 \mathrm{~mm}$, que em alguns casos são usados como corpos moedores. Em português, utiliza-se também a palavra seixos. 
superior ao de um moinho de bolas, os custos operacionais do primeiro são inferiores, pois os custos com corpos moedores diminuem.

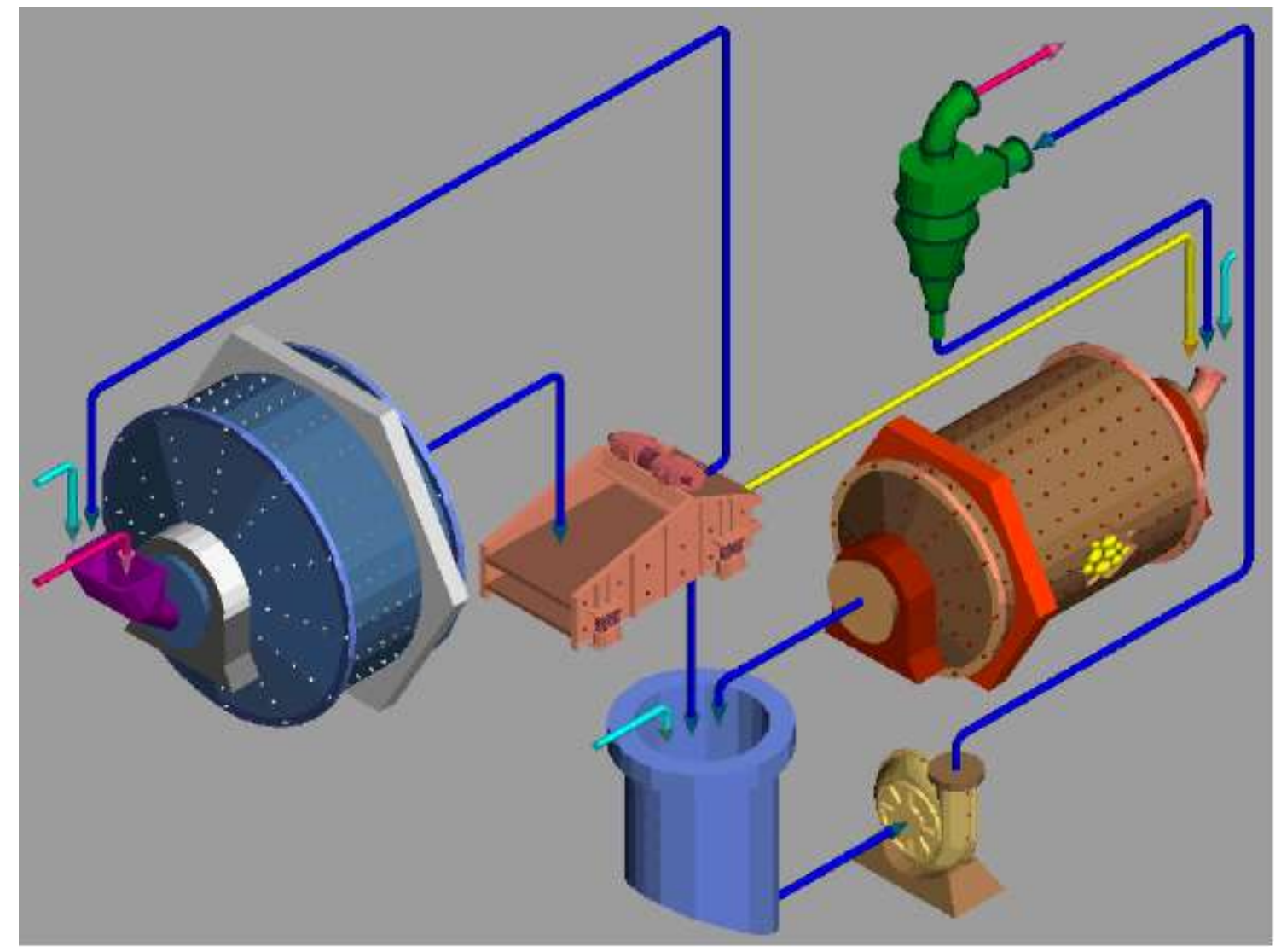

Fonte: Delboni Jr. (2007, p. 115)

Figura 3.10 - Circuito de moagem autógena seguida de moagem de pebbles.

\subsection{Circuito Moinho Autógeno + Moinho de Bolas (FAB)}

A configuração FAB - que também combina duas etapas de moagem: a moagem autógena primária e a moagem secundária em moinho de bolas - tem como vantagem, em relação à configuração FAP, a possibilidade de corrigir eventuais oscilações no circuito primário e, assim, possibilitar a regularidade da operação da moagem de bolas. A opção FAB apresenta consumo energético específico mais próximo ao do circuito convencional, constituído por britagem multiestagiada e moagem de barras / bolas. A Figura 3.11 ilustra esse tipo de circuito. 


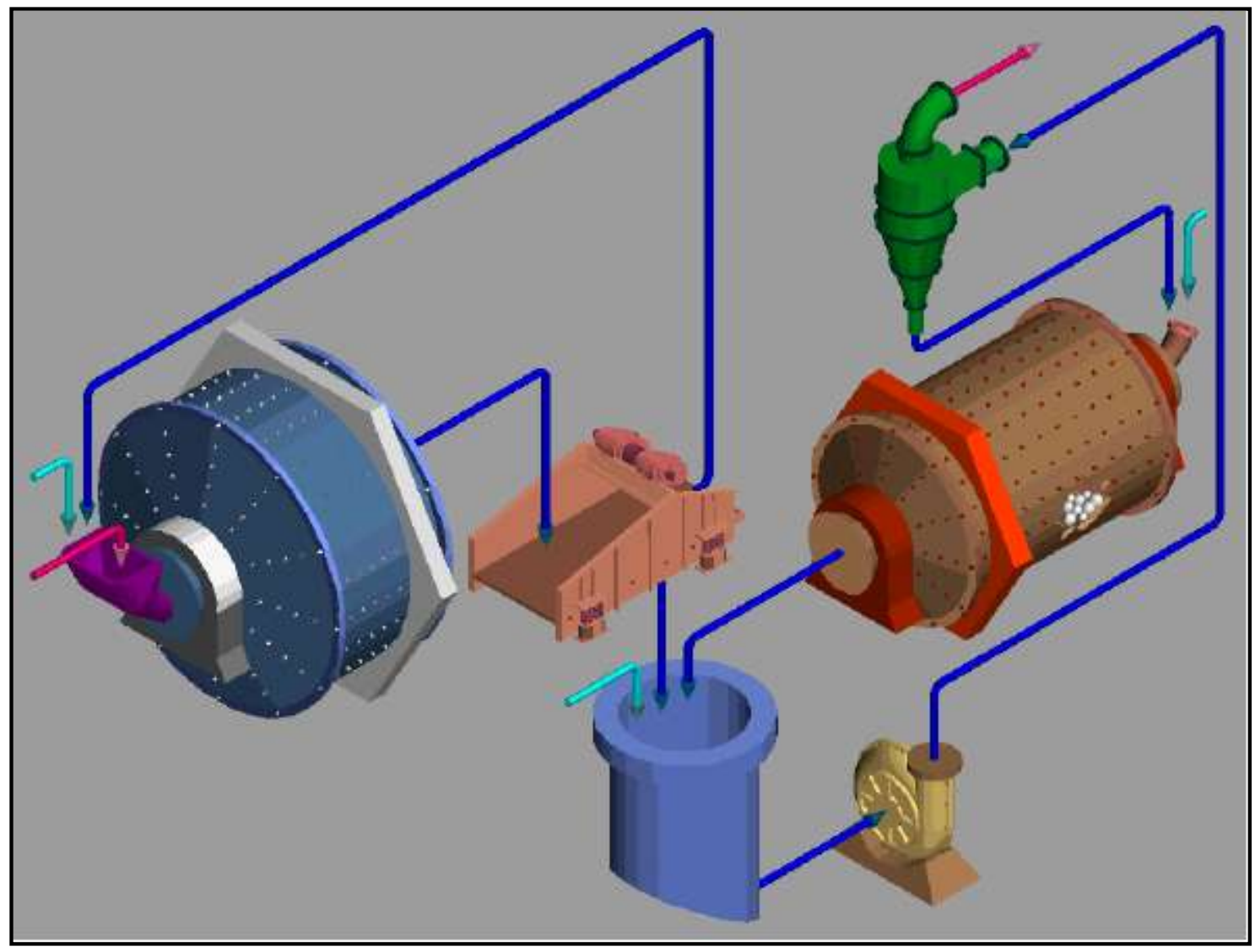

Fonte: Delboni Jr. (2007, p. 117)

Figura 3.11 - Circuito de moagem autógena seguida de moagem de bolas.

\subsection{Circuito Moinho SAG + Moinho de Bolas (SAB)}

No circuito $S A B$, a moagem primária semiautógena é seguida, no estágio secundário, pela moagem de bolas. A configuração SAB é capaz de suportar amplas faixas de variações do tamanho de transferência $\left(T_{80}\right)$ entre os circuitos primário e secundário.

O circuito SAB, ilustrado na Figura 3.12 requer investimentos cerca de $25 \%$ menores do que os circuitos convencionais de britagem e moagem. 


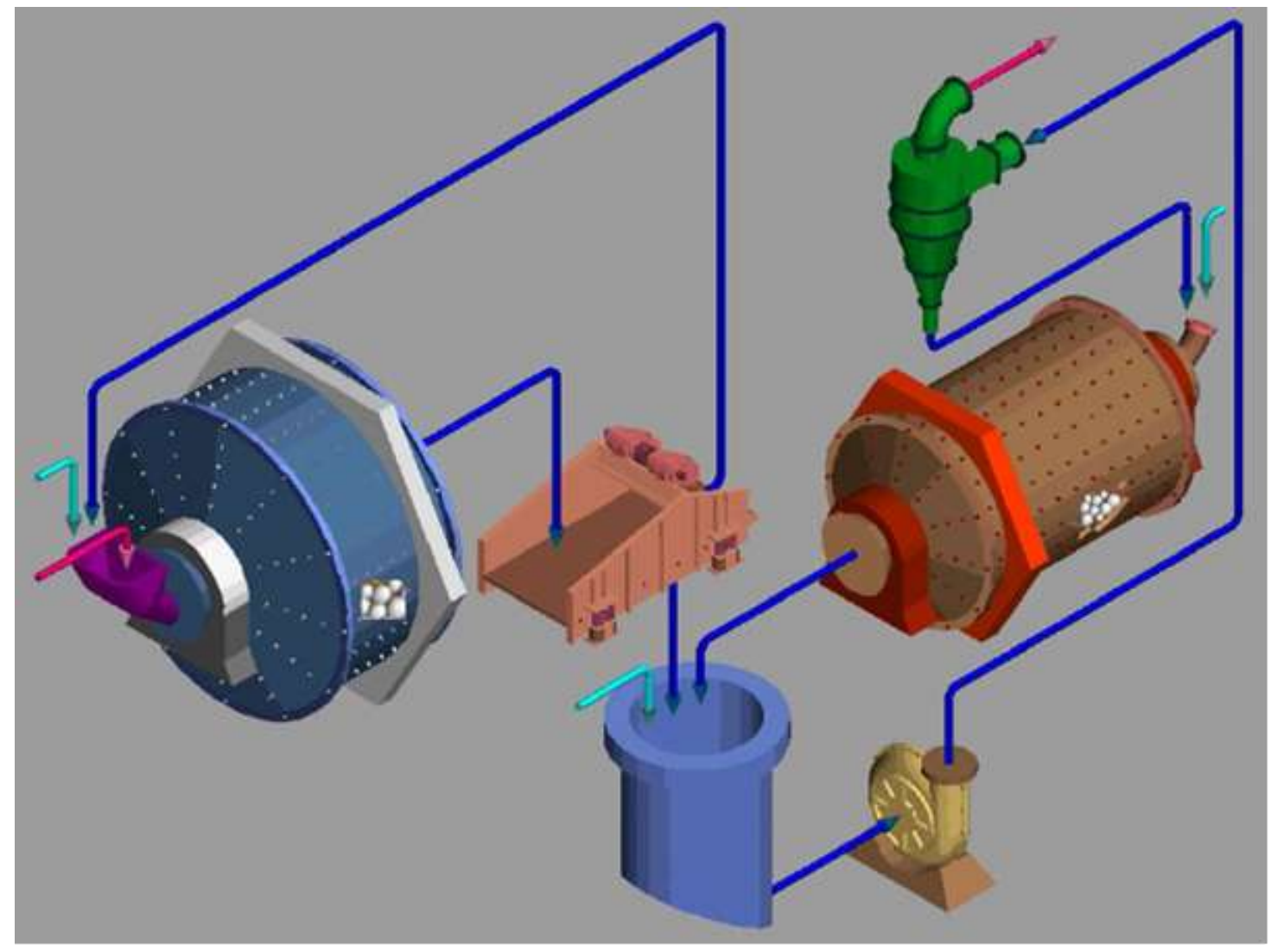

Fonte: Delboni Jr. (2007, p. 118)

Figura 3.12 - Circuito de moagem semiautógena seguida de moagem de bolas.

\subsubsection{Circuito Moinho SAG + Britador de Reciclo + Moinho de Bolas (SABC)}

O circuito SABC (SAG, Recycle Crusher, Ball) é empregado quando o minério processado tem maior tendência à formação de pebbles, que não são adequadamente cominuídos pelo moinho SAG. Nesse caso, são instaladas grelhas com aberturas maiores (50 a $100 \mathrm{~mm}$ ) - pebble ports -, que permitem a saída da fração crítica e o seu direcionamento para uma etapa de britagem, seguida do retorno do produto dessa etapa para a moagem primária.

A configuração de circuito de cominição SABC é extremamente robusta e, desde que adequadamente ajustada e operada, absorve os mais variados tipos de minério, seja no estágio primário, seja no secundário. A Figura 3.13 constitui-se em uma representação esquemática do circuito SABC, que apresenta 0 menor investimento unitário dentre todas as demais opções de circuitos. Já na Figura 3.14 vê-se o moinho SAG da Mineração Maracá (MMIC - GO), de 34 x 17,5 pés, operado em configuração SABC. 


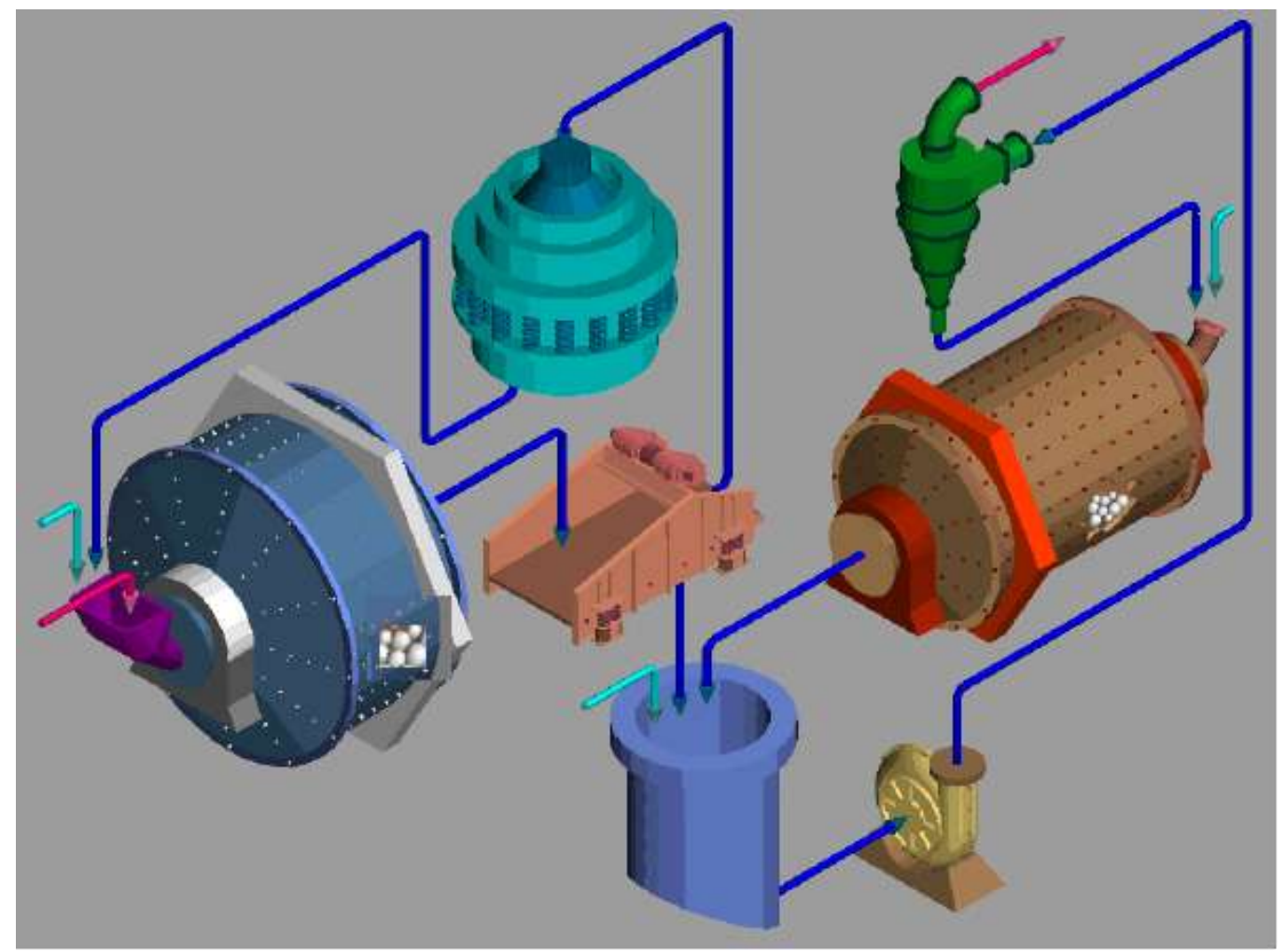

Fonte: Delboni Jr. (2007, p. 120)

Figura 3.13 - Circuito de moagem semiautógena com britagem de pebbles e seguida de moagem de bolas.

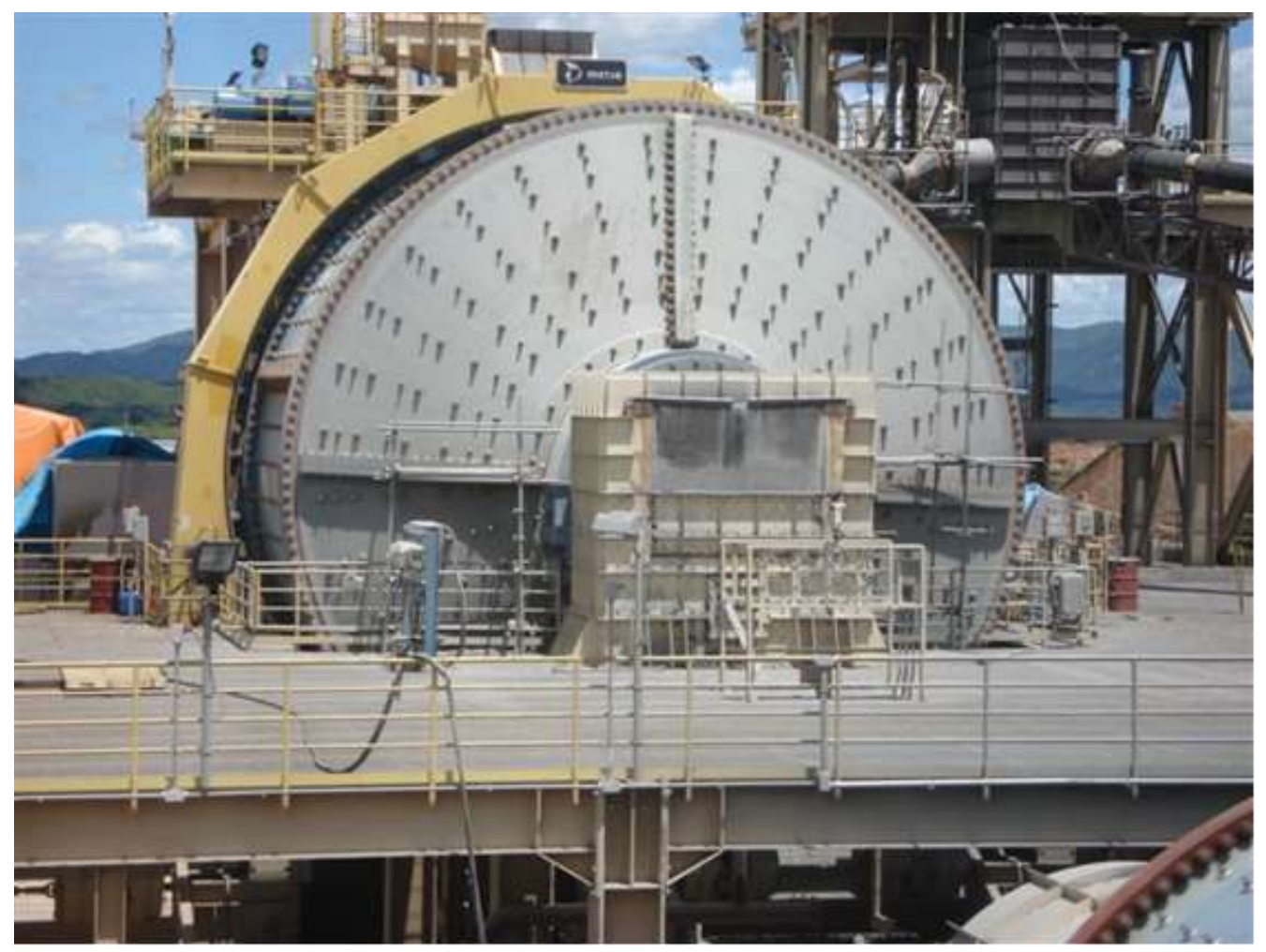

Fonte: Arquivo pessoal da autora

Figura 3.14 - Foto do moinho SAG de 34 x 17,5 pés da MMIC operado em configuração SABC. 


\subsubsection{Operação de Circuitos de Moagem Autógena e Semiautógena}

A operação de moinhos autógenos e semiautógenos objetiva maximizar a vazão de alimentação desses circuitos. Os fatores que afetam a operação de circuitos de moagem autógena podem ser classificados, de acordo com Bergerman (2009), em:

- DISTÚRBIOS: envolvem as características da alimentação, como resistência à moagem, à distribuição granulométrica e à densidade.

- VARIÁVEIS DO EQUIPAMENTO: envolvem as características do equipamento, como velocidade de rotação, distribuição de tamanho de bolas e área aberta de grelha, entre outras.

- VARIÁVEIS OPERACIONAIS: envolvem aspectos como carga circulante, vazão de sólidos e água, carga de bolas e de minério, nível de ruído devido ao impacto e granulometria de alimentação do moinho.

A moagem autógena é baseada em uma relação única entre a carga do moinho e as características de quebra. A interação entre essas funções determinará a condição de equilíbrio do moinho, bem como o desempenho de processo.

Um dos quesitos principais de processo é a relação entre a quantidade de corpos moedores alimentada ao moinho e a resistência destes à moagem. Assim, 0 excesso de fragmentos com grande resistência à moagem provoca a acumulação destes na câmara de moagem. Essa situação desequilibra a relação entre os corpos moedores e o minério a ser moído, que resulta em diminuição da vazão de alimentação do moinho, até um ponto em que o equilíbrio seja restaurado.

Por outro lado, a falta de corpos moedores em proporção adequada e/ou a baixa resistência destes à moagem resulta em acumulação de material a ser moído na câmara de moagem, situação esta que também resulta em diminuição da vazão de alimentação. Portanto, existe uma relação adequada entre as características de fragmentação e a distribuição granulométrica de alimentação do moinho na qual o desempenho do processo e ótimo.

A moagem autógena é aplicável mediante o correto balanço entre o minério alimentado ao moinho e as etapas anteriores à própria moagem. Assim, a disponibilidade de minérios competentes e a dosagem desses minérios na alimentação determinarão o desempenho do processo. Os principais aspectos que devem nortear a aplicação de moinhos autógenos são: 
- disponibilidade de minérios que fornecem blendagem adequada de alimentação;

- fragmentação prévia da alimentação do moinho - a combinação entre desmonte e britagem;

- manuseio de alimentação, que engloba empilhamento e retomada adequada do minério.

Conclui-se que uma boa relação entre as áreas de tratamento de minérios e de operação na mina é importante para garantir que a blendagem do minério e a fragmentação no desmonte sejam adequadas à moagem AG/SAG. Deficiências no fluxo de comunicação entre essas áreas resultarão em variabilidade na distribuição de tamanho da alimentação e dureza do minério, dificultando a manutenção do equilíbrio na moagem AG/SAG (NAPIER-MUNN et al., 1999).

A estratégia mais comum de controle da operação de moinhos AG/SAG é a manutenção de uma carga constante na câmara de moagem. Como o volume da carga é composto por minério $(A G)$ e quantidades relativamente pequenas de bolas (SAG), manutenção da carga significa o equilíbrio entre os corpos moedores e o minério a ser moído. Acumulações progressivas de determinadas frações levam a diminuições da vazão de alimentação, assim como a falta de corpos moedores resulta em enchimento do moinho.

A operação do moinho com níveis baixos de carga e/ou velocidades de rotação muito altas pode resultar em danos aos revestimentos e às próprias bolas no caso da moagem SAG -, em virtude do arremesso destas contra o revestimento. Para que esses danos sejam evitados e/ou minimizados, o peso ou a potência, que representam o enchimento adequado, devem ser conhecidos.

A potência que o moinho utiliza apresenta respostas mais lentas, o que dificulta o controle da operação de moagem. Já a carga do moinho, registrada por células de carga ou pressão do óleo no mancal, apresenta respostas rápidas e sensibilidade a variações relativamente pequenas na carga. Com o auxílio de calibrações, é possível estabelecer uma relação entre a massa registrada pela célula de carga e o volume da carga no moinho.

Outra estratégia de controle que pode ser adotada é a percepção do ruído próximo à carcaça quando há ocorrência de impacto de bolas no revestimento. Essa percepção pode ser feita pelo operador ou por equipamentos. A partir da detecção de ruído em níveis acima dos estabelecidos, as ações a serem tomadas são a 
redução da velocidade de rotação do moinho quando este é dotado de motor com rotação variável, ou o aumento do enchimento de minério no moinho quando este não dispõe do sistema de velocidade variável.

\subsection{ENSAIOS E CARACTERIZAÇÃO DO MINÉRIO QUANTO À COMINUIÇÃO}

\subsubsection{INTRODUÇÃO}

Há uma longa história de investigações voltadas à caracterização da fragmentação de partículas e de rochas na indústria mineral. Na área de cominuição, o principal foco dessas investigações tem sido a identificação dos mecanismos de fragmentação de um determinado material em um equipamento de cominuição (NAPIER-MUNN et al., 1999).

A caracterização tecnológica do minério processado e a parametrização dos mecanismos físicos envolvidos são fundamentais para o tratamento e a modelagem matemática dos processos de cominuição, e buscam estabelecer:

- correlacionar a energia aplicada e a fragmentação resultante;

- correlacionar a resistência à fragmentação e o tamanho dos fragmentos;

- quantificar a tendência de geração de finos e ultrafinos.

A caracterização de minérios para moagem SAG é particularmente complexa devido à ampla faixa de tamanho da alimentação e aos vários mecanismos de quebra desse equipamento. Ensaios de caracterização do minério, em escala de bancada e de planta piloto, são requeridos para garantir a confiabilidade das informações consideradas nos novos projetos e/ou na implantação de otimizações e expansões para projetos já em operação.

A literatura apresenta vários estudos sobre os ensaios e métodos de caracterização dos parâmetros de cominuição de minérios. Tais estudos analisam os requisitos necessários para a condução de ensaios dessa natureza, sua aplicabilidade e os custos que implicam (DOLL; BARRATT, 2011; VERRET; CHIASSON; McKEN, 2011).

Os principais métodos de caracterização para determinar as propriedades de materiais quanto à cominuição são apresentados nesta seção. 


\subsection{2 ÍNDICE DE ABRASÃo DE BOND (AI)}

Desenvolvido por Bond na década de 40, o índice de abrasão (Ai) quantifica o índice de abrasividade de um minério. Pode ser utilizado no cálculo do desgaste de britadores e do consumo de bolas em moinhos de bolas.

O ensaio para quantificação do índice de abrasividade utiliza $10 \mathrm{~kg}$ de amostra, representativa, entre 38 e $55 \mathrm{~mm}$. Depois de moer e peneirar a amostra, colhem-se quatro alíquotas entre 12,5 e $19 \mathrm{~mm}$, com peso de $400 \mathrm{~g}$. Cada uma dessas subamostras é colocada em um recipiente junto a uma placa metálica padrão, previamente pesada. A placa metálica é rotacionada a $632 \mathrm{rpm}$, em contato com a amostra de minério, durante 15 minutos. Após a execução dos quatro ensaios, a placa é novamente pesada; a perda de massa dessa placa, em gramas, constitui o Índice de Abrasão (PEREIRA, 2004).

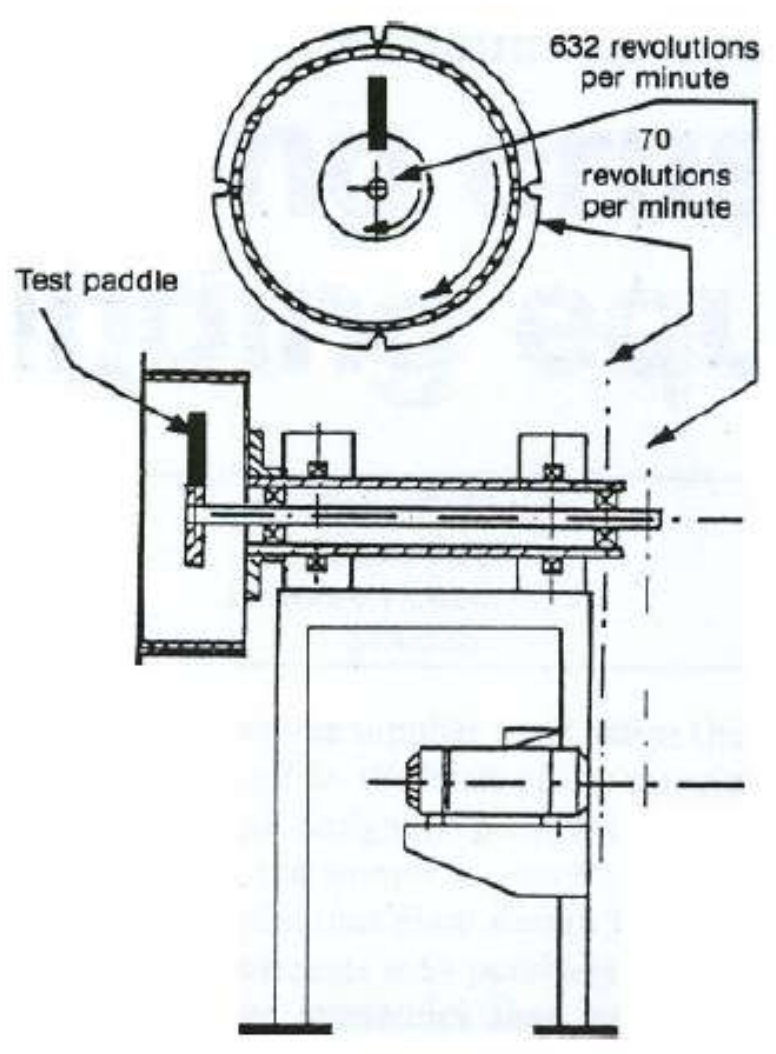

Fonte: Rolfsson (1983)

Figura 3.15 - Dispositivo para a realização do teste de abrasão de Bond. 


\subsubsection{ENSAIO DE BOND PARA MOINHO DE BOLAS (WI)}

Proposto por Bond em 1952, o Work Index de Bond (WI) - ou índice de trabalho - representa a quantidade de energia, em $\mathrm{kW}$, para reduzir a unidade de peso (tonelada curta $=907 \mathrm{~kg}$ ) do material considerado, desde um tamanho inicial teoricamente infinito até a granulometria $80 \%$ passante em $100 \mu \mathrm{m}$.

O ensaio de WI - realizado em um moinho padrão de 0,305 m de diâmetro e 0,305 m de comprimento, carregado com 285 bolas de aço totalizando $20.125 \mathrm{~g}$, a uma velocidade de rotação de $70 \mathrm{rpm}$, -- busca reproduzir, através de ciclos sucessivos, a operação de um circuito fechado de moagem em equilíbrio. Além de útil na estimativa da energia necessária à moagem, 0 WI possibilita dimensionamentos e avaliações da operação de circuitos de moagem de bolas, e permite comparações entre diferentes tipos de minérios. (NASCHENVENG, 2003).

Segundo a lei de Bond, a energia consumida na cominuição é proporcional à diferença entre os inversos das raízes quadradas dos tamanhos do produto e da alimentação. Essa lei pode ser expressa, considerando-se a moagem de bolas e a conversão dos resultados de kWh/st para kWh/t, pela seguinte equação:

$$
W I=1,102 x \frac{44,5}{A m^{0,23} \times \operatorname{Mob}^{0,82}\left(\sqrt{\frac{10}{P_{80}}}-\sqrt{\frac{10}{F_{80}}}\right)}
$$

onde:

$\mathrm{Am}=$ abertura da malha teste do ensaio, $\mu \mathrm{m}$;

Mob = média dos últimos três valores da moabilidade. A moabilidade é a massa passante na malha de classificação em cada ciclo de moagem;

$\mathrm{P}_{80}=$ abertura da peneira por onde passam $80 \%$ da massa do produto, $\mu \mathrm{m} ;$

$\mathrm{F}_{80}=$ abertura da peneira por onde passam $80 \%$ da massa da alimentação, $\mu \mathrm{m} ;$

$\mathrm{WI}=\quad$ índice de trabalho em moinho de bolas, $\mathrm{kWh} / \mathrm{t}$;

$1,102=$ fator de conversão de toneladas curtas $(\mathrm{kWh} / \mathrm{st})$ para toneladas $(\mathrm{kWh} / \mathrm{t})$

O teste de WI foi introduzido na Rio Paracatu Mineração em 1998, com parâmetros e procedimentos baseados no método adotado pelo Julius Kruttschnitt Mineral Research Center (JKMRC, 1995) e na Norma Técnica MB 3253 (ABNT, 1990). A Figura 3.16 mostra o moinho utilizado para ensaios de WI na RPM. 


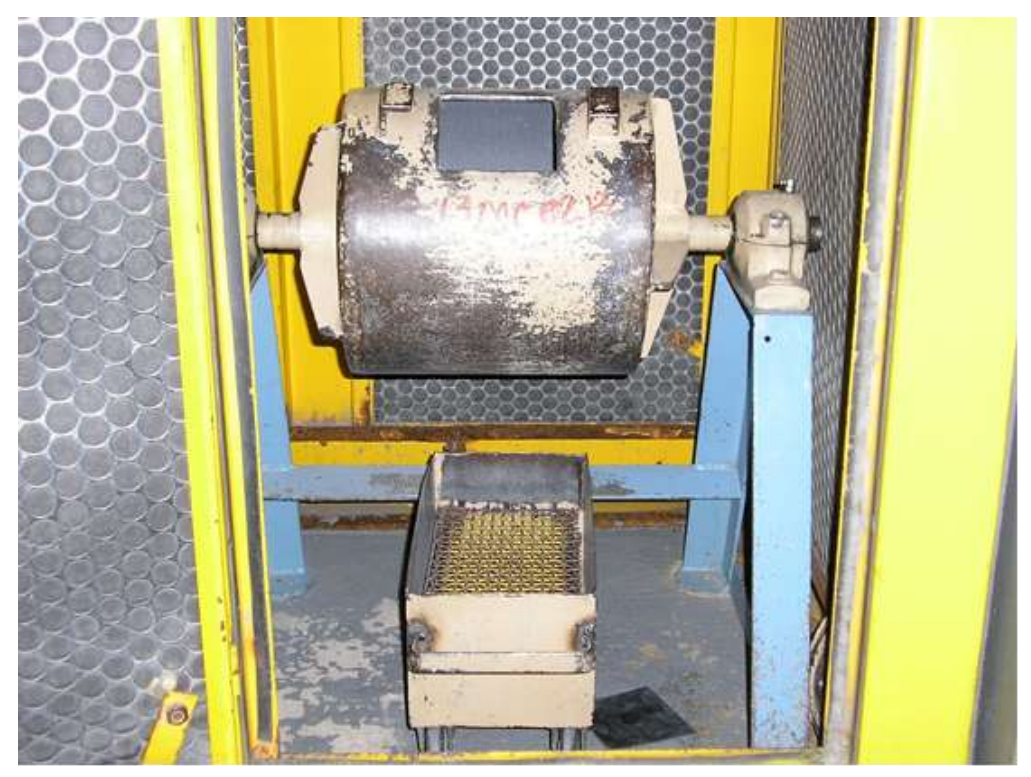

Fonte: Arquivo pessoal da autora

Figura 3.16 - Moinho utilizado para ensaios de WI na RPM.

\subsubsection{Ensaios de Carga Cadente ou Drop Weight Test (DWT)}

A equipe técnica do Julius Kruttschnitt Mineral Research Centre (JKMRC, 1995) desenvolveu um método de caracterização de minérios, em Célula de Impacto, denominado Drop Weight Test (DWT). O DWT tem três componentes: quebra por impacto de partículas individuais, abrasão de batelada em fragmentos britados entre 37,5 e $55 \mathrm{~mm}$ e determinação de peso específico. O ensaio de quebra de partículas individuais é usado para desenvolver dois itens: os parâmetros de moagem SAG e a função appearance para britagem.

O equipamento utilizado, conforme apresentado na Figura 3.17, consiste de uma plataforma metálica fixa e um cilindro de aço dotado de duas guias laterais que correm em barras verticais. Um guincho elétrico ou pneumático eleva o cilindro metálico, que é solto em seguida. Pela ação da gravidade, o cilindro cai sobre o fragmento de rocha disposto na plataforma metálica. 


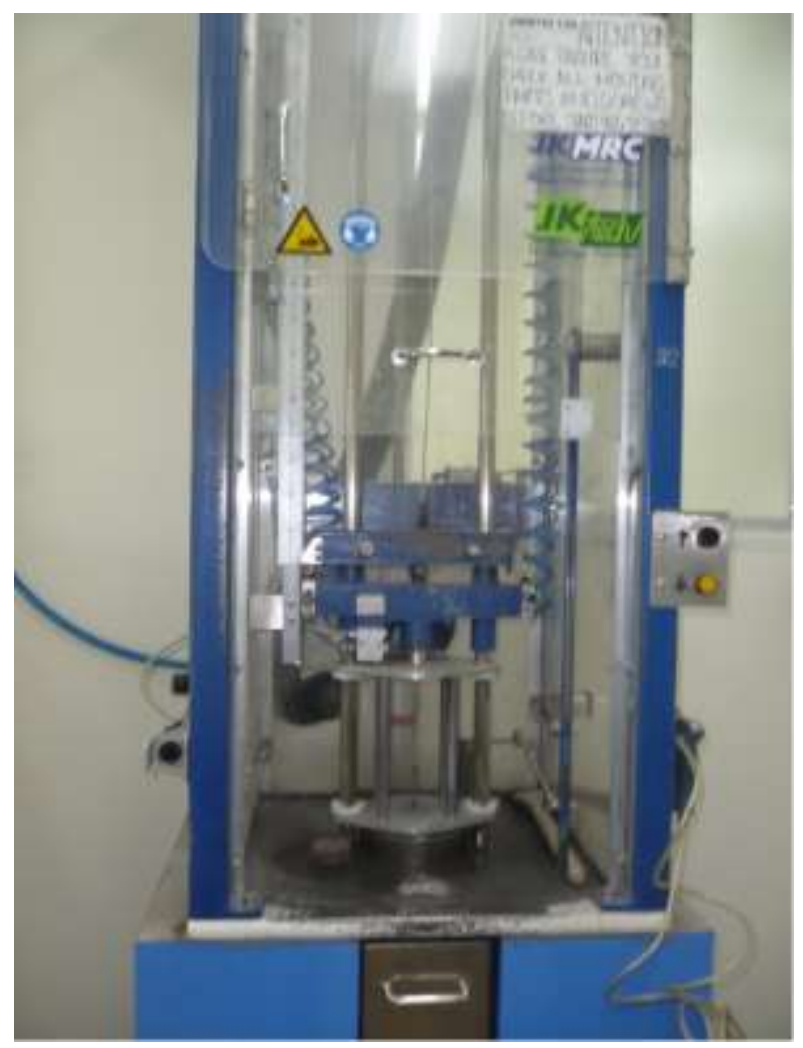

Fonte: Arquivo pessoal da autora

Figura 3.17 -Dispositivo para realização de ensaio DWT do Laboratório da ALS AMMTEC, Perth (Austrália).

A altura de queda e a massa do cilindro determinarão o valor da energia potencial. O DWT considera que toda a energia cinética entre o cilindro e 0 fragmento no momento do choque é transferida para o fragmento testado.

O ensaio padrão de DWT do Julius Kruttschnitt Mineral Research Center (JKMRC, 1995) considera um peso de $20 \mathrm{~kg}$, que pode ser estendido até $50 \mathrm{~kg}$. A altura efetiva de queda pode variar de $0,05 \mathrm{~m}$ a $1,00 \mathrm{~m}$, o que representa uma faixa de operação de energia específica de $0,01 \mathrm{kWh} / \mathrm{t}$ até $50 \mathrm{kWh} / \mathrm{t}$ (NAPIER-MUNN et al., 1999).

O procedimento padrão de DWT estabelece que sejam preparados 15 lotes de trinta fragmentos cada, de acordo com cinco diferentes frações granulométricas. Os fragmentos individuais são submetidos a impactos no DWT, conforme a especificação de massa e a altura de queda do cilindro, previamente calculadas. Após a quebra individual de cada um dos trinta fragmentos de cada lote, reúne-se o material para a análise granulométrica. A fragmentação é caracterizada pelo parâmetro $t_{10}$, que consiste na fração passante na malha igual a $10 \%$ do tamanho 
original da partícula. Para representar a relação entre energia aplicada (Ecs) e fragmentação resultante $\left(t_{10}\right)$, é empregada a seguinte equação paramétrica:

$t_{10}=A\left(1-e^{-b E c s}\right)$

onde:

$t_{10}=$ porcentagem passante na malha igual a $10 \%$ do tamanho original do fragmento;

Ecs = energia específica aplicada ao fragmento do minério, em kWh/t;

A e b parâmetros de fragmentação por impacto do minério, obtidos por meio de técnicas de regressão a partir dos quinze pares de valores $t_{10}$ e Ecs.

O fenômeno de fragmentação é convenientemente descrito por uma curva $t_{10} \times$ Ecs - com rápido crescimento inicial determinado pelo parâmetro "b", tendendo posteriormente a um valor assintótico determinado pelo parâmetro " $A$ ". A fragmentação é crescente, conforme o aumento da energia específica aplicada à partícula, até que um limite superior seja atingido, a partir do qual o processo de fragmentação deixa de ocorrer (Figura 3.18).

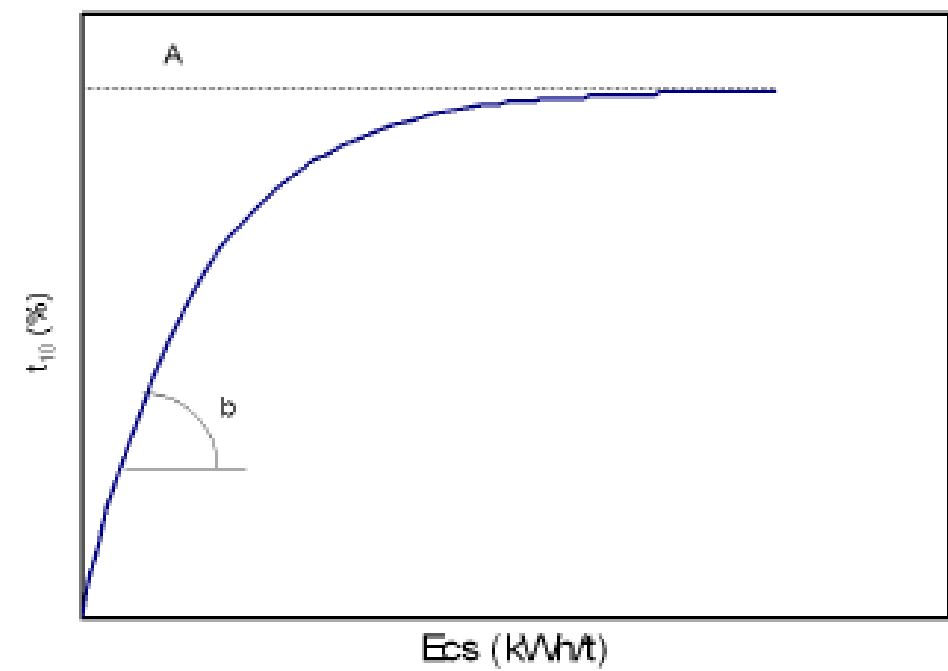

Figura 3.18 - Representação da relação energia / fragmentação obtida a partir de ensaios para amostras de minérios.

Os dois parâmetros A e b não são independentes, sendo a resistência ao impacto analisada em função do produto $A$ * $b$, denominado Índice de Quebra (IQ). Como se verifica na Tabela 3.1, quanto menor for o valor do parâmetro $A$ * $b$, maior será a resistência da amostra ao impacto. 
Tabela 3.1 - Classificação da resistência ao impacto como função do parâmetro A * b.

\begin{tabular}{|c|c|c|}
\hline do Parâmetro $A$ * $b$ & $\begin{array}{l}\text { lores } \\
A^{*} b\end{array}$ & \multirow[t]{2}{*}{ Resistência ao Impacto } \\
\hline Menor & Maior & \\
\hline 0 & 9,9 & Excepcionalmente Alta \\
\hline 10 & 19,9 & Extremamente Alta \\
\hline 20 & 29,9 & Muito Alta \\
\hline 30 & 39,9 & Alta \\
\hline 40 & 49,9 & Moderadamente Alta \\
\hline 50 & 59,9 & Média \\
\hline 60 & 69,9 & Moderadamente Baixa \\
\hline 70 & 89,9 & Baixa \\
\hline 90 & 109,9 & Muito Baixa \\
\hline \multicolumn{2}{|c|}{$>110$} & Extremamente Baixa \\
\hline
\end{tabular}

\subsubsection{Ensaio Drop Weight Test Simplificado (DWT-S)}

Chieregati e Delboni Jr. (2002) desenvolveram um ensaio considerando o emprego de amostras provenientes de testemunhos de sondagem de menor diâmetro, como os testemunhos de 2", que são as amostras geralmente disponíveis para estudos nas fases iniciais de pesquisa. O método é essencialmente o mesmo utilizado no ensaio DWT, com exceção dos seguintes fatores:

- No ensaio DWT-S, também conhecido como ensaio sintético de impacto, submetem-se ao impacto fragmentos contidos em uma única fração granulométrica. Assim, ao invés dos 15 lotes de trinta fragmentos requeridos para o ensaio DWT, apenas três lotes são analisados.

- O valor do parâmetro de abrasão - índice de abrasão ( $t_{a}$ ) - é estimado empiricamente como $1 \%$ do valor de $A{ }^{*} \mathrm{~b}$ da amostra ensaiada, já que o ensaio DWT-S considera a situação em que não se dispõe de fragmentos de rocha de tamanho necessário para a realização de ensaios de tamboramento.

Os métodos de caracterização que utilizam a Célula de Impacto contrapõemse conceitualmente aos métodos baseados em índices de consumo de energético específico ou às equações empíricas derivadas desse índice. A Célula de Impacto reproduz, separadamente, os mecanismos de fragmentação que ocorrem no interior de moinhos autógenos e semiautógenos, tanto em relação à intensidade quanto em relação ao tamanho do fragmento. 


\subsubsection{ENSAIO de ABRAsão}

O ensaio de abrasão é realizado em um moinho de 12" de diâmetro e 12" de comprimento. As condições do ensaio, padronizadas pelo JKMRC (1995) são: 3 kg de amostras entre 38 e $55 \mathrm{~mm}, 10$ minutos de tamboramento a $70 \%$ da velocidade crítica, 53 rpm. Após a conclusão de cada ensaio, o conteúdo do moinho é removido para análise granulométrica (NAPIER-MUNN et al., 1999).

O índice de abrasão, denominado $t_{a}$, representa o parâmetro de resistência da amostra à fragmentação por abrasão. $O$ valor do parâmetro $t_{a}$ é numericamente igual a um décimo do valor de $t_{10}$, obtido pela análise granulométrica do produto tamborado. Quanto menor for $0 t_{a}$, maior será a resistência da amostra à fragmentação por abrasão, como se verifica na Tabela 3.2.

Tabela 3.2 - Classificação da resistência à abrasão como função do parâmetro ta.

\begin{tabular}{|c|c|c|}
\hline \multicolumn{2}{|c|}{ Intervalo de Valores } & \multirow{2}{*}{ Resistência à Abrasão } \\
\hline Menor & Maior & \\
\hline 0,00 & 0,19 & Extremamente Alta \\
\hline 0,20 & 0,39 & Muito Alta \\
\hline 0,40 & 0,59 & Alta \\
\hline 0,60 & 0,79 & Moderadamente Alta \\
\hline 0,80 & 0,99 & Média \\
\hline 1,00 & 1,19 & Moderadamente Baixa \\
\hline 1,20 & 1,39 & Baixa \\
\hline 1,40 & 1,59 & Muito Baixa \\
\hline \multicolumn{2}{|c|}{$>1,60$} & Extremamente Baixa \\
\hline
\end{tabular}

\subsubsection{ENSAIO SAG POWER INDEX (SPI®)}

Desenvolvido na década de 1990 pela MinnovEX Technologies - empresa canadense baseada em Toronto (hoje SGS) -, o ensaio SAG Power Index (SPI®) assemelha-se ao Work Index de Bond mas utiliza padronizações diferentes daquelas estabelecidas no WI em relação às dimensões, ao perfil interno e à potência do moinho, à distribuição granulométrica da alimentação e à carga de bolas (SILVA; MAIA; DELBONI Jr., 2002). 
As condições padronizadas do SPI®, elencadas por Starkey e Dobby (1996), são apresentadas a seguir:

- moinho SAG com 304,8 mm de diâmetro e 101,6 mm de comprimento;

- carga de corpos moedores de aço correspondente a $15 \%$ do volume interno do moinho;

- alimentação do ensaio com $2 \mathrm{~kg}$ de amostra seca e britada em granulometria $80 \%$ passante em $12,7 \mathrm{~mm}$;

- $\quad$ produto requerido com granulometria $80 \%$ passante $\left(P_{80}\right)$ em $1,7 \mathrm{~mm}$

O ensaio de moagem é conduzido em estágios, até que o produto tenha um $\mathrm{P}_{80}$ de 1,7 mm. O tempo - em minutos - requerido para atingir a especificação de redução de tamanho, e a análise granulométrica da descarga do moinho são os parâmetros obtidos.

O SPI® é transformado em kWh/t e utilizado em simulações de circuito e em estimativas de produção com o uso do software Comminution Economic Evaluation Toll (CEET2®), desenvolvido com o suporte técnico e financeiro das treze maiores empresas de mineração.

\subsubsection{ENSAIOS dE MECÂNICA de ROCHAS}

Os ensaios de mecânica de rochas têm por objetivo definir as propriedades dos minérios, como a resistência que apresentam à compressão uniaxial (Unconfined Compressive Strength - UCS) e à carga pontual - configurada no ensaio de carga pontual (Point Load Test - PLT), entre outras.

\subsubsection{Ensaios em Planta Piloto}

Uma campanha de ensaios piloto é caracterizada por operação contínua e em condições e configurações similares às das unidades em escala industrial. A massa de amostras requerida é uma função do top $\operatorname{size}^{6}$ da amostra testada e do tamanho e da taxa de alimentação do equipamento da planta piloto.

\footnotetext{
6 Top Size: granulometria máxima ou tamanho máximo.
} 
Os ensaios piloto são, em geral, referência para determinar a potência total requerida para um circuito industrial de moagem. Para circuitos AG/SAG, os ensaios em escala piloto têm alimentação de até $5 \mathrm{t} / \mathrm{h}$. Em particular, ensaios contínuos com moinhos AG/SAG de 6 pés de diâmetro por 3 pés de comprimento são praticamente padrão para a análise de desempenho de tais configurações, pois têm a vantagem de empregar alimentação praticamente idêntica à faixa de tamanhos utilizada nos equipamentos industriais. As melhores instalações piloto são altamente instrumentadas e conectadas a sistemas de coleta de dados. A coleta dos dados e a amostragem do circuito são conduzidas quando o ensaio atinge a condição de equilíbrio. Os principais dados obtidos nos ensaios em planta piloto são:

- $\quad$ tonelagem de alimentação (t/h);

- potência $(\mathrm{kW})$ e energia de moagem $(\mathrm{kWh} / \mathrm{t})$;

- balanço de massa: granulometria, vazão e densidade para a descarga do moinho, a carga circulante e o produto de moagem;

- $\quad$ peso, volume e granulometria da carga do moinho.

As desvantagens e/ou limitações dos ensaios em planta piloto são: a necessidade de grandes quantidades de amostras para alcançar o estado de equilíbrio da operação; o tempo consumido para a realização dos ensaios; a dificuldade de obtenção de amostras representativas do depósito; e a necessidade de instrumentação para determinação dos parâmetros dos ensaios.

O dimensionamento de circuitos de cominuição considera resultados dos ensaios de fragmentação e o modelamento desses dados. Os modelos considerados são calibrados a partir de dados de plantas de tratamento de minérios existentes e algumas vezes, os ensaios em planta piloto podem ser excluídos. Em outras situações os ensaios em planta piloto são recomendados, como exemplo: quando as características do minério e/ou circuito não são usuais ou quando é necessária a produção de material para ensaios nas etapas seguinte, como flotação e lixiviação.

Os ensaios em planta piloto são importantes para a calibração de modelos existentes, pois fornecem o dimensionamento final do circuito de forma mais robusta (VERRET; CHIASSON; McKEN, 2011). 


\subsubsection{RELAÇÃo ENTRE O WI, O DWT E O TA}

Estudos realizados no JKMRC mostraram a relação entre os parâmetros de impacto $(A$ * $b)$ e de abrasão $\left(t_{a}\right)$ de diferentes tipos de minérios e o índice de trabalho em moinho de bolas (WI). As correlações entre esses parâmetros são apresentadas na Figura 3.19 (NAPIER-MUNN et al., 1999).
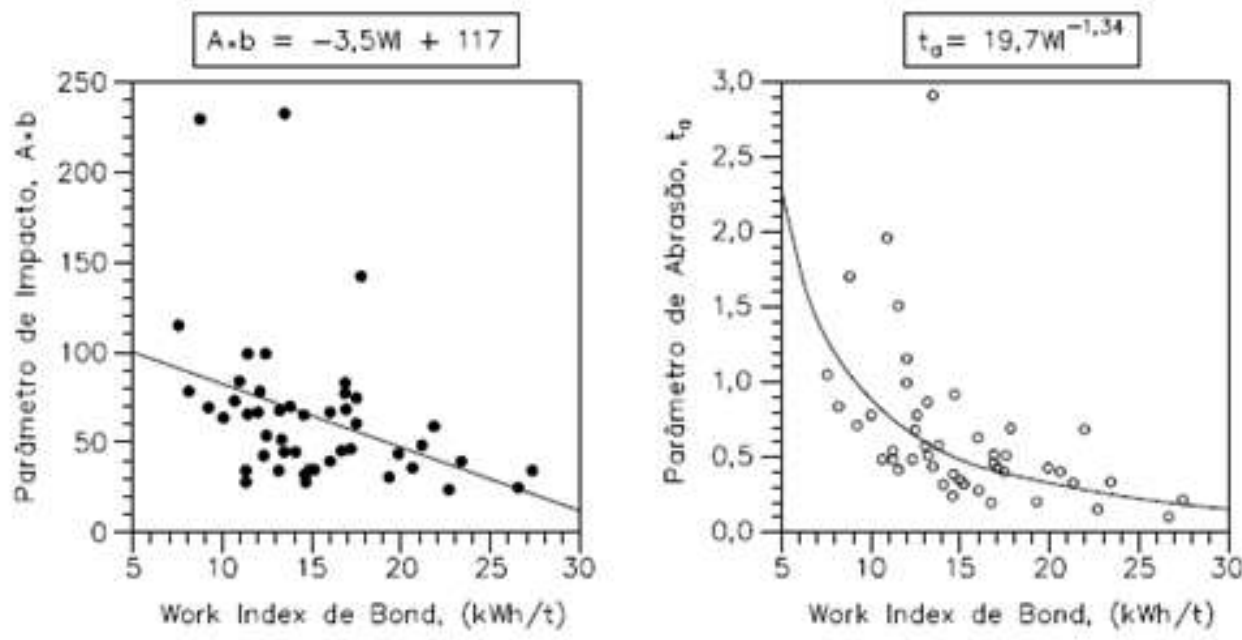

Fonte: Napier-Munn et al. (1999)

Figura 3.19 - Correlações entre os parâmetros $A$ * $b, t_{a}$ e WI.

A inexistência de correlação adequada entre o WI e os parâmetros $A$ * $b$ e $t_{a}$ decorre da diferença conceitual entre o WI e o DWT. Enquanto o Work Index de Bond busca analisar o comportamento coletivo das partículas - reproduzindo, em condições controladas, o processo de moagem em moinhos de bolas -, o Drop Weight Test objetiva avaliar a fragmentação de partículas individuais - separando a quebra por impacto da quebra por abrasão.

\subsection{FATORES QUE INFLUENCIAM A SELEÇÃO E O DIMENSIONAMENTO DE CIRCUITOS DE COMINUIÇÃO}

\subsubsection{INTRODUÇÃO}

Os elevados custos de capital e de operação associados às etapas de cominuição demandam a seleção de circuitos eficientes. Alguns dos muitos fatores a considerar quando da elaboração de projetos de circuitos de cominuição são abordados nesta seção. 
A análise e a compreensão das características do minério são fundamentais na definição de circuitos de cominuição. Diferentes tipos de minério requerem a avaliação e a estimativa dos parâmetros de cominuição, umidade, teores de minerais úteis e de ganga e tamanho de liberação. Da mesma forma, a seleção das amostras para ensaios em escala de bancada ou em planta piloto constitui-se em momento crítico para a definição das etapas de tratamento a serem consideradas.

Também devem ser avaliados fatores relacionados à planta, como vazão de alimentação, localização, clima, acessos e disponibilidade de água. E, finalmente, é necessário proceder a uma análise comparativa das várias opções de circuitos de cominuição, considerando as vantagens e as desvantagens relativas a cada um desses circuitos e avaliando os aspectos técnicos, econômicos e ambientais que os permeiam.

\subsubsection{INTERPRETAÇÃo Geológica e Requisitos de Amostragem}

Amostragem é a sequência de operações empreendidas para a obtenção de uma fração representativa de uma determinada população ou universo (BERGERMAN, 2009; FOGGIATO, 2009; OLIVEIRA; AQUINO, 2007). Assim sendo, e considerando que - como anteriormente mencionado - a análise e a compreensão das características do minério são fundamentais na definição dos circuitos de cominuição, o tipo de depósito e os padrões de mineralização de um dado material definem os requisitos de amostragem e, consequentemente, os procedimentos específicos a serem adotados para a obtenção desta (GY, 1998).

Tendo em vista que os métodos de amostragem para estudos de viabilidade dependem das características geológicas do depósito, os procedimentos de aquisição inicial de amostras devem ser adaptados a cada depósito particular. Para tanto, faz-se necessário determinar os constituintes minerais e suas quantidades relativas, o grau de disseminação e os principais tipos de minério existentes no depósito em estudo, sem deixar de considerar que amostras de superfície podem apresentar alterações decorrentes da intemperização a que estão sujeitas.

Como anteriormente mencionado, a cominuição é responsável pelo maior consumo de energia - e pelos maiores custos de operação - em uma usina de tratamento de minérios. Assim sendo, e considerando que a amostragem é uma das 
etapas do processo de seleção de circuitos de cominuição mais eficientes, há que manter foco nos custos relativos e no tempo despendido para a obtenção e o processamento das amostras. As campanhas de sondagem fornecem amostras preliminares, que podem subdivididas e utilizadas para a interpretação geológica do minério e para os testes geometalúrgicos. Amostras de superfície e/ou canaletas também podem ser utilizadas nos ensaios preliminares.

Na seleção das amostras, há que considerar a variabilidade do minério e as proporções dos tipos de minério. A fidelidade às características da população que representa é a qualidade fundamental de uma amostra.

\subsubsection{CARACTERIZAÇão MineralógicA E QuímicA}

As análises mineralógicas constituem-se em recurso essencial para a identificação dos constituintes do material e a determinação de suas propriedades. As técnicas e recursos de análise possibilitam a quantificação das espécies, viabilizando a determinação da composição mineral - ainda que estimada - e do grau de liberação do mineral útil (SANT'AGOSTINO; KAHN, 1997).

A difração de raios-X é fornece uma estimativa semiquantitativa das proporções minerais. Contudo, técnicas ópticas simples ou de raios- $X$ apresentam limitações na identificação dos minerais. Nesses casos, métodos sofisticados de análise, como a microscopia eletrônica de varredura (MEV), devem ser usados para determinar as características minerais e a ocorrência dos elementos associados.

O desenvolvimento da automatização de sistemas para identificar fases minerais e grau de liberação em amostras tem um impacto significativo no estudo da cominuição. Esses sistemas automatizados, como o Mineral Liberation Analyzer (MLA) e o Quantitative Evaluation of Materials - Scanning Electronic Microscopy (QEM*SEM), apresentam como vantagens a precisão e a velocidade na identificação das partículas portadoras e associações do elemento de interesse. O sistema $\mathrm{QEM}^{\star}$ SEM, inicialmente desenvolvido por Reid, Grant e coautores, permite a identificação de fases minerais e a determinação do grau de liberação das amostras de forma automatizada (HENLEY, 1983). 
A análise química apresenta boa precisão para definir quantitativamente os elementos selecionados, bem como para confirmar análises qualitativas e ou. semiquantitativas

\subsubsection{ESPECIFICAÇÕES DA ALIMENTAÇÃo}

Informações como planos de lavra, sequenciamento da mina, métodos de lavra e vazões de alimentação devem ser disponibilizadas e avaliadas, já que afetam a eleição do tamanho e do tipo de equipamentos de cominuição. Parâmetros como horas de operação para os circuitos, necessidades de estocagem do minério, blendagem e proporções de cada tipo na composição da alimentação, além de localização do circuito, dentre outros, também devem ser analisados.

A granulação da alimentação do circuito deve ser determinada previamente, já que a proporção de finos pode levar à necessidade de peneiramento do produto após a britagem primária. Outro aspecto importante é o tamanho máximo do produto da lavra, bem como o tamanho máximo do produto do britador primário.

A potência do moinho SAG é dinâmica e grandemente afetada pelas mudanças das condições operacionais. Como o desempenho da moagem SAG é fortemente influenciado por propriedades do minério - distribuição de tamanhos, tenacidade e densidade -, mudanças nas características da alimentação podem rapidamente alterar as condições operacionais do circuito.

Mais recentemente, programas de integração entre mina e usina (mine to mill) têm enfatizado a prática de desmonte com vistas ao melhor desempenho do circuito de cominuição.

\subsubsection{INFluência do Circuito de Cominuição nos Processos Metalúrgicos}

Os impactos dos métodos de cominuição nas operações subsequentes como flotação, gravimetria e lixiviação - devem ser investigados e avaliados sob o foco de aspectos técnicos e econômicos como a redução de custos operacionais, o acréscimo de recuperação metalúrgica etc. 
A resposta da flotação é influenciada por fatores como granulometria e liberação do produto do circuito de moagem. O ambiente eletroquímico dos moinhos também interfere no processo de flotação, com ênfase à presença de íons ferro.

O desempenho da flotação de sulfetos de minerais de cobre, zinco e chumbo tende a ser menor em circuitos de moagem tradicional - com o uso de meios moedores- do que em circuitos de moagem AG.

Outro aspecto a ser analisado quando projetos de circuitos autógenos são avaliados, é que o moinho pode apresentar variações muito elevadas na taxa de alimentação. Se essas variações não forem ajustadas nos processos metalúrgicos subsequentes, haverá diminuição de recuperação e/ou dos teores de produto, com consequências deletérias ao desempenho do processo. Em tais casos recomendase a blendagem de diferentes tipos de minério, de forma a aumentar a homogeneidade da alimentação do moinho.

O impacto dos métodos de moagem na recuperação metalúrgica por flotação tem sido objeto de estudos, e deve ser incorporado à avaliação econômica dos circuitos de cominuição (HEISKANEN; KALAPUDAS; KOIVISTOINEN, 2001). 


\section{DESCRIÇÃO DAS OPERAÇÕES}

\subsection{INTRODUÇÃO}

A Rio Paracatu Mineração - empresa do Grupo Kinross Gold Corporation (Kinross) - opera a Mina Morro do Ouro tratando o minério de baixo teor aurífero. Como ilustra a Figura 4.1, a Mina Morro do Ouro está localizada na cidade de Paracatu, no noroeste de Minas Gerais, a 480 km de Belo Horizonte e 230 km de Brasília.

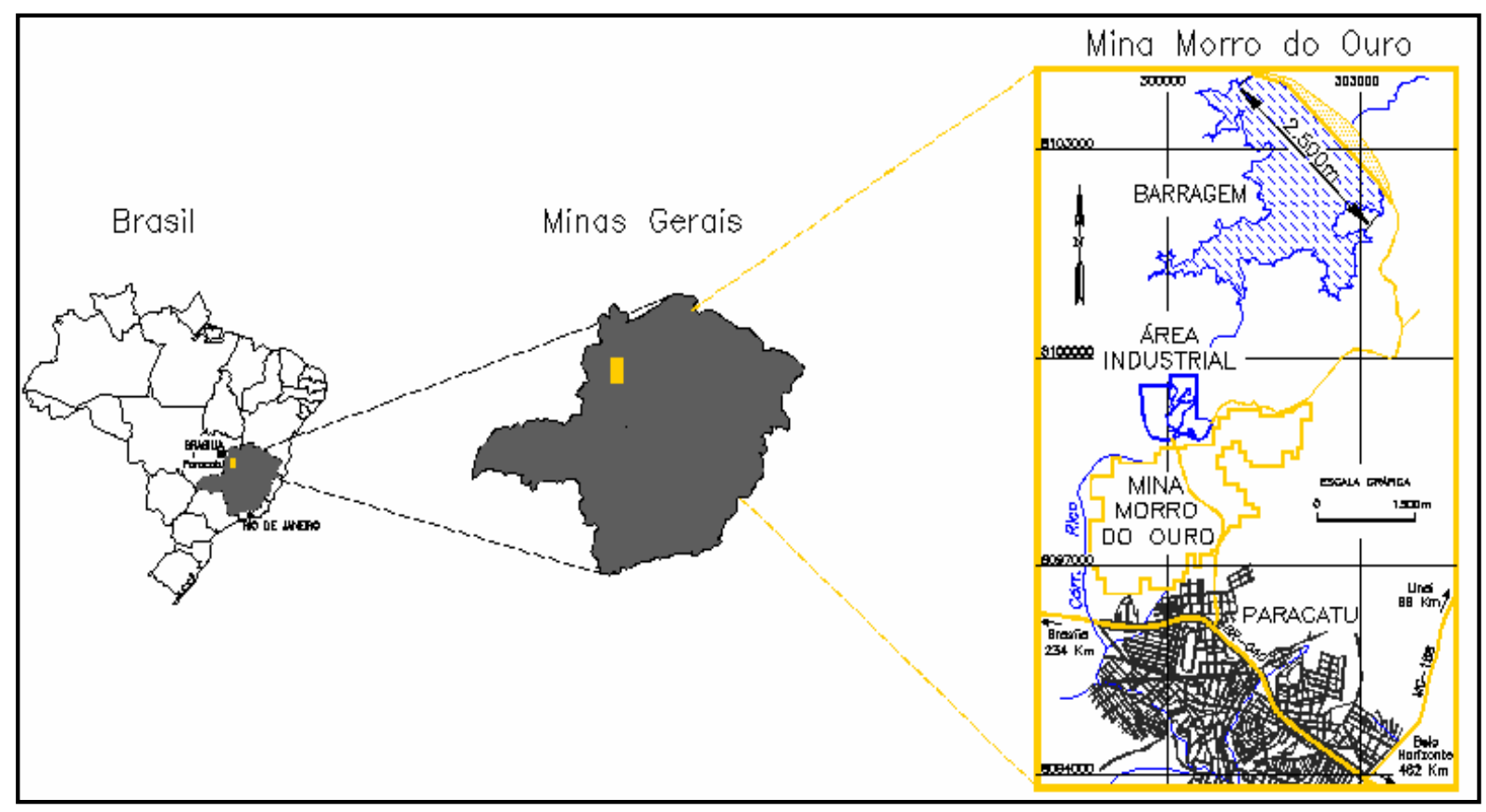

Figura 4.1 - Localização geográfica da Mina Morro do Ouro (Paracatu - MG).

A cidade de Paracatu nasceu no início do século XVIII, e o Morro do Ouro foi um dos primeiros núcleos de povoamento da cidade. Embora a ocorrência de ouro em Paracatu tenha sido registrada em 1722, o descobrimento das minas foi reconhecido somente em 1744. O período compreendido entre 1752 e 1787 foi o de maior produção de ouro em Paracatu. O esgotamento do ouro aluvial levou os mineradores ao Morro da Cruz das Almas - hoje conhecido como Morro do Ouro -, local de origem das jazidas. Mas dificuldades surgiram e não foram superadas, fazendo com que a produção de ouro na região entrasse em declínio (CARVALHO, 1992).

A partir daí, a atividade mineira de Paracatu ficou restrita ao garimpo, praticado como forma de subsistência pelos moradores de Paracatu até meados da 
década de 1980. Retomada em 1984 pela Rio Tinto, a exploração da região ganhou fôlego em 1987, com a associação entre aquela empresa e a Autram Mineração e Participações - posteriormente TVX Gold - para a constituição da RPM. A produção da RPM teve início em outubro de 1987 com o processamento de minério oxidado, e em dezembro daquele mesmo ano a empresa produziu o primeiro bullion ${ }^{16}$.

Em janeiro de 2003, os 49\% de capital pertencentes à TVX Gold foram adquiridos pela Kinross Gold Corporation que, em dezembro de 2004, adquiriu os $51 \%$ remanescentes da Rio Tinto. No final de 2005, as reservas provadas e prováveis totalizaram 1,18 bilhões de toneladas, com teor médio de 0,40 g/t de ouro. Naquele mesmo ano, a planta de beneficiamento da RPM processou 17 Mtpa e produziu 180.519 oz de ouro.

\subsection{GEOLOGIA E MINERALIZAÇÃO}

O depósito de ouro de Paracatu é um sistema metamórfico com mineralização de ouro finamente disseminada na rocha sedimentar hospedeira. A mineralização ocorre dentro da sequência sedimentar Morro do Ouro, localizada sobre o maciço Serra do Landim e constituída por uma série de filitos finamente laminados, cuja intrusão de Sudoeste (SO) a Nordeste (NE) provocou extensa deformação. Essa deformação foi responsável pela remobilização do ouro e dos sulfetos dentro do filito. A mineralização de ouro localiza-se dentro de uma zona altamente deformada, com espessura entre 120 e 140 metros e mergulho de $20^{\circ}$ a SO.

O minério de ouro lavrado pela RPM é um metapelito situado na base da Formação Paracatu, cuja sequencia foi informalmente denominada Fácies Morro do Ouro composta por filitos sericíticos carbonosos, com intercalações de até 8 metros de quartzitos e ocorrências de boudins ${ }^{17}$ de quartzo (MONTE et al., 2001).

${ }^{16}$ bullion - barra de ouro proveniente da etapa de fundição, cuja composição (na RPM) compreende ouro, prata e impurezas como $\mathrm{Cu}, \mathrm{Zn}, \mathrm{Fe}$ e $\mathrm{Pb}$.

17 boudins: tipo particular de lineação, de corpos alongados. A boudinage é uma estrutura típica de estratos competentes que fraturam a intervalos regulares, originando corpos cilindróides (os boudins) dispostos lado a lado. O conceito aqui usado refere-se às camadas de quartzo rompidas e mineralizadas com assembléia sulfetada em condições favoráveis de pressão de água e carga organometálica. 
O depósito de Paracatu é subdividido em quatro horizontes - definidos pelo grau de oxidação, intemperismo e minerais sulfetados associados -, denominados C, T, B1 e B2 (HANSON, 2005). A mineralização C, que se estende da superfície até 30 metros de profundidade, é completamente alterada, oxidada e sem sulfetos remanescentes. O horizonte $\mathrm{T}$ corresponde a uma zona de transição entre os horizontes C e B1. A unidade B1 apresenta coloração escura a preta devido à presença de material grafitoso; os sulfetos estão completamente oxidados, mas a presença de alguns sulfetos não oxidados pode ser verificada no interior dos boudins de quartzo. A mineralização $\mathrm{B} 2_{2}$ ou rocha fresca, contém os sulfetos disseminados ao longo da foliação da rocha e concentrados nos boudins de quartzo.

De vez que a tenacidade do minério - medida através de ensaios de Work Index em moinho de bolas - aumenta com a profundidade, o horizonte B2 detém os maiores valores para esse parâmetro. De menor tenacidade, os horizontes C e T estão quase que totalmente exauridos, ou seja: a maior parte das reservas está localizada nos horizontes B1 e B2. A Figura 4.2 apresenta uma secção geológica conceitual para o depósito de Paracatu.

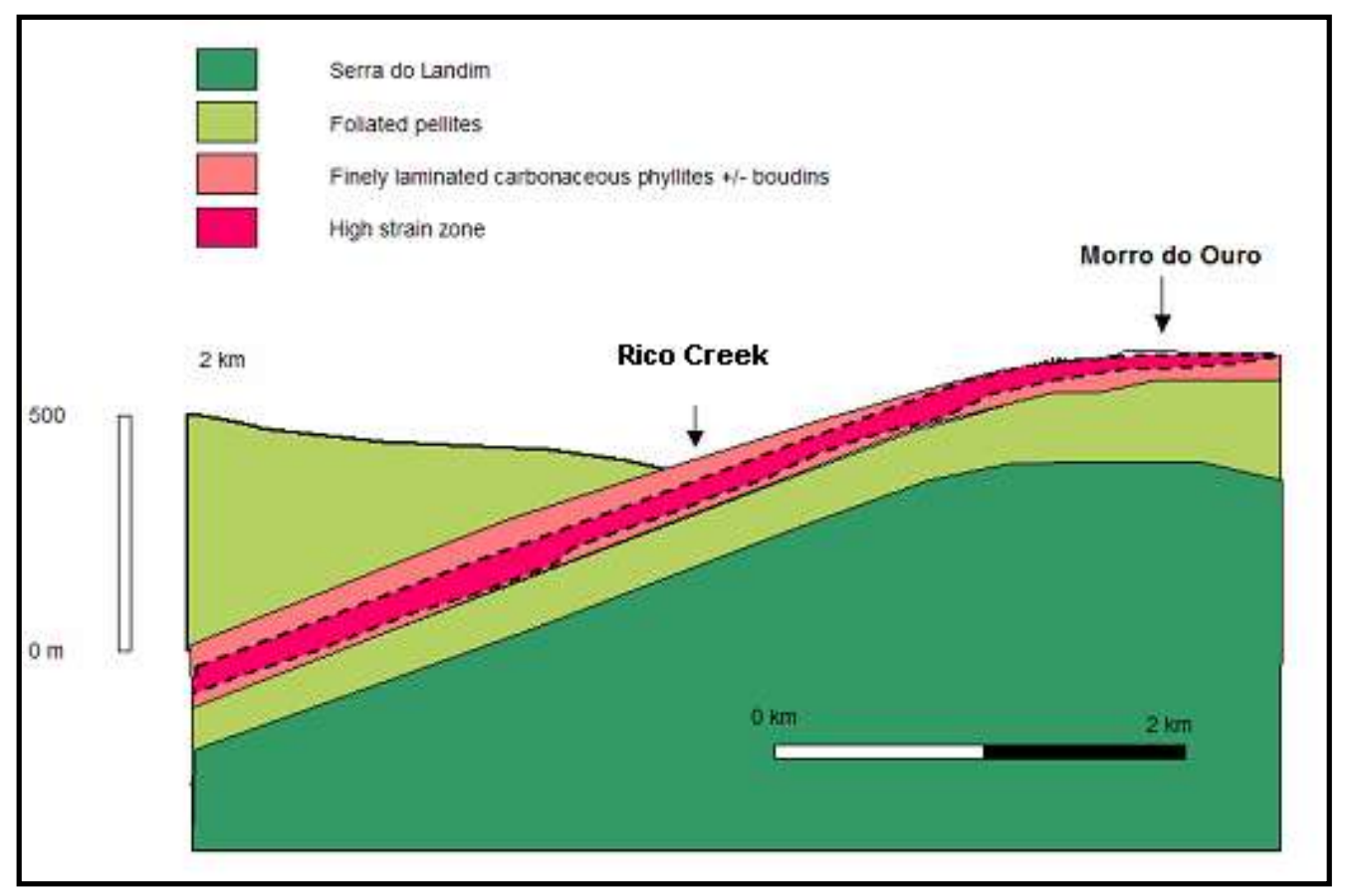

Figura 4.2 - Secção geológica conceitual do depósito de Paracatu.

A mineralização de ouro está relacionada a fluidos de natureza hidrotermal ricos em arsênio, ouro, chumbo e zinco. A mineralização de sulfetos é 
dominantemente arsenopirita e pirita e quantidades menores de pirrotita, calcopirita, esfarelita e galena. O ouro, associado à arsenopirita e à pirita, ocorre predominantemente em grãos finos, menores que $10-20 \mu \mathrm{m}$, nas fraturas ou nas bordas dos grãos de arsenopirita e de pirita, como demonstra a Figura 4.3. A maior parte dos grãos de ouro apresenta quantidades variadas de prata.

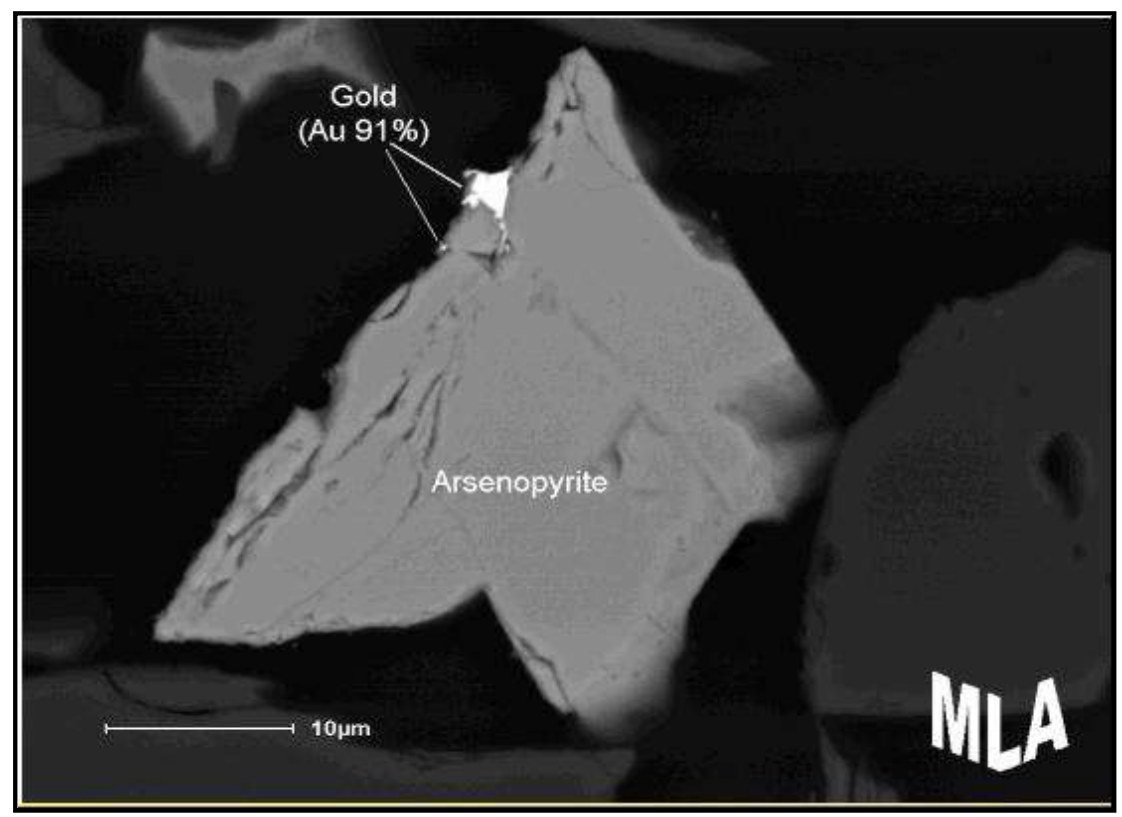

Figura 4.3 - Grãos de ouro associados à arsenopirita em amostra de minério da RPM.

Em função da variedade tipológica do horizonte $B 2$, os minérios nele presentes foram classificados em relação a: grau de deformação estrutural, teor de arsênio, textura dos sulfetos, tipos de sulfetos, graus de silificação (MÖLLER et al., 2001). Historicamente, a mineralização de sulfeto no horizonte mineralizado foi subdividida em três unidades, com base no conteúdo de arsênio (As):

- não-calha (As < 2500 ppm);

- $\quad$ calha (As > 2500 ppm);

- $\quad$ sulfeto intensamente deformado (As > 4000 ppm)

A arsenopirita, sulfeto mais comum, ocorre como grão fino $(<1 \mathrm{~mm})$ a agregados de grãos grosseiros (> $3 \mathrm{~mm}$ ). A quantidade desse elemento no minério afeta diretamente a recuperação metalúrgica.

Estudos mineralógicos de amostras da RPM, realizados nos laboratórios do JKMRC com o auxílio do Mineral Liberation Analyzer (MLA), indicaram que 92\% do 
ouro encontram-se liberado e menos de $8 \%$ encontra-se encapsulado por grãos de sulfeto ou sílica.

\subsection{LAVRA}

A lavra do minério é realizada a céu aberto, com bancadas de 8 metros. Até 2004, o desmonte era realizado apenas por "escarificação". A partir de 2004, explosivos passaram a ser utilizados nas áreas de minérios de maior dureza (horizonte B2). Os explosivos são empregados para "afrouxar" a rocha, o que favorece a ação da escavadeira.

As operações de lavra iniciam-se com o desmatamento e o decapeamento da cobertura vegetal, seguido pelo desmonte, o carregamento com carregadeira (Figura 4.4) e o transporte por caminhões.

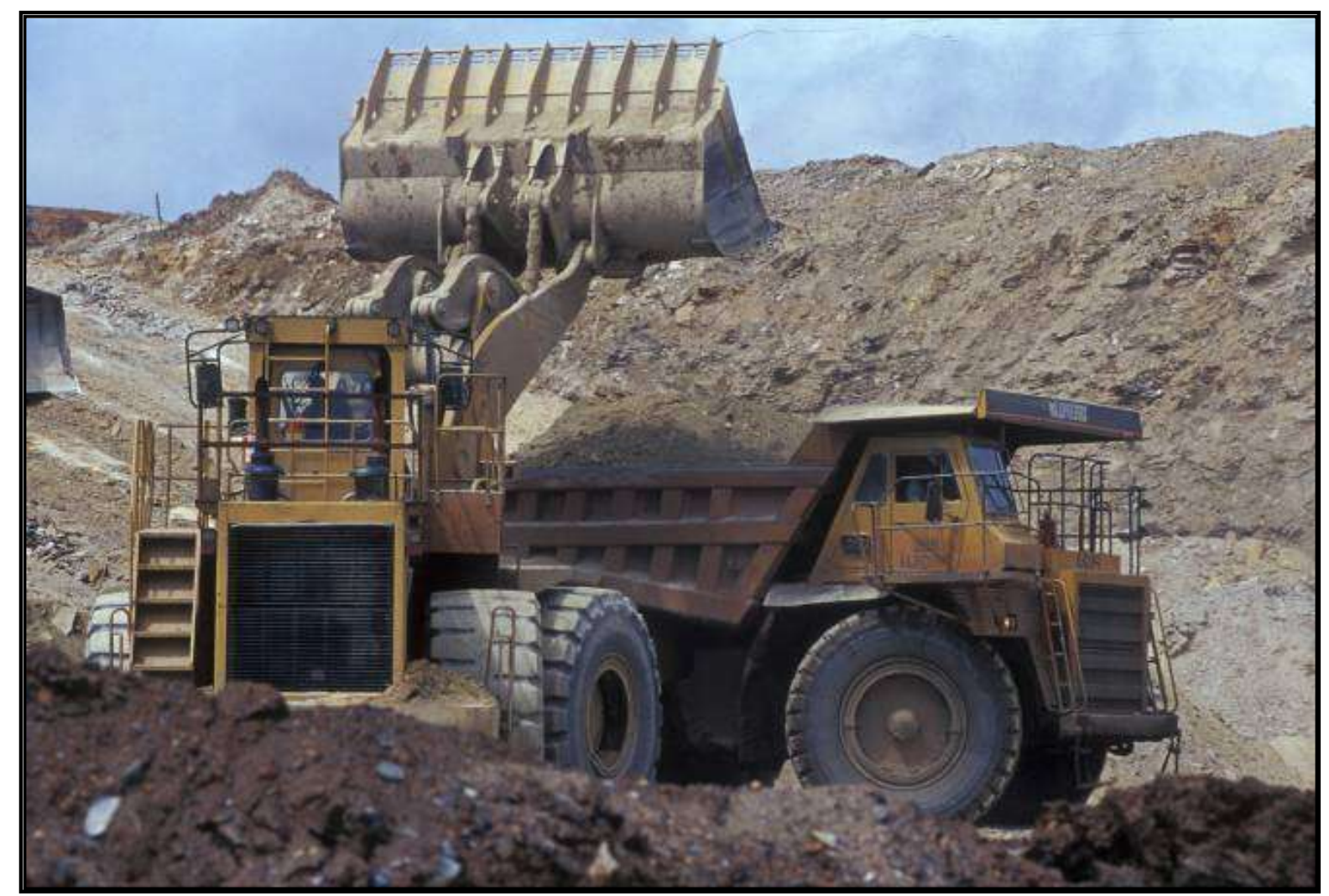

Figura 4.4 - Operação em frente de lavra da RPM. 


\subsection{BENEFICIAMENTO}

Na planta de 20 Mtpa, o fluxograma de beneficiamento da RPM compreende as seguintes etapas básicas: britagem, moagem, pré-concentração por flotação e gravimetria, extração metalúrgica por concentrador centrífugo, lixiviação e regeneração de carvão (Figura 4.5).

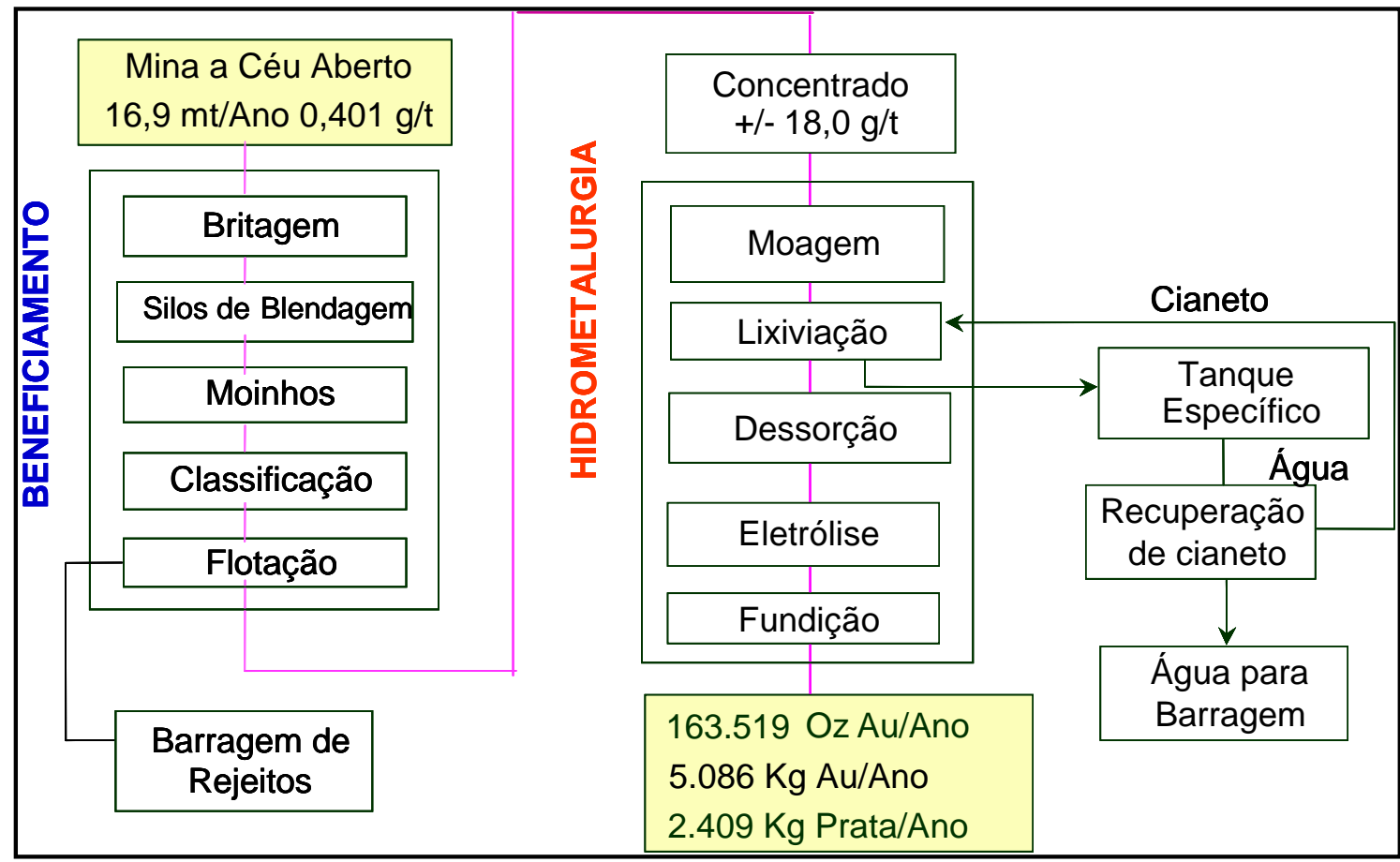

Figura 4.5 - Fluxograma simplificado do processo de beneficiamento da RPM.

\subsubsection{BRITAGEM}

Para a capacidade de $20 \mathrm{Mtpa}$, o circuito de britagem é configurado por quatro linhas paralelas, com capacidade de $1000 \mathrm{t} / \mathrm{h}$ cada. Em cada linha existe uma moega com capacidade de $100 \mathrm{~m}^{3}$ e um alimentador de sapatas de $500 \times 1500 \mathrm{~mm}$, que dirige o material para um peneiramento primário. $\mathrm{Na}$ etapa de peneiramento primário são utilizadas peneiras vibratórias com dois decks: no primeiro deles é utilizada uma tela de $75 \mathrm{~mm}$, e no segundo uma tela com abertura de $25 \mathrm{~mm}$. Produto final da britagem o material passante no segundo deck é encaminhado para o silo de blendagem.

O material retido no primeiro e segundo decks do peneiramento primário alimenta o sistema de britagem primária, constituído por um britador de impacto 
Hazemag modelo APSM 1320. O produto da britagem primária é encaminhado para o peneiramento secundário, realizado por uma peneira com dois decks, que apresentam aberturas de $40 \mathrm{~mm}$ e 18 x $50 \mathrm{~mm}$. O material passante nesse peneiramento constitui o produto final, e o material retido corresponde à alimentação de uma segunda etapa de britagem, na qual são utilizados britadores cônicos HP 200 Metso com abertura de trabalho de $16 \mathrm{~mm}$. O material resultante da britagem secundária é o produto final da etapa de britagem, e também é encaminhado para o silo de blendagem.

\section{4 .2}

\section{Moagem, Classificação, Flotação e Jigagem}

A etapa de moagem é conduzida através de quatro linhas de moagem paralelas, em cada uma das quais há um moinho de bolas de 15 x 19 pés. Cada linha de moagem primária também possui duas baterias de hidrociclones gMAX da Krebs de 20", com oito posições instaladas por bateria. O circuito de moagem secundária, denominado Quinto Moinho (Figura 25), é composto por três baterias com seis posições instaladas de hidrociclones de 20" cada, e por um moinho de 16,5 x 25 pés (Figura 4.6).

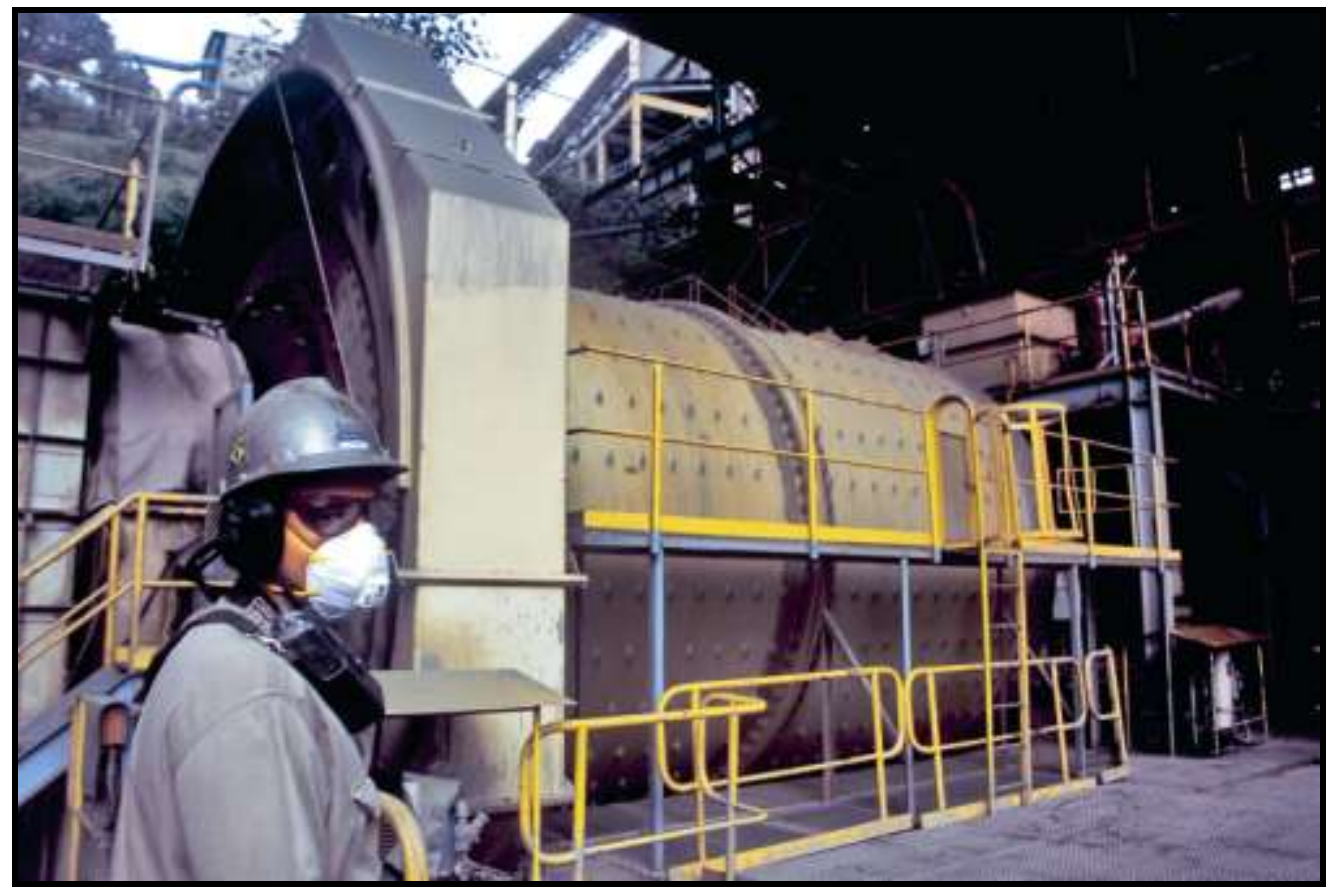

Figura 4.6 - Vista do moinho de bolas de 16,5 x 25 pés da RPM. 
O produto da britagem alimenta os moinhos primários, e a descarga da moagem classificada, overflow com $\mathrm{P}_{80}$ de $75 \mu \mathrm{m}$, é encaminhada para a etapa de flotação scavenger. Parte do underflow da classificação primária é encaminhada para o circuito de gravimetria, composto por duas baterias de oito jigues do tipo trapezoidal, Yuba. O restante do underflow da classificação primária e o rejeito da jigagem consistem na carga circulante, parte da qual é desviada para o circuito de classificação secundária (Quinto Moinho). O fluxo desviado para o circuito de moagem secundária é classificado sendo o overflow deste, também destinado à etapa de flotação scavenger e o underflow alimentado no Quinto Moinho. A descarga do Quinto Moinho retorna para a classificação da moagem primária. O oversize gerado nos moinhos é processado em um moinho de barras de $7,5 \times 10$ pés.

O circuito de flotação é composto por quatro linhas: nas linhas A e B são utilizadas células convencionais autoaeradas da Wemco, e de aeração forçada da Outokumpu, respectivamente; nas linhas C e D são utilizadas células tanque (Smart Cells da Wemco). O volume total de cada linha de flotação scavenger é de $508 \mathrm{~m}^{3}$.

O concentrado da flotação scavenger é encaminhado para o estágio de flotação cleaner, que utiliza células convencionais Wemco de $16 \mathrm{~m}^{3}$ cada uma, totalizando $160 \mathrm{~m}^{3}$ de volume. O concentrado da flotação cleaner, em conjunto com o concentrado da jigagem, constitui o concentrado final que alimenta a unidade de hidrometalurgia. A recuperação mássica do concentrado final é de cerca de $2 \%$ do total alimentado na planta de tratamento de minérios. O rejeito de flotação scavenger, rejeito final da planta, é encaminhado para deposição na barragem de rejeitos.

O fluxograma resumido dos processos de moagem, classificação e préconcentração - jigagem e flotação - é apresentado na Figura 4.7. 


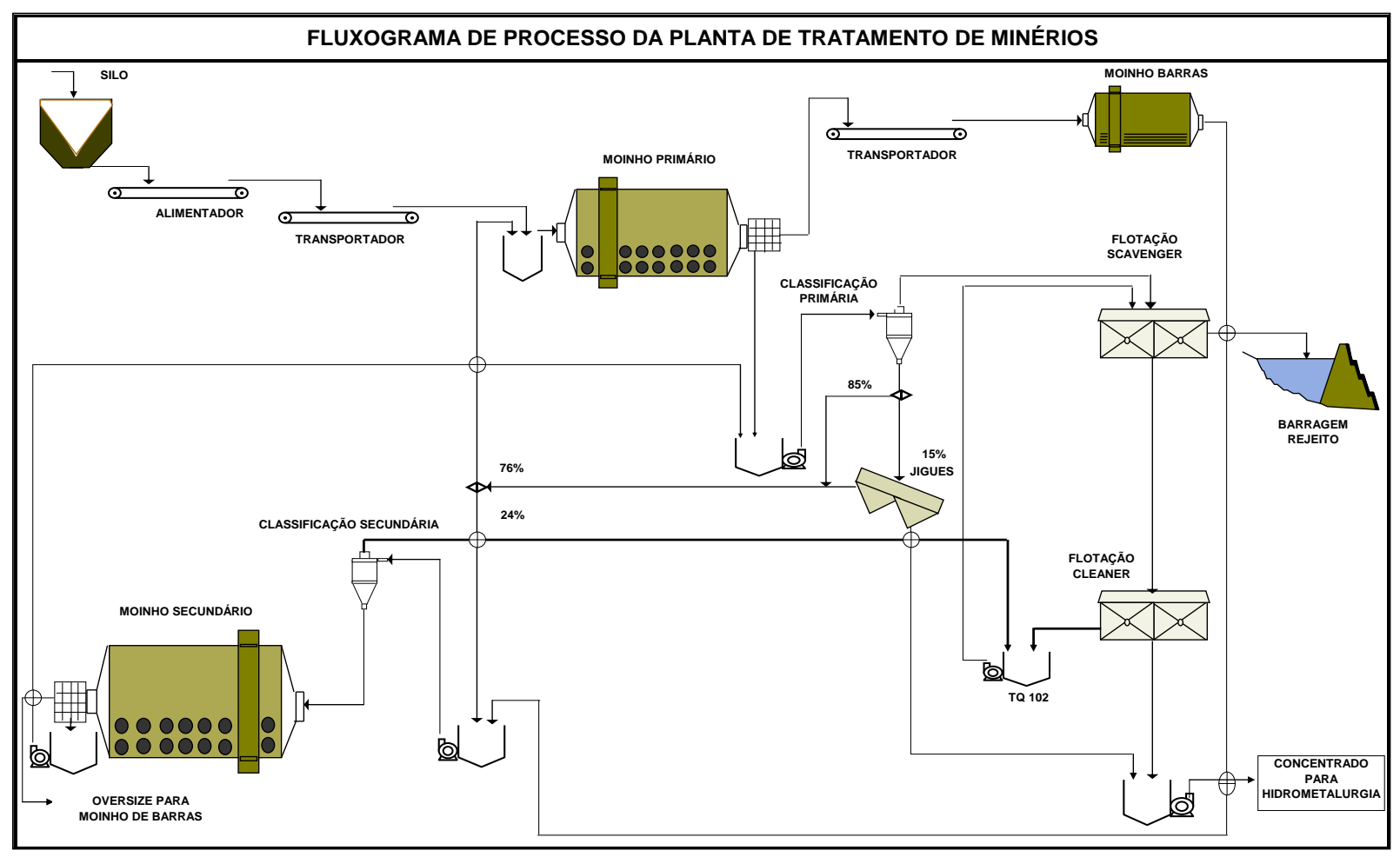

Figura 4.7 - Fluxograma das etapas de moagem, jigagem e flotação da RPM.

\subsubsection{HIDROMETALURGIA}

No circuito de hidrometalurgia, o concentrado final da planta de préconcentração é recebido em uma peneira, que atua como proteção contra corpos estranhos, e direcionado para um espessador de 16 metros de diâmetro. O underflow desse espessador alimenta a classificação da etapa de remoagem da hidrometalurgia. O overflow - água clarificada - retorna à planta.

A classificação da remoagem é composta por cinco hidrociclones de 15" da Krebs, mas usualmente são empregados três ciclones. $O$ underflow da classificação alimenta o circuito de remoagem, composto por dois moinhos de bolas em paralelo, um de $8 \times 11$ pés e outro de $7 \times 10$ pés. Uma parte do underflow da classificação é direcionada à etapa de concentração gravimétrica, realizada em um concentrador centrífugo knelson modelo XD-20. O overflow da classificação segue para um segundo espessador, também de 16 metros de diâmetro. 0 underflow desse espessador alimenta o circuito de lixiviação, e o overflow é água clarificada.

O circuito carbon in leach (CIL) utilizado na etapa de lixiviação é composto por oito tanques com capacidade nominal de $300 \mathrm{~m}^{3}$, dispostos em série. Em sete 
desses tanques utiliza-se carvão ativado em uma concentração de cerca de $3 \%$ volume/volume. A dosagem de cianeto de sódio e de leite de cal para ajuste do pH (pH 10,5 a 11) é realizada no primeiro tanque, correspondente à etapa de préaeração. Na base dos tanques é feita a injeção de oxigênio, e o carvão é movimentado em contracorrente.

O carvão carregado com o ouro passa por uma etapa de lavagem em solução a 3\% de ácido clorídrico e, após neutralização, é encaminhado para a etapa de dessorção. Após a dessorção, a solução pobre é reaquecida e devolvida, fechando o circuito. A solução carregada segue para a célula eletrolítica, e o material retido é submetido a uma peneira alimentada pelo carvão e encaminhado para regeneração em dois fornos contínuos.

A eletrodeposição do ouro em cátodos de lã de aço é resultante da eletrorrecuperação da solução carregada proveniente da eluição. Os cátodos são retirados manualmente e submetidos à secagem e à fundição, gerando bullions.

\subsection{Tratamento e Disposição de Rejeitos}

O rejeito do processo de pré-concentração do minério da RPM é disposto em uma barragem de rejeitos. Já o rejeito do circuito de lixiviação é submetido a uma etapa de tratamento - para redução dos níveis de concentração de cianeto na descarga dos efluentes - antes de ser disposto na barragem. Anteriormente realizado pelo processo de acidificação, volatilização e reneutralização (AVR), esse processo é conduzido pelo método $\mathrm{SO}_{2} / \mathrm{ar}$, com o uso de metabissulfito de sódio $\left(\mathrm{Na}_{2} \mathrm{~S}_{2} \mathrm{O}_{5}\right)$ e/ou bissulfito de amônio.

A Barragem de Rejeitos da RPM cumpre um importante papel no gerenciamento das águas, contribuindo para:

a decantação dos sólidos e a consequente clarificação da água contida na polpa do rejeito;

$>$ a degradação natural dos reagentes da flotação e do cianeto residual para níveis ambientalmente aceitáveis;

$>$ a reciclagem de cerca de $80 \%$ da água na planta de tratamento, o que diminui a demanda de captação de água nova;

$>$ a retenção de sólidos finos não decantados, possibilitada pela presença de filtros naturais, areia e brita no maciço da barragem. 


\subsection{MOTIVAÇÕES PARA O ESTUDO}

Iniciado em 1987 com uma escala de produção de $6 \mathrm{Mtpa}$, o tratamento de minério oxidado de superfície da RPM foi expandido para o patamar de produção de 11 Mtpa em 1993. Após a conclusão do Projeto de Expansão para tratamento de minério B2 em 1997, e a instalação do Quinto Moinho em 1999, a planta alcançou sua capacidade máxima - de 1,73 Mt/mês - em julho de 2000.

A planta da RPM, inicialmente projetada para processar minérios com WI de $3,0 \mathrm{kWh} / \mathrm{t}$, vem tratando minérios com WI superior a 6,0 kWh/t desde 2002. Com o aumento da tenacidade do minério, e sem investimentos substanciais na capacidade de britagem e de moagem, foi feita uma projeção em que o nível de alimentação da moagem estaria em declínio sendo, em 2026, alcançado o valor de 11 Mtpa. A Figura 4.8 demonstra o comportamento médio do WI e da taxa de alimentação para o minério da RPM no período de 2000 a 2006. O comportamento anômalo evidenciado em 2001 é decorrente da interrupção de atividade dos moinhos primários, submetidos a serviços de manutenção (solda).

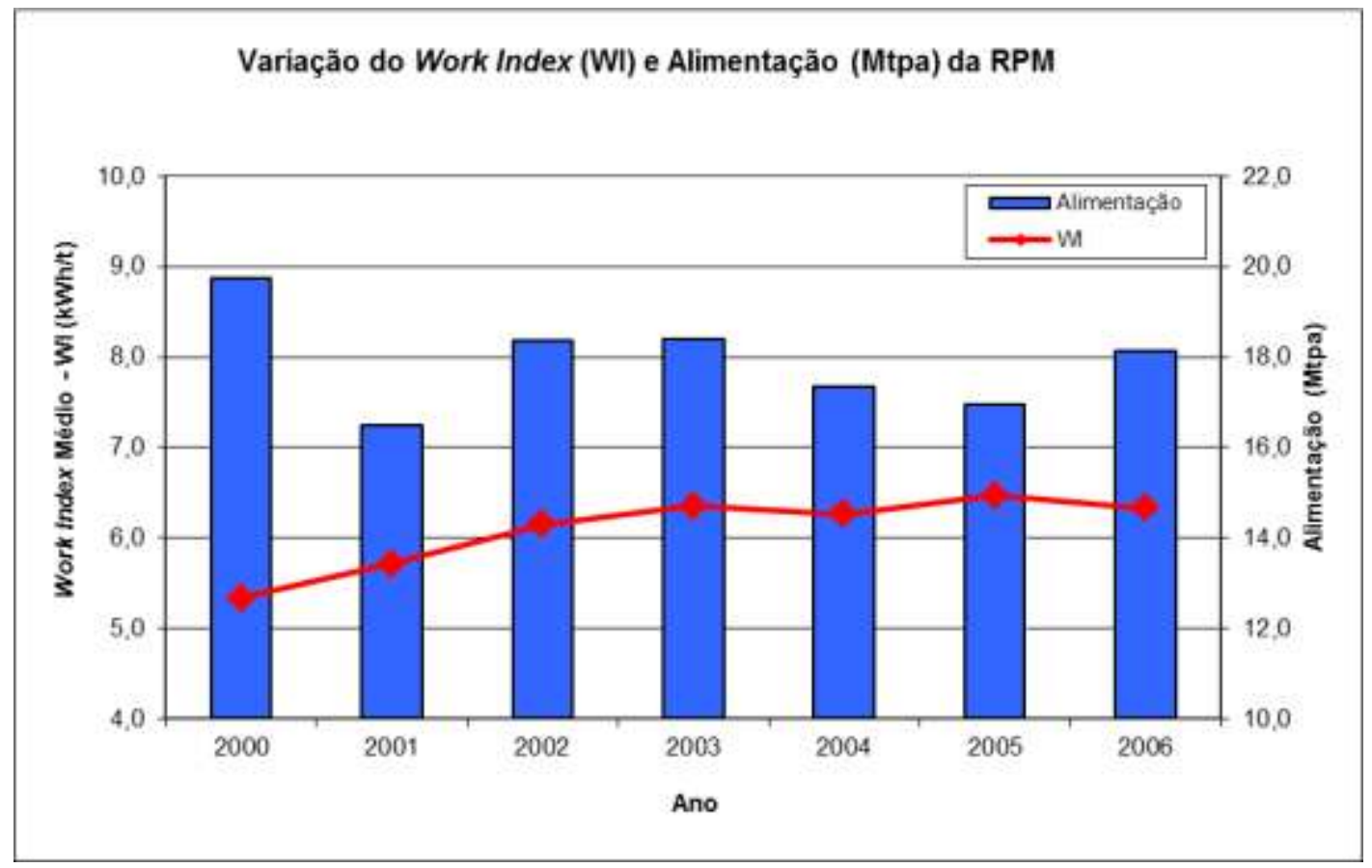

Figura 4.8 - Gráfico de variação do WI e alimentação da RPM no período de 2000 a 2006.

Com a aquisição da RPM pela Kinross em 2005, uma extensa campanha de sondagem - de 48.000m - foi realizada em Paracatu. Essa campanha indicou aumento das reservas e da vida da mina, além de confirmar o aumento de tenacidade do minério com a profundidade. 
Esse cenário - de aumento da tenacidade do minério e dos custos operacionais de processamento deste - evidenciou, aos gestores da RPM, a necessidade de aumentar a capacidade da planta e, consequentemente, da produção. Desde então, a RPM tem concentrado esforços na identificação de possibilidades voltadas ao aumento de sua capacidade de processamento. 


\section{MATERIAL E MÉTODOS}

\subsection{OBJETIVOS DOS ENSAIOS EM PLANTA PILOTO E DE CARACTERIZAÇÃO DAS AMOSTRAS}

A determinação de parâmetros para projetos de circuitos de moagem é mais confiável quando fundamentada em operações contínuas de circuitos de cominuição em escala piloto. Os ensaios em planta piloto com minérios da RPM, bem como a caracterização desses minérios, foram realizados com o objetivo de identificar as variáveis e/ou os parâmetros necessários ao dimensionamento de circuitos de moagem elencados a seguir:

- $\quad$ capacidade do circuito (t/h alimentada);

- consumo de energia na moagem (kWh/t);

- distribuição granulométrica do produto final;

- carga circulante $(\mathrm{t} / \mathrm{h})$;

- condições operacionais ótimas de moagem.

$E$, embora os referidos ensaios tenham também contemplado a avaliação do desempenho de diferentes configurações de circuitos de concentração metalúrgica flotação, jigagem e concentração centrífuga - para os minérios testados, estudos de concentração metalúrgica não são detalhados neste trabalho.

\subsection{MINÉRIOS EMPREGADOS NOS ENSAIOS}

A seleção dos tipos de minérios utilizados nos ensaios em planta piloto considerou as classes de minérios da reserva da RPM conhecidas até o ano de 2002, quando foi realizada. O resumo das informações obtidas na ocasião consta da Tabela 5.1.

Tabela 5.1 - Informações da reserva da RPM no ano de 2002.

\begin{tabular}{cccc}
\hline $\begin{array}{c}\text { Reserva } \\
\text { Total (Mt) }\end{array}$ & $\begin{array}{c}\text { Reserva } \\
\mathbf{W I}<\mathbf{7} \mathbf{~ k W h} / \mathbf{t}\end{array}$ & $\begin{array}{c}\text { Reserva } \\
\mathbf{7}<\mathbf{W I}>\mathbf{1 0} \mathbf{~ k W h} / \mathbf{t}\end{array}$ & $\begin{array}{c}\text { Reserva } \\
\mathbf{W I} \mathbf{1 0} \mathbf{~ k W h} / \mathbf{t}\end{array}$ \\
\hline 300,83 & $34 \%$ & $33,4 \%$ & $32,6 \%$ \\
\hline
\end{tabular}


A tenacidade do minério da RPM, verificada em ensaios de Bond Work Index em moinho de bolas, é influenciada pela tenacidade da matriz de filito, e pela presença e quantidade de boudins de quartzo. Os critérios de classificação dos minérios em função da textura da rocha constam da Tabela 5.2, que também apresenta os percentuais dos nove tipos de minérios - denominados TIPO 1 a TIPO 9 identificados.

Tabela 5.2 - Classificação das reservas da RPM em 2002.

\begin{tabular}{|c|c|c|c|}
\hline Classificação dos Minérios & $\begin{array}{c}\text { Reserva } \\
\text { WI }<7 \mathrm{kWh} / \mathrm{t} \\
\text { Tenacidade Baixa }\end{array}$ & $\begin{array}{c}\text { Reserva } \\
7<\mathrm{WI}>10 \mathrm{kWh} / \mathrm{t} \\
\text { Tenacidade Média }\end{array}$ & $\begin{array}{c}\text { Reserva } \\
\text { WI >10 kWh/t } \\
\text { Tenacidade Alta }\end{array}$ \\
\hline Filito sem boudins de quartzo (\%) & $28 \%$ (Tipo 1) & 19,7 \% (Tipo 4) & 18,5 \% (Tipo 7) \\
\hline Filito com boudins de quartzo (\%) & 3,8 \% (Tipo 2) & 10,6 \% (Tipo 5) & 10,4 \% (Tipo 8) \\
\hline Altas quantidades de boudins (\%) & $2,2 \%$ (Tipo 3) & $3,0 \%$ (Tipo 6) & 3,4 \% (Tipo 9) \\
\hline Total & $34 \%$ & $33,4 \%$ & $32,6 \%$ \\
\hline
\end{tabular}

Em virtude das dificuldades encontradas na obtenção de amostras de alguns tipos de minérios, bem como das limitações relacionadas ao número de ensaios piloto a serem realizados, não foram utilizados todos os tipos de minérios anteriormente descritos. Com foco na capacidade que tinham de representar as reservas da RPM, foram selecionados para os ensaios cinco tipos de minérios, cujas características gerais são apresentadas na Tabela 5.3.

Tabela 5.3 - Características gerais dos minérios da RPM selecionados para os ensaios piloto.

\begin{tabular}{cccc}
\hline Tipo de Minério & Textura da Rocha & Tenacidade & WI $(\mathbf{k W h} / \mathbf{t})$ \\
\hline Tipo B1 & $\begin{array}{c}\text { Min. de Superfície } \\
\text { (Oxidado) }\end{array}$ & Baixa (Macio) & $\mathrm{WI}<7$ \\
Tipo 1 & Filito sem boudins & Baixa (Macio) & $\mathrm{WI}<7$ \\
Tipo 4 & Filito sem boudins & Média & $7<\mathrm{WI}<10$ \\
Tipo 5 & Filito com boudins & Média & $7<\mathrm{WI}<10$ \\
Tipo 7 / Tipo 8 & $\begin{array}{c}\text { Filito duro sem e } \\
\text { com boudins }\end{array}$ & Alta & $\mathrm{WI}>10$ \\
\hline
\end{tabular}

Para representar as alimentações que seriam processadas no futuro, os ensaios em planta piloto compreenderam o tratamento individual e de composições - 
blendagens - dos minérios. A utilização de diferentes blendagens (Tabela 5.4) nos ensaios teve o objetivo de avaliar a influência da presença ou não de boudins de quartzo para valores próximos de WI, bem como de diferentes tenacidades de minério - baixa, média e alta - no desempenho da moagem.

Tabela 5.4 - Blendagens dos minérios da RPM utilizadas nos ensaios piloto.

\begin{tabular}{cccccc}
\hline \multirow{2}{*}{ Blendagem } & \multicolumn{5}{c}{ Proporções dos Minérios Utilizadas nos Ensaios (\% em peso) } \\
& Tipo B1 & Tipo 1 & Tipo 4 & Tipo 5 & Tipo 7/8 \\
\hline \multirow{3}{*}{ B1 e Tipo 4 } & 30 & 0 & 70 & 0 & 0 \\
& 50 & 0 & 50 & 0 & 0 \\
& 70 & 0 & 30 & 0 & 0 \\
Tipo 1 e Tipo 4 & 0 & 0 & 0 & 0 & 0 \\
& 0 & 0 & 100 & 0 & 0 \\
& 0 & 30 & 70 & 0 & 0 \\
Tipo 1 e Tipo 5 & 0 & 50 & 50 & 0 & 0 \\
& 0 & 70 & 30 & 0 & 0 \\
Tipo 7 e Tipo 8 & 0 & 0 & 0 & 100 & 0 \\
\hline
\end{tabular}

\subsection{PREPARAÇÃO DAS AMOSTRAS DE MINÉRIOS PARA OS ENSAIOS EM PLANTA PILOTO}

\subsubsection{Preparação de Amostras de SuPERfícle}

As amostras dos minérios selecionados expostas em superfície - TIPOS B1, 1 , 4 e 5 - foram lavradas em lotes de 100 t, os quais foram transportados por caminhão até a área de preparação de amostras, descarregados e identificados.

Cada um dos lotes de minério foi submetido a peneiramentos a seco em malhas de 200, 135, 75 e 31 mm - na sequência da maior para a menor - acopladas à carroceria de um caminhão. A transferência das alíquotas de cada lote de minério ao "caminhão-peneira" foi realizada por uma carregadeira, e a separação das frações passante e retida foi feita manualmente por operadores. As Figuras 5.1, 5.2 e 5.3 mostram algumas etapas do processo de peneiramento. 


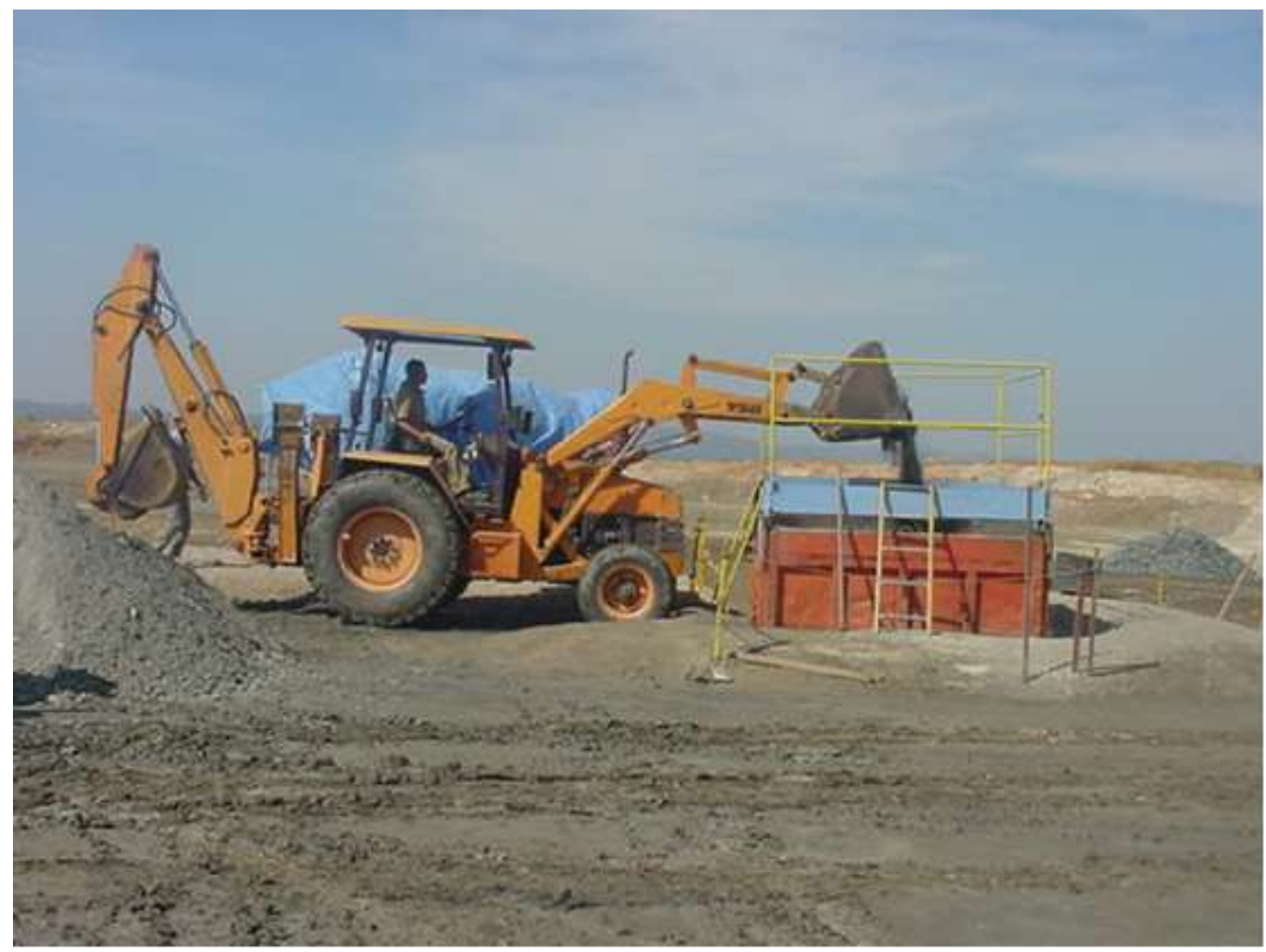

Figura 5.1 - Peneiramento das amostras de minério: carregamento do "caminhão-peneira".

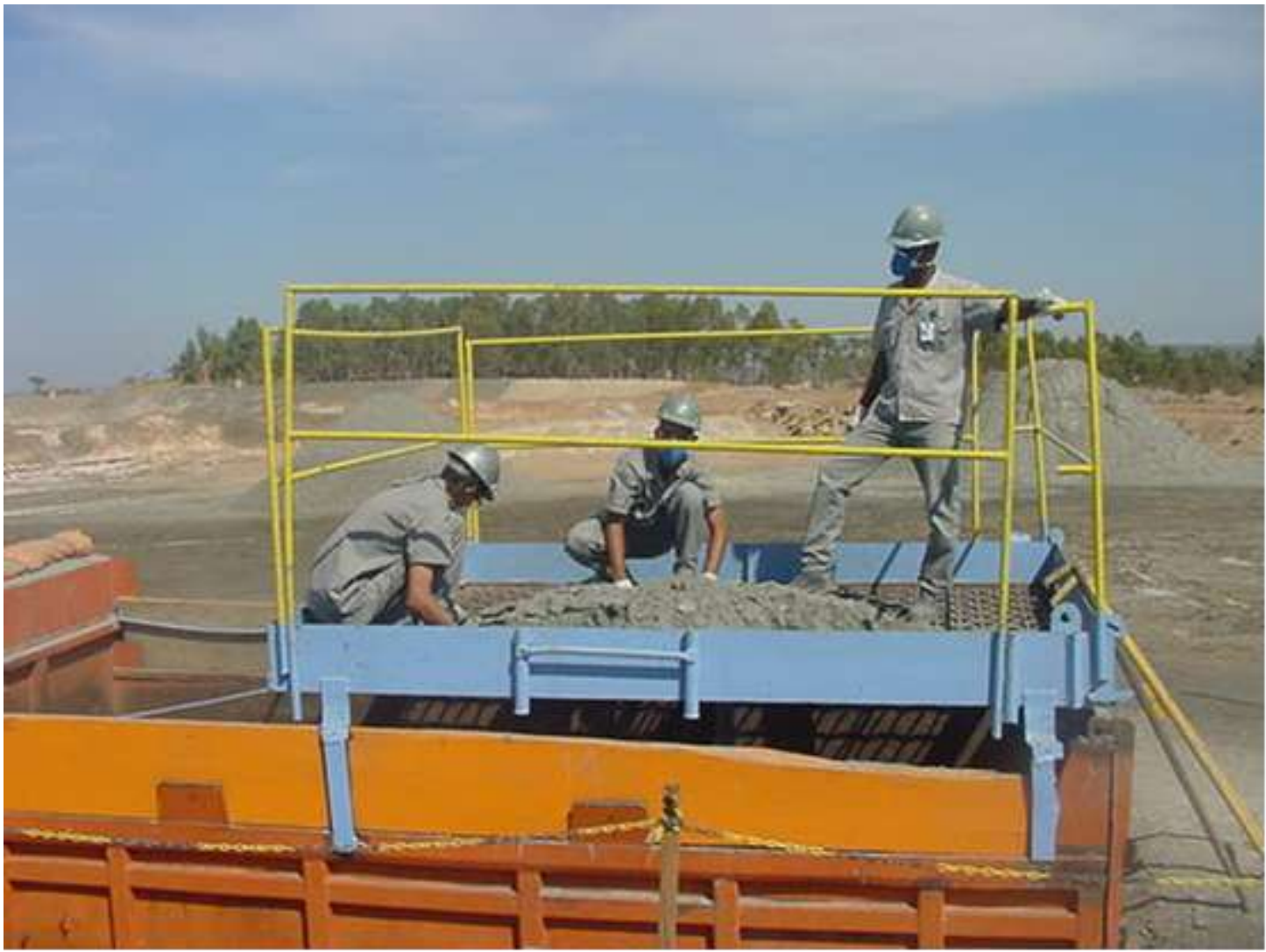

Figura 5.2 - Peneiramento das amostras de minério: separação manual na malha. 


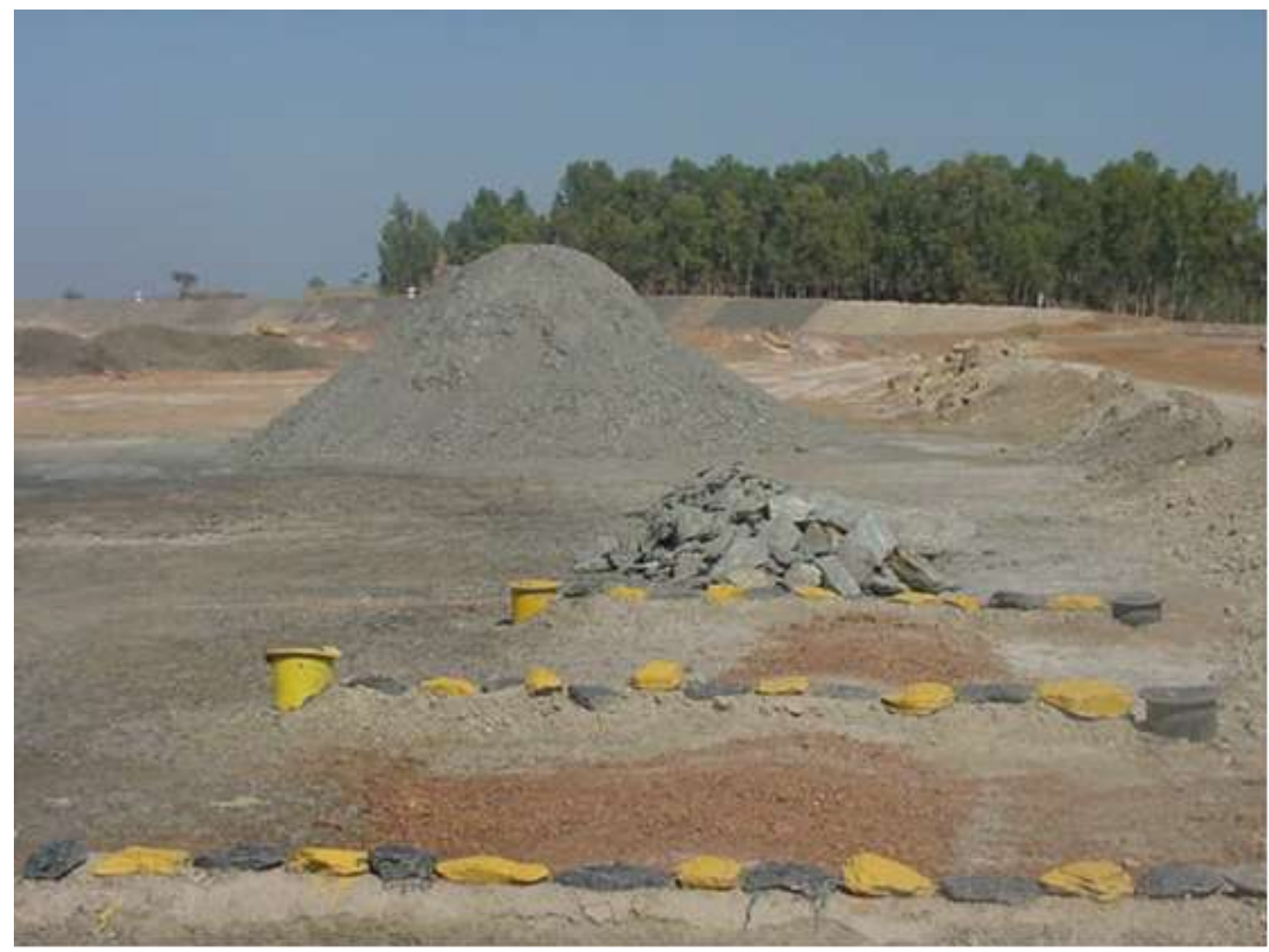

Figura 5.3 - Peneiramento das amostras de minério: frações obtidas dispostas em baias.

Após o peneiramento em uma determinada malha, a fração retida era separada e a fração passante era submetida a outra etapa de peneiramento, em malha de menor abertura. Essa seqüência foi repetida até que todo o lote de minério fosse separado nas quatro malhas.

As frações de minério de cada lote, geradas na etapa de peneiramento, foram transportadas por caminhão até um posto de pesagem. As frações foram pesadas individualmente e, a partir desse peso individual e do peso total do lote, foram calculados os percentuais de material retido e de material passante de cada tipo de minério.

Após a pesagem, as frações de cada minério foram transportadas até o pátio da Planta Piloto da RPM, no qual foram armazenadas e devidamente identificadas. O fluxograma resumo do processo de preparação das amostras de minério para os ensaios em planta piloto de moagem SAG é apresentado na Figura 5.4. 


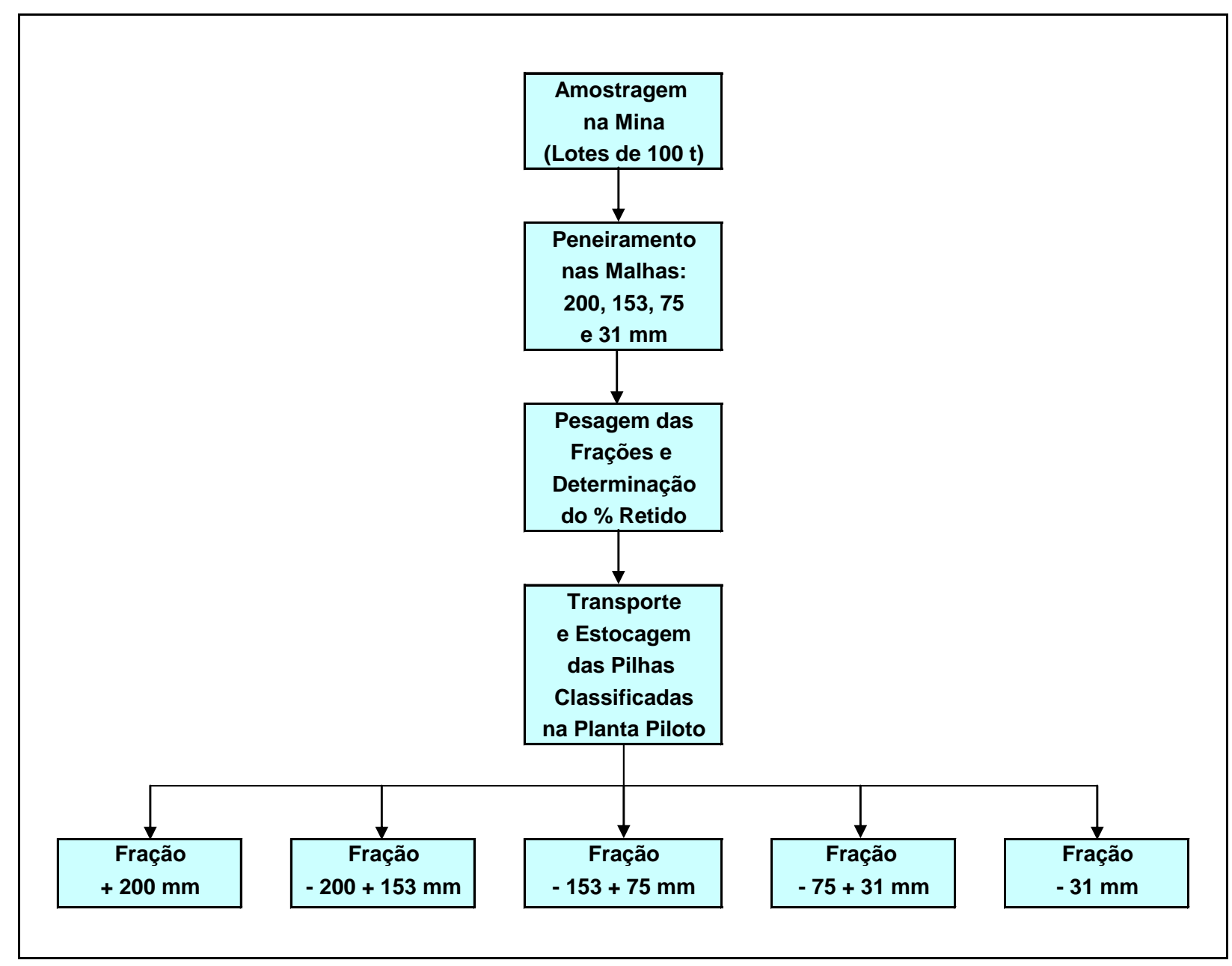

Figura 5.4 - Fluxograma de preparação das amostras para os ensaios em planta piloto.

\subsubsection{Preparação de Amostras de Testemunhos de Sondagem}

A amostra de tenacidade alta - TIPO 7/8 - não se encontrava disponível em superfície, razão pela qual foi empreendida uma campanha de sondagem para a obtenção de material com essa característica em quantidade suficiente para a realização de pelo menos um ensaio piloto de moagem SAG.

Nos trabalhos de sondagem, realizados por uma empresa contratada, foram obtidos doze furos com diâmetros de 5,75" e 6,5", totalizando cerca de 500 metros de testemunhos, com peso final de 20,5 t. Na Figura 5.5 observa-se parte dos testemunhos obtidos. 


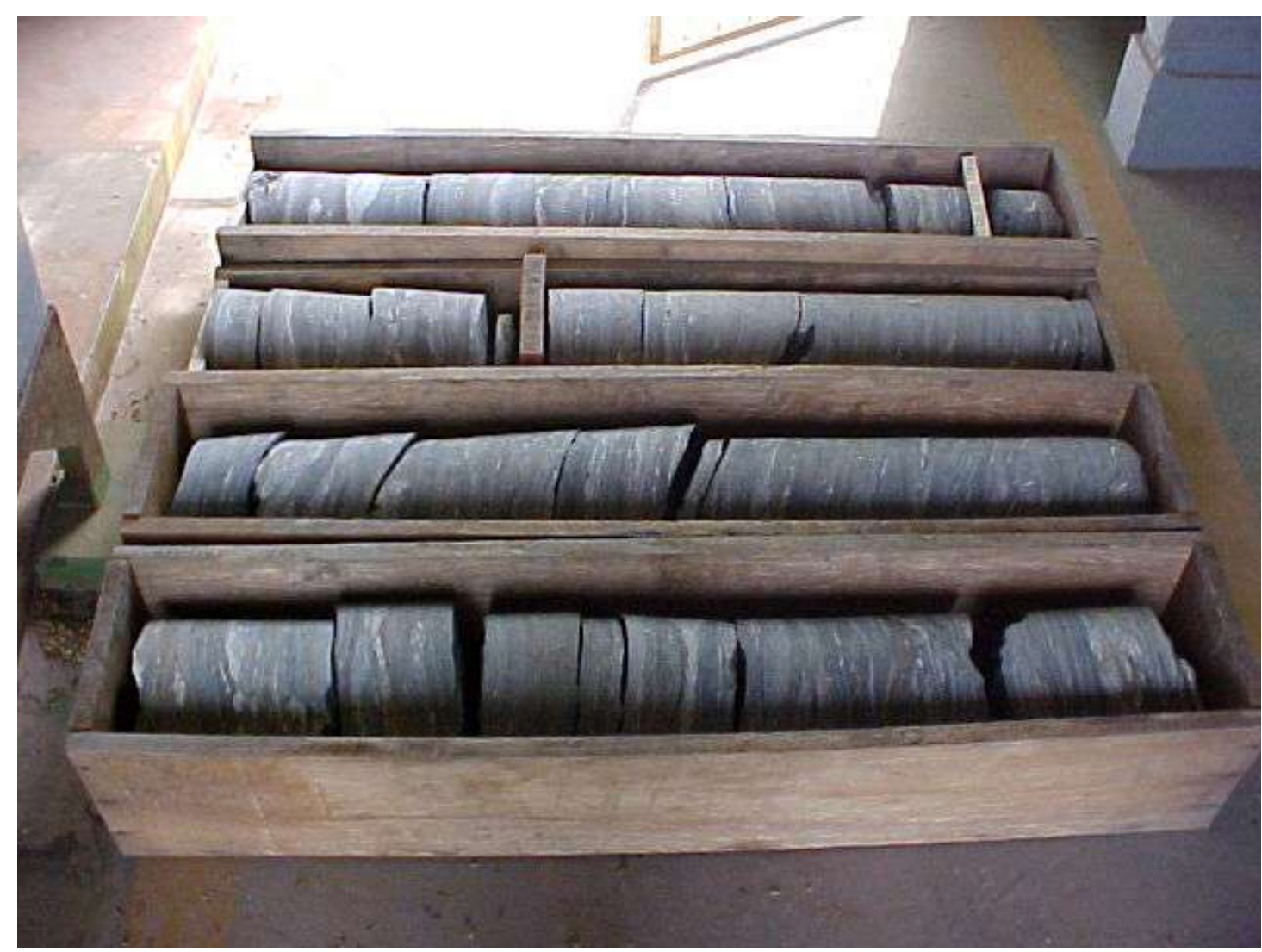

Figura 5.5 - Parte dos testemunhos de sondagem referentes à amostra TIPO 7/8.

Seguiu-se uma etapa de preparação da amostra obtida na sondagem, para simular a granulometria em que esse tipo de minério seria processado no circuito industrial. Para tal simulação, foi adotada como referência a curva granulométrica obtida para o minério TIPO 5 . Os testemunhos de sondagem foram submetidos a separação e quebra manuais, para obtenção das seguintes frações: $-200+153 \mathrm{~mm}$, -153 +75 mm e -75 +31 mm. Para obter a fração passante em $31 \mathrm{~mm}$, foi necessário reduzir a granulometria do minério com o auxílio de um britador de mandíbulas de laboratório. Depois de preparadas, as frações foram pesadas individualmente, a exemplo do procedimento adotado para as amostras de superfície. A Figura 5.6 apresenta uma das frações geradas na etapa de preparação da amostra de sondagem. 


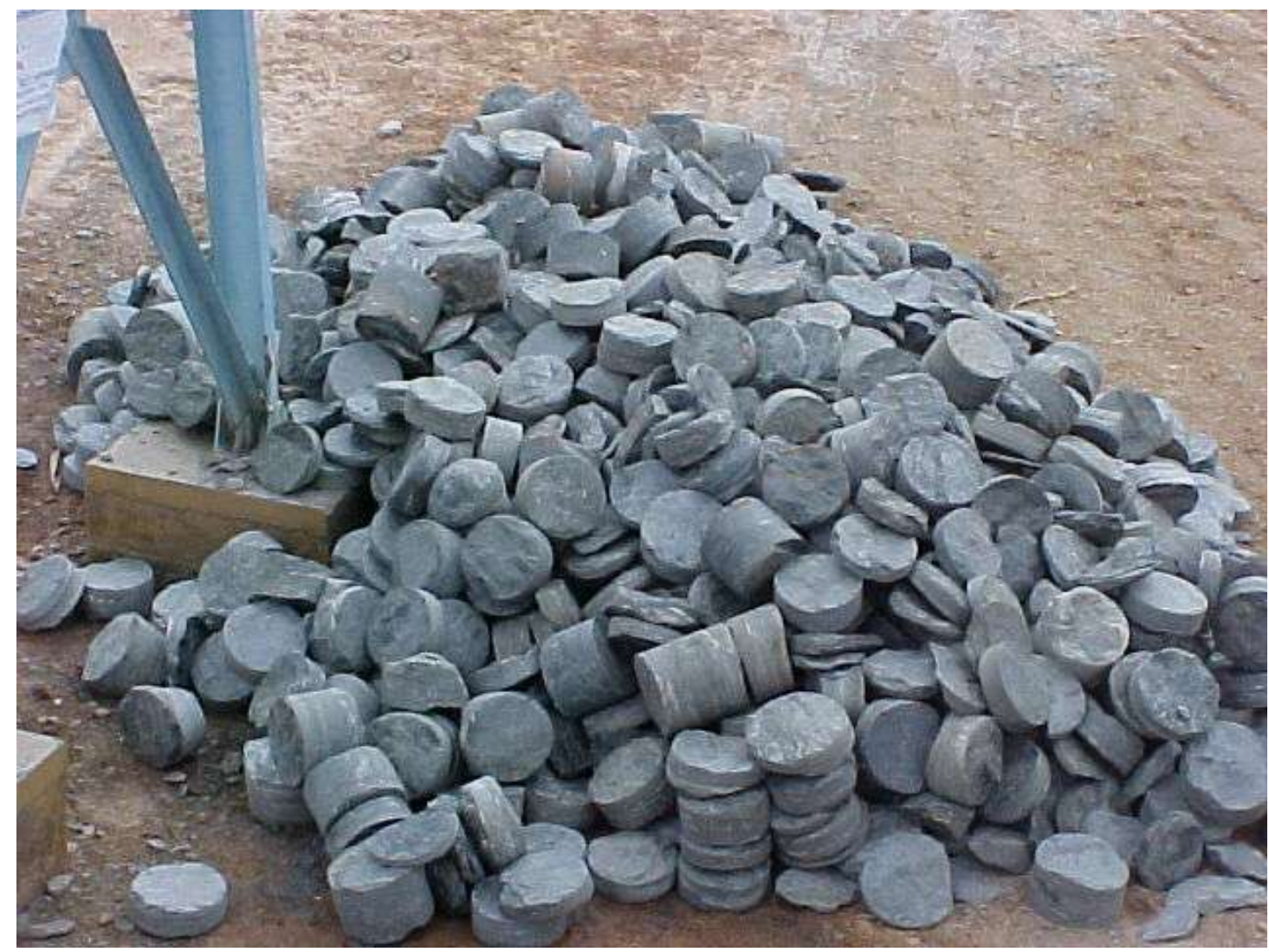

Figura 5.6 - Fração -153 + 75 mm, obtida após etapa de preparação da amostra TIPO 7/8.

\subsection{CARACTERIZAÇÃO DAS AMOSTRAS DE MINÉRIOS UTILIZADAS NOS ENSAIOS}

\subsubsection{DistribuiçÃo GRANULOMÉTRICA}

Com o auxílio de pá manual, coletou-se uma alíquota - de cerca de 100 kg representativa da fração passante em $31 \mathrm{~mm}$ de cada um dos minérios utilizados. Cada uma dessas alíquotas foi então fracionada - também com o auxílio de pá manual - até a obtenção de subalíquotas de aproximadamente $10 \mathrm{~kg}$, que foram individualmente submetidas a peneiramentos - em laboratório - nas seguintes malhas: 25,$0 ; 22,5 ; 19,0 ; 13,2 ; 11,2 ; 9,5 ; 6,3 ; 5,6 ; 4,75 ; 2,36 ; 1,18 ; 0,60 ; 0,30 ; 0,212$; 0,$150 ; 0,106 ; 0,075 ; 0,045$ e $0,038 \mathrm{~mm}$.

Curvas granulométricas de cada tipo de minério foram traçadas a partir dos dados do peneiramento de cada subalíquota da fração passante em $31 \mathrm{~mm}$ e dos dados obtidos para as frações acima de $31 \mathrm{~mm}$. Com base nos resultados da 
composição granulométrica, foi calculado o valor do $\mathrm{F}_{80}{ }^{18}$ para os minérios alimentados no circuito.

\subsubsection{ENSAIO DE BONd PARA MOINHO DE Bolas (WI)}

Uma alíquota de cada uma das frações obtidas de cada minério ensaiado foi retirada na etapa de preparação das amostras. Essas alíquotas foram encaminhadas ao Laboratório de Processo da RPM para determinação do índice de moabilidade para moinho de bolas $(\mathrm{WI})$, empregado rotineiramente pela RPM. O ensaio de moabilidade, introduzido na RPM em 1998 - tendo como referência o método adotado pelo JKMRC e a Norma Brasileira MB-3253 (ABNT, 1990) -, não será detalhado neste documento.

O valor do WI ponderado para cada tipo de minério foi determinado a partir dos dados de distribuição granulométrica dos minérios e do WI de cada fração amostrada. Diferenças entre esse valor médio calculado e o valor de WI da amostra composta podem existir e, portanto, devem ser consideradas.

\subsubsection{SAG POWER INDEX (SPI®)}

Foram preparadas amostras individuais de cada tipo de minério, bem como de composições destes na proporção de $50 \%$, para a realização de ensaios de caracterização tecnológica de fragmentação em moinho SPI® na empresa MinnovEX Technologies, localizada em Ouro Preto (MG).

\subsubsection{Drop Weight Test (DWT) E Point LoAd Test (PLT)}

Amostras de quatro tipos de minérios - tipos 1, 4, 5 e 7/8 - foram encaminhadas ao Laboratório de Simulação e Controle da Escola Politécnica da Universidade de São Paulo (LSC-USP). As amostras enviadas para essa caracterização foram preparadas nas seguintes frações: $-75 \mathrm{~mm},-31 \mathrm{~mm}$ e $-31+12$ $\mathrm{mm}$.

18 Conforme definido anteriormente, $F_{80}$ é o tamanho da malha em que $80 \%$ da alimentação é passante. 
Esse estudo foi complementado em 2007, com a realização de ensaios de DWT em mais onze amostras, também encaminhadas para o LSC-USP. Esse último lote apresentou índices de moabilidade para moinho de bolas que variavam de 5,6 a $13,1 \mathrm{kWh} / \mathrm{t}$, e também foi submetido aos ensaios de carga puntual na RPM. O PLT é conduzido na RPM de acordo com a International Society for Rock Mechanics (ISRM).

\subsubsection{Descrição das Amostras de SONDAgem}

Os testemunhos de sondagem referentes aos minérios tipo 7/8 foram descritos geologicamente. Características como classe, deformação, silificação, presença de boudins, sulfetação e textura da arsenopirita foram avaliadas durante essa etapa de descrição.

\subsection{ENSAIOS DE MOAGEM SEMIAUTÓGENA EM PLANTA PILOTO}

\subsubsection{EQUIPAMENTOS UTILIZADOS}

Para a execução dos ensaios de moagem semiautógena e de bolas e de concentração metalúrgica em planta piloto, foram usados os seguintes equipamentos básicos:

- $\quad$ moinho autógeno, modelo cascata (cascade pilot mill), com dimensões nominais de 6 pés de diâmetro e 2 pés de comprimento (Koppers Company Inc.), e volume interno de $1,31 \mathrm{~m}^{3}$, com:

- grelhas com aberturas de 6,35 e 12,7 mm e perfil trapezoidal, distribuídas simetricamente em torno do eixo do moinho;

- dezesseis içadores (comprimento $14,5 \mathrm{~cm}$, largura $10 \mathrm{~cm}$ e profundidade $4 \mathrm{~cm}$ ), instalados na câmara de moagem;

- trommel dotado de tela com abertura de $6,35 \mathrm{~mm}$;

- bomba de óleo para lubrificação dos mancais do moinho;

- chute de alimentação com diâmetro de 0,42 m;

- motor elétrico (Búfalo Ind. e Com. Ltda.) com a seguinte especificação: $25 \mathrm{CV}, 440 \mathrm{~V}, 12,5 \mathrm{~A}$ e redutor de velocidade com eixos paralelos e razão de redução de 40:1;

- correia transportadora com comprimento de $20 \mathrm{~m}$ e largura de 0,20 m;

- peneira vibratória com tela de abertura de 1,0 mm; 
- bomba de eixo vertical para direcionamento do undersize do trommel à peneira vibratória;

- sistema de classificação por ciclonagem (kit ciclone / bomba);

- moinho de bolas com dimensões de 3 pés de diâmetro e 3 pés de comprimento.

- concentrador centrífugo Knelson modelo XD-6;

- jigue - modelos:

- Joy Denver, tamanho 8" x 12", duas câmaras por jigue;

- Pan American 42" x 42", duas câmaras por jigue;

- banco de quatro células de flotação, Outokumpu modelo 4 R, com 36 pés $^{3}$ cada;

- balanças de diferentes capacidades.

A maior parte dos equipamentos - moinho autógeno, moinho de bolas, correia transportadora, peneira, kit de classificação por ciclonagem - foi alugada do Centro de Tecnologia Mineral - RJ (CETEM), o concentrado centrífugo foi alugado da Knelson, o jigue Pan American emprestado pela Fundação Centro Tecnológico de Minas Gerais (CETEC), e os demais itens foram adquiridos pela RPM.

\subsection{INSTRUMENTAÇÃo E Sistemas de MONitORAMENTO}

Para o controle e a coleta de dados foram utilizados os sistemas de monitoramento descritos a seguir.

- SISTEMA DE PESAGEM DA CARGa do MOINHO SAG: para a pesagem contínua da carga no interior do moinho SAG foi utilizado um sistema composto por seis células de cargas e com fornecimento da leitura em um mostrador (display). $O$ sistema foi zerado e aferido com peso padrão. As medições das células de carga foram interligadas ao Programa Factory Link Enterprise Control System ${ }^{T M}$ $(E C S)^{19}$, sendo os dados de pesagem armazenados em intervalos de 1 minuto.

- SISTEMA DE MEDIÇÃO DE POTÊNCIA $\left(\mathrm{CCK}^{20}\right)$ : esse sistema foi utilizado para registro da potência média - obtida por integralização em intervalos de 15 minutos -, bem como da potência instantânea correspondente à média de leituras efetuadas a cada 15 segundos.

19 Factory Link® ECS: software para monitoramento, supervisão e controle de processos industriais.

20 CCK automação: sistema de gerenciamento de energia elétrica que objetiva a obtenção da eficiência energética e, por consequência, a conservação de energia. Permite o registro e o armazenamento de dados e as medições de campo. 
A utilização desses dois sistemas de medição on line permitiu, entre outras facilidades, o melhor controle operacional dos ensaios e a maior confiabilidade dos resultados.

\subsubsection{Material E Equipamentos ComplementaRes Utilizados nos EnSAIOS}

Para a operação do circuito de planta piloto e a amostragem dos vários fluxos, foram empregados os seguintes acessórios:

- $\quad$ pás, enxadas, carrinhos de mão;

- caixa de ferramentas;

- baldes com tampas;

- cronômetros;

- amostradores;

- sistema de medição da altura da carga: régua, centralizador, medidor.

Para as etapas de preparação e caracterização das amostras foram utilizados, dentre outros, os seguintes equipamentos:

- peneiradores de bancada;

- peneiradores verticais;

- peneiradores semi-industriais;

- estufa para secagem de amostras;

- balanças diversas;

- quarteador Jones;

- divisor setorial com alimentador rotatório;

- moinho padrão para ensaio de WI;

- britadores de mandíbulas e de rolos de laboratório.

Acessórios complementares, como jogo de peneiras redondas e quadradas, espátulas, pás, bandejas e pincéis, entre outros, também foram utilizados.

\subsubsection{Estrutura FísicA E TÉCNICA}

Os equipamentos utilizados nos ensaios foram instalados na planta piloto da RPM existente em Paracatu (MG). A operação da planta piloto dentro da área da RPM facilitou a logística dos trabalhos de preparação e transporte das amostras de minério, bem como o tratamento das amostras de processo obtidas. Essa facilidade 
possibilitou a realização de maior número de ensaios e, por consequência, uma investigação mais detalhada das variáveis de cominuição para os diferentes tipos de minério da RPM. Outro aspecto positivo dessa opção foi a redução dos custos por ensaio em comparação à realização desse trabalho em centros de pesquisa reconhecidos, como o Centro de Investigación Minero y Metalúrgico (CIMM), sediado em Santiago Chile.

Os ensaios foram conduzidos por uma equipe constituída por técnicos e operadores da RPM e de empresas contratadas. A RPM também disponibilizou uma equipe de manutenção - mecânicos, eletricistas e instrumentistas - que garantiu a utilização dos equipamentos e a implantação das modificações de circuito necessárias. Técnicos do CETEM apoiaram o start-up da planta e a operação dos equipamentos.

As etapas de planejamento e acompanhamento dos ensaios foram realizadas pelo corpo técnico da RPM e da Rio Tinto, que então administrava a mineração de Paracatu, e por consultores independentes. Os trabalhos foram verificados por uma equipe de especialistas em projeto e em operação de circuitos de moagem SAG (Rio Tinto Technical Services, SMCC, Aker-Kvaerner, HDA). A condução dos ensaios em planta piloto e as informações geradas neste trabalho foram verificadas e validadas por esta equipe, assim como pela Kinross Technical Services, após da aquisição da RPM.

\subsubsection{CONDIÇÕES OPERACIONAIS}

As condições operacionais adotadas durante os ensaios de moagem semiautógena em escala piloto são elencadas a seguir:

- CONFIGURAÇÃO DO CIRCUITO: o moinho SAG foi operado em configurações de circuito aberto e circuito fechado, com peneira vibratória;

- PERCENTUAL DE SÓlidos NA DESCARGa do MOINHO: os ensaios foram conduzidos com diferentes valores de concentração de sólidos na descarga do moinho SAG - 60, 68, 70 e 75\%;

- VOlUme dA CARGA: a carga utilizada durante os ensaios ocupava 25 e $30 \%$ da capacidade interna do moinho SAG;

- VELOCIDADE DE ROTAÇÃO DO MOINHO SAG: a velocidade de rotação empregada durante os ensaios correspondia a $78,5 \%$ e $70,0 \%$ da velocidade crítica $\left(n_{c}\right)$, de 32,7 rpm. 
- CARGA DE BOLAS NO MOINHO SAG: correspondente a 4, 10 e 15\% do volume interno do moinho (\% vi).

- DISTRIBUIÇÃO DE BOLAS: os ensaios de moagem SAG utilizaram dois tipos de distribuição de bolas. Os valores em peso para cada carga adotada - e frações destes - são listados nas Tabelas 5.5 e 5.6.

Tabela 5.5 - Distribuição de carga de bolas tipo 1 utilizada nos ensaios de moagem SAG.

\begin{tabular}{ccccc}
\hline Diâmetro & Retido & \multicolumn{4}{c}{ Distribuição Tipo $\mathbf{c}$} \\
Poso das Bolas para Diferentes & Volumes de Carga (kg) \\
Bola (mm) & $(\%)$ & $\mathbf{4} \% \mathbf{~ v i}$ & $\mathbf{1 0} \% \mathbf{~ v i}$ & $\mathbf{1 5 \%} \mathbf{~ v i}$ \\
\hline 125 & 45 & 106 & 264 & 397 \\
100 & 35 & 82 & 206 & 308 \\
75 (Usadas 88) & 20 & 47 & 118 & 176 \\
Total & 100 & 235 & 588 & 881 \\
\hline
\end{tabular}

Tabela 5.6 - Distribuição de carga de bolas tipo 2 utilizada nos ensaios de moagem SAG.

\begin{tabular}{ccccc}
\hline Diâmetro & Retido & \multicolumn{4}{c}{$\begin{array}{c}\text { Distribuição Tipo 2 } \\
\text { Peso das Bolas para Diferentes }\end{array}$} \\
Bola $(\mathbf{m m})$ & $(\%)$ & $\mathbf{4} \% \mathbf{~ v i}$ & $\mathbf{1 0} \% \mathbf{~ v i}$ & $\mathbf{1 5} \% \mathbf{~ v i}$ \\
\hline 120 & 6 & 14 & 35 & 53 \\
86 & 42 & 99 & 247 & 370 \\
65 & 32 & 75 & 188 & 282 \\
50 & 20 & 47 & 118 & 176 \\
Total & 100 & 235 & 588 & 881 \\
\hline
\end{tabular}

- ABERTURA DA GRELHA DO MOINHO SAG: foram utilizadas grelhas com aberturas de 6,35 e $12,7 \mathrm{~mm}$, em configuração total e parcialmente aberta. A figura 5.7 apresenta um dos tipos de perfil e configuração utilizados. 


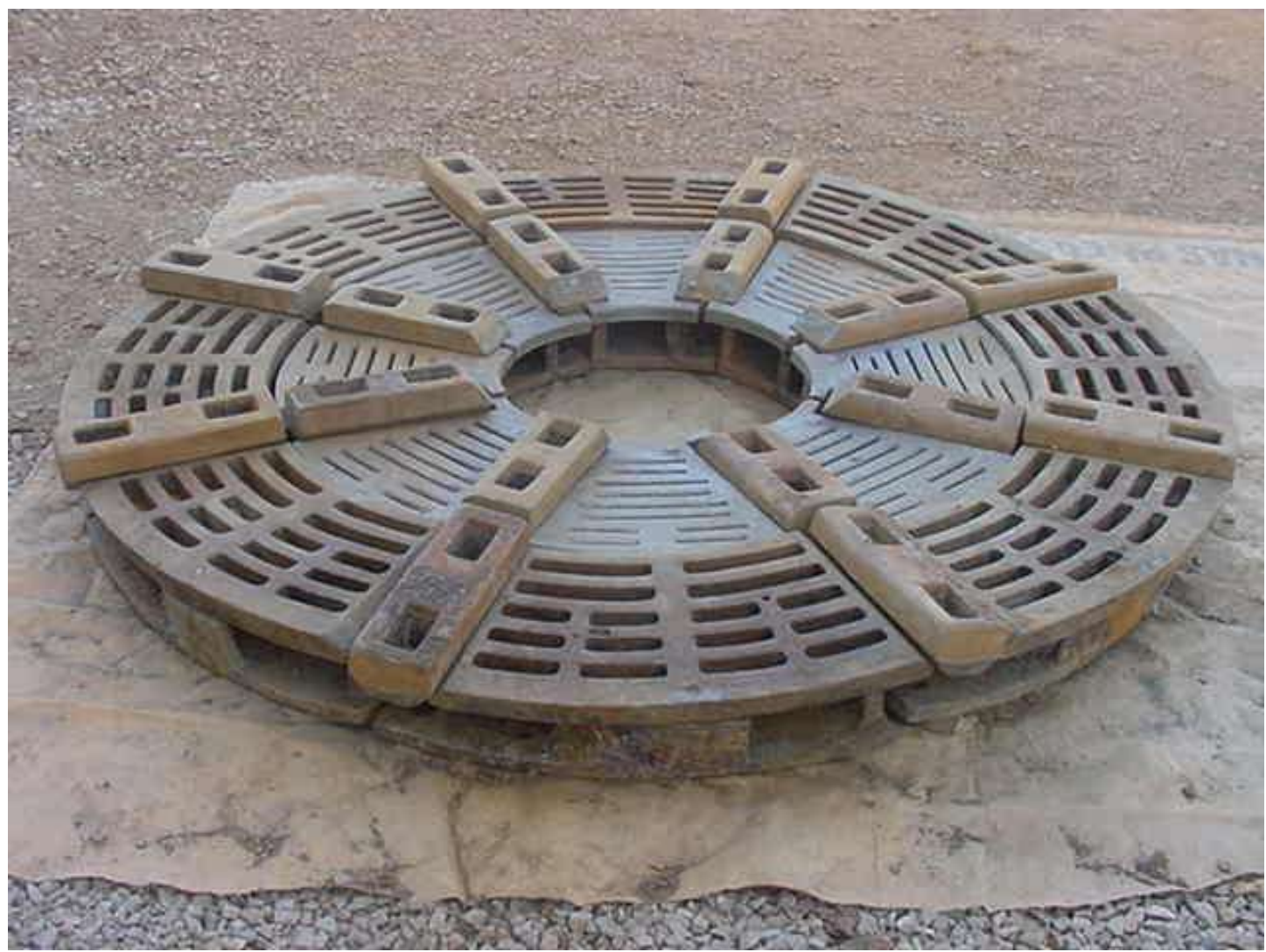

Figura 5.7 - Uma das configurações da grelha do moinho SAG utilizadas nos ensaios.

\subsubsection{Procedimento Operacional}

As diferentes etapas de operação adotadas para a condução dos ensaios em planta piloto são apresentadas nesta seção.

\subsubsection{Condução dos Ensaios}

$\mathrm{Na}$ primeira etapa dos ensaios procedeu-se à pesagem da carga de bolas, conforme distribuição prevista no plano do ensaio. Após a pesagem, a carga de bolas foi colocada no moinho sobre um pequeno leito formado com uma porção do próprio minério a ser ensaiado. A introdução das bolas sobre esse leito objetivava evitar e/ou reduzir o impacto das bolas contra o revestimento do moinho no início da operação.

Em uma segunda etapa foi realizada a pesagem de incrementos de $100 \mathrm{~kg}$ do minério, correspondentes à alimentação do circuito. Cada incremento de $100 \mathrm{~kg}$ 
era preparado pela recomposição das frações do minério, obedecendo à distribuição granulométrica obtida na etapa de peneiramento deste e indicada na Tabela 5.7. No caso dos ensaios com blendagens, utilizou-se uma alíquota de $100 \mathrm{~kg}$ - submetida à pesagem previamente - de cada um dos dois tipos de minérios empregados.

Tabela 5.7 - Distribuição granulométrica do material alimentado nos ensaios.

\begin{tabular}{cccccc}
\hline $\begin{array}{c}\text { Tamanho } \\
(\mathbf{m m})\end{array}$ & Tipo B1 & Tipo 1 & Retido em Peso (\%) & Tipo 5 & Tipo 7/8 \\
\hline+200 & 0 & 0 & 0 & 0 & 0 \\
$-200+153$ & 3,8 & 0,6 & 12,6 & 6,5 & 6,5 \\
$-153+75$ & 6,5 & 2,9 & 14,9 & 12,8 & 12,8 \\
$-75+31$ & 8,8 & 7,1 & 19,1 & 17,1 & 17,1 \\
-31 & 80,9 & 89,3 & 53,4 & 63,6 & 63,7 \\
Total & 100,0 & 100,0 & 100,0 & 100,0 & 100,0 \\
\hline
\end{tabular}

A recomposição das frações e a alimentação destas no circuito na forma de incrementos objetivou prevenir e/ou reduzir as flutuações e os distúrbios no sistema. Esse procedimento garante uma alimentação homogênea e com características constantes ao longo do ensaio piloto. A Figura 5.8 mostra a pesagem de um dos incrementos de minério feita em uma balança de plataforma com visor acoplado.

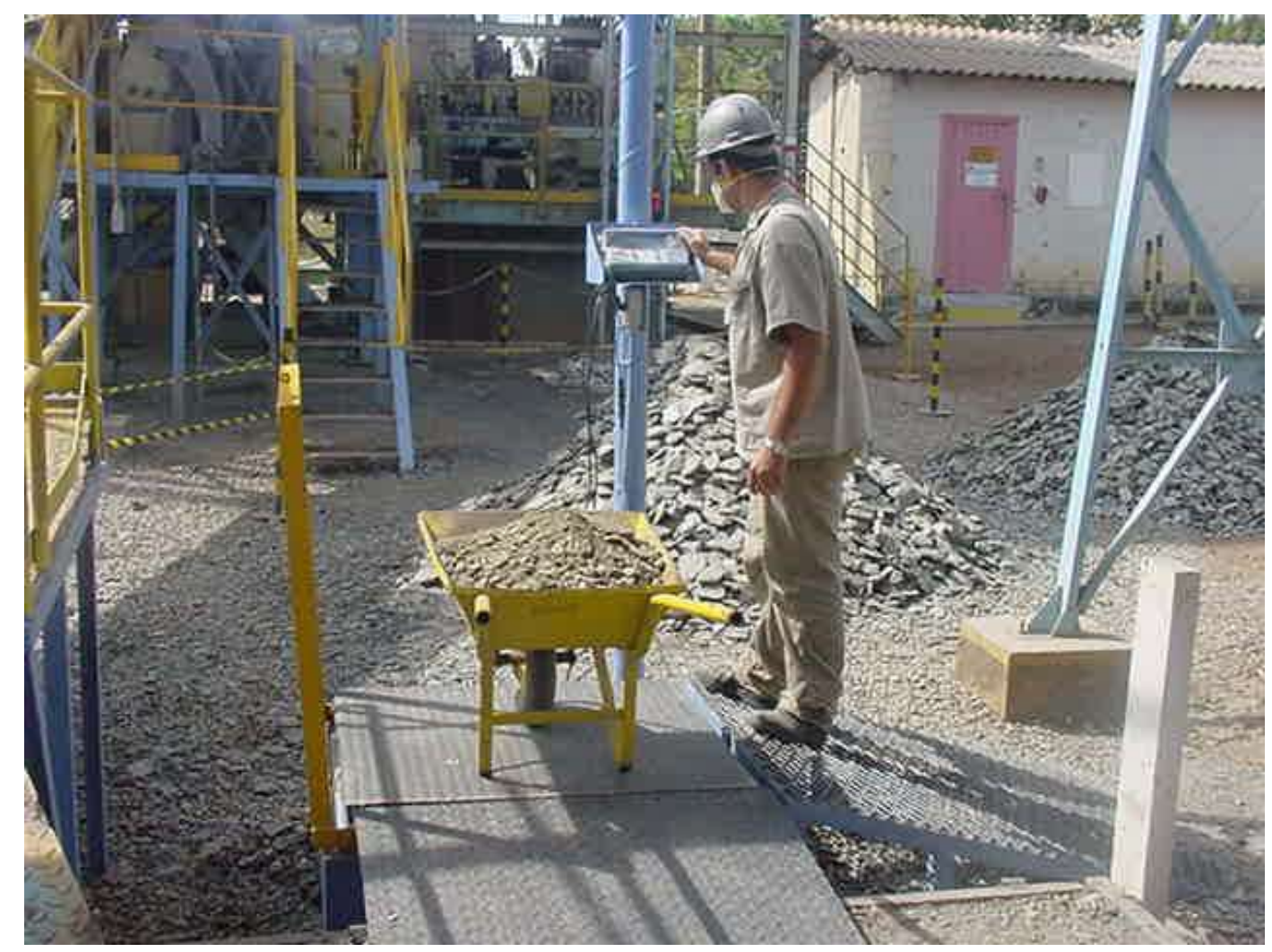

Figura 5.8 - Pesagem de um dos incrementos de minério. 
Cada incremento de $100 \mathrm{~kg}$ foi transferido para dois carrinhos de mão, para facilitar o transporte através da divisão do peso. No caso dos ensaios envolvendo blendagem, os incrementos foram pesados e transferidos para carrinhos de mão diferentes, identificados através de cores.

Cada carrinho de mão era levado à plataforma de alimentação, e seu conteúdo era vertido sobre a correia transportadora. A alimentação seguiu uma sequência que envolveu a blendagem do minério - proporção entre os minérios - e a estabilização da carga interna via célula de carga. A vazão de alimentação foi ajustada de acordo com tais parâmetros, sendo os incrementos alimentados continuamente ao circuito em intervalos de tempo pré-determinados.

O horário de introdução de cada incremento no circuito era registrado, assim como os valores de leitura das células de carga. Com base nesses dados, calculouse a vazão de alimentação em cada período e conferiu-se a proporção dos minérios correspondente à blendagem planejada para cada ensaio. Na Figura 5.9 vê-se a plataforma de alimentação do circuito.

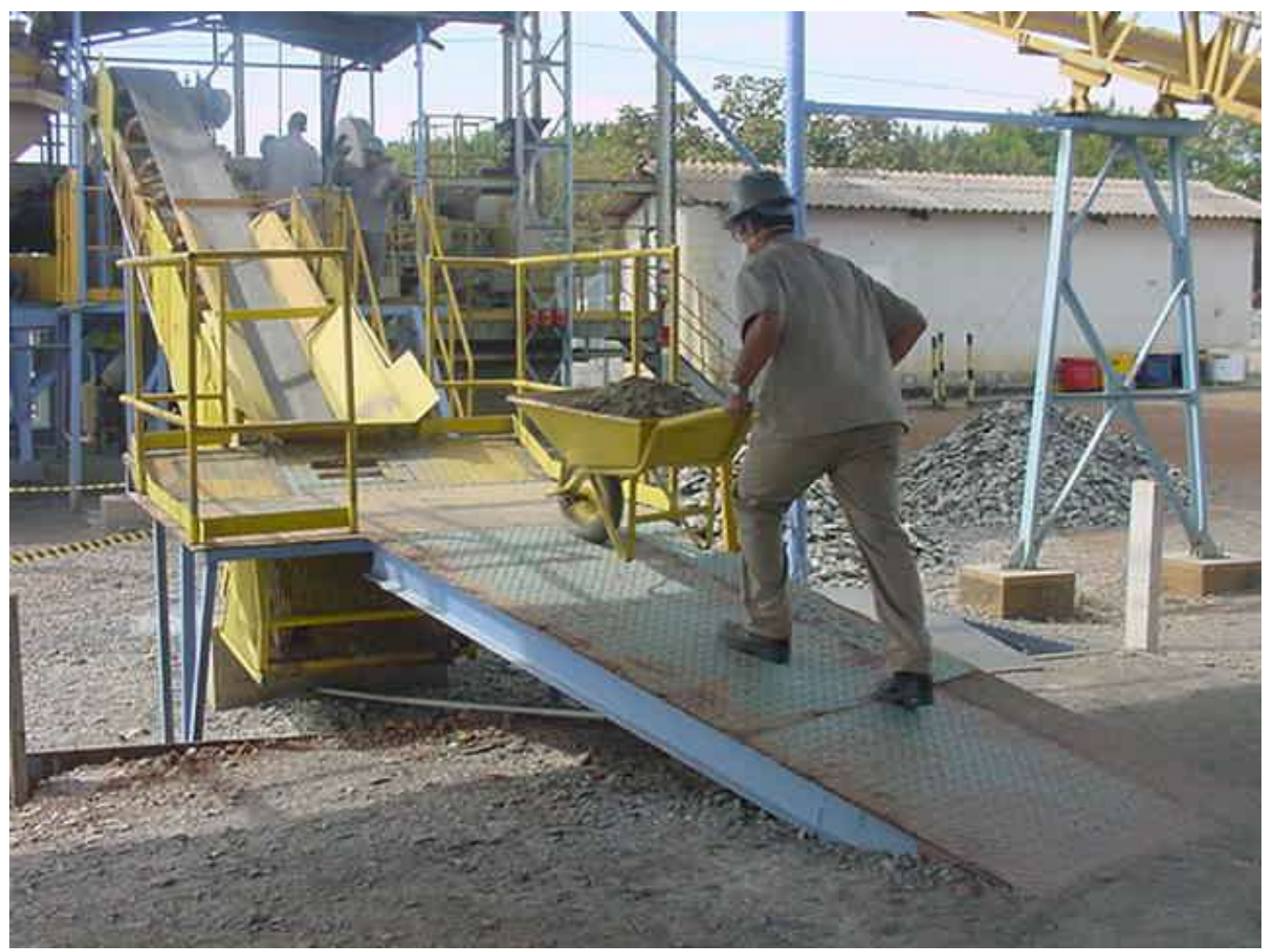

Figura 5.9 - Introdução do incremento de minério no circuito através da correia transportadora. 
O material alimentado foi transferido pela correia transportadora para uma calha, e desta para o chute de alimentação. Nessa etapa, dois operadores auxiliaram a introdução do material no moinho com o uso de enxadas.

Na descarga do moinho SAG, o material passante pela grelha era elevado ao cone central e encaminhado ao trommel de classificação. A fração retida no trommel era recolhida em baldes, e periodicamente retornava ao moinho. A fração passante no trommel fluía para uma caixa de bomba, que recebia água. A polpa era bombeada para a peneira vibratória com tela de abertura de 1,0 mm (Figura 5.10). A fração retida na peneira retornava ao moinho SAG através de uma calha. Nesse ponto também ocorreu a introdução de água. A vazão da água adicionada era calculada e controlada de acordo com a porcentagem de sólidos requerida no ensaio, e medida através de um rotâmetro.

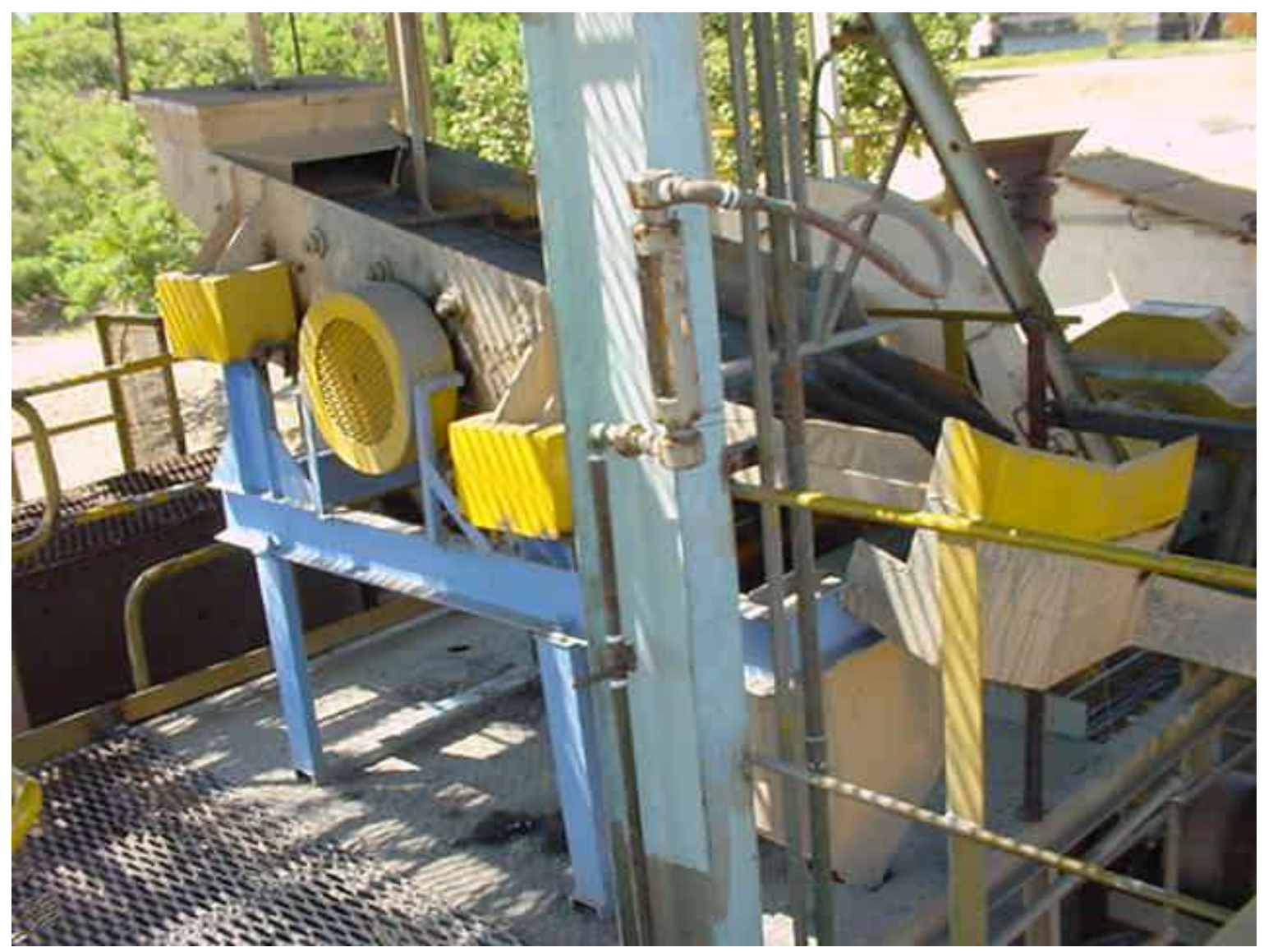

Figura 5.10 - Peneira vibratória utilizada nos ensaios piloto.

A fração passante na peneira, em conjunto com a água de lavagem da tela, fluía por gravidade para uma barragem piloto de rejeito ou para estágios seguintes do circuito piloto, como moagem de bolas e/ou concentração metalúrgica. Conforme 
comentado anteriormente, os ensaios focando concentração metalúrgica não serão abordados neste documento.

Em ensaios de moagem SAG sob configuração aberta não foi empregada peneira. Nesses casos, somente a fração retida no trommel retornava ao moinho.

\subsubsection{Controle do Percentual de Sólidos na Descarga do Moinho SAG}

Durante a execução dos ensaios, em intervalos de 15 minutos, foram retiradas amostras da descarga do moinho SAG, que foram armazenadas em um balde com volume fixo. Mediu-se a massa de polpa contida nesse recipiente, e calculou-se a densidade da amostra.

A partir da densidade da polpa calculada e do valor da densidade do minério, estimou-se o percentual de sólidos da amostra. A correção do percentual de sólidos pelo controle da adição de água ao circuito foi realizada com base no valor obtido e nas condições operacionais previstas para o ensaio.

\subsubsection{CARGA INTERNA DO MOINHO SAG}

Para evitar distúrbios operacionais, a carga interna do moinho SAG deve ser cuidadosamente controlada durante o ensaio piloto. Esse controle foi realizado com o auxílio dos procedimentos e sistemas listados a seguir.

\subsubsection{Sistema de Pesagem da Carga do Moinho SAG}

A plataforma do moinho foi instalada sobre um conjunto de seis células de carga. Esse conjunto, a plataforma, o moinho e o sistema de acionamento foram zerados e aferidos com peso padrão. As células de carga permitiram a pesagem contínua da carga interna do moinho.

A leitura do peso da carga, dada em toneladas, foi transferida para um monitor, possibilitando ao operador o controle dessa variável por meio da vazão de 
alimentação. A Figura 5.11 mostra uma das células de carga instalada na plataforma do moinho SAG (a), e o monitor de leitura do valor da célula de carga instalado em frente à plataforma de alimentação do circuito (b).

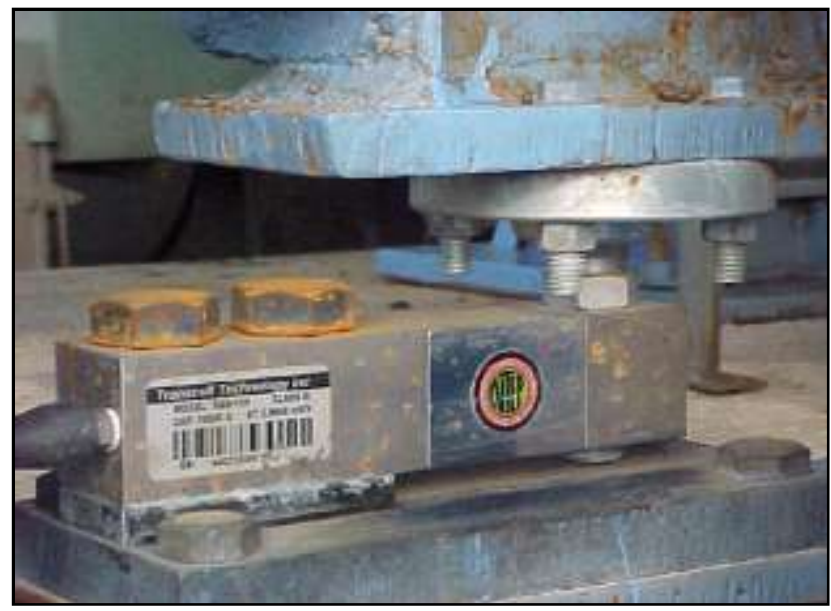

(a)

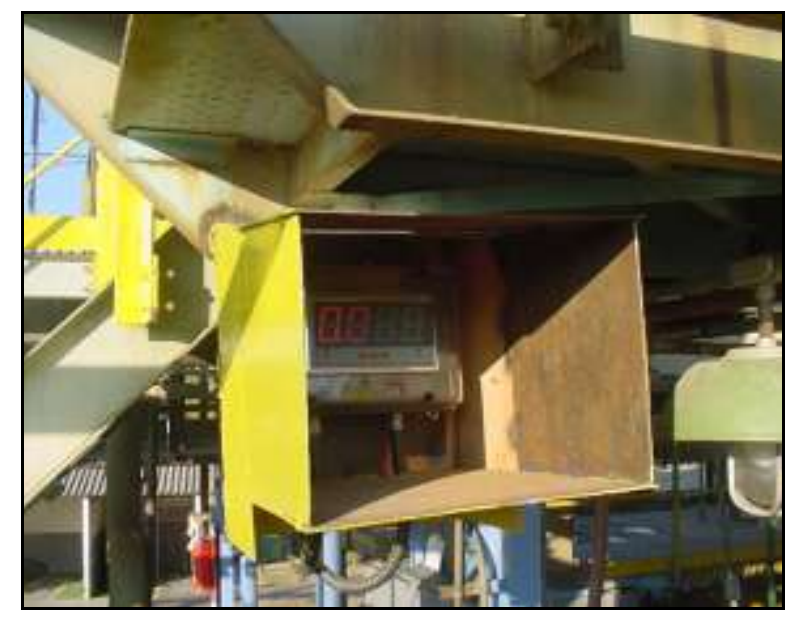

(b)

Figura 5.11 - (a) Célula de carga instalada na plataforma do moinho SAG e (b) monitor de leitura do valor da célula de carga instalado em frente à plataforma de alimentação do circuito.

\subsection{Medições do Volume da Carga Interna}

Após o período de estabilização da indicação da célula de carga e de potência, a atividade do moinho SAG era interrompida (Crash Stop ${ }^{21}$ ) para verificação do volume da carga interna. Na Figura 5.12 observa-se um gráfico de monitoramento dos valores de potência e da célula de carga para um dos ensaios de moagem. A manutenção do valor da carga interna do moinho foi considerada como a principal indicação da estabilidade da operação.

21 Crash Stop: Termo em inglês usado para descrever a parada do moinho cortando-se a alimentação de minério e de água. O objetivo é ter uma "fotografia" de como o moinho estava operando em termos de enchimento, acúmulo de polpa em seu interior etc. 


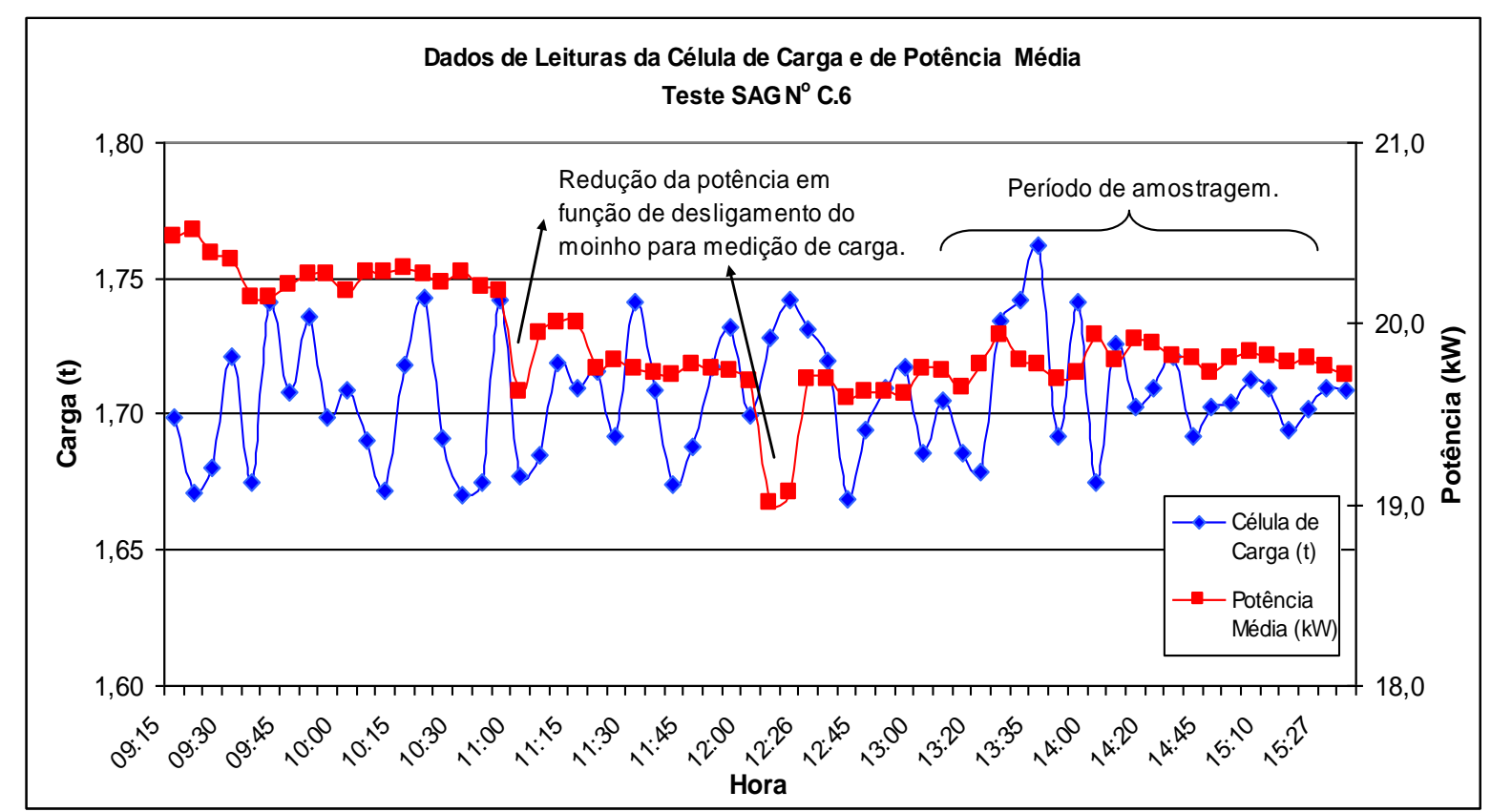

Figura 5.12 - Gráfico com dados de monitoramento de valores das células de carga e potência para um dos ensaios de moagem SAG conduzidos.

Após o desligamento do moinho SAG acertava-se o posicionamento da carga com uma enxada, de modo a deixá-la o mais horizontal possível. Para medição do volume do moinho ocupado pela carga, utilizava-se uma barra metálica posicionada horizontalmente ao longo do eixo longitudinal do moinho. Uma segunda barra metálica era introduzida perpendicularmente à primeira, até que tocasse a carga do moinho. A distância da superfície da carga até o eixo do moinho (Figura 5.13) era então marcada e medida com a utilização de uma escala com leitura em centímetros. A barra introduzida dentro da carga possuía uma base perpendicular que impedia sua penetração entre os corpos moedores. A medida da distância da carga até o eixo do moinho, denominada distância "d", foi utilizada no cálculo do percentual de volume interno do moinho ocupado pela carga. 


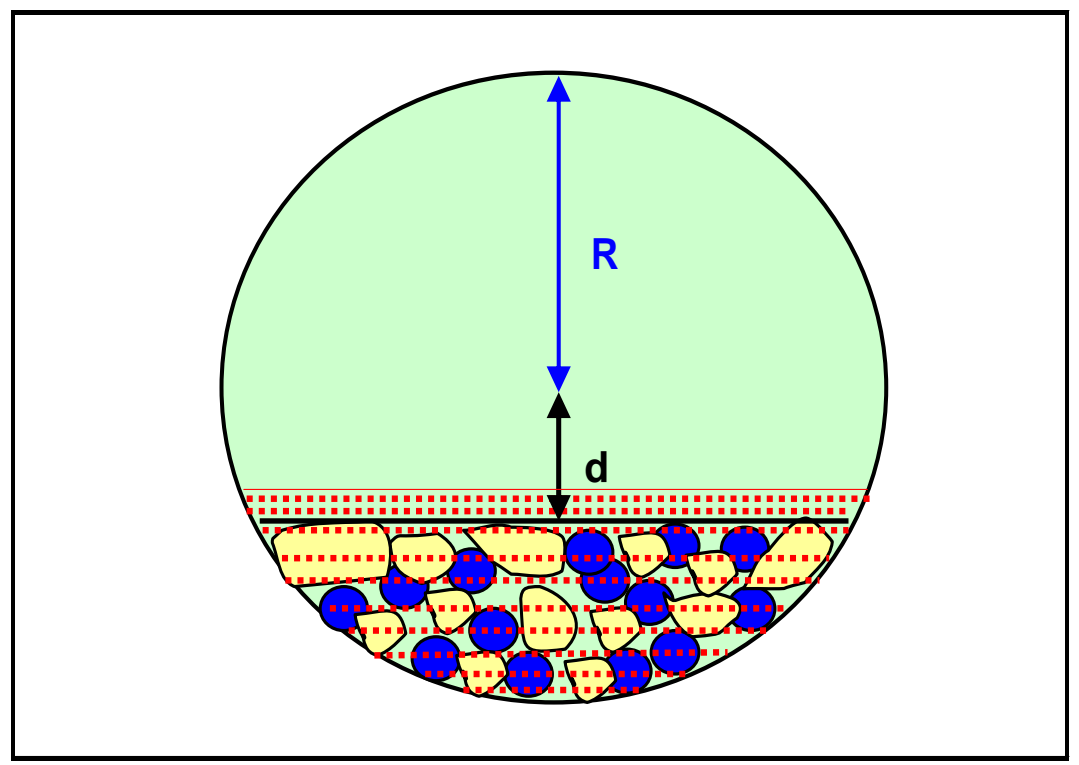

Figura 5.13 - Distância "d" entre a superfície da carga e o eixo do moinho.

Quando a carga do moinho atingia valores diferentes do especificado procedia-se à alteração da taxa de alimentação e, consequentemente, do valor de controle da célula de carga. A medição do volume da carga foi realizada antes e depois do período de amostragem.

\subsubsection{Retirada da Carga Interna do Moinho SAG}

Após a conclusão de cada ensaio piloto retirava-se a carga remanescente do moinho SAG, inicialmente com o auxílio de pás, e posteriormente com a entrada de um operador no moinho. Todo o material retirado manualmente - bolas e minério era recolhido e submetido ao procedimento de classificação (seção 5.5.10.1).

\subsubsection{MEDIÇÕES DE POTÊNCIA}

\subsubsection{Medição de Potência durante os Ensaios}

Durante os ensaios foram realizadas medidas de consumo de energia através de leituras das potências média e instantânea $(\mathrm{kW})$ fornecidas pelo sistema automatizado CCK. Os dados de potência de todo o período dos ensaios foram armazenados em tabelas e apresentados sob a forma de gráficos, como o exemplificado na Figura 5.12. 


\subsection{Medição de Potência em Vazio}

Para determinar a potência em vazio do moinho, foram conduzidas medições de potência do moinho sem carga. Para tanto, o moinho a potência do moinho operado sem carga foi monitorada durante cerca de oito horas. A determinação da potência vazia média do moinho SAG foi conduzida nas duas velocidades consideradas nos ensaios.

A Figura 5.14 apresenta o monitoramento da potência em vazio para a operação do moinho SAG em $70 \%$ da velocidade crítica $\left(\mathrm{n}_{\mathrm{c}}\right)$. Os dados médios de potência em vazio (No Load Power) obtidos para as duas velocidades de rotação do moinho SAG são apresentados na Tabela 5.8.

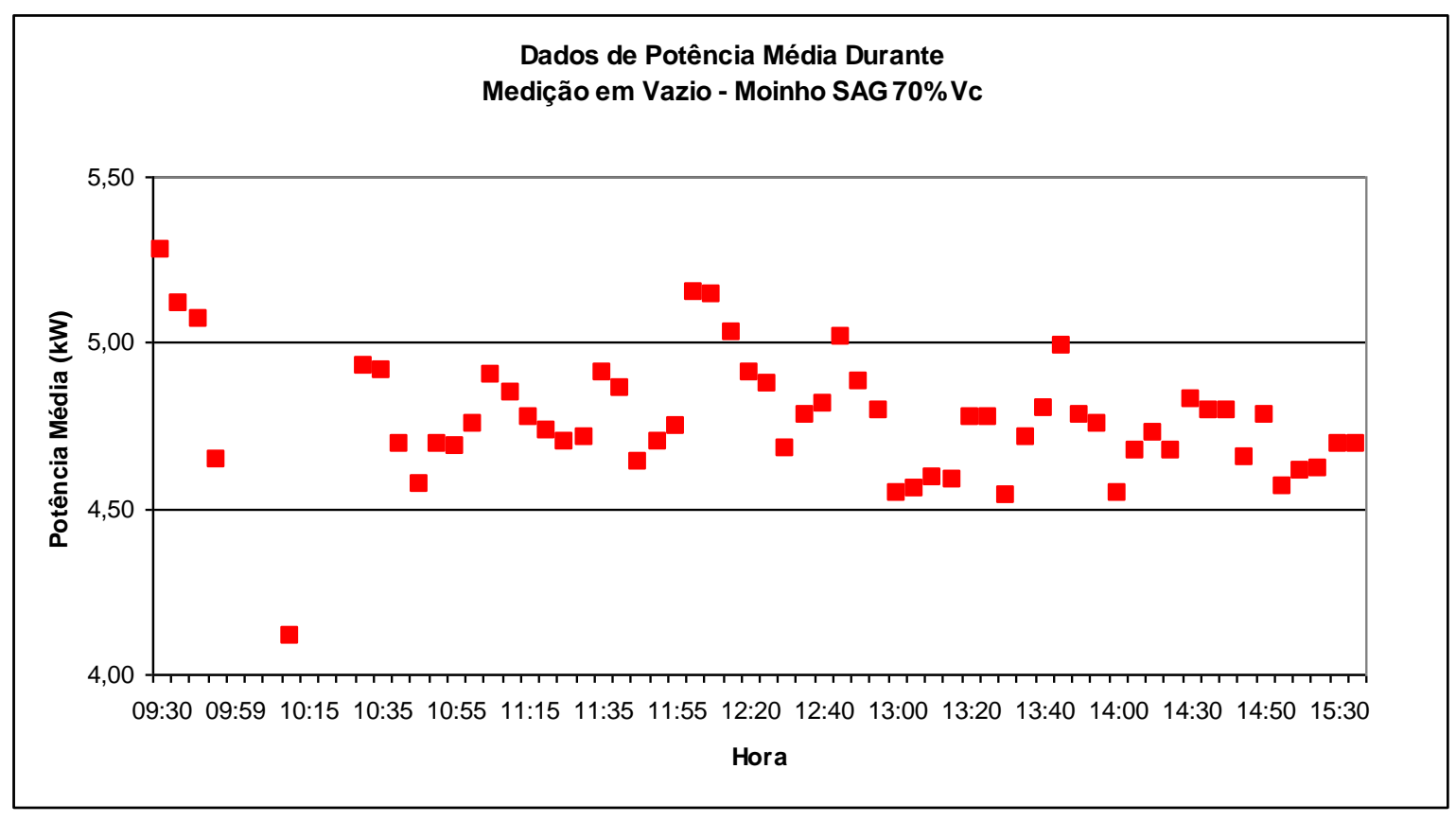

Figura 5.14 - Monitoramento de potência em vazio do moinho SAG com 70,0\% $n_{c}$.

Tabela 5.8 - Distribuição granulométrica do material alimentado nos ensaios.

\begin{tabular}{ccc}
\hline Velocidade SAG & Média (kW) & Desvio Padrão \\
\hline $70,0 \% \mathrm{n}_{\mathrm{c}}$ & 4,77 & 0,24 \\
$78,5 \% \mathrm{n}_{\mathrm{c}}$ & 4,96 & 0,14 \\
\hline
\end{tabular}




\subsubsection{Ensaio de Prony Brake}

O Prony Brake (freio de Prony) é um equipamento muito utilizado para medir a potência de saída de várias máquinas. No caso do moinho semiautógeno piloto, esse instrumento é utilizado para medir a potência no eixo de saída do redutor. Facilmente construído em qualquer oficina, o freio de Prony possui uma cinta - uma chapa de aço que se apoia noa flange da polia - à qual é acoplada uma lona de freio que, quando ajustada à polia, provoca a fricção e o freagem desta em decorrência do atrito entre as duas superfícies. As barras podem ser confeccionadas de tubo ou barra metálica maciça. A utilização de barra ou tubo rígido é recomendada para evitar a flambagem dos materiais durante o esforço. Desse modo, evitam-se imprecisões durante as medições.

O freio de Prony raramente suporta medidas de potência com valores superiores a 75hp, limitação atribuída à dificuldade de remover o calor gerado durante a operação. E, embora o sistema de refrigeração, com água aplicada sobre a área de fricção da polia e a cinta de freio, proporcione a remoção parcial do calor, a limitação ainda persiste. Além do efeito do aquecimento, o equipamento apresenta uma instabilidade operacional que favorece a ocorrência de acidentes, principalmente quando se utiliza balança em vez de dinamômetro. Deve ser lembrado que o gráfico que relaciona a potência medida no freio de Prony àquela medida no quilowattímetro - ambas expressas na mesma unidade - é uma reta. Assim sendo, torna-se dispensável a realização de ensaios com valores elevados da potência.

O Prony Brake pode ser visto na Figura 5.15, e detalhes sobre sua utilização nos ensaio piloto e cálculos de potência são apresentados no Apêndice A. 


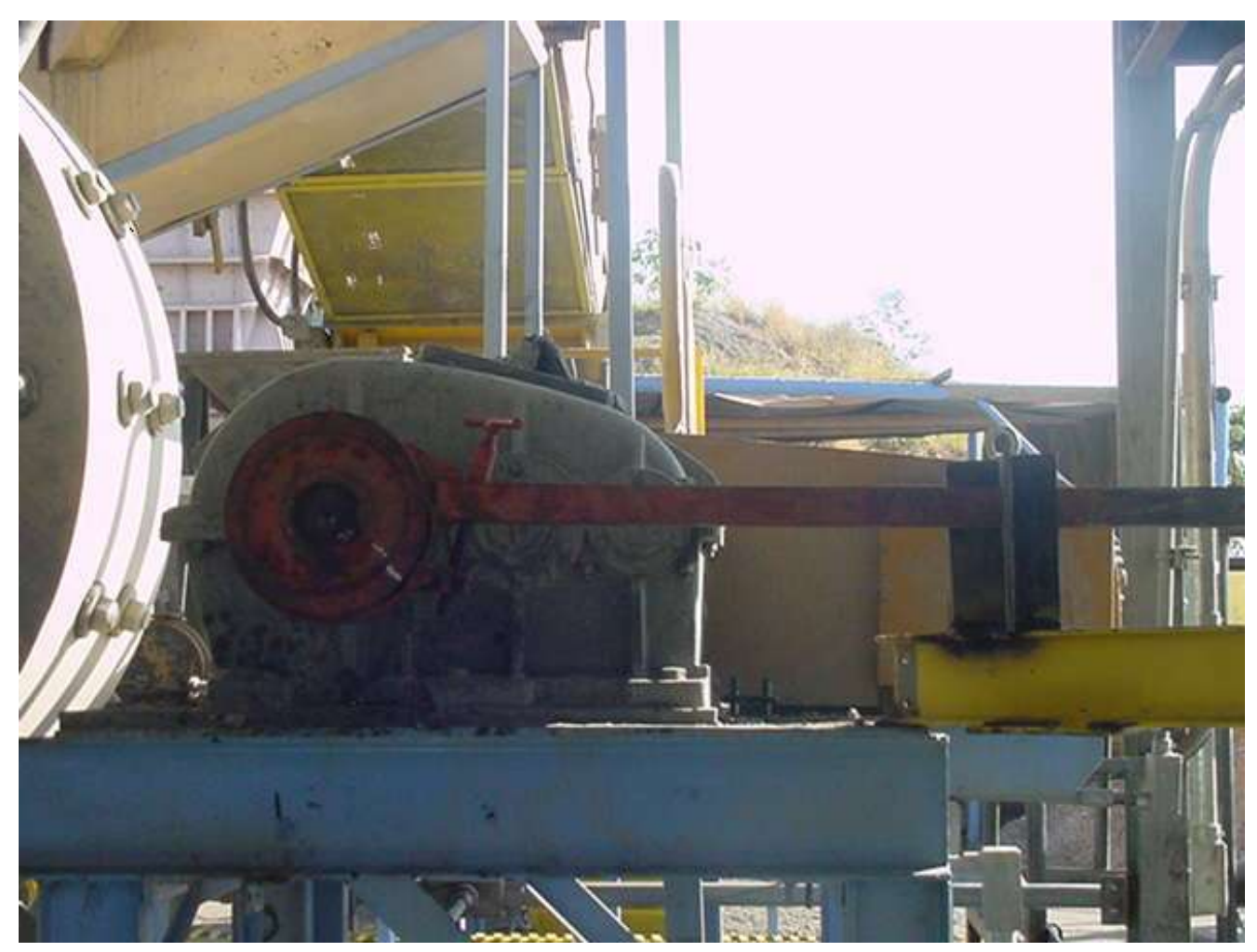

Figura 5.15 - Prony Brake utilizado nos ensaios.

Os dados dos ensaios conduzidos com o Prony Brake foram tabulados e, a partir destes e dos gráficos deles decorrentes, foram determinadas equações representativas das curvas obtidas. A Figura 5.16 mostra o gráfico comparativo entre a potência bruta e a potência total para o moinho SAG operando com $78,5 \% \mathrm{n}_{\mathrm{c}}$.

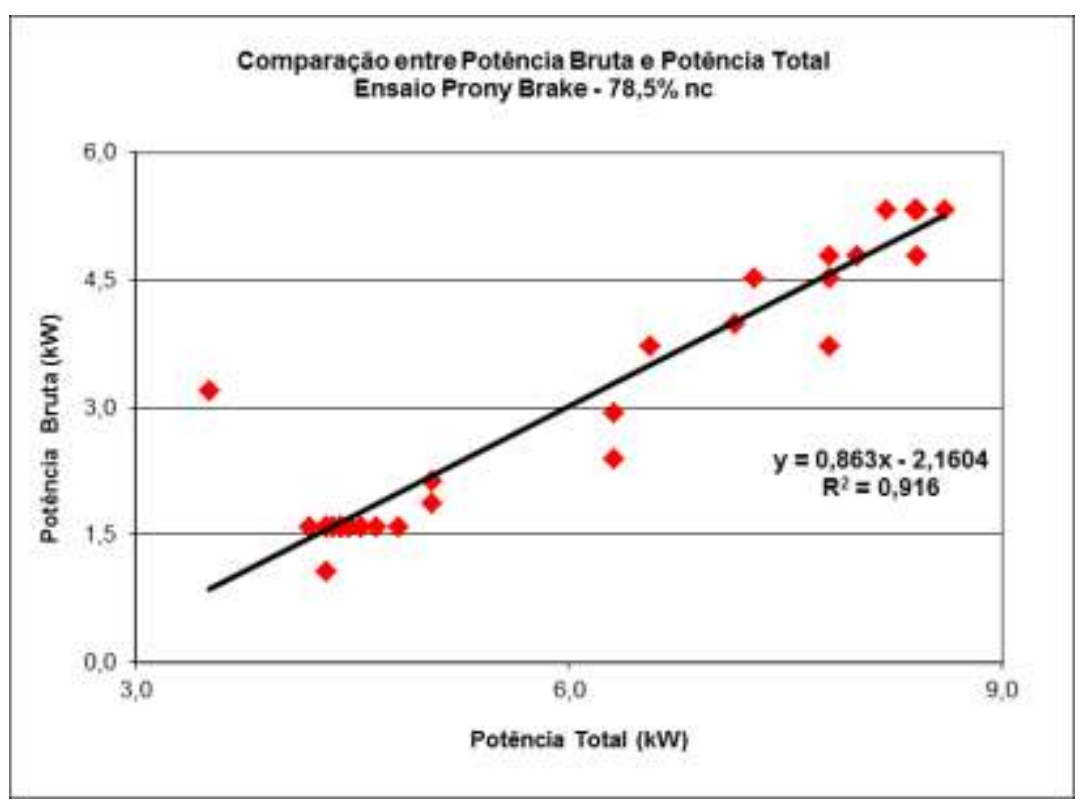

Figura 5.16 - Comparação entre potência bruta e total para o ensaio de Prony Brake - $78,5 \% \mathrm{n}_{\mathrm{c}}$. 


\subsubsection{Amostragem do Circuito Piloto}

\subsubsection{Amostragem dos Fluxos}

Após a estabilização do sistema, verificada pela variação das medidas da célula de carga, potência, taxa de alimentação e pelo acerto do volume da carga, conduzia-se a amostragem do sistema.

Durante os ensaios de moagem, foram amostrados os seguintes pontos do circuito: descarga do moinho - passante no trommel -, fração retida no trommel, fração retida na peneira, fração passante na peneira - produto de moagem. Também foram tomadas amostras relacionadas aos ensaios de moagem secundária e concentração underflow e overflow do ciclone, rejeito e concentrado do jigue, rejeito e concentrado do Knelson, alimentação e produto da moagem de bolas, concentrado e rejeito de flotação.

O fluxograma de uma das configurações de circuito empregada nos ensaios é mostrado na Figura 5.17, e os pontos de amostragem nos ensaios são apresentados na Figura 5.18.

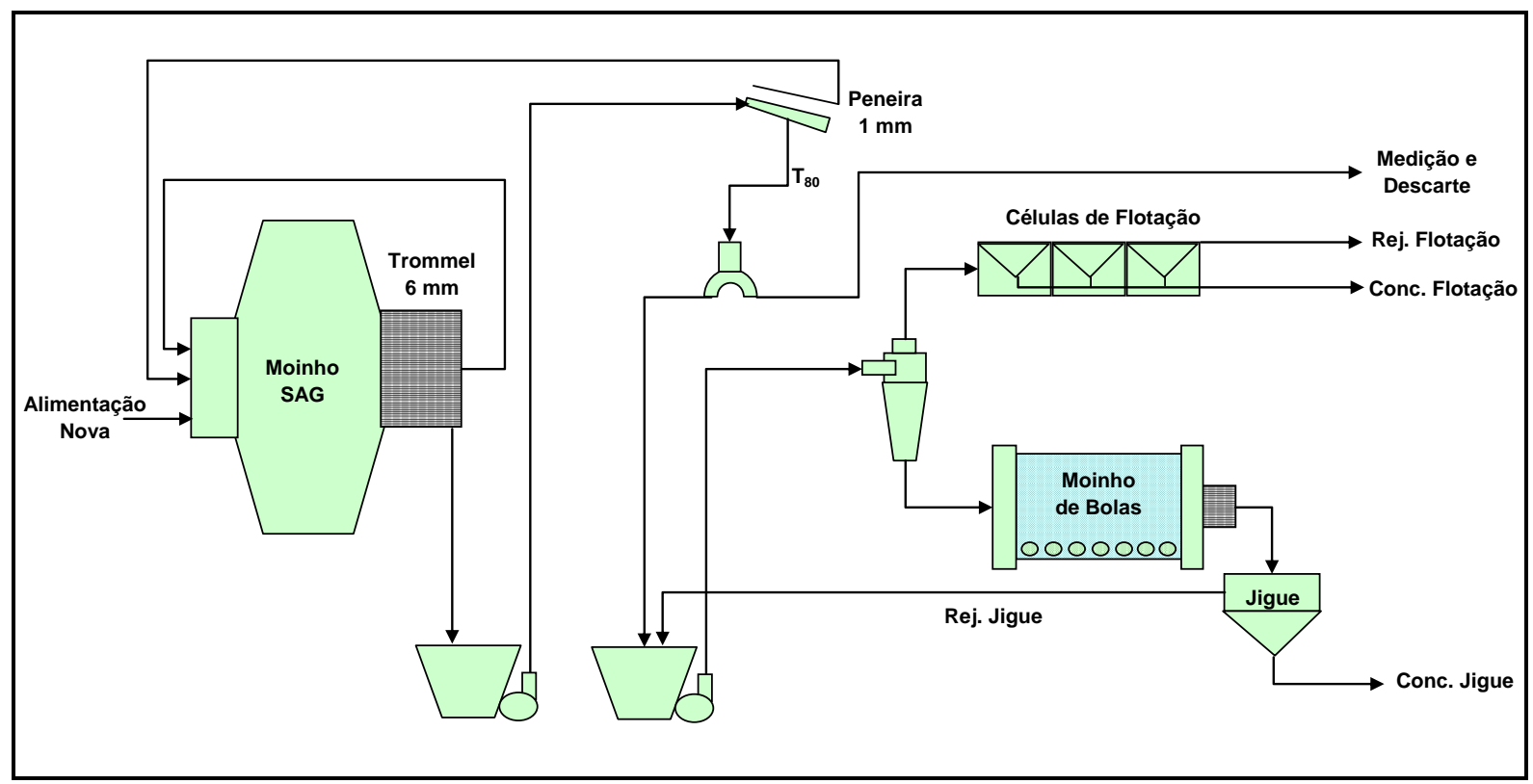

Figura 5.17 - Fluxograma típico dos ensaios piloto. 


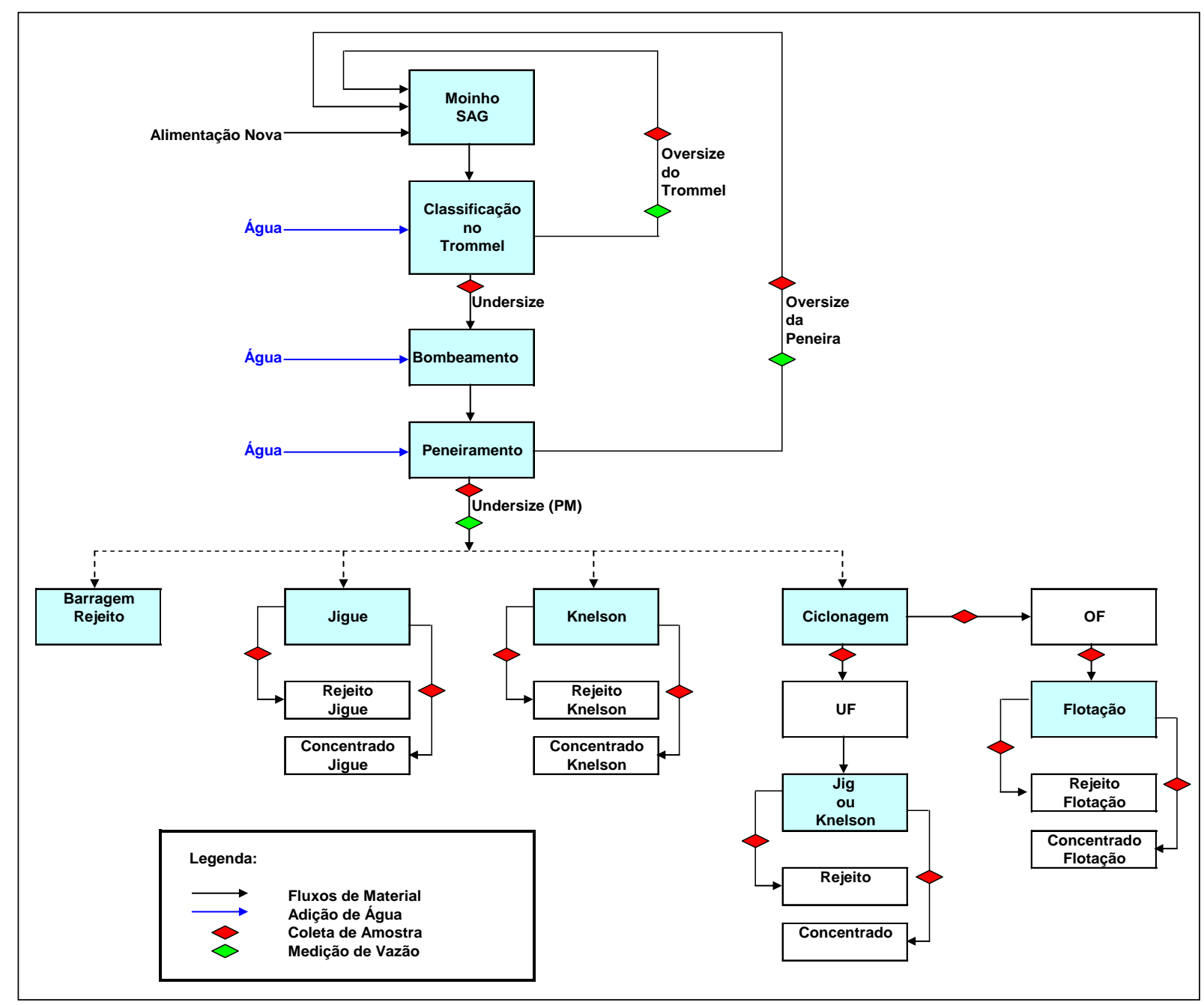

Figura 5.18 - Pontos de amostragem e de adição de água nos ensaios piloto.

\subsection{Medições de Vazão de Sólidos e de Polpa}

Foram coletadas alíquotas para avaliação da vazão de carga circulante de cada amostragem. Foram amostrados os seguintes pontos:

- Fração retida na peneira: coleta de amostra correspondente à vazão de 10 ou 5 segundos.

- Fração retida do trommel: coleta de amostra correspondente à vazão de 1 minuto.

As amostras coletadas foram secas em estufa e pesadas. As vazões de sólido das amostras $(\mathrm{kg} / \mathrm{h})$ foram determinadas com base no peso seco e no tempo de coleta destas últimas. 
A vazão da polpa do produto de moagem SAG foi determinada pela medição do tempo necessário para o preenchimento de um recipiente com volume de $220 \mathrm{~L}$.

Para calcular a vazão e estimar a recuperação mássica nos ensaios de concentração metalúrgica, foram tomados os pesos de concentrado - jigue, knelson, flotação - em função do tempo.

\subsubsection{Processamento e Caracterização das Amostras Obtidas nos Ensaios}

\subsubsection{Classificação da Carga Interna}

Após a conclusão dos ensaios, a carga remanescente no moinho SAG foi retirada e submetida ao processo de peneiramento. Inicialmente as bolas eram lavadas, separadas por tamanho, contadas e pesadas para verificação do consumo de bolas resultante do ensaio. A água utilizada na lavagem da carga de bolas era então incorporada à carga de minério retirada do moinho.

A carga de minério era separada inicialmente na malha de $1 / 2 "$. O material acima de 1/2" era submetido ao peneiramento nas malhas de: 6", 5", 4", 3", 2" e 1". Cada uma dessas frações era separada, identificada e pesada.

A fração abaixo de 1/2" era encaminhada ao Laboratório de Processo da RPM sendo colocada em estufas para secagem. Após a secagem, todo o material abaixo de $1 / 2$ " era pesado. O passante em $1 / 2$ " era então homogeneizado e quarteado a seco em divisor setorial com alimentador rotativo, gerando uma alíquota de cerca de 1000g. Essa alíquota era peneirada a seco/úmido. Nessa etapa, foram utilizadas as seguintes peneiras: 19,0;13,2; 9,5;6,3; 5,6;4,75;2,36;1,18;0,60;0,30;0,212; 0,$150 ; 0,106 ; 0,075 ; 0,045$ e $0,038 \mathrm{~mm}$.

O material retido em $1 / 2$ ", em conjunto com a carga de bolas, era fotografado para registro e verificação do aspecto físico da carga. A Figura 5.19 mostra a carga retirada do moinho SAG após a conclusão de um dos ensaios e a etapa de classificação. 


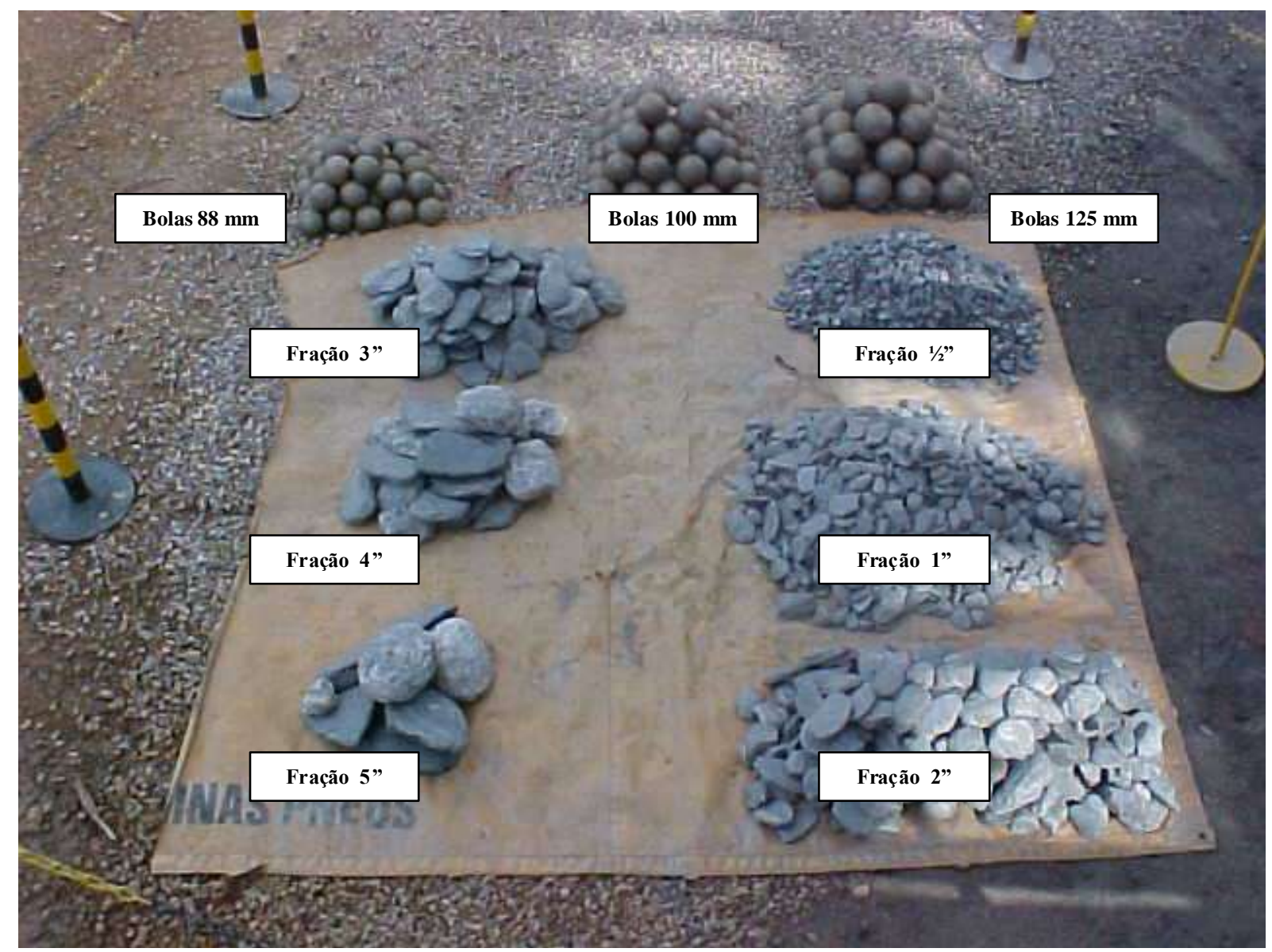

Figura 5.19 - Carga remanescente típica do moinho SAG.

\subsection{Determinações Granulométricas}

As amostras de produto de moagem, descarga do moinho, retido no trommel e retido na peneira eram submetidas a peneiramento, pesadas em polpa e quarteadas; a alíquota obtida no quarteamento era deslamada em 0,038 mm. A parcela da alíquota retida em $0,038 \mathrm{~mm}$ era submetida a peneiramento a seco. A partir dos pesos obtidos nas frações, calcularam-se os percentuais retidos e traçaram-se as curvas granulométricas para cada amostra.

Amostras de overflow e underflow do ciclone, bem como concentrado e rejeito do jigue, knelson e flotação foram também submetidas à determinação granulométrica. 


\subsection{Determinação do Índice de Moabilidade para o Produto de Moagem}

Foram tomadas amostras do passante na peneira - produto de moagem para a realização de ensaios de Bond Work Index para moinho de bolas. Tais amostras foram quarteadas, e uma das alíquotas obtida no quarteamento foi submetida ao peneiramento em 0,106 $\mathrm{mm}$. O material retido em 0,106 $\mathrm{mm}$ foi seco e destinado ao teste de $\mathrm{WI}$ e à determinação de $\mathrm{F}_{80}$ e $\mathrm{P}_{80}$.

\subsubsection{Análises Químicas}

Todas as amostras do produto de moagem foram submetidas à determinação granuloquímica. Os dados de granulometria e os teores de ouro, arsênio e enxofre foram tabulados e as curvas granuloquímicas traçadas. Os teores médios ponderados para a amostra do produto de moagem foram determinados a partir dos dados de granulometria.

As amostras de underflow e overflow do ciclone, concentrado e rejeito das etapas de concentração centrífuga, jigagem e fotação foram também submetidas às análises químicas de ouro, arsênio e enxofre.

\subsubsection{Determinação do Percentual de Sólidos}

Foram determinados os percentuais de sólidos das amostras de undersize da peneira, descarga do moinho, oversize da peneira, overflow e underflow do ciclone. As amostras em polpa foram pesadas, secas em estufa e o peso seco determinado para cálculo do percentual de sólido.

A partir dos dados de granulometria e percentual de sólido do underflow e overflow, foram calculadas as partições de água e sólidos da etapa de classificação por ciclone. 


\section{RESULTADOS E DISCUSSÃO}

Este capítulo apresenta alguns dos resultados obtidos na caracterização das amostras de minérios da RPM e nos ensaios em planta piloto, sob o enfoque geral da campanha e de forma específica para algumas das variáveis investigadas. Em função do volume de informações geradas no trabalho, são apresentados e discutidos apenas os resultados relacionados à moagem SAG. Assim sendo, os resultados relacionados às investigações de circuitos de moagem de bolas e à concentração por jigagem, centrífuga e flotação não são aqui mencionados.

\subsection{CARACTERIZAÇÃO DAS AMOSTRAS DE MINÉRIOS UTILIZADAS NOS ENSAIOS}

\subsubsection{DistribuIÇÃo GRANULOMÉTRICA E BOND WORK INDEX (WI)}

As amostras de minério bruto utilizadas nos ensaios piloto de moagem SAG foram submetidas à determinação da composição granulométrica e do índice de moabilidade para moinho de bolas no Laboratório de Processo da RPM. A Tabela 6.1 apresenta os resultados de WI referentes a quatro tipos de amostras utilizadas nos ensaios de moagem SAG, por faixa granulométrica obtida na etapa de preparação.

Tabela 6.1 - Resultados de WI para as faixas granulométricas obtidas na preparação.

\begin{tabular}{|c|c|c|c|c|c|}
\hline \multirow{2}{*}{$\begin{array}{c}\text { Tamanho } \\
(\mathrm{mm})\end{array}$} & \multicolumn{4}{|c|}{ WI (kWh/t) por Tipo de Minério } & \multirow[b]{2}{*}{ Tipo $7 / 8$} \\
\hline & Tipo B1 & Tipo 1 & Tipo 4 & Tipo 5 & \\
\hline+200 & 0,0 & 0,0 & 0,0 & 0,0 & - \\
\hline$-200+153$ & 4,4 & 5,5 & 11,5 & 8,1 & - \\
\hline$-153+75$ & 6,0 & 6,9 & 11,1 & 10,7 & - \\
\hline$-75+31$ & 10,1 & 6,6 & 8,6 & 7,7 & - \\
\hline-31 & _ & 6,3 & 8,7 & 7,2 & _ \\
\hline
\end{tabular}

Os resultados de WI ponderado e de $\mathrm{F}_{80}$ são apresentados na Tabela 6.2, para os cinco tipos de amostras utilizados nos ensaios em planta piloto. Como 
comentado anteriormente, a diferença entre o valor do WI ponderado e o WI para a amostra composta pode existir e, portanto, deve ser considerada ${ }^{22}$.

Tabela 6.2 - Resultados de WI ponderado e de $F_{80}$ para as amostras ensaiadas.

\begin{tabular}{cccccc}
\hline & Tipo B1 & Tipo 1 & Tipo 4 & Tipo 5 & Tipo 7/8 \\
\hline WI $(\mathrm{kWh} / \mathrm{t})$ & 5,4 & 6,3 & 9,4 & 7,8 & 12,3 \\
$\mathrm{~F}_{80}(\mathrm{~mm})$ & 24 & 19 & 115 & 73 & 73 \\
\hline
\end{tabular}

As curvas granulométricas obtidas para as amostras ensaiadas são mostradas na Figura 6.1.

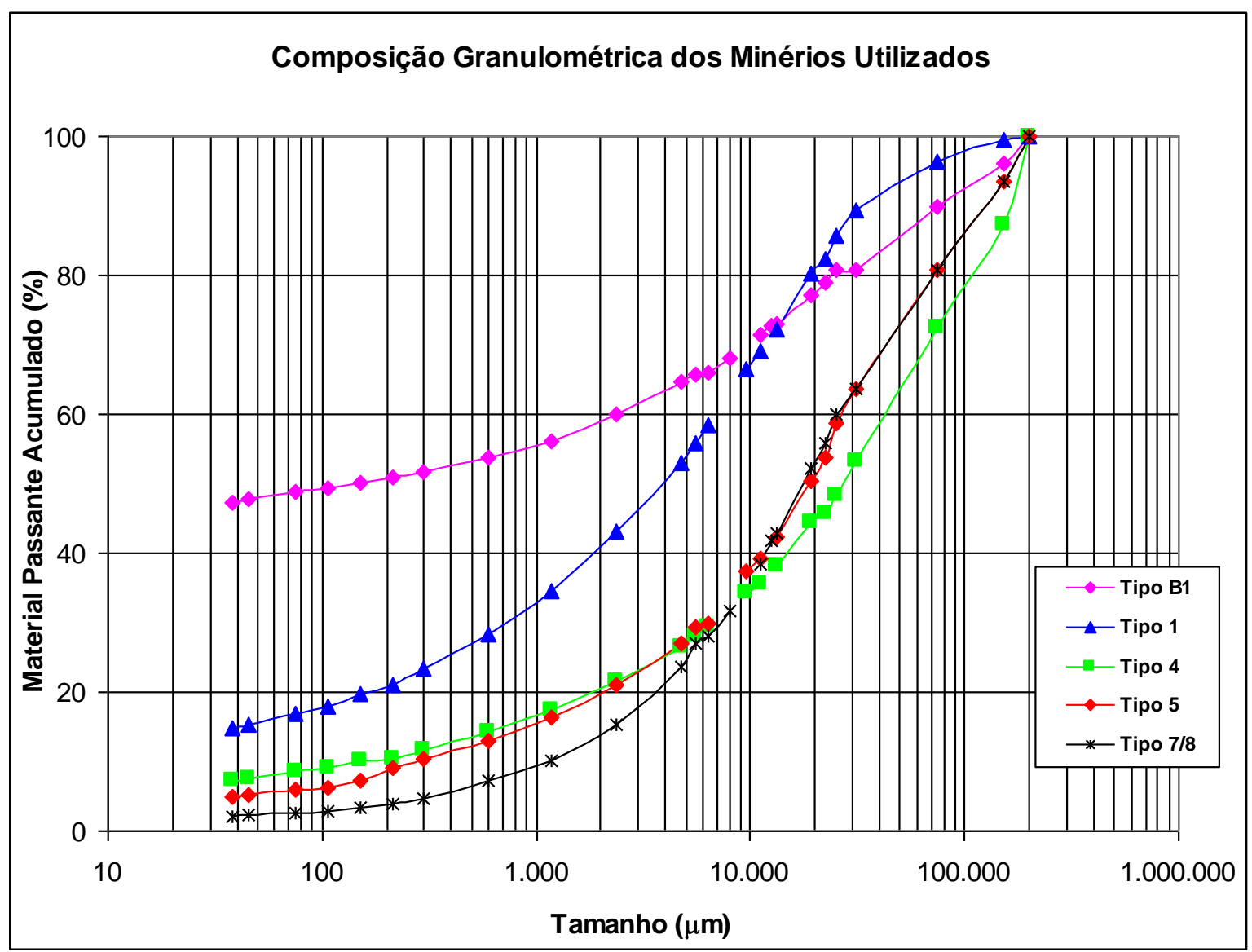

Figura 6.1 - Distribuição granulométrica das amostras de minérios utilizadas.

O minério TIPO 7/8, correspondente aos testemunhos de sondagem, apresentou o maior valor de WI, conforme planejado na etapa de seleção das amostras. O objetivo do preparo dessa amostra foi atingido: a curva granulométrica

22 No que concerne à ponderabilidade do WI, é necessário destacar os seguintes aspectos: (a) o WI não é ponderável; (b) no presente estudo, a ponderabilidade do WI foi considerada como uma tentativa de aproveitamento da grande base de dados da RPM, para o avanço do trabalho naquele momento; (c) estudos mais detalhados devem ser conduzidos sobre o assunto, aproveitando o histórico de dados de moabilidade da RPM e caracterizações complementares. 
obtida para o minério TIPO 7/8 assemelhou-se à curva granulométrica do minério TIPO 5, indicando a boa qualidade do trabalho de preparação.

O minério TIPO B1, oxidado, apresentou a menor tenacidade - indicada pelo menor valor de $\mathrm{WI}$ - e perfil granulométrico diferente das demais. Assim, como demonstrado na Figura 6.1, as curvas referentes aos minérios TIPOS 1, 4, 5 e 7/8 tinham perfis semelhantes, com $\mathrm{P}_{80}$ entre 20 e $100 \mathrm{~mm}$ e fração passante na malha mais fina inferior a $20 \%$. Já na amostra $B 1$, embora o $P_{80}$ tenha sido de cerca de 30 $\mathrm{mm}$ - portanto dentro da faixa acima - aproximadamente $50 \%$ do material passou pela malha mais fina. Isso indica que a amostra TIPO B1 tinha maior quantidade de finos do que as demais amostras analisadas.

\subsection{Drop Weight Test, Índice de Abrasão, Point LoAd Test}

Ensaios de Drop Weight Test Completo e de índice de abrasão ( $\mathrm{t}_{\mathrm{a}}$ ) para amostras de quatro tipos de minérios utilizados nos ensaios piloto - minérios TIPOS 1 , 4, 5 e 7/8 - foram realizados no LSC-EPUSP. A Tabela 6.3 apresenta os resultados de WI, do índice de quebra, do parâmetro $A^{*} b$ e do índice de abrasão obtidos para essas amostras.

Tabela 6.3 - Resultados de WI, DWT (A*b) e ta para as amostras ensaiadas em planta piloto.

\begin{tabular}{cccc}
\hline Amostra & WI (kWh/t) & $\begin{array}{c}\text { DWT } \\
\mathbf{A}^{*} \mathbf{b}\end{array}$ & $\mathbf{t}_{\mathbf{a}}$ \\
\hline Tipo 1 & 6,31 & 164,2 & 3,17 \\
Tipo 4 & 9,4 & 83,9 & 1,48 \\
Tipo 5 & 7,8 & 85,9 & 1,77 \\
Tipo $7 / 8$ & 12,32 & 58,6 & 1,46 \\
\hline
\end{tabular}

Com relação ao parâmetro $A^{*} b$, os maiores valores indicam menor resistência ao impacto, como visto na Tabela 3.1 (p. 56). Assim sendo, a resistência ao impacto da amostra de minério TIPO 1 - filito macio sem boudins - revelou-se "extremamente baixa", enquanto a amostra TIPO 7/8 - filito duro com boudins demonstrou "média" resistência ao impacto. Também no $t_{a}$, aos maiores valores correspondem as menores resistências à fragmentação por abrasão (Tabela 3.2, p. 
57). Portanto, a resistência à fragmentação por abrasão da amostra TIPO 1 foi classificada como "excepcionalmente baixa", e as amostras TIPO 4 e TIPO 7/8 foram classificadas como de "muito baixa" resistência à abrasão.

Como mencionado na seção anterior deste trabalho, os estudos de caracterização de amostras de minérios da RPM foram complementados em 2007. Um conjunto de onze amostras representativas dos minérios da RPM foi selecionado e submetido a ensaios de caracterização. Os ensaios de WI e Point Load Test foram realizados no Laboratório de Processo da RPM, enquanto os demais foram conduzidos no LSC-EPUSP. Os resultados de PLT, WI, DWT e $t_{a}$ obtidos para essas amostras são apresentados na Tabela 6.4.

Tabela 6.4 - Resultados de PLT, WI, DWT ( $\left.A^{*} b\right)$ e ta para amostras de minério da RPM.

\begin{tabular}{|c|c|c|c|c|c|}
\hline \multicolumn{2}{|c|}{ Identificação da Amostra } & \multirow{2}{*}{ PLT (MPa) } & \multirow{2}{*}{ Wl $(k W h / t)$} & \multirow{2}{*}{$\begin{array}{c}\text { DWT } \\
A^{*} \mathbf{b}\end{array}$} & \multirow{2}{*}{$t_{a}$} \\
\hline Banco & Bloco & & & & \\
\hline 708 & 806 & 23,68 & 5,57 & 187,9 & 2,77 \\
\hline 716 & 609 & 111,74 & 11,53 & - & - \\
\hline 724 & 512 & 78,35 & 6,52 & 162 & 1,44 \\
\hline 732 & 910 & 90,82 & 7,98 & 101,4 & 1,97 \\
\hline 740 & 711 & 28,12 & 6,1 & - & - \\
\hline 748 & 1313 & 94,89 & 8,31 & 151,1 & 2,5 \\
\hline 756 & 1511 & 130,18 & 10,09 & - & - \\
\hline 764 & 1014 & 46,58 & 5,42 & 170 & 2,59 \\
\hline 764 & 1514 & 73,51 & 8,85 & 159,6 & 1,86 \\
\hline 764 & 1812 & 145,01 & 11,84 & 58 & 0,96 \\
\hline 764 & 1813 & 157,8 & 10,61 & 77,6 & 1,53 \\
\hline 772 & 615 & 28,24 & - & - & - \\
\hline 772 & 1814 & 107,94 & 10,33 & 71,7 & 1,49 \\
\hline 772 & 2114 & 173,17 & 12,3 & 65,3 & 1,14 \\
\hline 764 & 1913 & _- & 13,07 & 63,8 & 1,17 \\
\hline
\end{tabular}

A classificação desse segundo lote de amostras de minérios da RPM no que tange à resistência ao impacto e à abrasão é mostrada na tabela 6.5. 
Tabela 6.5 - Classificação de amostras da RPM quanto à resistência ao impacto e à abrasão.

\begin{tabular}{|c|c|c|c|}
\hline \multicolumn{2}{|c|}{ Identificação da Amostra } & \multirow{2}{*}{ Resistência ao Impacto } & \multirow{2}{*}{ Resistência à Abrasão } \\
\hline Banco & Bloco & & \\
\hline 708 & 806 & Extremamente baixa & Excepcionalmente baixa \\
\hline 716 & 609 & - & - \\
\hline 724 & 512 & Extremamente baixa & Muito baixa \\
\hline 732 & 910 & Muito baixa & Extremamente baixa \\
\hline 740 & 711 & - & - \\
\hline 748 & 1313 & Extremamente baixa & Excepcionalmente baixa \\
\hline 756 & 1511 & - & - \\
\hline 764 & 1014 & Extremamente baixa & Excepcionalmente baixa \\
\hline 764 & 1514 & Extremamente baixa & Extremamente baixa \\
\hline 764 & 1812 & Média & Média \\
\hline 764 & 1813 & Baixa & Muito baixa \\
\hline 772 & 615 & - & - \\
\hline 772 & 1814 & Baixa & Muito baixa \\
\hline 772 & 2114 & Moderadamente baixa & Moderadamente baixa \\
\hline 764 & 1913 & Moderadamente baixa & Moderadamente baixa \\
\hline
\end{tabular}

O gráfico que relaciona os dados de WI e de DWT ( $\left.A^{*} b\right)$ obtidos nos estudos iniciais e nos estudos complementares de amostras de minério da RPM consta da Figura 6.2. Os resultados referentes às amostras de minérios utilizadas nos ensaios piloto de moagem SAG estão identificados no gráfico. O minério TIPO 1 encontra-se na região de minérios macios de baixa tenacidade $(\mathrm{Wl}<7 \mathrm{kWh} / \mathrm{t})$ referente aos minérios oxidados, TIPO $B 1$, ou filitos predominantemente sem ocorrências de boudins de quartzo. Já o minério TIPO 7/8 encontra-se na região classificada como de tenacidade alta $(\mathrm{Wl}>10 \mathrm{kWh} / \mathrm{t})$. A curva de regressão construída com base nos dados obtidos apresenta uma aderência razoável aos dados experimentais. 


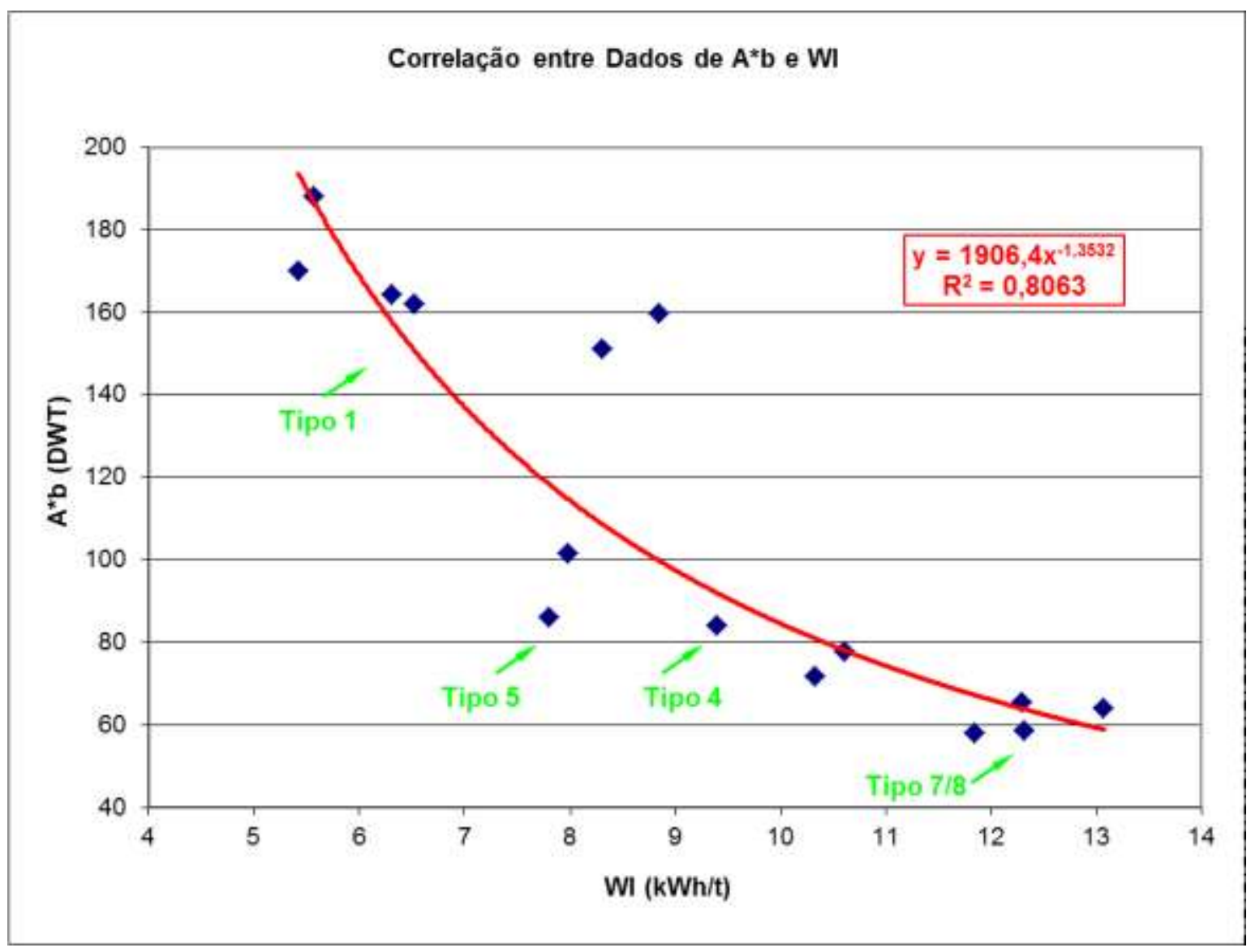

Figura 6.2 - Correlação entre WI e DWT para amostras de minério da RPM.

Como postulam NAPIER-MUNN et al. (1999), as tentativas de correlacionar os índices WI e A*b não resultam em índices de correlação altos, superiores a 95\%, já que a fragmentação envolve, em cada ensaio, tamanhos diferentes de grãos e quebra individual ou coletiva destes.

No presente trabalho, o objetivo de tentar correlacionar os dois índices - WI e $A^{*} b$ - foi analisar o perfil obtido, de forma a aproveitar a imensa base de dados da jazida da RPM caracterizada por WI. Essa tentativa buscou, portanto, utilizar as informações existentes para prever o desempenho do moinho SAG com os diferentes tipos de minério da RPM.

A relação entre os dados de PLT e WI foi investigada, e consta da Figura 6.3. A regressão linear obtida, com curva também lançada no gráfico, mostrou correlação razoável entre os resultados obtidos de PLT e WI. Essa relação deverá ser confirmada em uma campanha de ensaios mais extensa. A existência de correlação suficientemente robusta entre esses parâmetros indica a possibilidade de utilização do ensaio PLT na estimativa do valor de WI e, indiretamente, das taxas de 
alimentação do circuito de moagem. Essa é uma vantagem quando são conduzidas campanhas de sondagem e não se dispõe de amostras em quantidade suficiente para a realização dos ensaios de WI, além da economia de custos e de tempo que os ensaios de PLT representam em relação a esse método de caracterização.

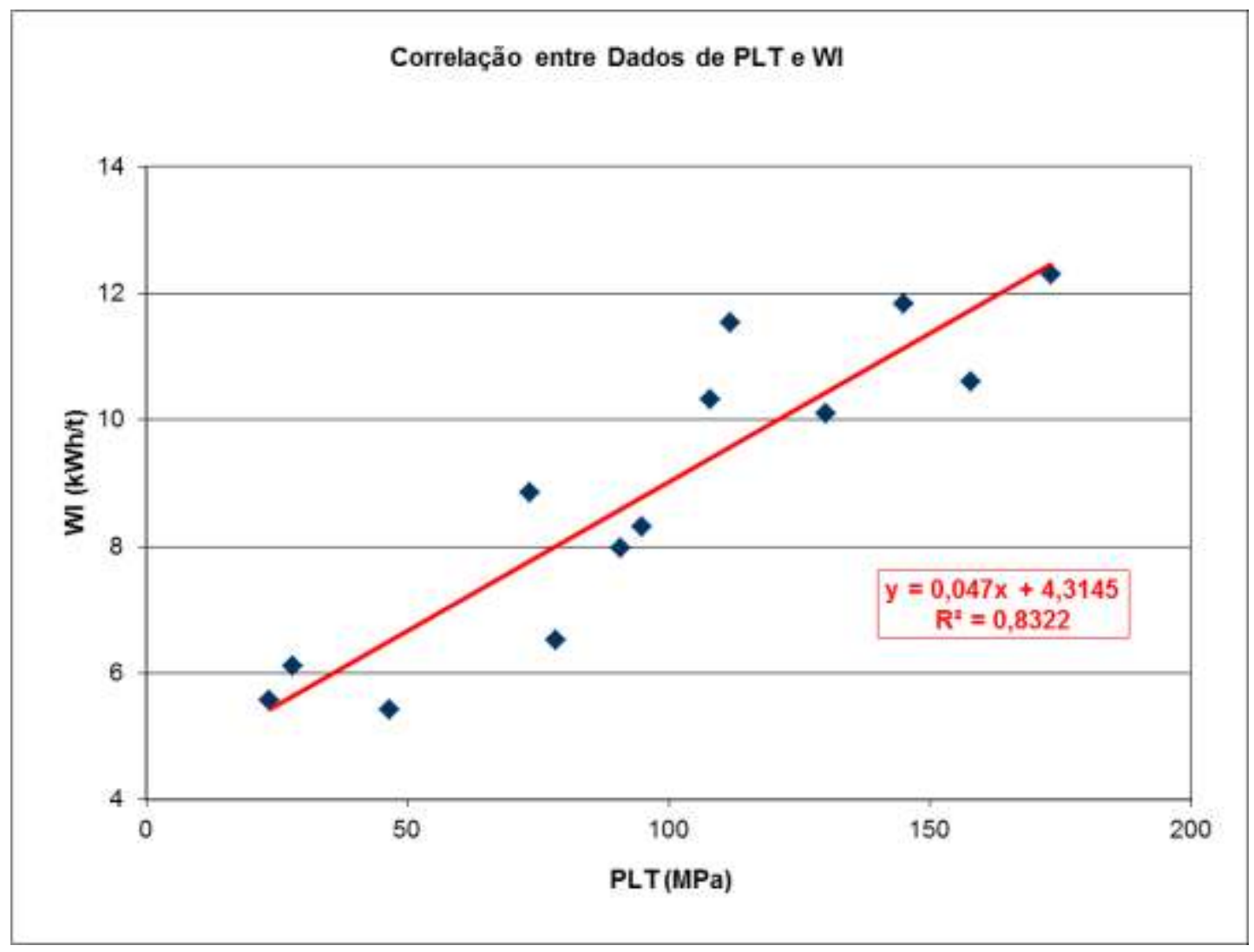

Figura 6.3 - Correlação entre PLT e BWI para amostras de minério da RPM.

Embora haja uma nítida tendência de uma função linear entre os valores de PLT e WI, a dispersão e também observada. Dependendo da sensibilidade do índice ao desempenho do futuro circuito a relação poderá, como acima mencionado, ser empregada como índice característico para a previsão de desempenho.

\subsection{ENSAIOS EM PLANTA PILOTO}

\subsubsection{Resumo dos Trabalhos}

Os estudos em planta piloto com minérios da RPM foram realizados ao longo de onze meses de trabalho, e incluíram:

- $\quad$ oito ensaios exploratórios para operação inicial dos equipamentos, treinamento da equipe na metodologia, identificação de problemas e oportunidades de melhorias relacionadas à operação da planta piloto e à condução dos ensaios; 
- 69 (sessenta e nove) ensaios para diferentes condições operacionais, que serão descritas posteriormente;

- cinco ensaios para determinação de potência em vazio para o moinho SAG piloto, operando com velocidades correspondentes a 70,0\% e 78,5\% da velocidade crítica; nesses ensaios também foram realizadas as aferições do sistema de células de carga do moinho SAG - medições em vazio e com carga padrão de 1,5 toneladas.

- três ensaios de Prony Brake para o moinho SAG piloto operando com $70 \%$ e $78,5 \%$ da velocidade crítica.

A Tabela 6.6 apresenta um resumo dos trabalhos conduzidos. Foram totalizadas cerca de 450 horas de operação do circuito piloto, que utilizou aproximadamente 1.400 t de amostras de minério. A duração média de cada ensaio foi de 6,1 horas, e a quantidade total de alimentação média por ensaio foi de 19,3 t de minério. Os ensaios foram divididos em blocos, considerando apenas o fechamento de etapas de tratamento das amostras e de análises de dados. A classificação e a identificação adotadas para os blocos de ensaios, assim como para cada ensaio, não se refere, portanto, a nenhuma categorização específica.

Tabela 6.6 - Resumo dos ensaios em planta piloto conduzidos com minérios da RPM.

\begin{tabular}{|c|c|c|c|c|}
\hline $\begin{array}{l}\text { Identificação do } \\
\text { Bloco }\end{array}$ & $\begin{array}{l}\text { Número de } \\
\text { Ensaios }\end{array}$ & Codificação dos Ensaios & $\begin{array}{l}\text { Minério Total } \\
\text { Processado (t) }\end{array}$ & $\begin{array}{l}\text { Período Total dos } \\
\text { Ensaios (h) }\end{array}$ \\
\hline $\begin{array}{c}\text { Ensaios } \\
\text { Exploratórios }\end{array}$ & 8 & $\begin{array}{l}\text { E01; E02; E03; E04; SAG 03; SAG E04; } \\
\text { SAG 05, SAG E10 }\end{array}$ & 26 & 29 \\
\hline Bloco 1 & 9 & $\begin{array}{c}\mathrm{B} 1.1 ; \mathrm{B} 1.1 \mathrm{R} ; \mathrm{B} 1.2 ; \mathrm{B} 1.3 ; \mathrm{B} 1.4 ; \mathrm{B} 1.4 \mathrm{R} ; \\
\mathrm{B} 1.5 ; \mathrm{B} 1.6 ; \mathrm{B} 1.6 \mathrm{R}\end{array}$ & 200 & 60 \\
\hline Bloco 2 & 7 & $\begin{array}{c}\text { B2.1; B2.2; B2.3; B2.4; B2.4R; B2.5; } \\
\text { B2.6 }\end{array}$ & 175 & 47 \\
\hline Bloco 4 & 3 & B4.1; B4.2; B4.3 & 48 & 16 \\
\hline Bloco 6 & 2 & B6.1; B6.2 & 37 & 13 \\
\hline Bloco C1 - C8R & 10 & $\begin{array}{c}\mathrm{C} 1 ; \mathrm{C} 2 ; \mathrm{C} 3 ; \mathrm{C} 4 ; \mathrm{C} 5 ; \mathrm{C} 6 ; \mathrm{C} 7 ; \mathrm{C} 7 \mathrm{R} ; \mathrm{C} 8 ; \\
\mathrm{C} 8 \mathrm{R}\end{array}$ & 195 & 63 \\
\hline Bloco C9 - C20 & 13 & $\begin{array}{l}\text { C9; C10; C11; C12; C13; C13R; C14; } \\
\text { C15; C16; C17; C18; C19; C20 }\end{array}$ & 157 & 64 \\
\hline Bloco C21 - C33B & 15 & $\begin{array}{c}\mathrm{C} 21 ; \mathrm{C} 22 ; \mathrm{C} 23 ; \mathrm{C} 24 ; \mathrm{C} 25 ; \mathrm{C} 26 ; \mathrm{C} 15 \mathrm{R} ; \\
\mathrm{C} 27 ; \mathrm{C} 28 ; \mathrm{C} 29 ; \mathrm{C} 30 ; \mathrm{C} 31 ; \mathrm{C} 32 ; \mathrm{C} 33 \mathrm{~A} \\
\text { C33B }\end{array}$ & 288 & 98 \\
\hline Bloco C33C - C41 & 10 & $\begin{array}{c}\text { C33C; C34A; C34B; C35; C36; C37; } \\
\text { C38; C39; C40; C41 }\end{array}$ & 233 & 60 \\
\hline Total & $\begin{array}{l}69 \text { (77 incluindo } \\
\text { os exploratórios) }\end{array}$ & - & 1359 & 450 \\
\hline
\end{tabular}


Os 69 ensaios em planta piloto foram conduzidos em diferentes condições operacionais permitindo, assim, o estudo detalhado das variáveis de processo da moagem SAG. As tabelas 6.7 a 6.12 apresentam a classificação dos ensaios, conforme as condições operacionais utilizadas.

Tabela 6.7 - Classificação dos ensaios piloto, segundo configuração de grelhas do moinho SAG.

\begin{tabular}{ccc}
\hline Abertura Grelha & Configuração da Grelha & Número de Ensaios \\
\hline $6,35 \mathrm{~mm}$ & Parcialmente aberta & 63 \\
$6,35 \mathrm{~mm}$ & Completamente aberta & 1 \\
$12,7 \mathrm{~mm}$ & Parcialmente aberta & 4 \\
$12,7 \mathrm{~mm}$ & Completamente aberta & 1 \\
\hline
\end{tabular}

Tabela 6.8 - Classificação dos ensaios piloto, segundo percentual de sólidos na descarga do moinho SAG.

\begin{tabular}{cc}
\hline \% Sólidos na Descarga do Moinho SAG & Número de Ensaios \\
\hline $60 \%$ & 25 \\
$68 \%$ & 1 \\
$70 \%$ & 1 \\
$75 \%$ & 42 \\
\hline
\end{tabular}

Tabela 6.9 - Classificação dos ensaios piloto, segundo distribuição e carga de bolas do moinho SAG.

\begin{tabular}{ccccc}
\hline & \multicolumn{5}{c}{ Número de Ensaios } \\
\hline $\begin{array}{c}\text { Distribuição de } \\
\text { Bolas }\end{array}$ & $\mathbf{4} \%$ & Carga de Bolas (\% volume interno ocupado) \\
\hline Tipo 1 & 24 & $\mathbf{1 0 \%}$ & $\mathbf{1 4 \%}$ & $\mathbf{1 5 \%}$ \\
\hline Tipo 2 & 9 & 20 & 0 & 2 \\
\hline
\end{tabular}


Tabela 6.10 - Classificação dos ensaios piloto, segundo carga total ocupada do moinho SAG.

\begin{tabular}{cc}
\hline \multicolumn{2}{c}{ Número de Ensaios } \\
\hline \multicolumn{2}{c}{ Carga Total (\% vi ocupado) } \\
$\mathbf{2 5 \%}$ & $\mathbf{3 0 \%}$ \\
\hline 63 & 6 \\
\hline
\end{tabular}

Tabela 6.11 - Classificação dos ensaios piloto, segundo velocidade de rotação do moinho SAG.

\begin{tabular}{cc}
\hline \multicolumn{2}{c}{ Número de Ensaios } \\
\hline \multicolumn{2}{c}{ Rotação Moinho SAG $\left(\% \mathbf{n}_{\mathrm{c}}\right)$} \\
$\mathbf{7 0 , 0 \%}$ & $\mathbf{7 8 , 5 \%}$ \\
\hline 33 & 36 \\
\hline
\end{tabular}

Tabela 6.12 - Classificação dos ensaios piloto, segundo tipo de configuração do moinho SAG.

\begin{tabular}{cc}
\hline \multicolumn{2}{c}{ Número de Ensaios } \\
\hline $\begin{array}{c}\text { Configuração Circuito SAG } \\
\text { Aberto }\end{array}$ & Fechado \\
\hline 7 & 62 \\
\hline
\end{tabular}

O sumário das principais condições de operação praticadas em cada um dos 69 ensaios piloto de moagem SAG é apresentado na Tabela 6.13. Os dados de tipos de minérios e blendagens utilizados, ou seja, proporções em peso para cada um dos ensaios, são indicados na Tabela 6.14. 
Tabela 6.13 - Sumário das condições operacionais dos ensaios piloto de moagem SAG.

\begin{tabular}{|c|c|c|c|c|c|c|c|c|c|c|c|}
\hline Bloco & $\mathrm{N}$. & Ensaio & $\begin{array}{l}\text { Abertura e } \\
\text { Configuração } \\
\text { da Grelha } \\
\text { (mm) }\end{array}$ & $\begin{array}{c}\text { Abertura } \\
\text { Trommel } \\
(\mathrm{mm})\end{array}$ & $\begin{array}{c}\text { Abertura } \\
\text { Peneira } \\
(\mathrm{mm})\end{array}$ & $\begin{array}{c}\text { Sólidos na } \\
\text { Descarga } \\
\text { SAG (\%) }\end{array}$ & $\begin{array}{c}\text { Carga Bolas } \\
\text { (\%vi) }\end{array}$ & $\begin{array}{c}\text { Distribuição } \\
\text { de Bolas }\end{array}$ & $\begin{array}{c}\text { Carga Total } \\
\text { (\%vi) }\end{array}$ & $\begin{array}{l}\text { Velocidade } \\
\text { SAG }(\% \mathrm{nc})\end{array}$ & $\begin{array}{c}\text { Configuração } \\
\text { do Circuito } \\
\text { SAG }\end{array}$ \\
\hline \multirow{9}{*}{$\begin{array}{l}\bar{o} \\
\frac{0}{0}\end{array}$} & 1 & B1.1 & 6,35 PA & 6,35 & 1 & 75 & 10 & 1 & 25 & 78,5 & Fechado \\
\hline & 2 & B1.1R & 6,35 PA & 6,35 & 1 & 75 & 10 & 1 & 25 & 78,5 & Fechado \\
\hline & 3 & B1.2 & 6,35 PA & 6,35 & 1 & 75 & 10 & 1 & 25 & 78,5 & Fechado \\
\hline & 4 & B1.3 & $6,35 \mathrm{PA}$ & 6,35 & 1 & 75 & 10 & 1 & 25 & 78,5 & Aberto \\
\hline & 5 & B1.4 & $6,35 \mathrm{PA}$ & 6,35 & 1 & 75 & 4 & 1 & 25 & 78,5 & Fechado \\
\hline & 6 & B1.5 & $6,35 \mathrm{PA}$ & 6,35 & 1 & 75 & 4 & 1 & 25 & 78,5 & Fechado \\
\hline & 7 & B1.6 & 6,35 PA & 6,35 & 1 & 75 & 4 & 1 & 25 & 78,5 & Aberto \\
\hline & 8 & B1.4 R & $6,35 \mathrm{PA}$ & 6,35 & 1 & 75 & 4 & 1 & 25 & 78,5 & Fechado \\
\hline & 9 & B1.6R & $6,35 \mathrm{PA}$ & 6,35 & 1 & 75 & 4 & 1 & 25 & 78,5 & Aberto \\
\hline \multirow{7}{*}{$\begin{array}{l}N \\
\circ \\
\stackrel{O}{0} \\
\frac{0}{\infty}\end{array}$} & 10 & B2.1 & $6,35 \mathrm{PA}$ & 6,35 & 1 & 75 & 10 & 1 & 25 & 78,5 & Fechado \\
\hline & 11 & B2.2 & 6,35 PA & 6,35 & 1 & 75 & 10 & 1 & 25 & 78,5 & Fechado \\
\hline & 12 & B2.3 & $6,35 \mathrm{PA}$ & 6,35 & 1 & 75 & 10 & 1 & 25 & 78,5 & Aberto \\
\hline & 13 & B2.4 & 6,35 PA & 6,35 & 1 & 75 & 4 & 1 & 25 & 78,5 & Fechado \\
\hline & 14 & B2.4R & 6,35 PA & 6,35 & 1 & 75 & 4 & 1 & 25 & 78,5 & Fechado \\
\hline & 15 & B2.5 & $6,35 \mathrm{PA}$ & 6,35 & 1 & 75 & 4 & 1 & 25 & 78,5 & Fechado \\
\hline & 16 & B2.6 & $6,35 \mathrm{PA}$ & 6,35 & 1 & 75 & 4 & 1 & 25 & 78,5 & Aberto \\
\hline \multirow{3}{*}{$\begin{array}{l}\text { + } \\
\text { Oे } \\
\text { o }\end{array}$} & 17 & B4.1 & $6,35 \mathrm{PA}$ & 6,35 & 1 & 75 & 10 & 1 & 25 & 78,5 & Fechado \\
\hline & 18 & B4.2 & 6,35 PA & 6,35 & 1 & 75 & 10 & 1 & 25 & 78,5 & Fechado \\
\hline & 19 & B4.3 & $6,35 \mathrm{PA}$ & 6,35 & 1 & 75 & 10 & 1 & 25 & 78,5 & Fechado \\
\hline \multirow{2}{*}{$\begin{array}{l}0 \\
: \\
\frac{0}{\infty}\end{array}$} & 20 & B6.1 & 6,35 PA & 6,35 & 1 & 75 & 15 & 1 & 25 & 78,5 & Fechado \\
\hline & 21 & B6.2 & $6,35 \mathrm{PA}$ & 6,35 & 1 & 75 & 10 & 1 & 25 & 78,5 & Fechado \\
\hline \multirow{10}{*}{$\begin{array}{l}\frac{1}{\infty} \\
0 \\
1 \\
1 \\
0 \\
0 \\
\frac{0}{\infty}\end{array}$} & 22 & C. 1 & $6,35 \mathrm{PA}$ & 6,35 & 1 & 75 & 10 & 1 & 25 & 78,5 & Fechado \\
\hline & 23 & C. 2 & 6,35 PA & 6,35 & 1 & 75 & 10 & 2 & 25 & 78,5 & Fechado \\
\hline & 24 & C. 3 & $6,35 \mathrm{PA}$ & 6,35 & 1 & 75 & 15 & 2 & 25 & 78,5 & Fechado \\
\hline & 25 & C. 4 & 6,35 PA & 6,35 & 1 & 75 & 15 & 2 & 30 & 78,5 & Fechado \\
\hline & 26 & C. 5 & 6,35 PA & 6,35 & 1 & 60 & 15 & 2 & 30 & 78,5 & Fechado \\
\hline & 27 & C. 6 & 6,35 PA & 6,35 & 1 & 68 & 15 & 2 & 30 & 78,5 & Fechado \\
\hline & 28 & C. 7 & $12,7 \mathrm{PA}$ & 6,35 & 1 & 75 & 10 & 1 & 25 & 78,5 & Fechado \\
\hline & 29 & C.7R & $12,7 \mathrm{PA}$ & 6,35 & 1 & 75 & 10 & 1 & 25 & 78,5 & Fechado \\
\hline & 30 & C. 8 & $12,7 \mathrm{PA}$ & 6,35 & 1 & 75 & 10 & 1 & 25 & 78,5 & Fechado \\
\hline & 31 & C.8R & $12,7 \mathrm{PA}$ & 6,35 & 1 & 75 & 10 & 1 & 25 & 78,5 & Fechado \\
\hline
\end{tabular}

Legenda: PA: Configuração de grelhas parcialmente aberta. TA: Configuração de grelhas totalmente aberta.

(continua...) 
Tabela 6.13 - Sumário das condições operacionais dos ensaios piloto de moagem SAG (conclusão).

\begin{tabular}{|c|c|c|c|c|c|c|c|c|c|c|c|}
\hline Bloco & N. & Ensaio & $\begin{array}{c}\text { Abertura e } \\
\text { Configuração } \\
\text { da Grelha } \\
\text { (mm) }\end{array}$ & $\begin{array}{c}\text { Abertura } \\
\text { Trommel } \\
(\text { (mm) }\end{array}$ & $\begin{array}{c}\text { Abertura } \\
\text { Peneira } \\
(\mathrm{mm})\end{array}$ & $\begin{array}{l}\text { Sólidos na } \\
\text { Descarga } \\
\text { SAG (\%) }\end{array}$ & $\begin{array}{c}\text { Carga Bolas } \\
\text { (\%vi) }\end{array}$ & $\begin{array}{l}\text { Distribuição } \\
\text { de Bolas }\end{array}$ & $\begin{array}{c}\text { Carga Total } \\
\text { (\%vi) }\end{array}$ & $\begin{array}{l}\text { Velocidade } \\
\text { SAG (\%nc) }\end{array}$ & $\begin{array}{c}\text { Configuração } \\
\text { do Circuito } \\
\text { SAG }\end{array}$ \\
\hline \multirow{13}{*}{ 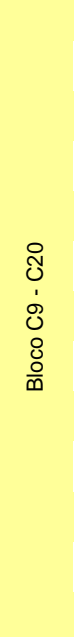 } & 32 & C.9 & 12,7 TA & 6,35 & 1 & 75 & 10 & 1 & 25 & 78,5 & Fechado \\
\hline & 33 & C10 & $6,35 \mathrm{TA}$ & 6,35 & 1 & 75 & 10 & 1 & 25 & 78,5 & Fechado \\
\hline & 34 & C. 11 & $6,35 \mathrm{PA}$ & 6,35 & 1 & 75 & 10 & 1 & 25 & 78,5 & Fechado \\
\hline & 35 & C. 12 & $6,35 \mathrm{PA}$ & 6,35 & 1 & 60 & 10 & 1 & 25 & 78,5 & Fechado \\
\hline & 36 & C. 13 & $6,35 \mathrm{PA}$ & 6,35 & 1 & 75 & 4 & 1 & 25 & 70 & Fechado \\
\hline & 37 & C.13R & 6,35 PA & 6,35 & 1 & 75 & 4 & 1 & 25 & 70 & Fechado \\
\hline & 38 & C. 14 & $6,35 \mathrm{PA}$ & 6,35 & 1 & 75 & 15 & 1 & 30 & 70 & Fechado \\
\hline & 39 & C. 15 & $6,35 \mathrm{PA}$ & 6,35 & 1 & 60 & 4 & 1 & 25 & 70 & Fechado \\
\hline & 40 & C.16 & $6,35 \mathrm{PA}$ & 6,35 & 1 & 75 & 4 & 2 & 25 & 70 & Fechado \\
\hline & 41 & C. 17 & $6,35 \mathrm{PA}$ & 6,35 & 1 & 60 & 4 & 2 & 25 & 70 & Fechado \\
\hline & 42 & C. 18 & $6,35 \mathrm{PA}$ & 6,35 & 1 & 75 & 15 & 2 & 30 & 70 & Fechado \\
\hline & 43 & C. 19 & 6,35 PA & 6,35 & 1 & 75 & 10 & 2 & 25 & 70 & Fechado \\
\hline & 44 & C. 20 & $6,35 \mathrm{PA}$ & 6,35 & 1 & 75 & 10 & 2 & 25 & 70 & Fechado \\
\hline \multirow{15}{*}{ 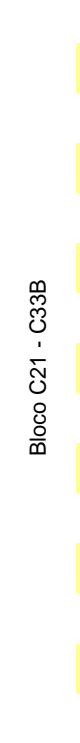 } & 45 & C. 21 & $6,35 \mathrm{PA}$ & 6,35 & 1 & 60 & 4 & 1 & 25 & 70 & Fechado \\
\hline & 46 & C.22 & $6,35 \mathrm{PA}$ & 6,35 & 1 & 75 & 4 & 1 & 25 & 70 & Fechado \\
\hline & 47 & C. 23 & $6,35 \mathrm{PA}$ & 6,35 & 1 & 60 & 4 & 1 & 25 & 70 & Fechado \\
\hline & 48 & C. 24 & $6,35 \mathrm{PA}$ & 6,35 & 1 & 60 & 4 & 1 & 25 & 70 & Fechado \\
\hline & 49 & C. 25 & $6,35 \mathrm{PA}$ & 6,35 & 1 & 60 & 4 & 1 & 25 & 70 & Fechado \\
\hline & 50 & C. 26 & $6,35 \mathrm{PA}$ & 6,35 & 1 & 60 & 4 & 1 & 25 & 70 & Fechado \\
\hline & 51 & C15R & $6,35 \mathrm{PA}$ & 6,35 & 1 & 60 & 4 & 1 & 25 & 70 & Fechado \\
\hline & 52 & C. 27 & $6,35 \mathrm{PA}$ & 6,35 & 1 & 70 & 10 & 2 & 30 & 78,5 & Fechado \\
\hline & 53 & C. 28 & $6,35 \mathrm{PA}$ & 6,35 & 1 & 60 & 4 & 1 & 25 & 70 & Fechado \\
\hline & 54 & C.29 & $6,35 \mathrm{PA}$ & 6,35 & 1 & 60 & 4 & 1 & 25 & 70 & Fechado \\
\hline & 55 & C. 30 & $6,35 \mathrm{PA}$ & 6,35 & 1 & 60 & 4 & 1 & 25 & 70 & Fechado \\
\hline & 56 & C. 31 & $6,35 \mathrm{PA}$ & 6,35 & 1 & 60 & 4 & 1 & 25 & 70 & Fechado \\
\hline & 57 & C. 32 & $6,35 \mathrm{PA}$ & 6,35 & 1 & 60 & 4 & 1 & 25 & 70 & Fechado \\
\hline & 58 & С.33 A & $6,35 \mathrm{PA}$ & 6,35 & 1 & 60 & 14 & 2 & 25 & 70 & Fechado \\
\hline & 59 & C.33 B & $6,35 \mathrm{PA}$ & 6,35 & 1 & 60 & 14 & 2 & 25 & 70 & Fechado \\
\hline \multirow{10}{*}{ 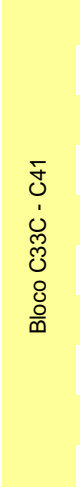 } & 60 & C.33C & $6,35 \mathrm{PA}$ & 6,35 & 1 & 60 & 10 & 2 & 25 & 70 & Fechado \\
\hline & 61 & C.34A & $6,35 \mathrm{PA}$ & 6,35 & 1 & 75 & 10 & 2 & 25 & 70 & Aberto \\
\hline & 62 & C.34B & $6,35 \mathrm{PA}$ & 6,35 & 1 & 75 & 10 & 2 & 25 & 70 & Aberto \\
\hline & 63 & C. 35 & 6,35 PA & 6,35 & 1 & 60 & 4 & 2 & 25 & 70 & Fechado \\
\hline & 64 & C. 36 & $6,35 \mathrm{PA}$ & 6,35 & 1 & 60 & 4 & 2 & 25 & 70 & Fechado \\
\hline & 65 & С. 37 & $6,35 \mathrm{PA}$ & 6,35 & 1 & 60 & 4 & 2 & 25 & 70 & Fechado \\
\hline & 66 & C. 38 & $6,35 \mathrm{PA}$ & 6,35 & 1 & 60 & 4 & 2 & 25 & 70 & Fechado \\
\hline & 67 & C.39 & $6,35 \mathrm{PA}$ & 6,35 & 1 & 60 & 4 & 2 & 25 & 70 & Fechado \\
\hline & 68 & C. 40 & $6,35 \mathrm{PA}$ & 6,35 & 1 & 60 & 4 & 2 & 25 & 70 & Fechado \\
\hline & 69 & C. 41 & 6,35 PA & 6,35 & 1 & 60 & 4 & 2 & 25 & 70 & Fechado \\
\hline
\end{tabular}

Legenda: PA: Configuração de grelhas parcialmente aberta. TA: Configuração de grelhas totalmente aberta. 
Tabela 6.14 - Sumário dos tipos e proporções de minérios utilizados nos ensaios piloto de moagem SAG.

\begin{tabular}{|c|c|c|c|c|c|c|c|c|c|}
\hline \multirow[b]{2}{*}{ Bloco } & \multirow[b]{2}{*}{ N. } & \multirow[b]{2}{*}{ Ensaio } & \multicolumn{7}{|c|}{ Proporções dos Minérios Utilizadas nos Ensaios (\% em peso) } \\
\hline & & & $\begin{array}{c}\text { Tipo B1 } \\
\text { WI }<7 \\
\text { Minério de } \\
\text { superficie }\end{array}$ & $\begin{array}{c}\text { Tipo } 1 \\
\text { WI }<7 \\
\text { Filito sem } \\
\text { boudin } \\
\end{array}$ & $\begin{array}{l}\quad \text { Tipo } 4 \\
\begin{array}{l}7<\text { WI }<10 \\
\text { Filito sem } \\
\text { boudin }\end{array} \\
\end{array}$ & $\begin{array}{l}\quad \text { Tipo } 5 \\
7<\text { WI }<10 \\
\begin{array}{l}\text { Filito com } \\
\text { boudin }\end{array} \\
\end{array}$ & $\begin{array}{r}\text { Tipo } 7 \\
\text { Wi }>10 \\
\text { Filito sem } \\
\text { boudin }\end{array}$ & $\begin{array}{r}\text { Tipo } 8 \\
\text { Wi }>10 \\
\text { Filito com } \\
\text { boudin } \\
\end{array}$ & $\begin{array}{c}\text { Alimentado } \\
\text { da Operação } \\
\text { Atual } \\
\text { (740 1109 A/C) }\end{array}$ \\
\hline \multirow{9}{*}{$\begin{array}{l}\bar{o} \\
\overline{0} \\
\frac{\circ}{\infty}\end{array}$} & 1 & B1.1 & 0 & 0 & 0 & 100 & 0 & 0 & 0 \\
\hline & 2 & B1.1R & 0 & 0 & 0 & 100 & 0 & 0 & 0 \\
\hline & 3 & B1.2 & 0 & 30 & 0 & 70 & 0 & 0 & 0 \\
\hline & 4 & B1.3 & 0 & 30 & 0 & 70 & 0 & 0 & 0 \\
\hline & 5 & B1.4 & 0 & 50 & 0 & 50 & 0 & 0 & 0 \\
\hline & 6 & B1.5 & 0 & 70 & 0 & 30 & 0 & 0 & 0 \\
\hline & 7 & B1.6 & 0 & 50 & 0 & 50 & 0 & 0 & 0 \\
\hline & 8 & B1.4 R & 0 & 50 & 0 & 50 & 0 & 0 & 0 \\
\hline & 9 & $\mathrm{~B} 1.6 \mathrm{R}$ & 0 & 50 & 0 & 50 & 0 & 0 & 0 \\
\hline \multirow{7}{*}{$\begin{array}{l}\text { N } \\
\text { O } \\
\frac{\delta}{\infty}\end{array}$} & 10 & B2.1 & 0 & 0 & 100 & 0 & 0 & 0 & 0 \\
\hline & 11 & B2.2 & 0 & 30 & 70 & 0 & 0 & 0 & 0 \\
\hline & 12 & B2.3 & 0 & 30 & 70 & 0 & 0 & 0 & 0 \\
\hline & 13 & B2.4 & 0 & 50 & 50 & 0 & 0 & 0 & 0 \\
\hline & 14 & B2.4R & 0 & 50 & 50 & 0 & 0 & 0 & 0 \\
\hline & 15 & B2.5 & 0 & 70 & 30 & 0 & 0 & 0 & 0 \\
\hline & 16 & B2.6 & 0 & 50 & 50 & 0 & 0 & 0 & 0 \\
\hline \multirow{3}{*}{$\begin{array}{l}\stackrel{+}{\circ} \\
\stackrel{8}{0} \\
\frac{\circ}{\infty}\end{array}$} & 17 & B4.1 & 0 & 0 & 100 & 0 & 0 & 0 & 0 \\
\hline & 18 & B4.2 & 0 & 0 & 100 & 0 & 0 & 0 & 0 \\
\hline & 19 & B4.3 & 0 & 0 & 100 & 0 & 0 & 0 & 0 \\
\hline \multirow{2}{*}{$\begin{array}{l}0 \\
\stackrel{0}{0} \\
\frac{0}{\infty}\end{array}$} & 20 & B6.1 & 0 & 0 & 100 & 0 & 0 & 0 & 0 \\
\hline & 21 & B6.2 & 0 & 0 & 0 & 100 & 0 & 0 & 0 \\
\hline \multirow{10}{*}{$\begin{array}{l}\frac{1}{\infty} \\
0 \\
1 \\
\frac{1}{0} \\
0 \\
\frac{0}{\infty}\end{array}$} & 22 & C. 1 & 0 & 0 & 100 & 0 & 0 & 0 & 0 \\
\hline & 23 & C. 2 & 0 & 0 & 100 & 0 & 0 & 0 & 0 \\
\hline & 24 & C. 3 & 0 & 0 & 100 & 0 & 0 & 0 & 0 \\
\hline & 25 & C. 4 & 0 & 0 & 100 & 0 & 0 & 0 & 0 \\
\hline & 26 & C. 5 & 0 & 0 & 100 & 0 & 0 & 0 & 0 \\
\hline & 27 & C. 6 & 0 & 0 & 100 & 0 & 0 & 0 & 0 \\
\hline & 28 & C.7 & 0 & 0 & 0 & 100 & 0 & 0 & 0 \\
\hline & 29 & C.7R & 0 & 0 & 0 & 100 & 0 & 0 & 0 \\
\hline & 30 & C. 8 & 0 & 0 & 100 & 0 & 0 & 0 & 0 \\
\hline & 31 & C.8R & 0 & 0 & 100 & 0 & 0 & 0 & 0 \\
\hline
\end{tabular}

(continua...) 
Tabela 6.14 - Sumário dos tipos e proporções de minérios utilizados nos ensaios piloto de moagem SAG (conclusão).

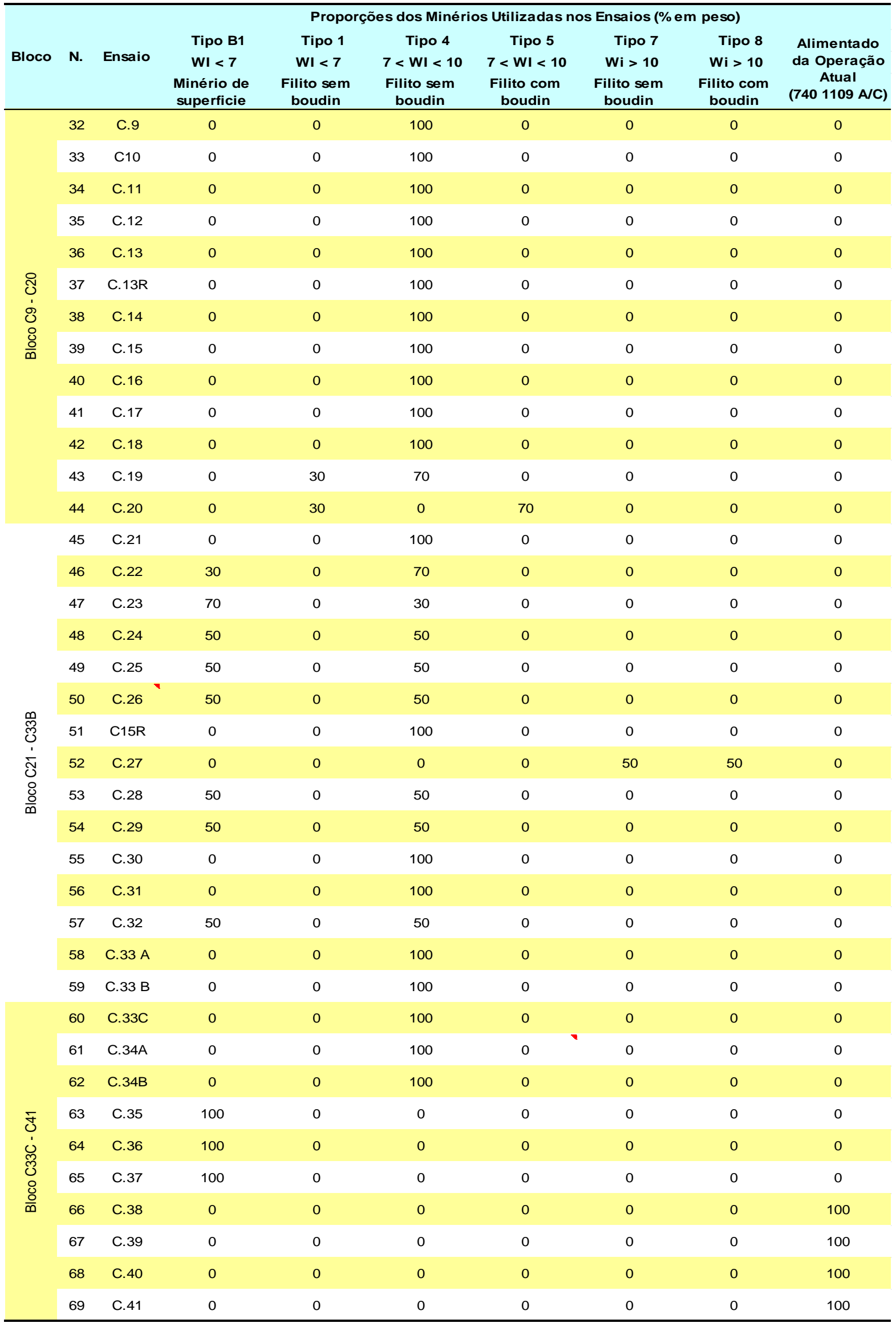




\subsection{Protocolo de Amostragem e Estabilização da Operação}

O protocolo de amostragem adotado nos ensaios de moagem piloto e a estabilização do circuito foram verificados em quatro amostragens sequenciais. Durante o ensaio B1.1R foram constituídas quatro amostras, correspondentes a intervalos de tempo de uma hora, após o alcance das condições de equilíbrio do circuito. Tais amostras, referentes aos diferentes pontos do circuito de moagem piloto, foram compostas por incrementos amostrais tomados a cada 15 minutos.

Cada um desses quatro lotes de amostras foi submetido individualmente à etapa de processamento. A Tabela 6.15 apresenta um comparativo entre as quatro amostragens realizadas para um mesmo ensaio. A maior parte dos parâmetros apresentou valores de coeficiente de variação abaixo de $5 \%$. Verificou-se portanto que, após a estabilização do equilíbrio, não ocorreram mudanças significativas nos valores dos parâmetros de moagem SAG. O procedimento de amostragem adotado então, após a estabilização do circuito, foi a tomada de incrementos amostrais a cada 15 minutos durante intervalos de tempo de duas horas para a composição de cada amostra.

Tabela 6.15 - Comparação entre amostragens realizadas em um mesmo ensaio de moagem SAG.

\begin{tabular}{|c|c|c|c|c|c|c|c|}
\hline Parâmetros & $\begin{array}{c}\text { Amostra } 1 \\
1^{\mathrm{a}} \text { hora }\end{array}$ & $\begin{array}{c}\text { Amostra } 2 \\
2^{\mathrm{a}} \text { hora }\end{array}$ & $\begin{array}{c}\text { Amostra } 3 \\
3^{a} \text { hora }\end{array}$ & $\begin{array}{c}\text { Amostra } 4 \\
4^{\mathrm{a}} \text { hora }\end{array}$ & Média, $\mu$ & $\begin{array}{c}\text { Desvio } \\
\text { Padrão, s }\end{array}$ & $\begin{array}{c}\text { Coeficiente } \\
\text { de Variação } \\
(\%)\end{array}$ \\
\hline Alimentação (Kg/h) & 2779 & 2858 & 2779 & 3115 & 2883 & 159,31 & 5,53 \\
\hline Vazão CC (kg/h) & 4309 & 5075 & 4314 & 3789 & 4372 & 529,43 & 12,11 \\
\hline $\mathrm{T}_{80}(\mu \mathrm{m})$ & 354 & 367 & 357 & 375 & 363 & 10 & 2,68 \\
\hline Vazão Oversize (kg/h) & 85,6 & 90,9 & 79,7 & 99,9 & 89,0 & 8,56 & 9,62 \\
\hline \% Sólido - DM & 68,4 & 69,6 & 64,2 & 71,0 & 68,3 & 2,92 & 4,27 \\
\hline \% Sólido Oversize - CC & 59,1 & 58,9 & 60,1 & 59,5 & 59,4 & 0,52 & 0,87 \\
\hline Leitura da Célula Carga (t) & 1,31 & 1,31 & 1,30 & 1,33 & 1,31 & 0,01 & 1,09 \\
\hline Potência (kW) & 16,86 & 17,04 & 17,00 & 16,94 & 16,96 & 0,08 & 0,44 \\
\hline \% Sólido Undersize - PM & 30,2 & 25,8 & 28,7 & 28,2 & 28,23 & 1,81 & 6,41 \\
\hline Vazão PM (m³/h) & 8,37 & 8,37 & 8,18 & 8,09 & 8,25 & 0,14 & 1,70 \\
\hline Densidade PM $\left(\mathrm{t} / \mathrm{m}^{3}\right)$ & 1,24 & 1,20 & 1,23 & 1,22 & 1,22 & 0,02 & 1,42 \\
\hline Produto Moagem (t/h) & 3,1 & 2,6 & 2,9 & 2,8 & 2,8 & 0,23 & 7,93 \\
\hline
\end{tabular}
em que $80 \%$ do material é passante).

DM: Descarga do moinho SAG.

PM: Produto do moinho SAG. 


\subsubsection{RESULtAdOS dos EnSAIOS: ASPECtOS GERAIS}

A estatística descritiva de alguns parâmetros de moagem SAG, nos 69 ensaios conduzidos, é apresentada na Tabela 6.16.

Tabela 6.16 - Estatística de alguns parâmetros de moagem SAG, nos 69 ensaios.

\begin{tabular}{|c|c|c|c|c|c|c|c|}
\hline \multirow[b]{2}{*}{ Estatística } & \multicolumn{7}{|c|}{ Parâmetros de Moagem SAG (69 Ensaios Piloto) } \\
\hline & $\begin{array}{c}\text { Vazão de } \\
\text { Aliment. } \\
(\mathrm{t} / \mathrm{h})\end{array}$ & $\begin{array}{l}\text { Potência } \\
\text { Líquida } \\
\text { (kW) }\end{array}$ & $\begin{array}{c}\text { Consumo } \\
\text { Energético } \\
\text { Específico } \\
(\mathbf{k W h} / \mathbf{t})\end{array}$ & $\begin{array}{c}\text { Carga } \\
\text { Circulante } \\
\text { (\%) }\end{array}$ & $\mathrm{T}_{80}(\mu \mathrm{m})$ & $\begin{array}{c}\text { WI ROM } \\
\text { (kWh/t) }\end{array}$ & $\begin{array}{l}\text { WI } \\
\text { Produto } \\
\text { Moagem } \\
(\mathrm{kWh} / \mathrm{t})\end{array}$ \\
\hline Média & 3,17 & 7,58 & 2,57 & 107 & 305 & 8,46 & 12,24 \\
\hline Erro padrão & 0,10 & 0,24 & 0,11 & 7,7 & 20 & 0,16 & 0,22 \\
\hline Mediana & 3,11 & 7,85 & 2,78 & 101 & 254 & 9,40 & 12,35 \\
\hline Desvio padrão & 0,84 & 1,95 & 0,88 & 61 & 166 & 1,27 & 1,55 \\
\hline Coeficiente de Variação (\%) & 26,66 & 25,76 & 34,09 & 57 & 54,4 & 14,99 & 12,66 \\
\hline Variância da amostra & 0,71 & 3,82 & 0,77 & 3.710 & 27.631 & 1,61 & 2,40 \\
\hline Intervalo & 4,59 & 9,05 & 4,75 & 278,14 & 850 & 6,96 & 6,81 \\
\hline Mínimo & 1,15 & 3,25 & 0,73 & 0,82 & 180,7 & 5,36 & 8,94 \\
\hline Máximo & 5,74 & 12,30 & 5,48 & 279 & 1.031 & 12,32 & 15,75 \\
\hline Soma & 218,61 & 515,77 & 174,68 & 6.638 & 20.457 & 549,84 & 599,79 \\
\hline Contagem & 69,00 & 68,00 & 68,00 & 62 & 67 & 65,00 & 49,00 \\
\hline
\end{tabular}

Os valores de vazão de alimentação obtidos nos ensaios variaram no intervalo compreendido entre 1,15 e 5,74 t/h. A Figura 6.4 apresenta a variação dos resultados de vazão de alimentação para a seqüência de ensaios conduzidos. As setas indicativas constantes do gráfico indicam os ensaios de circuito aberto.

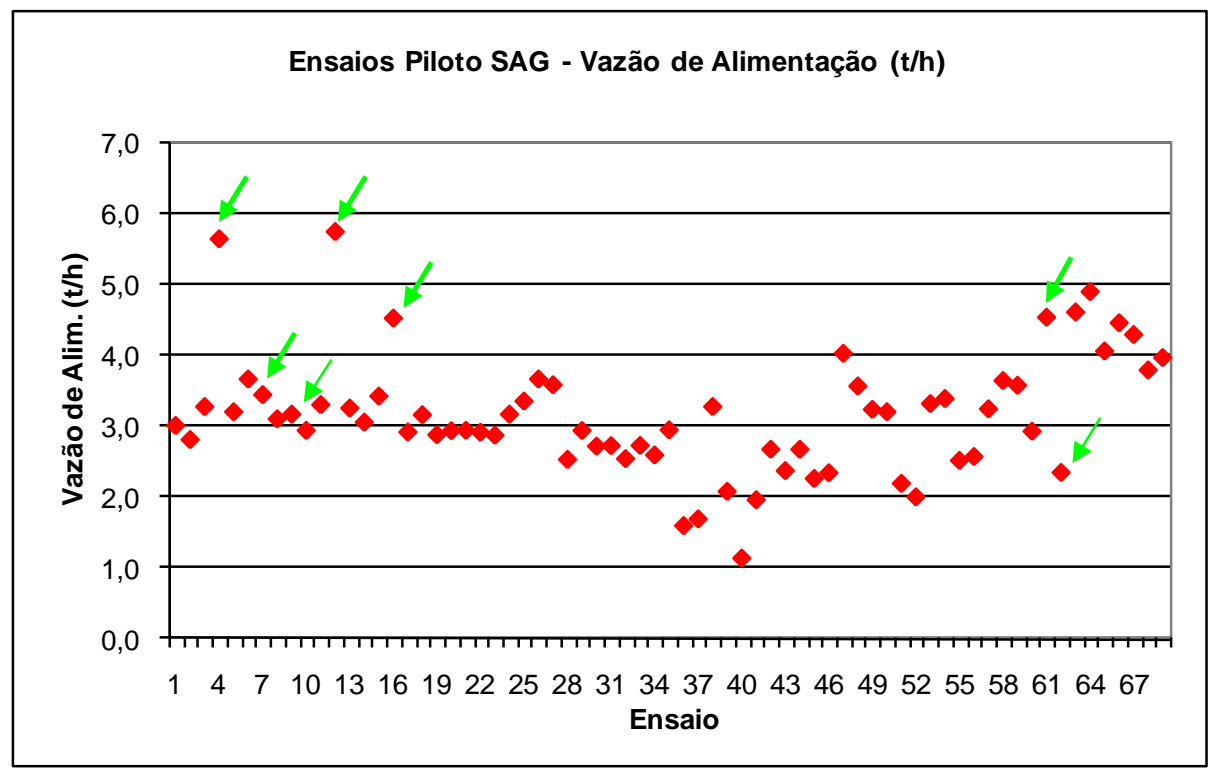

Figura 6.4 - Vazão de alimentação do circuito SAG para a sequência de ensaios conduzidos. 
Os resultados dos 69 ensaios realizados em planta piloto indicaram um valor médio de consumo energético específico, Ecs, na moagem SAG, de 2,57 kWh/t. O maior valor de consumo energético específico obtido foi referente ao ensaio C.27, no qual processou-se a amostra de minério de maior tenacidade, TIPO 7/8. Os menores valores de consumo energético específico foram aqueles relacionados às amostras de minérios de superfície, ou seja, oxidados. A Figura 6.5 apresenta 0 comportamento do consumo energético específico ao longo da sequência de ensaios.

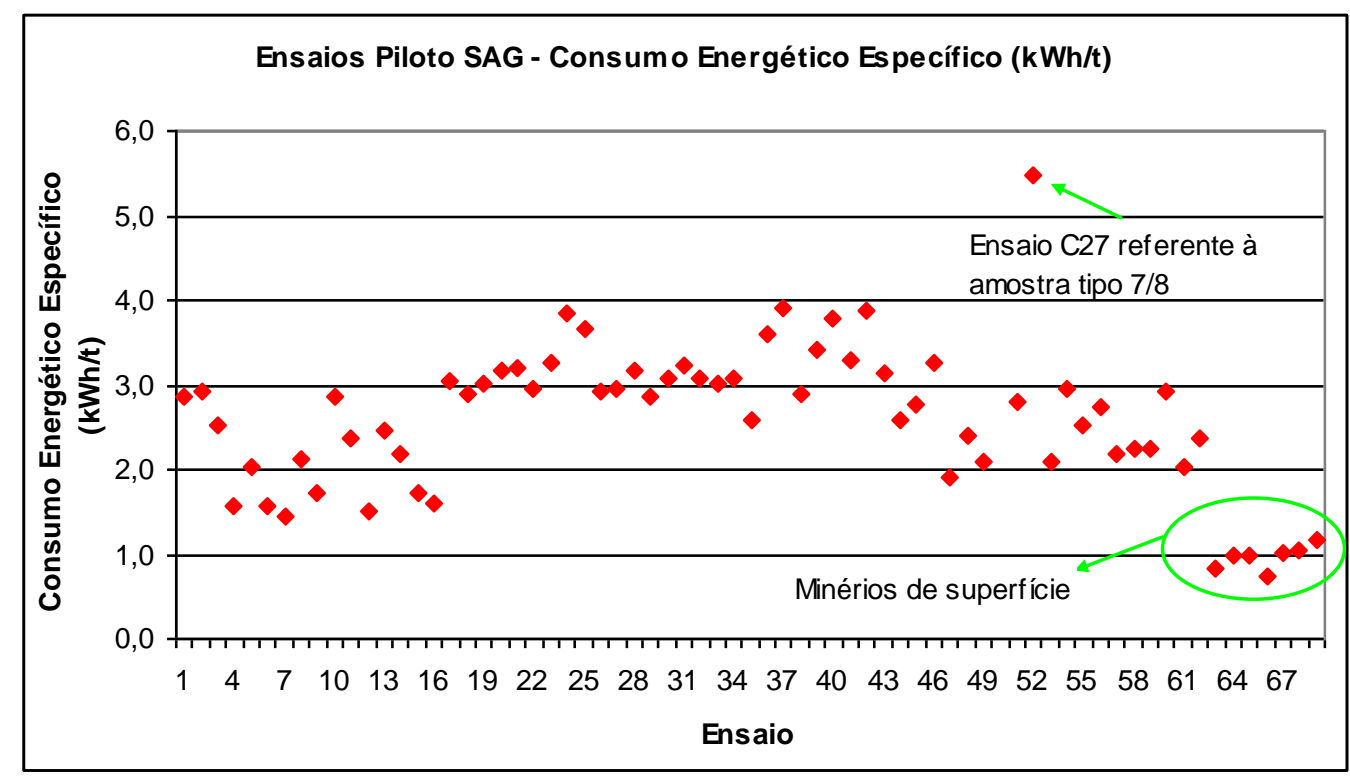

Figura 6.5 - Consumo energético específico para a sequência de ensaios conduzidos.

Já os valores da potência líquida variaram entre 3,25 e 12,3kW, com média de 7,58 kW. Os maiores valores de potência líquida foram obtidos nos ensaios com maior carga de bolas - 15\% do volume interno do moinho SAG -, e no ensaio C.27 que processou o minério TIPO 7/8, de maior dureza. A Figura 6.6 mostra os dados de potência líquida obtidos e a identificação dos pontos de maior potência referentes aos ensaios com maior proporção de carga. 


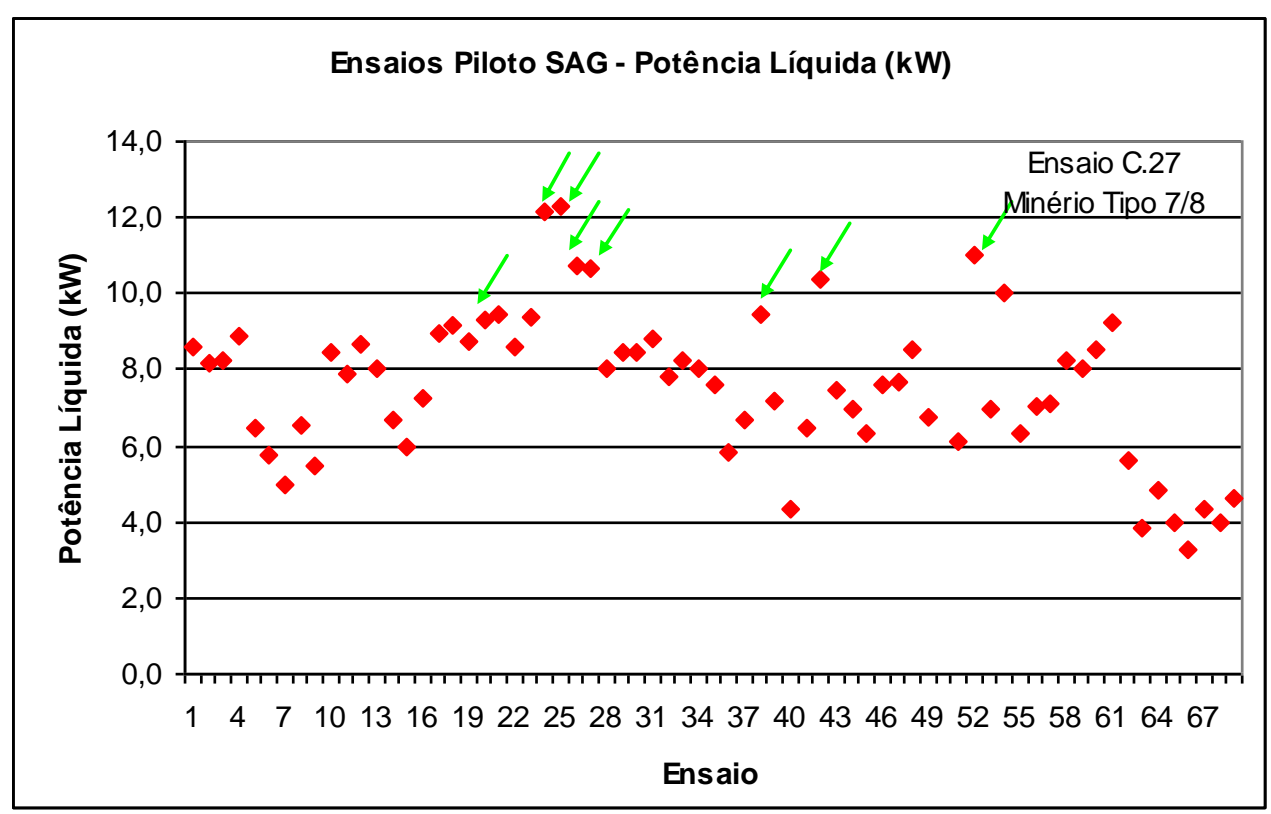

Figura 6.6 - Resultados de potência líquida, em kW, para a sequência de ensaios conduzidos.

Outro parâmetro avaliado foi o tamanho de transferência $\left(T_{80}\right)$, ou seja, tamanho da malha em que $80 \%$ do produto do moinho SAG é passante. Os resultados de $T_{80}$ na campanha de ensaios piloto, apresentados na Figura 6.7, variaram no intervalo compreendido entre 181 e $1031 \mu \mathrm{m}$. Os maiores resultados de $\mathrm{T}_{80}$ obtidos são referentes aos ensaios em circuito de moagem SAG aberto, sinalizados por setas no gráfico.

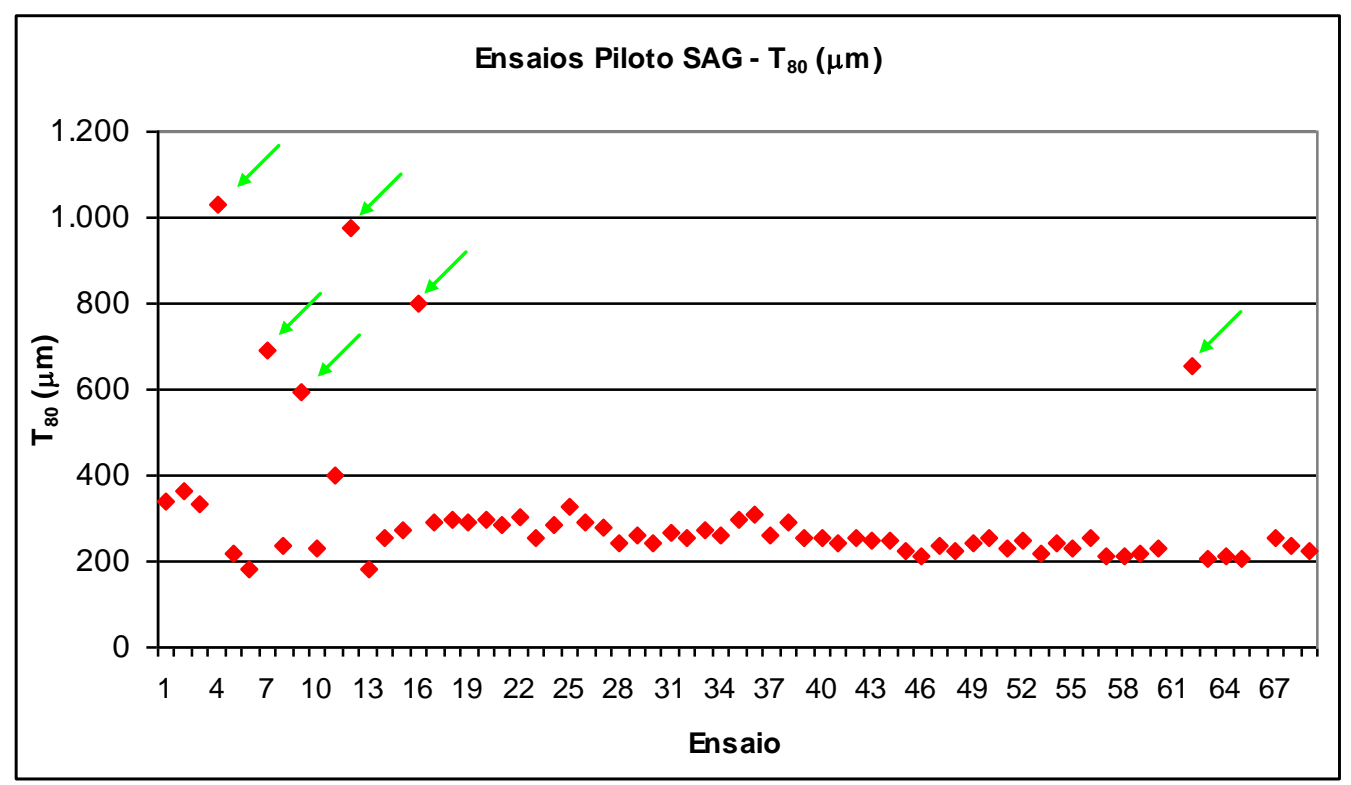

Figura 6.7 - Resultados de $T_{80}$, em $\mu \mathrm{m}$, para a sequência de ensaios conduzidos. 
Os resultados completos para os principais parâmetros de moagem SAG, assim como as condições operacionais referentes a estes, são apresentados na Tabela 6.17.

Tabela 6.17 - Resultados de alguns parâmetros de moagem SAG.

\begin{tabular}{|c|c|c|c|c|c|c|c|c|c|c|c|c|c|c|c|c|}
\hline Bloco & N. & Ensaio & $\begin{array}{c}\text { Configur. } \\
\text { da } \\
\text { Grelha } \\
(\mathrm{mm})\end{array}$ & $\begin{array}{l}\text { Sólidos } \\
\text { da } \\
\text { Descarga } \\
\text { SAG (\%) }\end{array}$ & $\begin{array}{l}\text { Carga } \\
\text { Bolas } \\
\text { (\%vi) }\end{array}$ & $\begin{array}{l}\text { Distrib. } \\
\text { de Bolas } \\
\text { (Tipo) }\end{array}$ & $\begin{array}{l}\text { Carga } \\
\text { Total } \\
\text { (\%vi) }\end{array}$ & $\begin{array}{l}\text { Velocid. } \\
\text { SAG } \\
\text { (\%nc) }\end{array}$ & $\begin{array}{l}\text { Configur. } \\
\text { Circuito } \\
\text { SAG }\end{array}$ & $\begin{array}{c}\text { Vazão de } \\
\text { Aliment. } \\
\text { (t/h) }\end{array}$ & $\begin{array}{l}\text { Potência } \\
\text { Líquida } \\
\text { (kW) }\end{array}$ & $\begin{array}{c}\text { Consumo } \\
\text { Energético } \\
\text { Específico } \\
(\mathbf{k W h} / \mathbf{t})\end{array}$ & $\begin{array}{l}\text { Carga } \\
\text { Circulante } \\
(\%)\end{array}$ & $\mathrm{T}_{80}(\mu \mathrm{m})$ & $\begin{array}{l}\text { WI ROM } \\
\text { (kWh/t) }\end{array}$ & $\begin{array}{c}\text { WI } \\
\text { Produto } \\
\text { de } \\
\text { Moagem } \\
\text { (kWh/t) }\end{array}$ \\
\hline \multirow{9}{*}{$\begin{array}{l}\overline{0} \\
\overline{0} \\
\frac{0}{0}\end{array}$} & 1 & B1.1 & 6,35 PA & 75 & 10 & 1 & 25 & 78,5 & Fechado & 3,02 & 8,63 & 2,86 & 120 & 342 & 7,80 & 12,34 \\
\hline & 2 & $\mathrm{~B} 1.1 \mathrm{R}$ & 6,35 PA & 75 & 10 & 1 & 25 & 78,5 & Fechado & 2,82 & 8,21 & 2,91 & 158 & 365 & 7,80 & 12,35 \\
\hline & 3 & B1.2 & 6,35 PA & 75 & 10 & 1 & 25 & 78,5 & Fechado & 3,28 & 8,27 & 2,52 & 142 & 334 & 7,35 & 10,47 \\
\hline & 4 & B1.3 & 6,35 PA & 75 & 10 & 1 & 25 & 78,5 & Aberto & 5,64 & 8,87 & 1,57 & 2 & 1031 & 7,35 & 9,34 \\
\hline & 5 & B1.4 & 6,35 PA & 75 & 4 & 1 & 25 & 78,5 & Fechado & 3,21 & 6,48 & 2,02 & 93 & 220 & 7,05 & 11,32 \\
\hline & 6 & B1.5 & 6,35 PA & 75 & 4 & 1 & 25 & 78,5 & Fechado & 3,67 & 5,77 & 1,57 & 110 & 181 & 6,76 & 10,73 \\
\hline & 7 & B1.6 & $6,35 \mathrm{PA}$ & 75 & 4 & 1 & 25 & 78,5 & Aberto & 3,45 & 4,99 & 1,45 & 1 & 693 & 7,05 & 8,94 \\
\hline & 8 & B1.4 R & 6,35 PA & 75 & 4 & 1 & 25 & 78,5 & Fechado & 3,11 & 6,56 & 2,11 & 86 & 235 & 7,05 & 12,16 \\
\hline & 9 & B1.6R & 6,35 PA & 75 & 4 & 1 & 25 & 78,5 & Aberto & 3,18 & 5,49 & 1,73 & 1 & 596 & 7,05 & 9,29 \\
\hline \multirow{7}{*}{$\begin{array}{l}N \\
o \\
\delta \\
\frac{O}{\infty}\end{array}$} & 10 & B2.1 & $6,35 \mathrm{PA}$ & 75 & 10 & 1 & 25 & 78,5 & Fechado & 2,95 & 8,44 & 2,86 & 151 & 233 & 9,40 & 11,88 \\
\hline & 11 & B2.2 & 6,35 PA & 75 & 10 & 1 & 25 & 78,5 & Fechado & 3,31 & 7,86 & 2,38 & 173 & 402 & 8,47 & 12,09 \\
\hline & 12 & B2.3 & $6,35 \mathrm{PA}$ & 75 & 10 & 1 & 25 & 78,5 & Aberto & 5,74 & 8,66 & 1,51 & 2 & 975 & 8,47 & 9,10 \\
\hline & 13 & B2.4 & 6,35 PA & 75 & 4 & 1 & 25 & 78,5 & Fechado & 3,26 & 8,05 & 2,47 & 153 & 182 & 7,85 & 12,30 \\
\hline & 14 & B2.4R & 6,35 PA & 75 & 4 & 1 & 25 & 78,5 & Fechado & 3,06 & 6,71 & 2,19 & 93 & 254 & 7,85 & 12,82 \\
\hline & 15 & B2.5 & $6,35 \mathrm{PA}$ & 75 & 4 & 1 & 25 & 78,5 & Fechado & 3,43 & 5,94 & 1,73 & 148 & 271 & 7,23 & 12,08 \\
\hline & 16 & B2.6 & 6,35 PA & 75 & 4 & 1 & 25 & 78,5 & Aberto & 4,53 & 7,26 & 1,60 & 2 & 800 & 7,85 & 9,12 \\
\hline \multirow{3}{*}{$\begin{array}{l}\stackrel{+}{0} \\
\stackrel{0}{0} \\
\frac{\circ}{\infty}\end{array}$} & 17 & B4.1 & 6,35 PA & 75 & 10 & 1 & 25 & 78,5 & Fechado & 2,93 & 8,94 & 3,06 & & 294 & 9,40 & 11,54 \\
\hline & 18 & B4.2 & 6,35 PA & 75 & 10 & 1 & 25 & 78,5 & Fechado & 3,17 & 9,15 & 2,89 & 117 & 298 & 9,40 & \\
\hline & 19 & B4.3 & 6,35 PA & 75 & 10 & 1 & 25 & 78,5 & Fechado & 2,89 & 8,74 & 3,03 & 101 & 291 & 9,40 & 12,46 \\
\hline \multirow{2}{*}{$\begin{array}{l}0 \\
0 \\
0 \\
\frac{0}{0}\end{array}$} & 20 & B6.1 & $6,35 \mathrm{PA}$ & 75 & 15 & 1 & 25 & 78,5 & Fechado & 2,94 & 9,31 & 3,16 & 279 & 299 & 9,40 & 13,18 \\
\hline & 21 & B6.2 & 6,35 PA & 75 & 10 & 1 & 25 & 78,5 & Fechado & 2,95 & 9,45 & 3,20 & 214 & 286 & 7,80 & 12,87 \\
\hline \multirow{10}{*}{$\begin{array}{l}\frac{\pi}{\infty} \\
0 \\
1 \\
\overline{0} \\
0 \\
0 \\
\frac{0}{\infty}\end{array}$} & 22 & C.1 & 6,35 PA & 75 & 10 & 1 & 25 & 78,5 & Fechado & 2,92 & 8,60 & 2,95 & 179 & 304 & 9,40 & 12,73 \\
\hline & 23 & C. 2 & 6,35 PA & 75 & 10 & 2 & 25 & 78,5 & Fechado & 2,88 & 9,36 & 3,25 & 88 & 254 & 9,40 & 12,13 \\
\hline & 24 & C. 3 & $6,35 \mathrm{PA}$ & 75 & 15 & 2 & 25 & 78,5 & Fechado & 3,18 & 12,17 & 3,83 & 130 & 288 & 9,40 & 12,44 \\
\hline & 25 & C. 4 & 6,35 PA & 75 & 15 & 2 & 30 & 78,5 & Fechado & 3,36 & 12,30 & 3,66 & 123 & 330 & 9,40 & 12,16 \\
\hline & 26 & C. 5 & 6,35 PA & 60 & 15 & 2 & 30 & 78,5 & Fechado & 3,67 & 10,76 & 2,93 & 103 & 293 & 9,40 & 13,54 \\
\hline & 27 & C.6 & 6,35 PA & 68 & 15 & 2 & 30 & 78,5 & Fechado & 3,59 & 10,65 & 2,97 & 132 & 281 & 9,40 & 12,53 \\
\hline & 28 & C.7 & 12,7 PA & 75 & 10 & 1 & 25 & 78,5 & Fechado & 2,54 & 8,06 & 3,17 & 174 & 240 & 7,80 & 12,63 \\
\hline & 29 & C.7R & 12,7 PA & 75 & 10 & 1 & 25 & 78,5 & Fechado & 2,95 & 8,46 & 2,87 & 122 & 259 & 7,80 & \\
\hline & 30 & C. 8 & 12,7 PA & 75 & 10 & 1 & 25 & 78,5 & Fechado & 2,73 & 8,42 & 3,09 & 99 & 242 & 9,40 & 10,40 \\
\hline & 31 & C.8R & 12,7 PA & 75 & 10 & 1 & 25 & 78,5 & Fechado & 2,73 & 8,79 & 3,22 & 141 & 264 & 9,40 & \\
\hline
\end{tabular}

Legenda: PA: Configuração de grelhas parcialmente aberta.

TA: Configuração de grelhas totalmente aberta.

(continua...) 
Tabela 6.17 - Resultados de alguns parâmetros de moagem SAG (conclusão).

\begin{tabular}{|c|c|c|c|c|c|c|c|c|c|c|c|c|c|c|c|c|}
\hline Bloco & $\mathrm{N}$. & Ensaio & $\begin{array}{c}\text { Configur. } \\
\text { da } \\
\text { Grelha } \\
(\mathrm{mm})\end{array}$ & $\begin{array}{l}\text { Sólidos } \\
\text { da } \\
\text { Descarga } \\
\text { SAG (\%) }\end{array}$ & $\begin{array}{c}\text { Carga } \\
\text { Bolas } \\
(\% \text { vi) }\end{array}$ & $\begin{array}{l}\text { Distrib. } \\
\text { de Bolas } \\
\text { (Tipo) }\end{array}$ & $\begin{array}{l}\text { Carga } \\
\text { Total } \\
\text { (\%vi) }\end{array}$ & $\begin{array}{l}\text { Velocid. } \\
\text { SAG } \\
(\% \mathrm{nc})\end{array}$ & $\begin{array}{l}\text { Configur. } \\
\text { Circuito } \\
\text { SAG }\end{array}$ & $\begin{array}{l}\text { Vazão de } \\
\text { Aliment. } \\
\text { (t/h) }\end{array}$ & $\begin{array}{c}\text { Potência } \\
\text { Líquida } \\
\text { (kW) }\end{array}$ & $\begin{array}{c}\text { Consumo } \\
\text { Energético } \\
\text { Específico } \\
(\mathbf{k W h} / \mathbf{t})\end{array}$ & $\begin{array}{c}\text { Carga } \\
\text { Circulante } \\
(\%)\end{array}$ & $T_{80}(\mu \mathrm{m})$ & $\begin{array}{c}\text { WI ROM } \\
(\mathbf{k W h} / \mathbf{t})\end{array}$ & $\begin{array}{c}\text { WI } \\
\text { Produto } \\
\text { de } \\
\text { Moagem } \\
(\mathrm{kWh} / \mathrm{t})\end{array}$ \\
\hline \multirow{13}{*}{$\begin{array}{l}\text { ণิ } \\
\dot{1} \\
0 \\
\circ \\
\circ \\
\frac{0}{0}\end{array}$} & 32 & C.9 & 12,7 TA & 75 & 10 & 1 & 25 & 78,5 & Fechado & 2,55 & 7,84 & 3,07 & 238 & 257 & 9,40 & 11,95 \\
\hline & 33 & C10 & 6,35 TA & 75 & 10 & 1 & 25 & 78,5 & Fechado & 2,74 & 8,24 & 3,01 & 241 & 273 & 9,40 & 13,01 \\
\hline & 34 & C.11 & 6,35 PA & 75 & 10 & 1 & 25 & 78,5 & Fechado & 2,60 & 8,01 & 3,08 & 196 & 258 & 9,40 & 13,41 \\
\hline & 35 & C.12 & 6,35 PA & 60 & 10 & 1 & 25 & 78,5 & Fechado & 2,96 & 7,60 & 2,57 & 171 & 294 & 9,40 & 11,44 \\
\hline & 36 & C.13 & 6,35 PA & 75 & 4 & 1 & 25 & 70 & Fechado & 1,61 & 5,82 & 3,61 & 102 & 309 & 9,40 & 13,12 \\
\hline & 37 & C. $13 R$ & 6,35 PA & 75 & 4 & 1 & 25 & 70 & Fechado & 1,70 & 6,66 & 3,91 & 111 & 259 & 9,40 & \\
\hline & 38 & C. 14 & 6,35 PA & 75 & 15 & 1 & 30 & 70 & Fechado & 3,28 & 9,45 & 2,88 & 135 & 289 & 9,40 & 13,27 \\
\hline & 39 & C. 15 & 6,35 PA & 60 & 4 & 1 & 25 & 70 & Fechado & 2,09 & 7,15 & 3,42 & 35 & 252 & 9,40 & 13,11 \\
\hline & 40 & C. 16 & 6,35 PA & 75 & 4 & 2 & 25 & 70 & Fechado & 1,15 & 4,36 & 3,78 & 36 & 253 & 9,40 & 13,75 \\
\hline & 41 & C.17 & 6,35 PA & 60 & 4 & 2 & 25 & 70 & Fechado & 1,97 & 6,50 & 3,30 & 50 & 244 & 9,40 & 14,53 \\
\hline & 42 & C.18 & 6,35 PA & 75 & 15 & 2 & 30 & 70 & Fechado & 2,68 & 10,38 & 3,87 & 53 & 254 & 9,40 & \\
\hline & 43 & C. 19 & 6,35 PA & 75 & 10 & 2 & 25 & 70 & Fechado & 2,38 & 7,45 & 3,13 & 86 & 251 & 8,47 & \\
\hline & 44 & C. 20 & 6,35 PA & 75 & 10 & 2 & 25 & 70 & Fechado & 2,68 & 6,93 & 2,58 & 80 & 251 & 7,35 & 11,74 \\
\hline \multirow{15}{*}{ 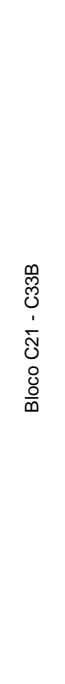 } & 45 & C. 21 & 6,35 PA & 60 & 4 & 1 & 25 & 70 & Fechado & 2,27 & 6,33 & 2,78 & & 226 & 9,40 & \\
\hline & 46 & C.22 & 6,35 PA & 75 & 4 & 1 & 25 & 70 & Fechado & 2,35 & 7,64 & 3,25 & 36 & 212 & 8,19 & 13,56 \\
\hline & 47 & C. 23 & 6,35 PA & 60 & 4 & 1 & 25 & 70 & Fechado & 4,03 & 7,65 & 1,90 & & 239 & 6,57 & \\
\hline & 48 & C. 24 & 6,35 PA & 60 & 4 & 1 & 25 & 70 & Fechado & 3,57 & 8,52 & 2,38 & 64 & 225 & 7,38 & 14,69 \\
\hline & 49 & C. .25 & 6,35 PA & 60 & 4 & 1 & 25 & 70 & Fechado & 3,24 & 6,77 & 2,09 & 69 & 241 & 7,38 & 13,74 \\
\hline & 50 & C. 26 & 6,35 PA & 60 & 4 & 1 & 25 & 70 & Fechado & 3,21 & & & 66 & 254 & 7,38 & \\
\hline & 51 & C15R & 6,35 PA & 60 & 4 & 1 & 25 & 70 & Fechado & 2,20 & 6,14 & 2,79 & & 230 & 9,40 & 12,36 \\
\hline & 52 & C. 27 & 6,35 PA & 70 & 10 & 2 & 30 & 78,5 & Fechado & 2,01 & 11,03 & 5,48 & 79 & 250 & 12,32 & 14,02 \\
\hline & 53 & C. 28 & 6,35 PA & 60 & 4 & 1 & 25 & 70 & Fechado & 3,33 & 6,93 & 2,09 & 56 & 216 & 7,38 & \\
\hline & 54 & C. 29 & 6,35 PA & 60 & 4 & 1 & 25 & 70 & Fechado & 3,39 & 10,02 & 2,95 & 87 & 240 & 7,38 & \\
\hline & 55 & C. 30 & 6,35 PA & 60 & 4 & 1 & 25 & 70 & Fechado & 2,53 & 6,36 & 2,52 & 98 & 228 & 9,40 & \\
\hline & 56 & C.31 & 6,35 PA & 60 & 4 & 1 & 25 & 70 & Fechado & 2,58 & 7,06 & 2,74 & 82 & 252 & 9,40 & \\
\hline & 57 & C. 32 & 6,35 PA & 60 & 4 & 1 & 25 & 70 & Fechado & 3,25 & 7,09 & 2,18 & 55 & 209 & 7,38 & \\
\hline & 58 & C. $33 \mathrm{~A}$ & 6,35 PA & 60 & 14 & 2 & 25 & 70 & Fechado & 3,65 & 8,23 & 2,26 & 156 & 214 & 9,40 & \\
\hline & 59 & C. $33 \mathrm{~B}$ & 6,35 PA & 60 & 14 & 2 & 25 & 70 & Fechado & 3,58 & 8,04 & 2,25 & 170 & 217 & 9,40 & 13,50 \\
\hline \multirow{10}{*}{$\begin{array}{l}\bar{y} \\
\dot{0} \\
\text { J } \\
\text { ठ } \\
\text { ठ } \\
\frac{0}{\infty}\end{array}$} & 60 & C. $.33 \mathrm{C}$ & 6,35 PA & 60 & 10 & 2 & 25 & 70 & Fechado & 2,94 & 8,56 & 2,92 & 130 & 233 & 9,40 & 14,98 \\
\hline & 61 & C. $34 \mathrm{~A}$ & 6,35 PA & 75 & 10 & 2 & 25 & 70 & Aberto & 4,54 & 9,22 & 2,03 & & & 9,40 & 11,80 \\
\hline & 62 & С.34B & 6,35 PA & 75 & 10 & 2 & 25 & 70 & Aberto & 2,36 & 5,62 & 2,38 & 1 & 656 & 9,40 & \\
\hline & 63 & C. 35 & 6,35 PA & 60 & 4 & 2 & 25 & 70 & Fechado & 4,61 & 3,85 & 0,83 & 127 & 204 & 5,36 & 10,63 \\
\hline & 64 & C. 36 & 6,35 PA & 60 & 4 & 2 & 25 & 70 & Fechado & 4,90 & 4,80 & 0,98 & 90 & 215 & 5,36 & 10,49 \\
\hline & 65 & C. .37 & 6,35 PA & 60 & 4 & 2 & 25 & 70 & Fechado & 4,06 & 3,99 & 0,98 & 109 & 206 & 5,36 & \\
\hline & 66 & C.38 & 6,35 PA & 60 & 4 & 2 & 25 & 70 & Fechado & 4,46 & 3,25 & 0,73 & 96 & & & \\
\hline & 67 & C.39 & 6,35 PA & 60 & 4 & 2 & 25 & 70 & Fechado & 4,30 & 4,33 & 1,01 & 98 & 254 & & 15,75 \\
\hline & 68 & C. 40 & 6,35 PA & 60 & 4 & 2 & 25 & 70 & Fechado & 3,80 & 3,95 & 1,04 & & 233 & & \\
\hline & 69 & C. 41 & 6,35 PA & 60 & 4 & 2 & 25 & 70 & Fechado & 3,97 & 4,65 & 1,17 & & 222 & & \\
\hline
\end{tabular}

Legenda: PA: Configuração de grelhas parcialmente aberta.

TA: Configuração de grelhas totalmente aberta. 


\subsubsection{Resultados dos ENSAIOS: ASPECtOS ESPECíficos}

O número de variáveis de processo e os níveis em que estas variáveis foram estudadas foi muito grande, o que permitiu múltiplas combinações e análises. Assim sendo, esta subseção apresenta algumas das avaliações específicas realizadas, considerando o efeito de variáveis de processo nos parâmetros de moagem SAG. A título de exemplo, o detalhamento das informações obtidas em um ensaio é apresentado no Apêndice B. O sumário dos resultados obtidos nos 69 ensaios conduzidos consta do Apêndice $\mathrm{C}$.

\subsection{Efeito da Blendagem e Tipos de Minérios}

O efeito da blendagem e dos tipos de minérios foi um dos aspectos avaliados. Como exemplo, os resultados de consumo energético específico correspondente às blendagens de minérios dos TIPOS 1 e 5 são apresentados na Figura 6.8.

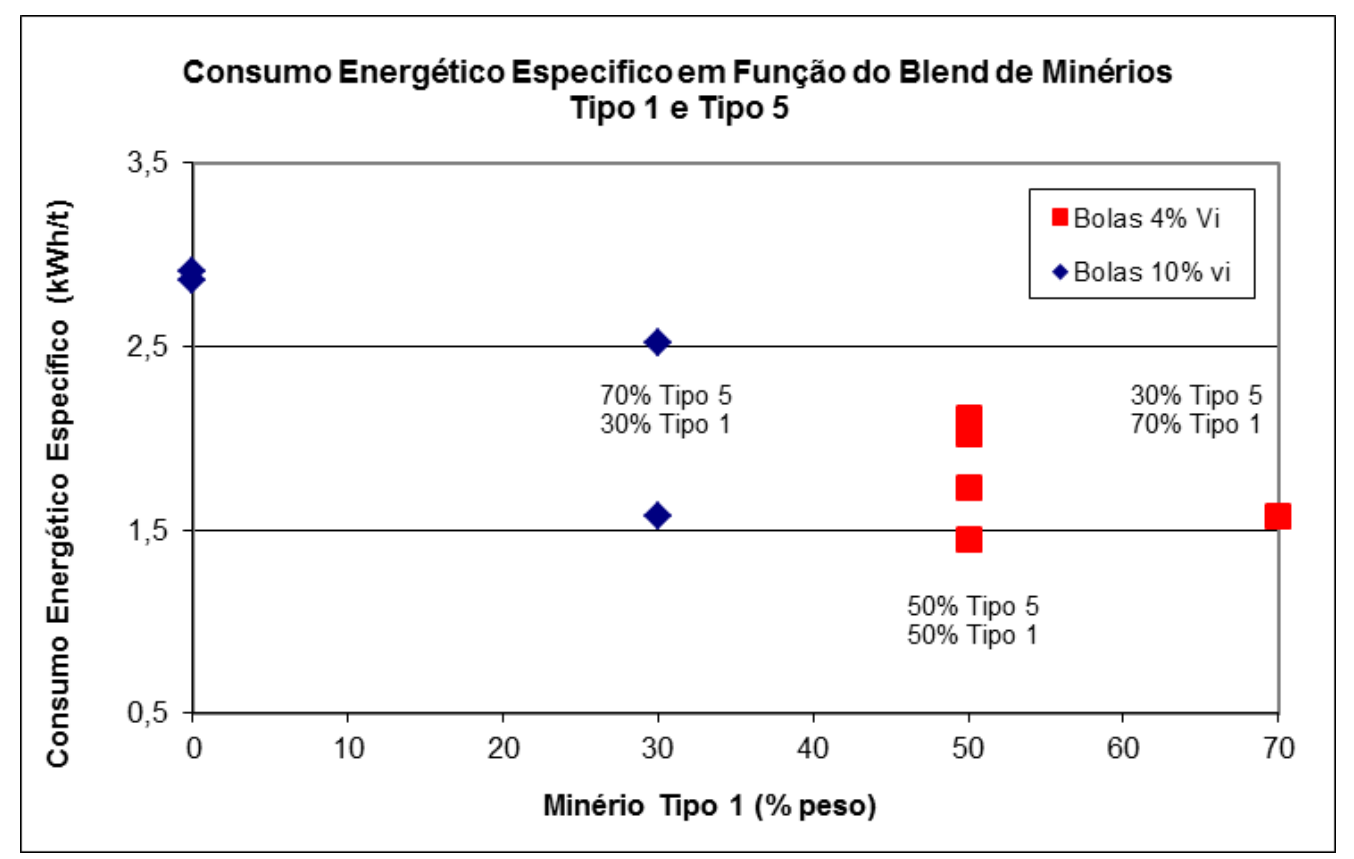

Figura 6.8 - Consumo energético específico para blendagens de minérios TIPOS 1 e 5 .

O gráfico apresenta uma tendência de redução de consumo energético específico, em função da diminuição da proporção de minério de maior tenacidade TIPO 5 (WI 7,8 kWh/t) -, e aumento do percentual em peso do minério macio - TIPO 1 (WI 5,4 kWh/t). 


\section{Efeito da Tenacidade da Alimentação de Minérios}

Os resultados obtidos dos parâmetros vazão de alimentação e consumo energético específico foram comparados à variável tenacidade dos minérios alimentados à planta, indicada pelo WI. Os dados demonstram tendência de redução da vazão de alimentação do circuito com o aumento do WI do minério alimentado. Já em relação ao parâmetro consumo energético específico verificou-se uma relação inversa, ou seja, aumento do consumo energético em função do aumento de tenacidade do minério e/ou da blendadem de minérios. As Figuras 6.9 e 6.10 ilustram esses comportamentos.

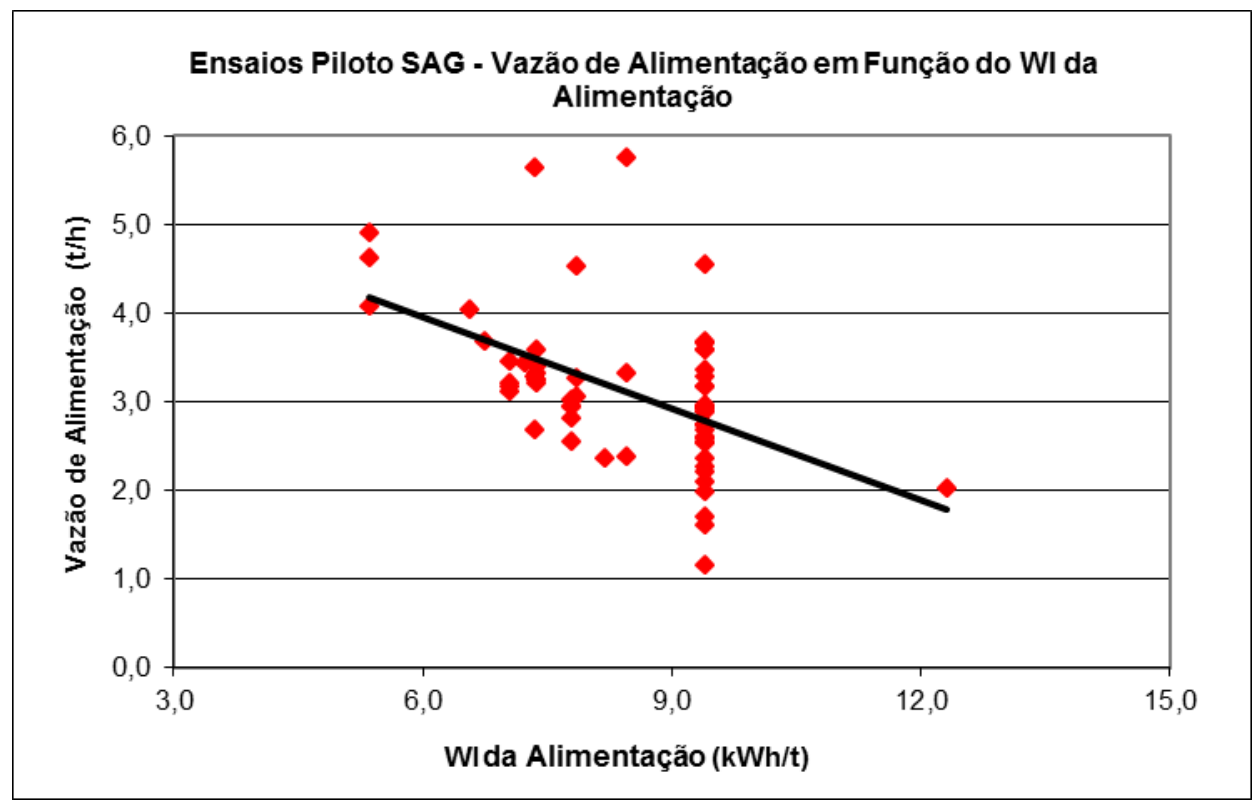

Figura 6.9 - Vazão de alimentação em função do WI da alimentação.

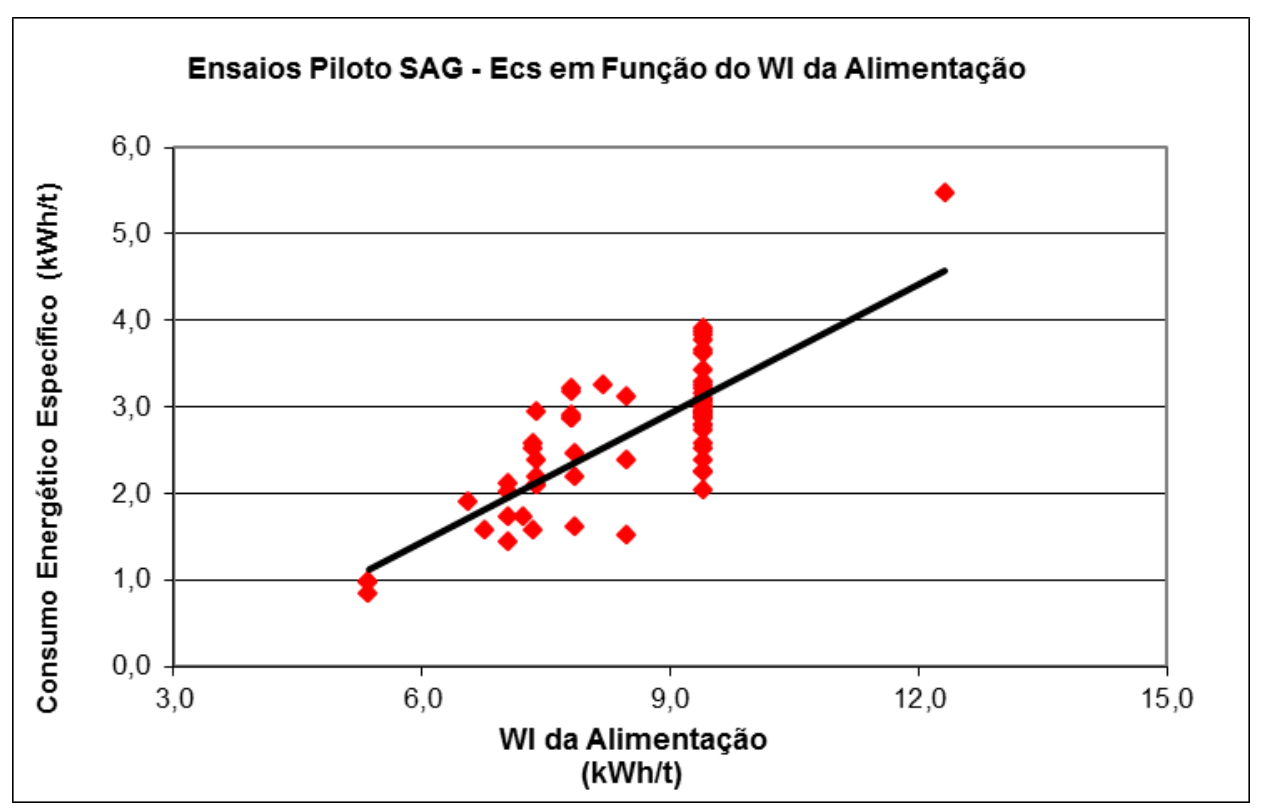

Figura 6.10 - Consumo energético específico em função do WI da alimentação. 
As retas existentes nas duas figuras indicam a tendência de relação entre as variáveis selecionadas. Não há portanto, intenção de estabelecer correlação entre as variáveis, apenas e tão somente o indicativo de tendência de relação entre estas.

\subsubsection{Efeito da Distribuição da Carga de Bolas}

Para avaliar o efeito da distribuição da carga de bolas no desempenho da moagem foram feitas duas comparações entre ensaios praticados em condições idênticas, à exceção do tipo de distribuição da carga de bolas e do volume ocupado por esta. Esses quatro ensaios (C.1, C.2, C.13 e C.16) foram conduzidos com alimentações de $100 \%$ de minério TIPO 4, grelhas de 6,35 mm parcialmente abertas, $75 \%$ de sólidos na descarga do moinho SAG, carga total equivalente a $25 \%$ do volume interno do moinho e velocidade de rotação do moinho de $78,5 \% \mathrm{n}_{\mathrm{c}}$.

A Figura 6.11 mostra o efeito da distribuição de bolas sobre o valor do tamanho de transferência, $\mathrm{T}_{80}$.

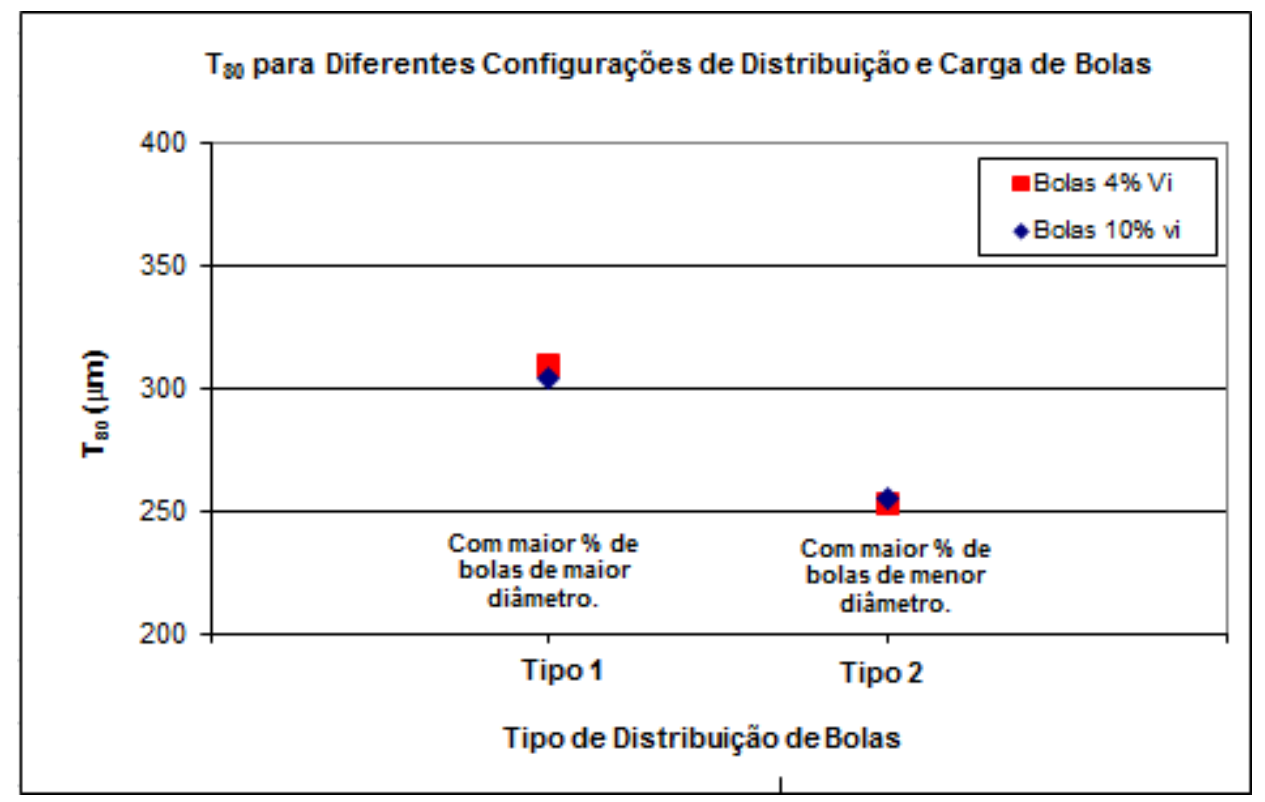

Figura 6.11 - Resultados de $T_{80}$, em $\mu \mathrm{m}$, para diferentes distribuições e volumes de carga de bolas.

Observa-se que a distribuição de bolas tipo 2, com maior proporção de bolas de menor diâmetro, apresentou um produto de moagem SAG mais fino. Nota-se que, para a distribuição tipo $10 \mathrm{~T}_{80}$ foi de $300 \mu \mathrm{m}$, enquanto a distribuição tipo 2 apresentou $\mathrm{T}_{80}$ de $250 \mu \mathrm{m}$. 


\section{Efeito da Carga de Bolas}

Os dados de consumo energético específico para as três cargas de bolas (4\%, 10\% e $14-15 \%$ do volume interno do moinho SAG) utilizadas nos 69 ensaios foram lançados no gráfico constante da Figura 6.12.

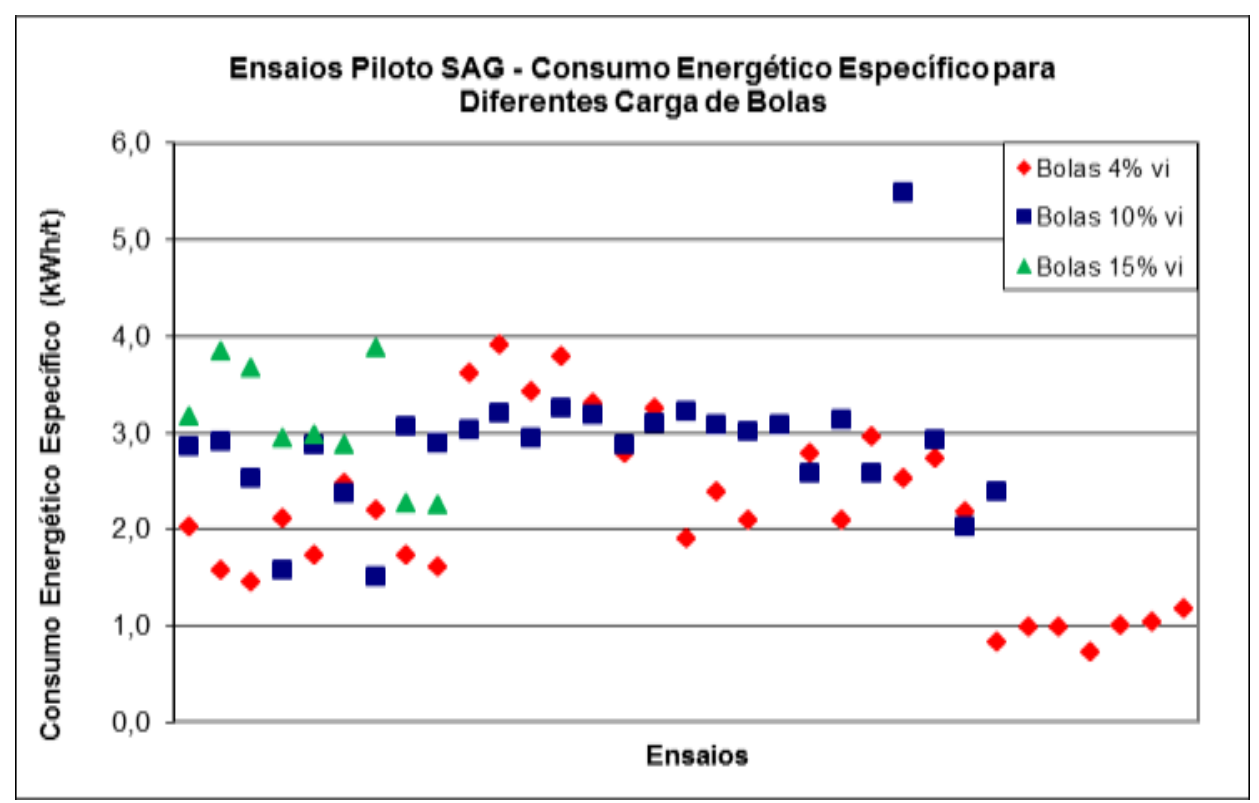

Figura 6.12 - Consumo energético específico para diferentes cargas de bolas.

A Tabela 6.18 apresenta as médias obtidas para o consumo energético específico de cada um dos três grupos investigados. A despeito das diferenças existentes nas demais variáveis dos ensaios, que inviabilizam uma comparação direta, observa-se tendência de aumento do consumo energético específico em função do aumento da carga de bolas.

Tabela 6.18 - Valores médios do consumo energético específico para diferentes cargas de bolas.

\begin{tabular}{ccc}
\hline $\begin{array}{c}\text { Carga de Bolas } \\
(\% \text { vi) }\end{array}$ & $\begin{array}{c}\text { N. Ensaios Na } \\
\text { Condição }\end{array}$ & $\begin{array}{c}\text { Média de Consumo } \\
\text { Energético } \\
\text { Específico (kWh/t) }\end{array}$ \\
\hline 4 & 33 & 2,17 \\
10 & 27 & 2,87 \\
$14-15$ & 9 & 3,09 \\
\hline
\end{tabular}




\subsection{Efeito da Velocidade de Rotação do Moinho SAG}

Os ensaios conduzidos na campanha piloto incluíram a operação do moinho SAG sob diferentes velocidades de rotação, correspondentes a $70 \%$ e $78,5 \%$ da velocidade crítica. As Figuras 6.13 e 6.14 apresentam os dados de consumo energético específico e do tamanho de transferência - $T_{80}$, para as duas velocidades de rotação utilizadas. As informações referentes aos ensaios com circuito de moagem SAG aberto foram excluídas.

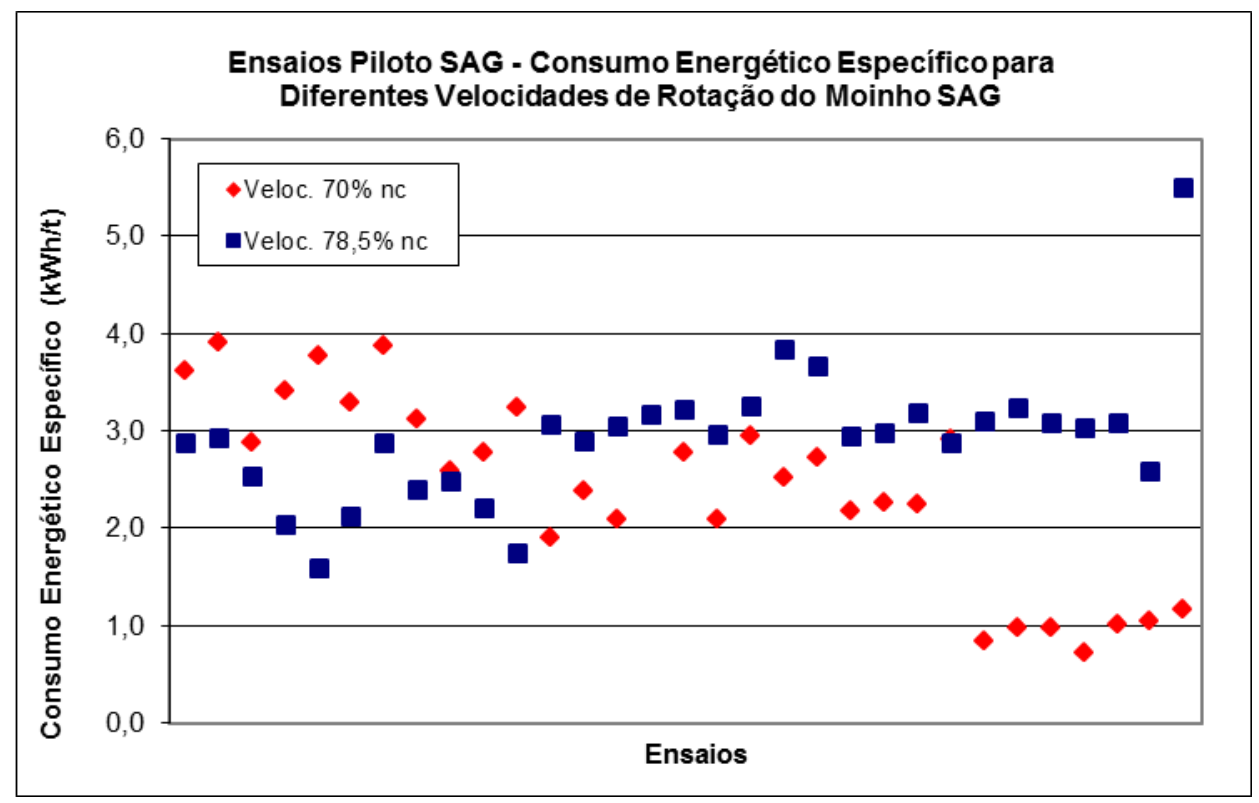

Figura 6.13 - Consumo energético específico para diferentes velocidades de rotação.

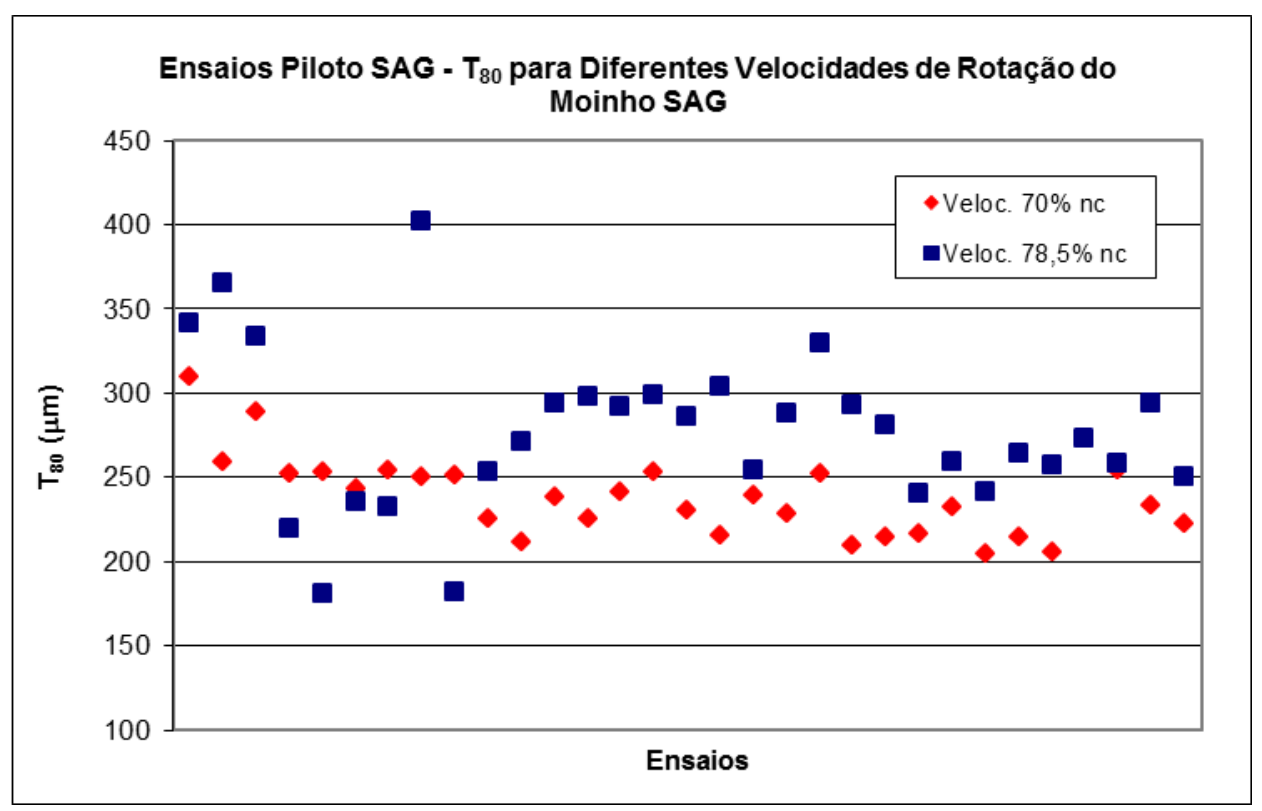

Figura $6.14-T_{80}$ para diferentes velocidades de rotação. 
Os dados médios obtidos para todos os ensaios, com exceção daqueles relacionados aos circuitos em configuração aberta, constam da Tabela 6.19. Observa-se tendência de aumento do consumo energético específico e da granulação do produto de moagem com o aumento da velocidade de rotação, e diminuição do valor médio do WI para o produto de moagem SAG. O consumo médio energético específico para a condição de velocidade do moinho SAG de $70 \%$ $\mathrm{n}_{\mathrm{c}}$ foi de $2,41 \mathrm{kWh} / \mathrm{t}$, enquanto que na velocidade de $78,5 \% \mathrm{n}_{\mathrm{c}}$ o consumo médio de energia foi de $2,91 \mathrm{kWh} / \mathrm{t}$.

Tabela 6.19 - Valores médios de parâmetros de moagem em função da velocidade de rotação.

\begin{tabular}{ccccc}
\hline $\begin{array}{c}\text { Velocidade de } \\
\text { Rotação do Moinho } \\
\text { SAG }\left(\% \mathbf{n}_{\mathbf{c}}\right)\end{array}$ & $\begin{array}{c}\text { N. Ensaios Nesta } \\
\text { Condição }\end{array}$ & $\begin{array}{c}\text { Média Consumo } \\
\text { Energético } \\
\text { Específico }(\mathbf{k W h} / \mathbf{t})\end{array}$ & Média $\mathbf{T}_{\mathbf{8 0}}(\boldsymbol{\mu m})$ & $\begin{array}{c}\text { WI Produto de } \\
\text { Moagem SAG (kWh/t) }\end{array}$ \\
\hline 70,0 & 31 & 2,41 & 238 & 13,28 \\
78,5 & 31 & 2,91 & 277 & 12,25 \\
\hline
\end{tabular}

* Desconsiderando os ensaios em circuito aberto

Quando se avalia o efeito do parâmetro velocidade de rotação fixando as demais condições operacionais, observa-se um comportamento diferente. Como exemplo, a Figura 6.15 apresenta um comparativo entre os ensaios C.4 e C.18, que foram realizados com $100 \%$ de minério TIPO 4, grelhas com aberturas de $6,35 \mathrm{~mm}$ parcialmente abertas, $75 \%$ de sólidos na descarga do moinho SAG, carga de bolas de $15 \%$ volume interno (vi), distribuição de bolas tipo 2 e circuito fechado. Nesse exemplo, a velocidade de rotação do moinho SAG foi a única variável alterada, pois o ensaio C.4 foi realizado em $78,5 \% \mathrm{n}_{\mathrm{c}}$, e o ensaio C.18, em $70,0 \% \mathrm{n}_{\mathrm{c}}$. Nesse caso, o aumento da velocidade de rotação do moinho SAG resultou em um produto com granulação mais grossa, porém com diminuição do consumo energético específico. 


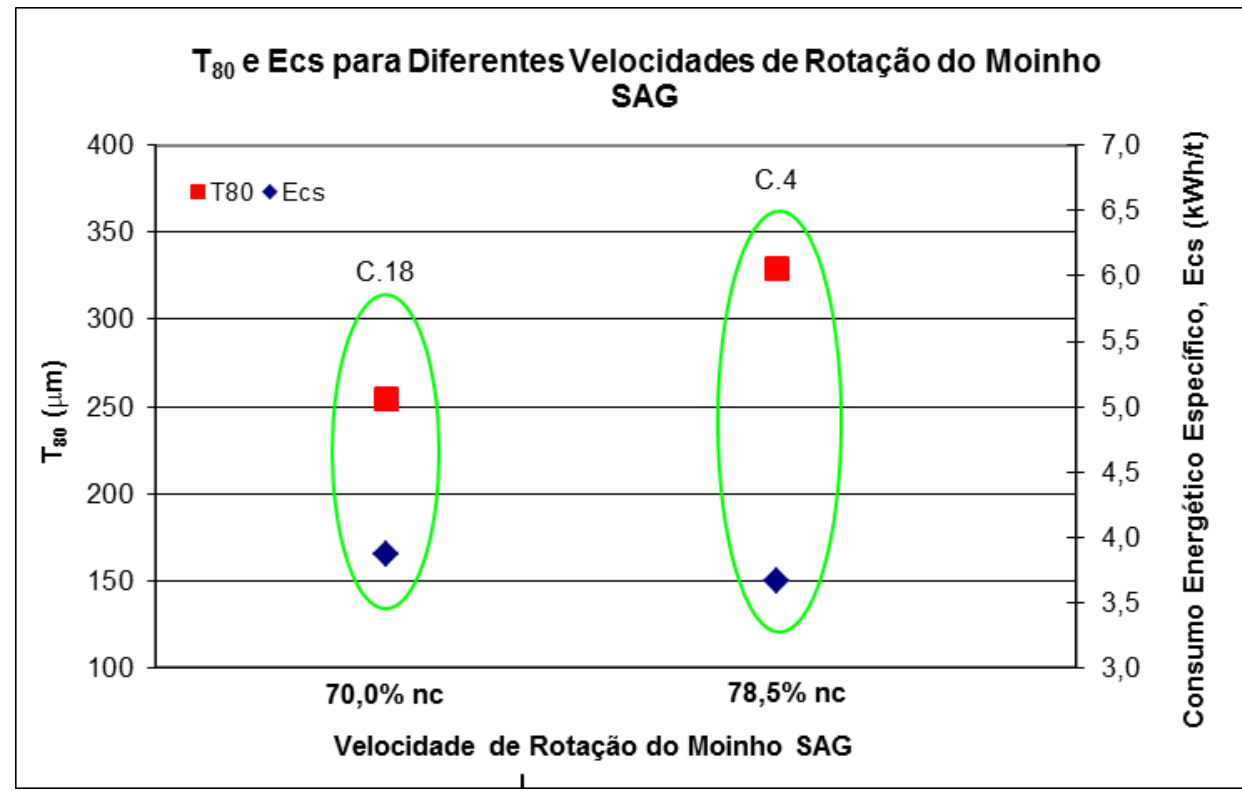

Figura 6.15 - Consumo energético específico e $T_{80}$ para diferentes velocidades de rotação.

\subsection{Efeito do Tipo de Circuito de Moagem SAG}

O circuito de moagem SAG foi operado nas configurações aberta e fechada, mediante 0 uso de uma peneira vibratória com abertura de $1 \mathrm{~mm}$. A comparação entre os testes B1.2 (circuito fechado) e B1.3 (circuito aberto), mostrada na Figura 6.16 , foi um dos casos avaliados. O produto gerado nos ensaios de configuração aberta apresentou granulometria mais grosseira- maior $T_{80}$ - que o produto obtido no ensaio similar, porém com configuração aberta. $O$ consumo energético específico foi menor na configuração aberta do que no circuito fechado.

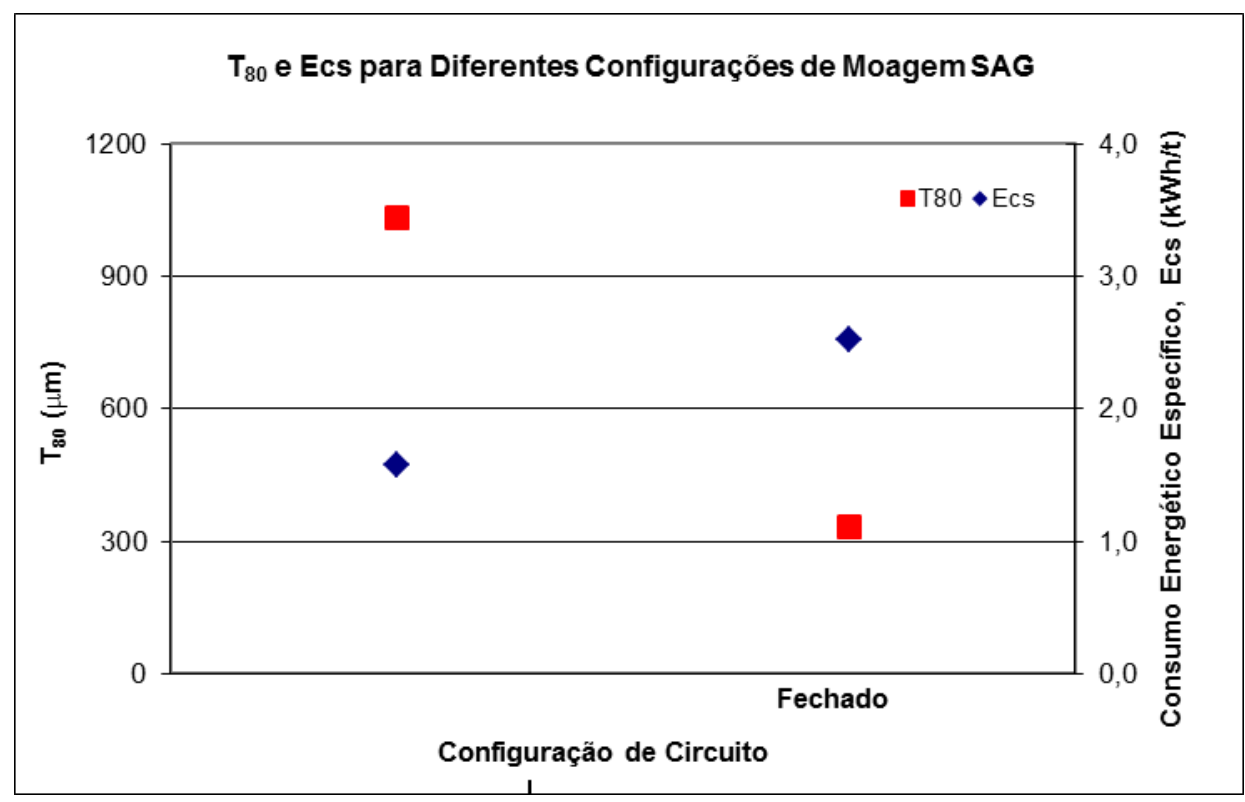

Figura 6.16 - Consumo energético específico e $T_{80}$ para diferentes configurações de circuito. 
A Tabela 6.20 apresenta um resumo dos valores médios obtidos nas configurações de circuito - aberto e fechado - utilizadas. Os resultados médios apresentaram o mesmo comportamento observado no exemplo anterior, ou seja, menores consumos energéticos específicos e produto com granulação mais grossa para os ensaios realizados em circuito aberto do que naqueles operados em configuração fechada.

Tabela 6.20 - Valores médios de parâmetros de moagem em função da configuração do circuito.

\begin{tabular}{ccccc}
\hline $\begin{array}{c}\text { Configuração do } \\
\text { Circuito de } \\
\text { Moagem SAG }\end{array}$ & $\begin{array}{c}\text { N. Ensaios Nesta } \\
\text { Condição }\end{array}$ & $\begin{array}{c}\text { Média Consumo } \\
\text { Energético } \\
\text { Específico }(\mathbf{k W h} / \mathbf{t})\end{array}$ & Média $\mathbf{T}_{\mathbf{8 0}}(\boldsymbol{\mu} \mathbf{m})$ & $\begin{array}{c}\text { WI Produto de } \\
\text { Moagem SAG (kWh/t) }\end{array}$ \\
\hline Aberto & 7 & 1,75 & 792 & 9,60 \\
Fechado & 62 & 2,66 & 257 & 12,61 \\
\hline
\end{tabular}




\section{CONCLUSÕES}

O método de estudo utilizado - caracterização de amostras de minérios e ensaios em escala piloto - avaliou os parâmetros de moagem e concentração metalúrgica, em especial da moagem semiautógena, para o minério da RPM, objeto deste trabalho.

A instalação da planta piloto - compreendendo diferentes tipos de equipamentos de cominuição e concentração metalúrgica - na mina da Rio Paracatu Mineração permitiu a realização de 69 ensaios com diferentes minérios e blendagens destes. Durante os 11 meses de duração da campanha piloto foram consumidas cerca de 1400t de minério. As variáveis de processo de moagem SAG investigadas em diferentes níveis foram: configuração do circuito, percentual de sólidos na descarga do moinho, volume da carga total, volume e tipo de distribuição da carga de bolas, configuração e tamanho de abertura das grelhas do moinho e velocidade de rotação deste.

Tendo em vista o grande volume de informações geradas na campanha piloto, somente algumas das correlações obtidas foram contempladas na seção anterior, referente aos resultados e à discussão destes. Os parâmetros de moagem SAG avaliados foram taxa de processamento e tamanho da alimentação, granulometria do produto de moagem, carga circulante, potência, Bond Work Index para produto de moagem e consumo energético específico. $O$ método de análise empregado considerou o efeito dos diferentes tipos de variáveis - e de seus níveis sobre os parâmetros de moagem semiautógena.

Um dos pontos de relevância deste trabalho foi a utilização do conjunto de informações obtidas nos 69 ensaios realizados para o dimensionamento do circuito de expansão da RPM. A capacidade de processamento foi aumentada - de $18 \mathrm{Mtpa}$ para $61 \mathrm{Mtpa}$ - com a instalação de uma nova planta de beneficiamento, apta a processar $41 \mathrm{Mtpa}$ de ROM. O projeto aprovado contou com investimentos da ordem de US $\$ 470$ milhões e considerou, entre outros equipamentos, um moinho SAG de grandes dimensões ( $38 \times 22$ pés).

O estudo dos tipos de minérios e das blendagens destes demonstrou que o aumento da tenacidade da alimentação - indicada pelo BWI - promove aumento do 
consumo energético específico. Elevação do consumo energético específico também foi verificada quando do aumento do grau de enchimento do moinho SAG com bolas, outra variável do processo.

A distribuição da carga de bolas foi outro aspecto investigado. Distribuições com maior proporção de bolas de menor diâmetro contribuíram para a obtenção de um produto com granulação mais fina, ou seja, menor $\mathrm{T}_{80}$. Já na avaliação relativa ao efeito da velocidade de rotação do moinho sobre a qualidade do produto de moagem SAG, constatou-se que velocidades maiores ocasionam elevação do tamanho de transferência.

No que concerne ao tipo de circuito, observou-se menor consumo energético específico nos ensaios conduzidos em circuito aberto do que naqueles realizados em configuração fechada. Além disso, o circuito aberto contribui para o aumento da vazão de alimentação do circuito e da granulometria do produto de moagem SAG.

Todas as fases - planejamento, execução e tratamento dos dados - da campanha de ensaios em planta piloto em foram objeto de processos de auditorias internas e externas, que demonstraram a robustez do método e a consistência dos resultados obtidos. Pontos falhos - e/ou não cobertos pelo programa - capazes de comprometer a confiabilidade das informações geradas não foram registrados.

O estudo dos parâmetros e das variáveis de moagem SAG, associado às informações de caracterização das amostras e às investigações metalúrgicas, permitiu o conhecimento das características do minério da RPM e do comportamento deste frente às diferentes condições de processo. O método mostrou-se essencial às etapas de dimensionamento e projeto de circuitos de moagem autógena. Portanto, o método apresentado é uma ferramenta adequada e validada, capaz de suportar os trabalhos de modelagem e simulação e, assim, pode ser utilizado na elaboração de projetos de instalação e otimização de circuitos de cominuição,.

Durante a operação inicial, a capacidade do circuito de moagem SAG introduzido na RPM era de $3.200 \mathrm{t} / \mathrm{h}$. A partir de ajustes operacionais - alteração da área aberta da grelha de $2 \frac{1}{2}$ " para 11/2", e aumento da carga de bolas de $10 \%$ para $12 \%$-, a capacidade desse circuito chegou a $5.400 \mathrm{t} / \mathrm{h}$, valor superior àquele estabelecido no projeto, de 5.087t/h (SANTOS Jr. et al., 2011). 


\section{REFERÊNCIAS}

ASSOCIAÇÃO BRASILEIRA DE NORMAS TÉCNCIAS (ABNT). MB-3253: Moinho de bolas: determinação do índice de trabalho. Rio de Janeiro. 1990.

BERALDO, J. L. Moagem de minérios em moinhos tubulares. São Paulo: Edgard Blücher, 1987. $143 p$.

BERGERMAN, M. G. Modelagem e simulação do circuito de moagem de sossego. 2009. 207 p. Dissertação (Mestrado) - Escola Politécnica, Universidade de São Paulo, São Paulo, 2009.

BOND, F. C. The third theory of comminution. Transactions of the American Institute of Mining and Metallurgical Engineers, New York, v. 193, p. 484-494, 1952.

CARVALHO, M. C. A. M. Paracatu: o morro do ouro. São Paulo: Gráfica Círculo do Livro, 1992. (Projeto Patrocinado pela Rio Paracatu Mineração S/A).

CHAVES, A. P.; PERES, A. E. C. Moagem. In: CHAVES, A. P. Teoria e prática do tratamento de minérios. 3aㅡ ed. São Paulo: Signus, 2006. v. 3, cap. 1. p. 571-652.

CHIEREGATI, A. C.; DELBONI JR., H. Novo método de caracterização tecnológica para cominuição de minérios. In: ENCONTRO NACIONAL DE TRATAMENTO DE MINÉRIOS E METALURGIA EXTRATIVA, 19., 2002, Recife. Anais... Recife: UFPE, 2002. v. 1, p. 49-54.

DELBONI Jr., H. A load-interactive model of autogenous and semi-autogenous mills. 1999. 415 p. Thesis (Philosophy Doctor) - University of Queensland, Brisbane, 1999.

DELBONI Jr., H. Cominuição. Parte II: tecnologia mineral. In: FERNANDES, F. R. C. et al. Tendências tecnológicas Brasil 2015: geociência e tecnologia. Rio de Janeiro: CETEM/MCT, 2007. cap. 2, p. 103-131.

DELBONI Jr, H.; MORREL, S. A load-interactive model for predicting the performance of autogenous and semi-autogenous mills. KONA, Osaka, v. 20, n. 1, p. 120-35, 2002.

DOLL, A.; BARRATT, D. Grinding: Why so Many Test? In: $43^{\text {rd }}$ ANNUAL MEETING OF CANADIAN MINERAL PROCESSORS, 2011, Ontario. Proceedings... Ontario, 2011. $19 \mathrm{p}$.

FERREIRA, A. B. H. Aurélio século XXI: o dicionário da língua portuguesa. 3. ed. rev. e ampl. Rio de Janeiro: Nova Fronteira, 1999. 
FOGGIATTO, B. Previsão de desempenho do circuito de moagem de Carajás. 2009. 230 p. Dissertação (Mestrado) - Escola Politécnica, Universidade de São Paulo, São Paulo, 2009.

GY, P. Sampling for analytical purposes. Translate by A. G. Royle. West Sussex: John Wiley \& Sons, 1998.

HANSON, W. Paracatu mine technical report. Paracatu, 2005. 189 p. (Relatório Interno Kinross Gold Corporation).

HEISKANEN, K.; KALAPUDAS, R.; KOIVISTOINEN, P. Impact of SAG and autogenous grinding on flotation results. In: INTERNATIONAL AUTOGENOUS AND SEMIAUTOGENOUS GRINDING TECHNOLOGY, 2001, Vancouver. Proceedings... Vancouver: IASAGT, 2001. v. 1, p. 1314-1325.

HENLEY, K. J. Ore-dressing mineralogy: a review of techniques applications and recent developments. In: INTERNATIONAL CONGRESS ON APPLIED MINERALOGY, 1981, Johannesburg. Proceedings... Johannesburg: Geological Society of South Africa, 1983. p. 175-200.

JANKOVIC, A.; DUNDAR, H.; METHA, R. Relationships between comminution energy and product size for a magnetite ore. Journal of Southern African Institute of Mining and Metallurgy, v. 110, p. 141-146, 2010.

JONES Jr., S. M. Autogenous and semiautogenous mills 2005 update. In: INTERNATIONAL AUTOGENOUS AND SEMIAUTOGENOUS GRINDING TECHNOLOGY, 2006, Vancouver. Proceedings... Vancouver: IASAGT, 2006. p. |398-1425.

JONES Jr., S. M.; FRESKO, M. Autogenous and SemiAutogenous Mills 2010 Update. In: INTERNATIONAL AUTOGENOUS AND SEMIAUTOGENOUS GRINDING TECHNOLOGY, 2011, Vancouver. Proceedings... Vancouver: IASAGT, 2011.

LUZ, A. B.; SAMPAIO, J. A.; ALMEIDA, S. L. M. Tratamento de minérios. 4ª ed. Rio de Janeiro: CETEM-MCT, 2004. 867 p.

MÖLLER, J.C. et al. The geology and characterization of mineral resources of Morro do Ouro. In: PINTO, C. P.; MARTINS-NETO, M. A. Bacia do São Francisco: geologia e recursos naturais. Belo Horizonte: SBG, 2001. p. 199-234.

MONTE, M. B. M. et al. Rio Paracatu. Mineração. Ouro. In: SAMPAIO, J. A.; LUZ, A. B.; LINS, F. F. Usinas de beneficiamento de minérios do Brasil. Rio de Janeiro: CETEM/MCT, 2001. p. 317-325. 
NAPIER-MUNN, T. J. et al. Mineral comminution circuits: their operation and optimisation. Indooroopilly: Julius Kruttschnitt Mineral Research Centre / University of Queensland. Austrália. 1999. 413 p.

NASCHENVENG, A. C. Modelagem e simulação do circuito de moagem da Ultrafértil. São Paulo, 2003. 101 p. Dissertação (Mestrado) - Escola Politécnica, Universidade de São Paulo, São Paulo, 2003.

PEREIRA, P. E. C. Comparação entre diferentes testes de moagem sag para determinação da energia unitária para cominuição de minérios sulfetados de cobre. 2004. 811 p. Dissertação (Mestrado) - Escola de Engenharia, Universidade Federal de Minas Gerais, Belo Horizonte, 2004.

ROLFSSON, R. Selecting crushing and grinding equipment. In: WORLD MINING, 1983. p. 45-47.

ROWLAND Jr., C. A.; KJOS, D. M. Rod and ball mills. In: MULAR, A. L.; BHAPPU, R. B. (co-editors). Mineral processing plant design symposium. $2^{\text {nd }}$ ed. New York: Society of Mining Engineers (SME), 1980. p. 239-278.

SAMPAIO, J. A. et al. Estudo de moagem semi-autógena (SAG) com minério de ouro da RPM. In: ENCONTRO NACIONAL DE TRATAMENTO DE MINÉRIOS E METALURGIA EXTRATIVA, 19., 2002, Recife. Anais... Recife: UFPE, 2002. v. 1, p. 140-145.

SANT'AGOSTINO, L. M.; KAHN, H. Metodologia para caracterização tecnológica de matérias-primas minerais. Boletim Técnico da Escola Politécnica da USP. Departamento de Engenharia de Minas. São Paulo: EPUSP, 1997. 29 p.

SANTOS Jr. et al. Kinross Paracatu: start-up and otimization of SAG circuit. In: INTERNATIONAL AUTOGENOUS AND SEMIAUTOGENOUS GRINDING TECHNOLOGY, 2011, Vancouver. Proceedings... Vancouver: IASAGT, 2011. 7 p.

SEMINÁRIO MOLY-COP. Operación y control molienda sag - moly-cop chile. Salvador, jul. 2006.

SILVA, E. C.; MAIA, G. S.; DELBONI Jr.,, H. Dimensionando circuitos de moagem SAG: a experiência do centro de desenvolvimento mineral da CVRD. In: ENCONTRO NACIONAL DE TRATAMENTO DE MINÉRIOS E METALURGIA EXTRATIVA, 19., 2002, Recife. Anais... Recife: UFPE, 2002. v. 1, p. 168-174.

STARKEY, J.; DOBBY, G. Application of the Minnovex SAG power index at five Canadian SAG plants. In: INTERNATIONAL AUTOGENOUS AND SEMIAUTOGENOUS GRINDING TECHNOLOGY, 1996, Vancouver. Proceedings... Vancouver: IASAGT, 1996. p. I345-I360. 
VERRET, F. O.; CHIASSON, G.; MCKEN, A. SAG mill testing: an overview of the procedures available to characterize ore grindability. In: INTERNATIONAL AUTOGENOUS AND SEMIAUTOGENOUS GRINDING TECHNOLOGY, 2011, Vancouver. Proceedings... Vancouver: IASAGT, 2011. 14 p. 


\section{APÊNDICE A - Utilização do Freio Prony}

O sistema de medição da potência no eixo de saída do redutor do moinho piloto, Freio Prony, utiliza um dinamômetro ou uma balança com capacidade mínima de $100 \mathrm{~kg}$ e precisão de pelo menos 0,5 kg. A Figura A.1 apresenta, de forma esquemática, o dispositivo do Freio de Prony. $O$ ângulo $(\phi)$ deve ser reto e medido no ponto de içamento (Ponto I), isto é, entre o Braço do Freio de Prony e a reta que passa pelo centro do dinamômetro, ou entre o braço e a haste que se apoia sobre a balança. Nos ensaios realizados neste trabalho não foi utilizada balança, e sim um dinamômetro.

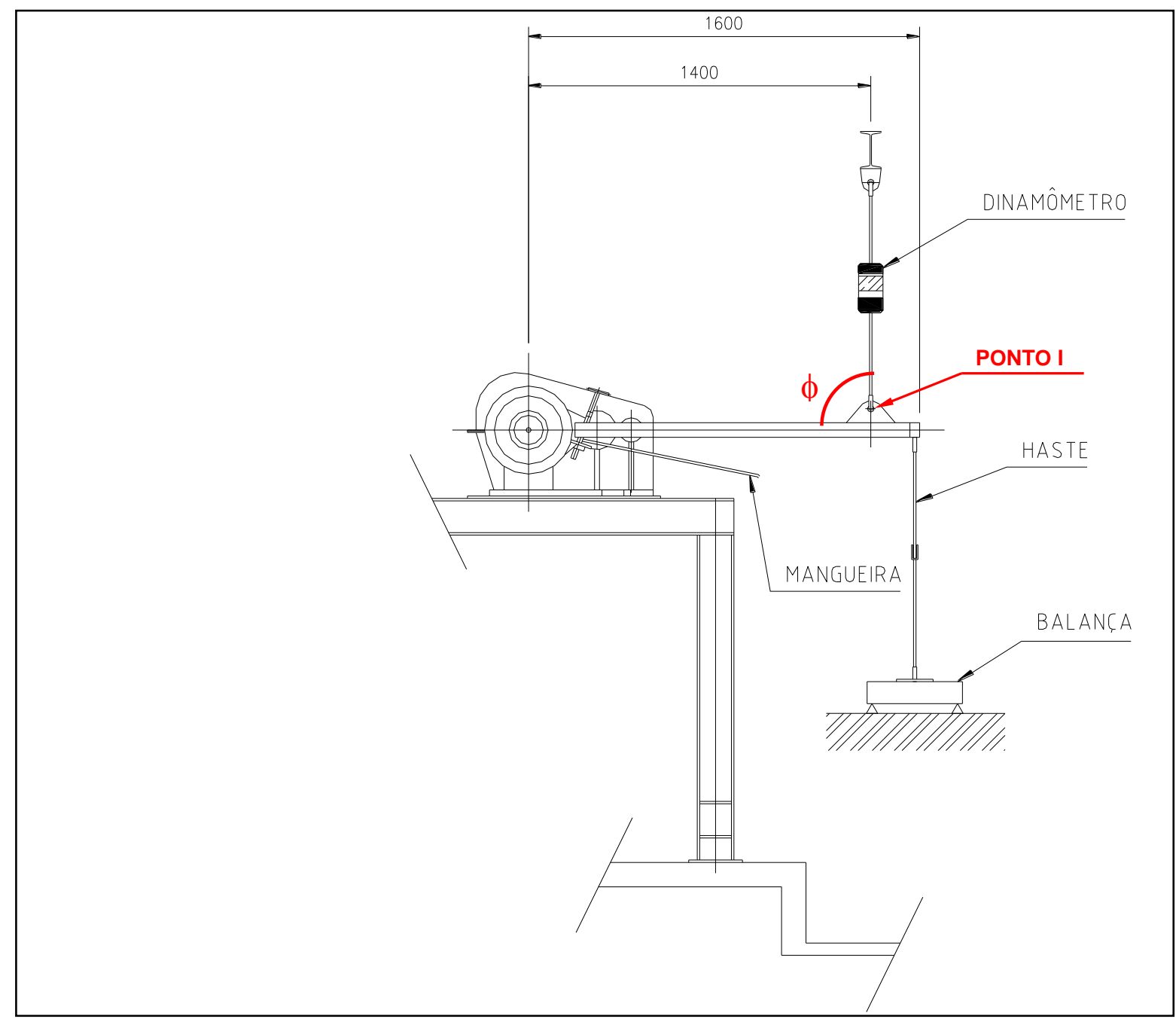

Figura A.1 - Esquema do dispositivo de Prony Brake utilizado. 
Na prática, é aconselhável efetuar as medidas de peso com valores abaixo de $60 \mathrm{~kg}$. Nesta condição, além dos resultados serem confiáveis, existe maior segurança na operação do equipamento. É recomendável utilizar o dinamômetro ao invés da balança, já que esta última favorece, em muito, a ocorrência de acidentes. A refrigeração contínua da cinta do Freio de Prony elimina o aquecimento deste. Nos ensaios deste estudo conduzidos com o Freio de Prony, a refrigeração do sistema foi mantida com o auxílio de uma mangueira que fornecia um fluxo contínuo de água fria.

Para calcular o valor da potência no eixo de saída do redutor - potência bruta -, utiliza-se a seguinte fórmula:

$$
P_{B H P}=\frac{2 \pi L R o t W}{33.000}
$$

onde:

$\mathrm{L}=\quad$ comprimento do braço do Freio de Prony, em pés;

Rot $=$ rotação por minuto, medida antes do ensaio, na ponta do eixo de saída do redutor, em rpm;

$\mathrm{W}=\quad$ peso medido no dinamômetro ou em balança, em Ib;

$\mathrm{P}_{\mathrm{BHP}}=$ potência bruta, em hp

Nos ensaios de moagem AG/SAG em unidade piloto, as medidas da demanda de potência são feitas em kW. Já os valores dos pesos, obtidos por meio de dinamômetro ou de balança, são expressos em kg e não em libra. Logo, torna-se necessária a adequação do sistema de unidades para a obtenção direta do valor da potência bruta em kW, com o auxílio da Equação 22. Dessa forma, deve-se considerar:

$\mathrm{W}=2,205 \mathrm{P}$;

$\mathrm{L}=5934$ pés (comprimento do braço do Freio de Prony utilizado de 1,4 m); onde:

$\mathrm{P}=\quad$ peso obtido no dinamômetro ou balança, em $\mathrm{kg}$.

Considerando esses valores na Equação 22, temos:

$$
\begin{aligned}
& P_{B H P}=\left(\frac{2 \times 3,1416 \times 4,5934 \times 2,205}{33.000}\right) \times \operatorname{Rot} \times P \\
& P_{B H P}=1,9285 \times 10^{-3} \times \operatorname{Rot} \times P
\end{aligned}
$$


Existe um valor de rotação no eixo de saída do redutor para cada polia do motor. Assim, para uma velocidade do moinho de $78,5 \%$ da velocidade crítica, a rotação do redutor foi de 92,4 rpm, correspondente à polia de $251 \mathrm{~mm}$ de diâmetro do motor. Neste caso, a potência bruta era calculada pelas seguintes equações.

$$
\begin{aligned}
& P_{B H P}=1,9285 \times 10^{-3} \times 92,4 \times P \\
& P_{B H P}=0,1782 \times P
\end{aligned}
$$

O valor da potência bruta, $\mathrm{P}_{\mathrm{BHP}}$, está expresso em hp. A conversão deste valor para kW deve considerar que 1,0 hp corresponde a 0,7457 kW. Logo, a potência bruta em kW ( $\left.P_{B}\right)$, é dada pelas seguintes equações:

$$
\begin{aligned}
& P_{B}=0,1782 \times 0,7457 \times P \\
& P_{B}=0,1329 \times P
\end{aligned}
$$

Para a velocidade correspondente a $70,0 \%$ da velocidade crítica, as Equações 25 a 28 foram modificadas, considerando-se a rotação do redutor obtida para essa condição $(80,4$ rpm). 


\section{APÊNDICE B - Exemplo: Informações Referentes a um Ensaio Piloto}

Teste de Operação da Planta Piloto SAG - Teste N. C.1

\begin{tabular}{clcc}
\hline \hline Amostra: & Tipo $4(2314 / 764-100 \%)$ & Data: & $19 / 07 / 2002$ \\
Período de Teste: & 08:42 - 15:14 (6,53 h) & \\
Arquivo: & dep_pcs / Admin. / Diret. Pessoais / ALS / SAG / Testes / Testescomplementares / TesteSAG-C.1xls & \\
\hline \hline
\end{tabular}

1 - Objetivo:

Este teste objetivou otimizar as condições de moagem SAG, em circuito fechado, do minério Tipo 4

(100\% 2314/764), com uma alimentação tendo a distribuição igual a do minério tipo 5.

Neste teste foi utilizado o knelson, tratando o undersize da peneira (produto de moagem).

A operação do knelson foi conduzida com tempos de descarga de $30 \mathrm{~min}$.

\section{2 - Condições Operacionais Gerais:}

\begin{tabular}{|c|c|c|}
\hline Variáveis & Unidades & Valores \\
\hline Velocidade Crítica $^{\text {\% }}$ & $\% \mathrm{vc}$ & 78,5 \\
\hline Abertura da Grelha $^{*}$ & $\mathrm{~mm}$ & 6 \\
\hline Abertura Trommel & $\mathrm{mm}$ & 6 \\
\hline Abertura da Peneira & $\mathrm{mm}$ & 1 \\
\hline Sólido Desc. Moinho & $\%$ sólidos & 75 \\
\hline Carga Total & $\%$ vi & 25 \\
\hline Tipo de Circuito & - & Fechado \\
\hline
\end{tabular}

${ }^{*}$ Grelhas parcialmente abertas.

3 - Carga de Bolas:

Distribuição de Bolas: Tipo 1

\begin{tabular}{|c|c|c|c|c|}
\hline $\begin{array}{c}\text { Diâmetro } \\
\text { Bola }(\mathbf{m m})\end{array}$ & $\begin{array}{c}\text { Distribuição } \\
(\mathbf{\%})\end{array}$ & $\begin{array}{c}\text { Peso Teórico } \\
(\mathbf{K g})\end{array}$ & $\begin{array}{c}\text { Peso Medido } \\
\mathbf{( K g )}\end{array}$ & $\begin{array}{c}\text { N. Bolas } \\
\text { Utilizadas }\end{array}$ \\
\hline 125 & 45 & 264,22 & 262,1 & 34 \\
\hline 100 & 35 & 205,66 & 207,2 & 53 \\
\hline 75 (Usadas de 88 mm) & 20 & 117,52 & 118 & 45 \\
\hline \multicolumn{2}{r|}{ Total } & $\mathbf{5 8 7 , 4}$ & $\mathbf{5 8 7 , 3}$ & $\mathbf{1 3 2}$ \\
\hline
\end{tabular}

Volume da Carga de Bolas Utilizada: $10 \%$ do Volume Interno do Moinho.

\section{4 - Distribuição do Material Alimentado:}

4.1 - Minério Tipo 4 (2314/764):

\begin{tabular}{|c|c|c|c|c|}
\hline Tamanho $(\mathbf{m m})$ & Peso Ret. (Kg) & Retido (\%) & Pass. Acum (\%) & Retido (\%) \\
\hline 200 & 0 & $\mathbf{0}$ & 100 & $\mathbf{0}$ \\
\hline 153 & 5000 & $\mathbf{1 2 , 6 5}$ & 87,35 & $\mathbf{6 , 4 9}$ \\
\hline 75 & 5900 & $\mathbf{1 4 , 9 3}$ & 72,43 & $\mathbf{1 2 , 7 9}$ \\
\hline 31 & 7540 & $\mathbf{1 9 , 0 7}$ & 53,35 & $\mathbf{1 7 , 1}$ \\
\hline$<31$ & 21090 & $\mathbf{5 3 , 3 5}$ & 0,00 & $\mathbf{6 3 , 6 2}$ \\
\hline Total & $\mathbf{3 9 5 3 0}$ & $\mathbf{1 0 0}$ & & \\
\hline
\end{tabular}




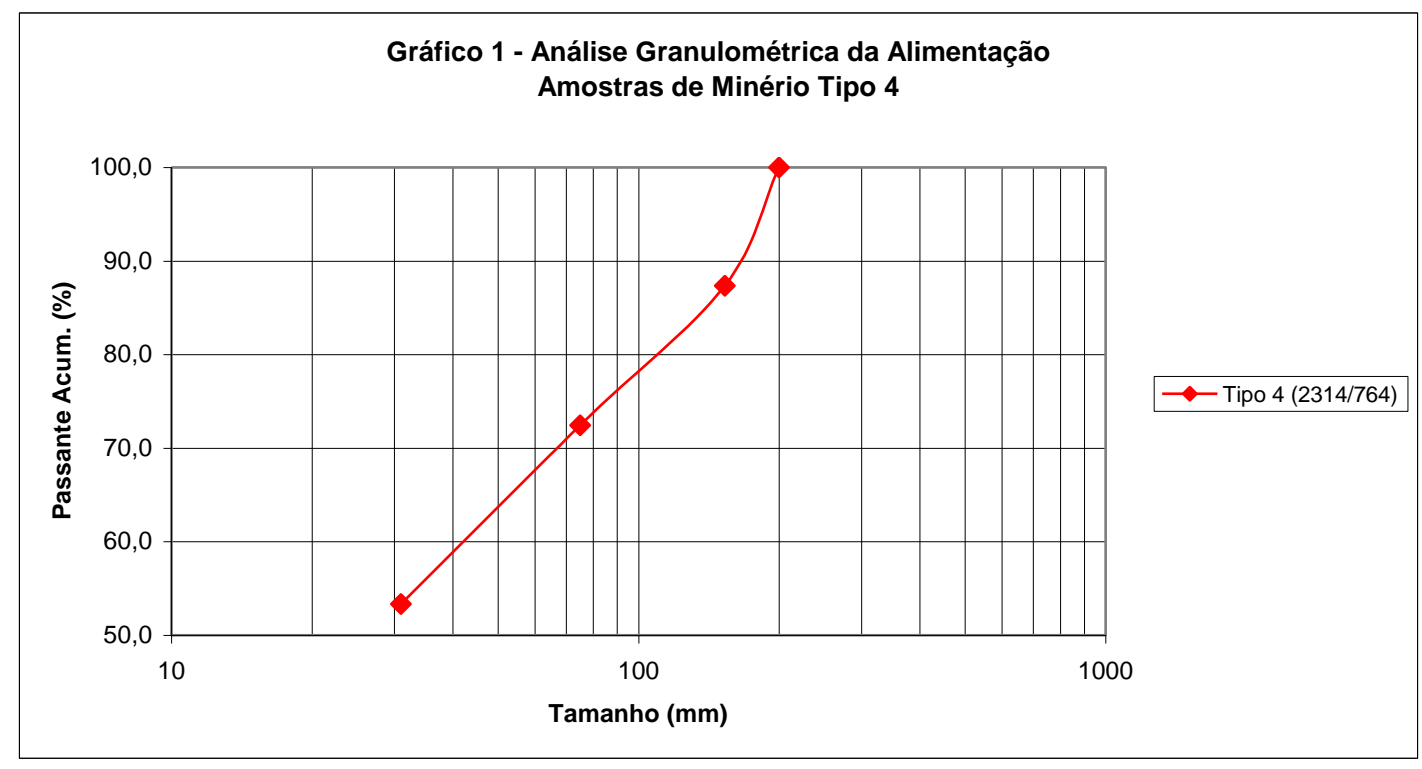

Para a amostra minério Tipo 4 tem-se um $F 80$ estimado de $114,6 \mathrm{~mm}$.

\section{5 - Dados do Teste (Alimentação, Peso Material no Moinho, Potência):}

\begin{tabular}{|l|c|}
\hline \multicolumn{1}{|c|}{ Variáveis } & Valores \\
\hline Minério Alimentado no Teste (ton) & 18,099 \\
\hline Tempo Efetivo de Teste (h) & 6,13 \\
\hline Alimentação Média Durante Amostragem (t/h) & 2,921 \\
\hline Leitura Média Célula Carga Durante Amostragem (ton) & 1,41 \\
\hline Valor Médio de Potência para Período de Amostragem (kW) & 17,43 \\
\hline Tempo Efetivo de Amostragem (h) & 2,00 \\
\hline Potência Bruta (kW) & 16,13 \\
\hline Potência sem Carga (kW) & 5,20 \\
\hline Potência Líquida $(\mathrm{kW})$ & 10,93 \\
\hline Potência Específica $(\mathrm{kWh} / \mathrm{t})$ & 3,74 \\
\hline
\end{tabular}

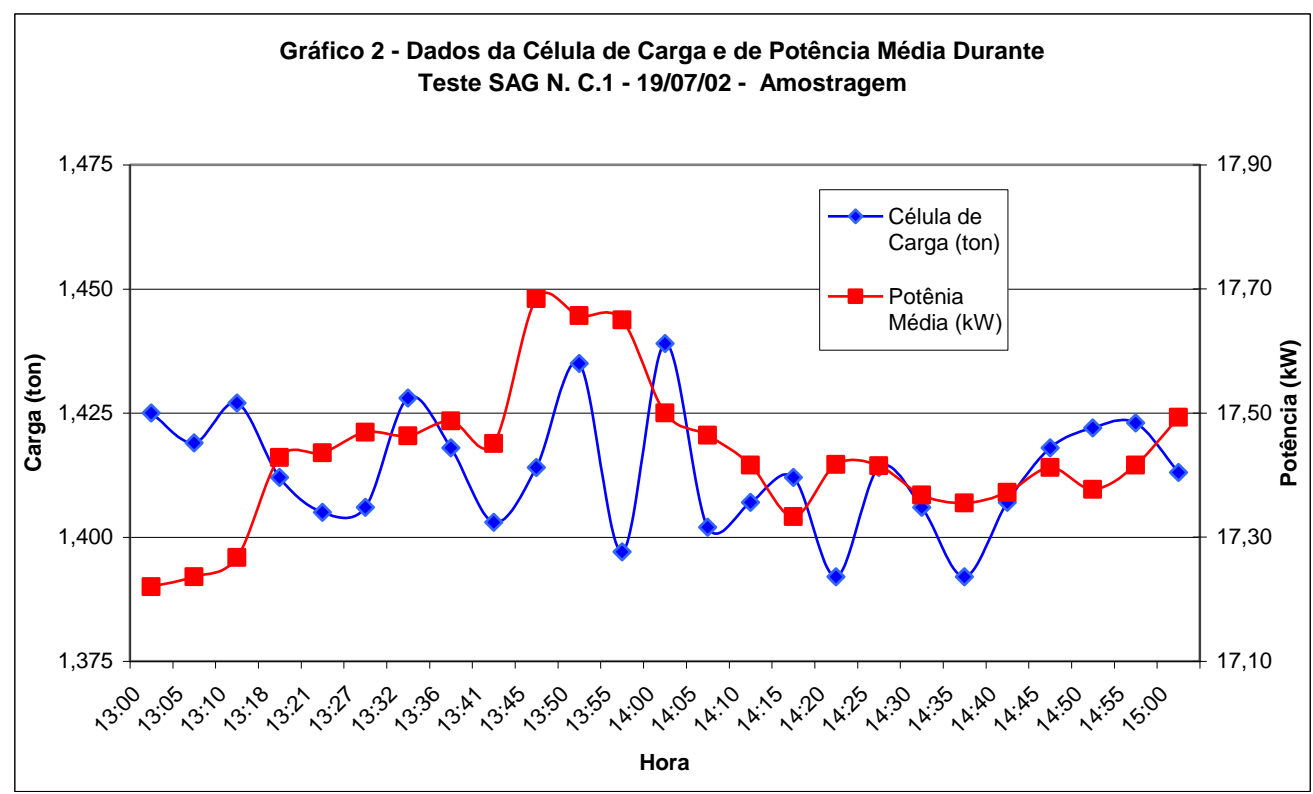




\section{6 - Granulometria das Amostras Coletadas:}

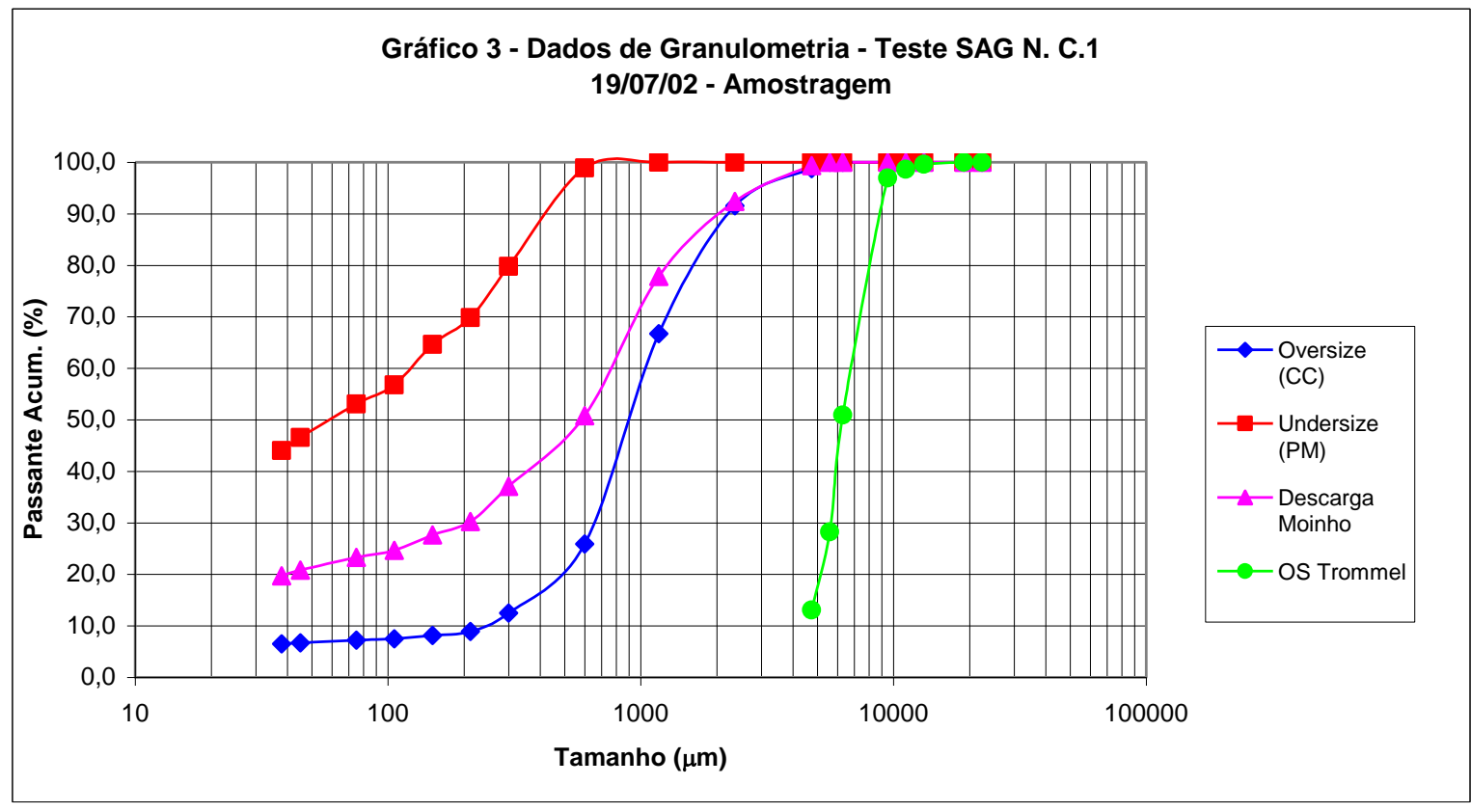

P80 Amostra $303,9 \mu \mathrm{m}$

7 - Percentagem de Sólido das Amostras Coletadas:

\begin{tabular}{|c|c|c|c|}
\hline Amostra & Oversize (CC) & Undersizer (PM) & Descar. Moinho \\
\hline Amostragem & 65,39 & 36,99 & 69,19 \\
\hline
\end{tabular}

\section{8 - Vazões de Sólidos (Kg/h):}

\begin{tabular}{|c|c|c|c|c|}
\hline Amostra & OS do Trommel & CC (Oversize Pen.) & CC Total & \% CC / Alim \\
\hline Amostragem & 156,63 & 5984,64 & 6141,27 & 210,23 \\
\hline
\end{tabular}

\section{9 - Work Index:}

\section{1 - Minério Tipo 4 (2314/764):}

\begin{tabular}{|c|c|c|c|c|}
\hline Amostra & Wi (kWh/t) & $\mathrm{F} 80(\mu \mathrm{m})$ & $\mathbf{P} 80(\mu \mathrm{m})$ & \\
\hline Minério < 200; > 153 & 11,46 & 1940 & 73,48 & \multirow{3}{*}{$\begin{array}{c}\text { Wi Minério } \\
\text { Composto Frações } \\
9,40\end{array}$} \\
\hline Minério < 153; > 75 & 11,05 & 1814 & 75,95 & \\
\hline Minério < 75; > 31 & 8,6 & 2090 & 62,68 & \\
\hline Minério < 31 & 8,73 & 1640 & 70,56 & \\
\hline
\end{tabular}

\section{2 - Produto de Moagem:}

\begin{tabular}{|c|c|c|c|}
\hline Amostra & Wi $(\mathbf{k W h} / \mathbf{t})$ & $\mathbf{F 8 0}(\mu \mathrm{m})$ & $\mathbf{P 8 0}(\mu \mathrm{m})$ \\
\hline Produto Final & 12,73 & 393,8 & 76,65 \\
\hline
\end{tabular}




\section{APÊNDICE C - Sumário dos Resultados Obtidos nos Ensaios Piloto}
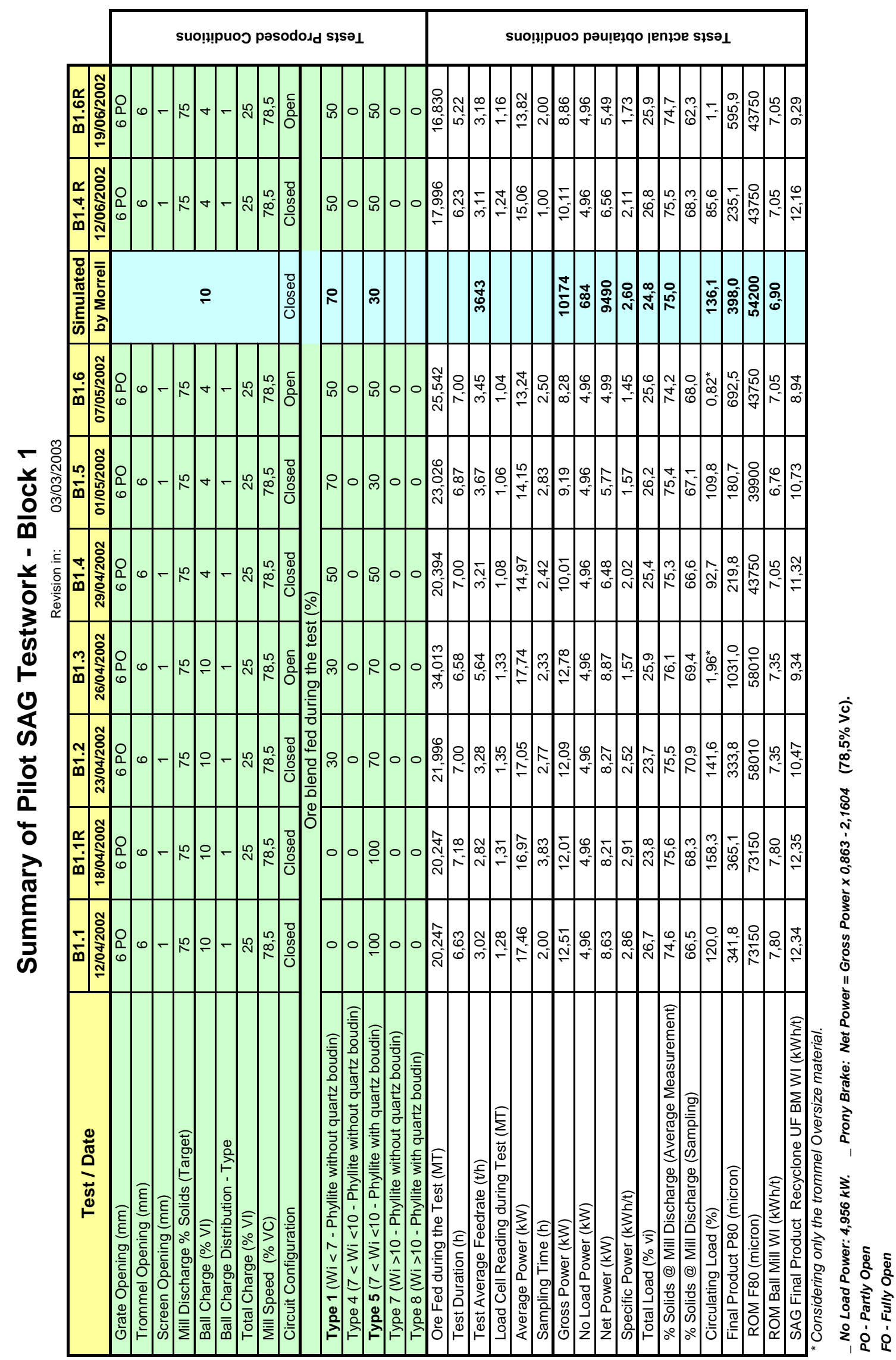
๑. ลุำ

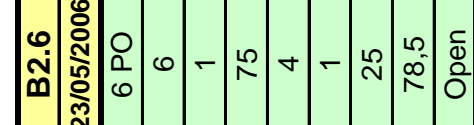

ठำ

స్

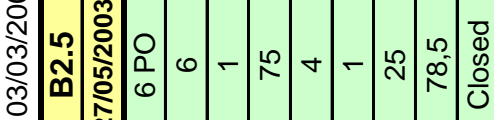

N

$\frac{y}{0}$

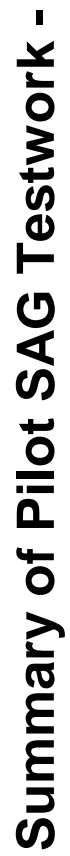

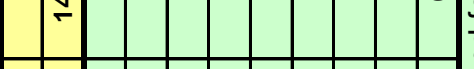
$\oplus$ ㅇํㅇ

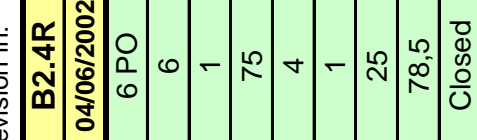

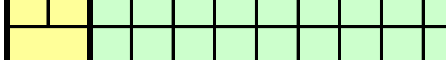

in ○ is i

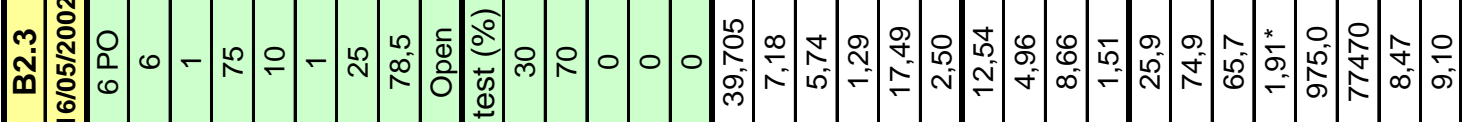

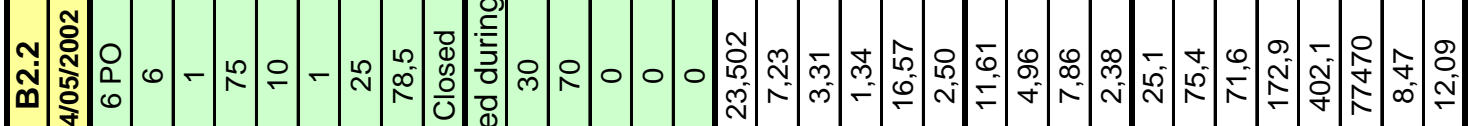

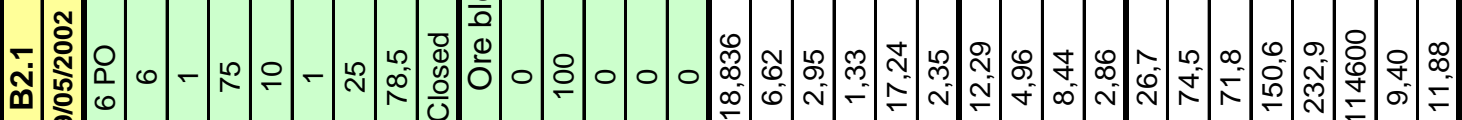
要

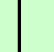

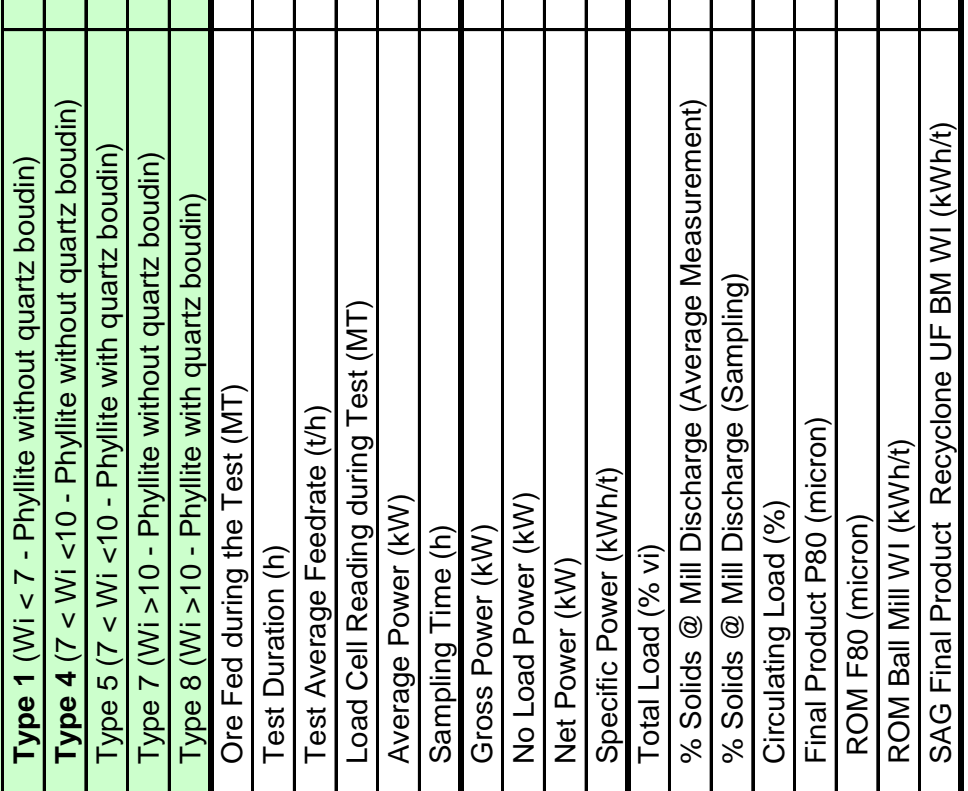




\section{Summary of Pilot SAG Testwork - Block 4}

\begin{tabular}{|c|c|c|c|c|}
\hline \multirow{3}{*}{ Test / Date } & & & evision in: & \multirow[t]{3}{*}{ 03/03/2003 } \\
\hline & B4.1 & B4.2 & B4.3 & \\
\hline & $25 / 06 / 2002$ & $27 / 06 / 2002$ & 03/07/2002 & \\
\hline Grate Opening $(\mathrm{mm})$ & $6 \mathrm{PO}$ & $6 \mathrm{PO}$ & $6 \mathrm{PO}$ & \multirow{15}{*}{ 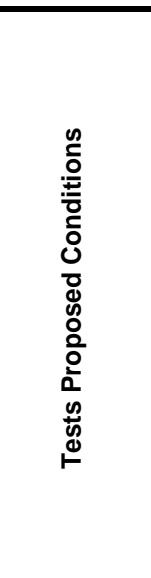 } \\
\hline Trommel Opening $(\mathrm{mm})$ & 6 & 6 & 6 & \\
\hline Screen Opening $(\mathrm{mm})$ & 1 & 1 & 1 & \\
\hline Mill Discharge \% Solids (Target) & 75 & 75 & 75 & \\
\hline Ball Charge (\% VI) & 10 & 10 & 10 & \\
\hline Ball Charge Distribution - Type & 1 & 1 & 1 & \\
\hline Total Charge (\% VI) & 25 & 25 & 25 & \\
\hline Mill Speed (\% VC) & 78,5 & 78,5 & 78,5 & \\
\hline Circuit Configuration & Closed & Closed & Closed & \\
\hline \multicolumn{4}{|c|}{ Ore blend fed during the test (\%) } & \\
\hline Type 1 (Wi $<7$ - Phyllite without quartz boudin) & 0 & 0 & 0 & \\
\hline Type 4 ( $7<\mathrm{Wi}<10$ - Phyllite without quartz boudin $)$ & 100 & 100 & 100 & \\
\hline Type 5 ( $7<$ Wi $<10$ - Phyllite with quartz boudin) & 0 & 0 & 0 & \\
\hline Type 7 (Wi >10 - Phyllite without quartz boudin) & 0 & 0 & 0 & \\
\hline Type 8 (Wi >10 - Phyllite with quartz boudin) & 0 & 0 & 0 & \\
\hline Ore Fed during the Test (MT) & 13,630 & 16,659 & 18,078 & \multirow{18}{*}{ 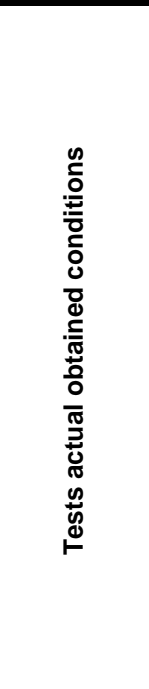 } \\
\hline Test Duration (h) & 4,88 & 5,32 & 5,52 & \\
\hline Test Average Feedrate (t/h) & 2,93 & 3,17 & 2,89 & \\
\hline Load Cell Reading during Test (MT) & 1,42 & 1,38 & 1,43 & \\
\hline Average Power (kW) & 17,82 & 18,06 & 17,59 & \\
\hline Sampling Time $(\mathrm{h})$ & 1,00 & 2,00 & 2,00 & \\
\hline Gross Power (kW) & 12,86 & 13,10 & 12,63 & \\
\hline No Load Power (kW) & 4,96 & 4,96 & 4,96 & \\
\hline Net Power (kW) & 8,94 & 9,15 & 8,74 & \\
\hline Specific Power $(\mathrm{kWh} / \mathrm{t})$ & 3,06 & 2,89 & 3,03 & \\
\hline Total Load (\% vi) & 26,3 & 26,1 & 25,8 & \\
\hline \% Solids @ Mill Discharge (Average Measurement) & 75,5 & 75,8 & 75,1 & \\
\hline \% Solids @ Mill Discharge (Sampling) & 67,2 & 62,4 & 70,9 & \\
\hline Circulating Load (\%) & & 117,4 & 101,3 & \\
\hline Final Product P80 (micron) & 293,7 & 297,9 & 291,5 & \\
\hline ROM F80 (micron) & 114600 & 114600 & 114600 & \\
\hline ROM Ball Mill WI (kWh/t) & 9,40 & 9,40 & 9,40 & \\
\hline SAG Final Product Recyclone UF BM WI (kWh/t) & 11,54 & & 12,46 & \\
\hline
\end{tabular}

_ No Load Power: 4,956 kW. _ Prony Brake: Net Power = Gross Power x 0,863 - 2,1604 (78,5\% Vc).

PO - Partly Open

FO - Fully Open 


\section{Summary of Pilot SAG Testwork - Block 6}

\begin{tabular}{|c|c|c|c|c|}
\hline & & & Revision in: & \multirow[t]{3}{*}{ 03/03/2003 } \\
\hline \multirow{2}{*}{ Test / Date } & B6.1 & B6.2 & & \\
\hline & $01 / 07 / 2002$ & 05/07/2002 & & \\
\hline Grate Opening (mm) & $6 \mathrm{PO}$ & $6 \mathrm{PO}$ & & \multirow{15}{*}{ 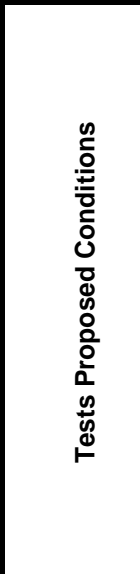 } \\
\hline Trommel Opening (mm) & 6 & 6 & & \\
\hline Screen Opening $(\mathrm{mm})$ & 1 & 1 & & \\
\hline Mill Discharge \% Solids (Target) & 75 & 75 & & \\
\hline Ball Charge (\% VI) & 15 & 10 & & \\
\hline Ball Charge Distribution - Type & 1 & 1 & & \\
\hline Total Charge (\% VI) & 25 & 25 & & \\
\hline Mill Speed (\% VC) & 78,5 & 78,5 & & \\
\hline Circuit Configuration & Closed & Closed & & \\
\hline \multicolumn{4}{|c|}{ Ore blend fed during the test (\%) } & \\
\hline Type 1 (Wi < 7 - Phyllite without quartz boudin) & 0 & 0 & & \\
\hline Type 4 ( $7<\mathrm{Wi}<10$ - Phyllite without quartz boudin) & 100 & 0 & & \\
\hline Type 5 ( $7<\mathrm{Wi}<10$ - Phyllite with quartz boudin) & 0 & 100 & & \\
\hline Type 7 (Wi >10 - Phyllite without quartz boudin) & 0 & 0 & & \\
\hline Type 8 (Wi >10 - Phyllite with quartz boudin) & 0 & 0 & & \\
\hline Ore Fed during the Test (MT) & 19,404 & 17,146 & & \multirow{18}{*}{ 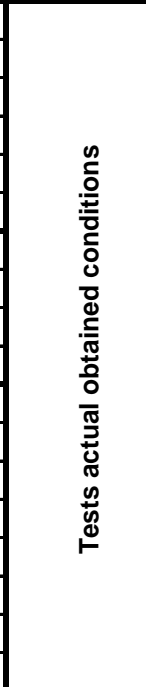 } \\
\hline Test Duration (h) & 6,62 & 6,18 & & \\
\hline Test Average Feedrate ( $t / h)$ & 2,94 & 2,95 & & \\
\hline Load Cell Reading during Test (MT) & 1,73 & 1,73 & & \\
\hline Average Power (kW) & 18,25 & 18,41 & & \\
\hline Sampling Time $(\mathrm{h})$ & 2,00 & 2,00 & & \\
\hline Gross Power $(\mathrm{kW})$ & 13,29 & 13,45 & & \\
\hline No Load Power (kW) & 4,96 & 4,96 & & \\
\hline Net Power (kW) & 9,31 & 9,45 & & \\
\hline Specific Power (kWh/t) & 3,16 & 3,20 & & \\
\hline Total Load (\% vi) & 25,8 & 26,1 & & \\
\hline \% Solids @ Mill Discharge (Average Measurement) & 74,5 & 75,4 & & \\
\hline \% Solids @ Mill Discharge (Sampling) & 68,6 & 67,4 & & \\
\hline Circulating Load (\%) & 279,0 & 213,8 & & \\
\hline Final Product P80 (micron) & 298,6 & 285,9 & & \\
\hline ROM F80 (micron) & 114600 & 73150 & & \\
\hline ROM Ball Mill WI (kWh/t) & 9,40 & 7,80 & & \\
\hline SAG Final Product Recyclone UF BM WI (kWh/t) & 13,18 & 12,87 & & \\
\hline
\end{tabular}

_ No Load Power: 4,956 kW. _ Prony Brake: Net Power = Gross Power x 0,863-2,1604 (78,5\% Vc).

PO - Partly Open

FO - Fully Open 


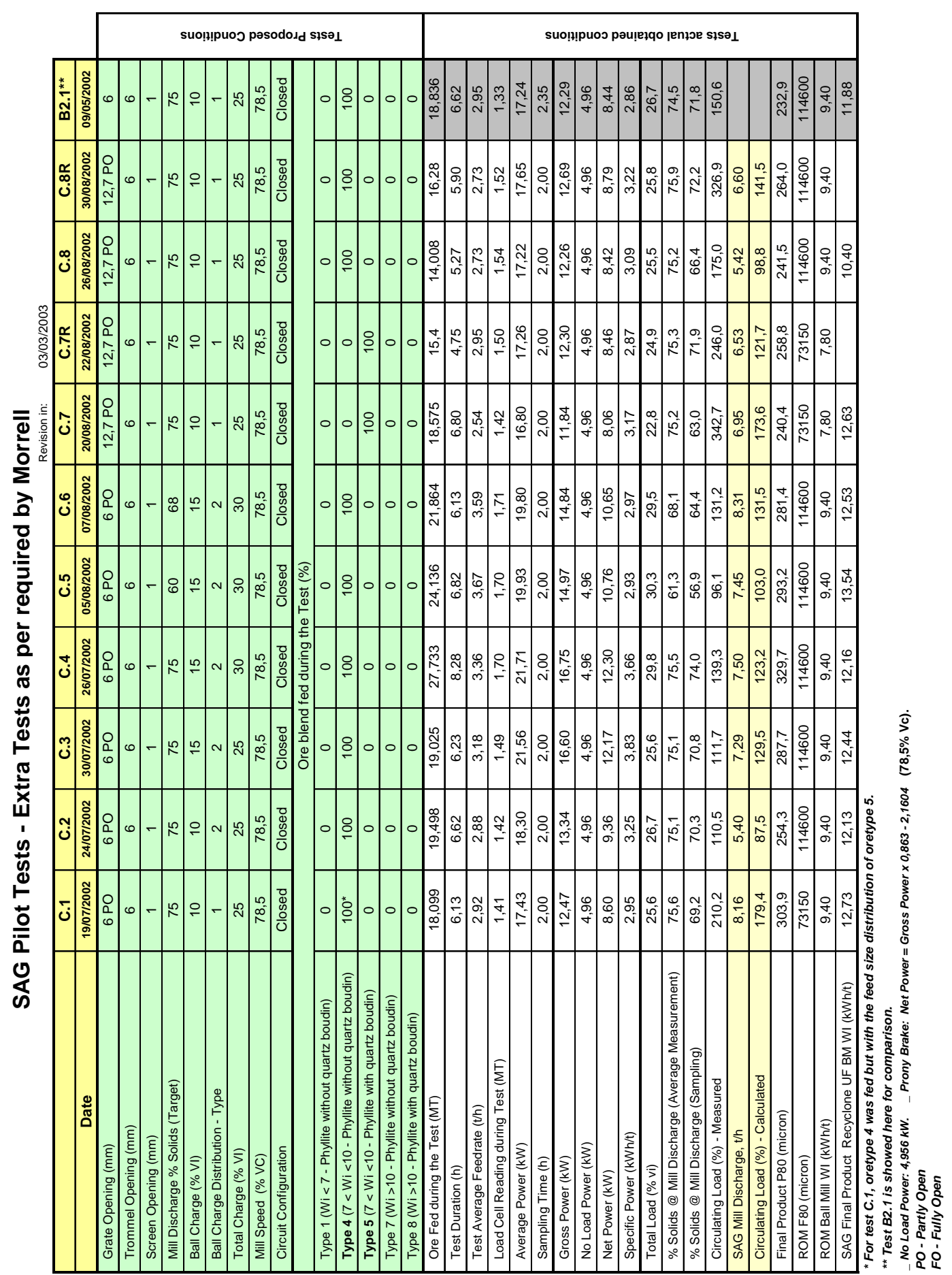




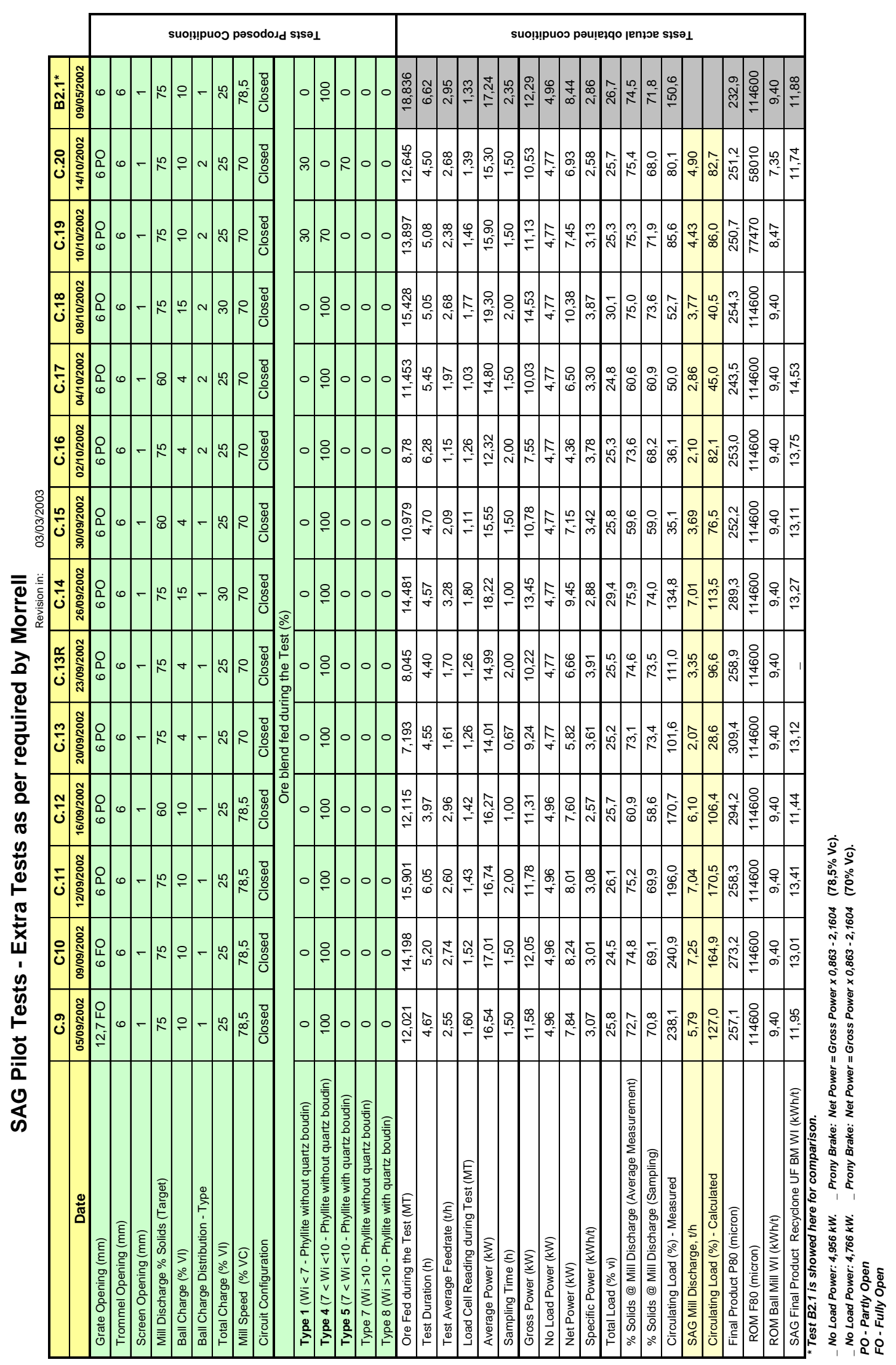




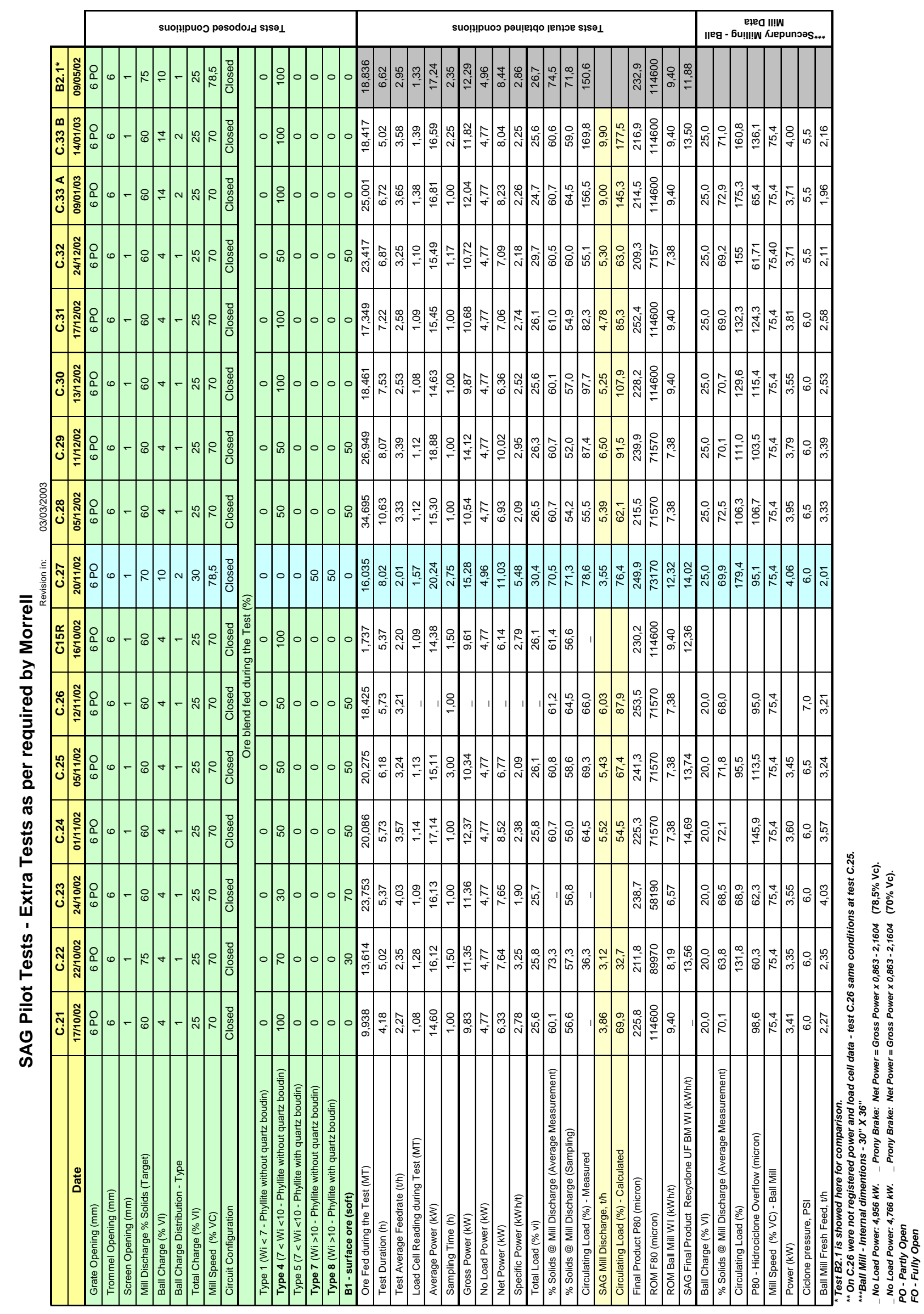


SAG Pilot Tests - Extra Tests as per required by Morrell

\begin{tabular}{|c|c|c|c|c|c|c|c|c|c|c|c|}
\hline & & & & & & & Revision in: & 03/03/2003 & & & \\
\hline Teste & C.33C & C.34A & C.34B & C.35 & C.36 & C.37 & C.38 & C.39 & C.40 & C.41 & \\
\hline Data do Teste & $23 / 01 / 03$ & $17 / 01 / 03$ & $20 / 01 / 03$ & $27 / 01 / 03$ & 29/01/03 & $30 / 01 / 03$ & $05 / 02 / 03$ & $06 / 02 / 03$ & $10 / 02 / 03$ & $11 / 02 / 03$ & \\
\hline Grate Opening $(\mathrm{mm})$ & $6 \mathrm{PO}$ & $6 \mathrm{PO}$ & 6 Po & $6 \mathrm{PO}$ & $6 \mathrm{PO}$ & $6 \mathrm{PO}$ & $6 \mathrm{PO}$ & $6 \mathrm{PO}$ & $6 \mathrm{PO}$ & $6 \mathrm{PO}$ & \multirow{17}{*}{ 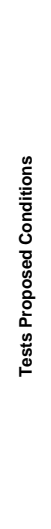 } \\
\hline Trommel Opening (mm) & 6 & 6 & 6 & 6 & 6 & 6 & 6 & 6 & 6 & 6 & \\
\hline Screen Opening $(\mathrm{mm})$ & 1 & 1 & 1 & 1 & 1 & 1 & 1 & 1 & 1 & 1 & \\
\hline Mill Discharge \% Solids (Target) & 60 & 75 & 75 & 60 & 60 & 60 & 60 & 60 & 60 & 60 & \\
\hline Ball Charge $(\% \mathrm{VI})$ & 10 & 10 & 10 & 4 & 4 & 4 & 4 & 4 & 4 & 4 & \\
\hline Ball Charge Distribution - Type & 2 & 2 & 2 & 2 & 2 & 2 & 2 & 2 & 2 & 2 & \\
\hline Total Charge $(\% \mathrm{VI})$ & 25 & 25 & 25 & 25 & 25 & 25 & 25 & 25 & 25 & 25 & \\
\hline Mill Speed (\% VC) & 70 & 70 & 70 & 70 & 70 & 70 & 70 & 70 & 70 & 70 & \\
\hline Circuit Configuration & Closed & Open & Open & Closed & Closed & Closed & Closed & Closed & Closed & Closed & \\
\hline Type 1 (Wi < 7 - Phyllite without quartz boudin) & 0 & 0 & 0 & 0 & 0 & 0 & 0 & 0 & 0 & 0 & \\
\hline Type $4(7<$ Wi $<10$ - Phyllite without quartz boudin $)$ & 100 & 100 & 100 & 0 & 0 & 0 & 0 & 0 & 0 & 0 & \\
\hline Type $5(7<$ Wi $<10$ - Phyllite with quartz boudin) & 0 & 0 & 0 & 0 & 0 & 0 & 0 & 0 & 0 & 0 & \\
\hline B1 - surface ore (soft) & 0 & 0 & 0 & 100 & 100 & 100 & 0 & 0 & 0 & 0 & \\
\hline Type 7 (Wi >10 - Phyllite without quartz boudin) & 0 & 0 & 0 & 0 & 0 & 0 & 0 & 0 & 0 & 0 & \\
\hline Type 8 (Wi >10 - Phyllite with quartz boudin) & 0 & 0 & 0 & 0 & 0 & 0 & 0 & 0 & 0 & 0 & \\
\hline $7401109 \mathrm{C}$ & 0 & 0 & 0 & 0 & 0 & 0 & 100 & 0 & 0 & 0 & \\
\hline $7401109 \mathrm{~A}$ & 0 & 0 & 0 & 0 & 0 & 0 & 0 & 100 & 100 & 100 & \\
\hline Ore Fed during the Test (MT) & 31,051 & 18,417 & 15,659 & 26,228 & 25,465 & 20,184 & 27,675 & 31,914 & 14,893 & 21,631 & \multirow{20}{*}{ 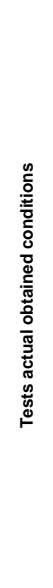 } \\
\hline Test Duration (h) & 10,58 & 4,00 & 5,25 & 5,98 & 5,57 & 5,15 & 6,57 & 7,77 & 3,87 & 5,52 & \\
\hline Test Average Feedrate $(t / h)$ & 2,94 & 4,54 & 2,36 & 4,61 & 4,90 & 4,06 & 4,46 & 4,30 & 3,80 & 3,97 & \\
\hline Load Cell Reading during Test (MT) & 1,17 & 1,23 & 1,24 & 1,04 & 1,03 & 1,04 & 1,05 & 1,03 & 1,05 & 1,02 & \\
\hline Average Power (kW) & 17,19 & 17,95 & 13,78 & 11,73 & 12,83 & 11,89 & 11,03 & 12,29 & 11,85 & 12,66 & \\
\hline Sampling Time (h) & 4,50 & 1,00 & 1,75 & 2,00 & 1,00 & 1,00 & 3,00 & 3,00 & 1,50 & 1,50 & \\
\hline Gross Power $(\mathrm{kW})$ & 12,42 & 13,18 & 9,01 & 6,96 & 8,06 & 7,12 & 6,26 & 7,52 & 7,08 & 7,89 & \\
\hline No Load Power (kW) & 4,77 & 4,77 & 4,77 & 4,77 & 4,77 & 4,77 & 4,77 & 4,77 & 4,77 & 4,77 & \\
\hline Net Power (kW) & 8,56 & 9,22 & 5,62 & 3,85 & 4,80 & 3,99 & 3,25 & 4,33 & 3,95 & 4,65 & \\
\hline Specific Power (kWh/t) & 2,92 & 2,03 & 2,38 & 0,83 & 0,98 & 0,98 & 0,73 & 1,01 & 1,04 & 1,17 & \\
\hline Total Load (\% vi) & 25,5 & 26,8 & 27,4 & 25,7 & 26,0 & 25,9 & 25,2 & 25,5 & 25,6 & 26,9 & \\
\hline \% Solids @ Mill Discharge (Average Measurement) & 60,8 & 60,5 & 74,4 & 60,8 & 60,5 & 60,5 & 60,5 & 60,5 & 61,4 & 60,5 & \\
\hline \% Solids@ @ill Discharge (Sampling) & 58,0 & _- & 69,3 & 63,7 & 62,1 & 61,5 & & 57,4 & & 63,2 & \\
\hline Circulating Load (\%) - Measured & 130,2 & _- & 1,1 & 127,4 & 89,9 & 109,0 & 95,7 & 98,1 & & & \\
\hline \multicolumn{11}{|l|}{ SAG Mill Discharge, $t / h$} & \\
\hline \multicolumn{11}{|l|}{ Circulating Load (\%) - Calculated } & \\
\hline Final Product P80 (micron) & 232,7 & & 655,9 & 204,3 & 214,9 & 206,1 & & 254,3 & 233,4 & 222,3 & \\
\hline ROM F80 (micron) & 114600 & 114600 & 114600 & 23880 & 23880 & 23880 & & & & & \\
\hline ROM Ball Mill WI $(\mathrm{kWh} / \mathrm{t})$ & 9,40 & 9,40 & 9,40 & 5,36 & 5,36 & 5,36 & & & & & \\
\hline SAG Final Product Recyclone UF BM WI (kWh/t) & 14,98 & 11,80 & & 10,63 & 10,49 & & & 15,75 & & & \\
\hline Ball Charge $(\% \mathrm{VI})$ & 30,0 & & 30,0 & 30,0 & 30,0 & 30,0 & & & & & \multirow{8}{*}{ 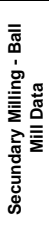 } \\
\hline \% Solids @ Mill Discharge (Average Measurement) & 66,0 & & 65,5 & 66,6 & 67,5 & 68,8 & & & & & \\
\hline Circulating Load (\%) & 215,1 & & 165,5 & 63,0 & 102,3 & 151,5 & & & & & \\
\hline P80 - Hidrociclone Overflow (micron) & 124,2 & & 58,5 & 58,7 & 44,8 & 52,4 & & & & & \\
\hline Mill Speed (\% VC) - Ball Mill & 75,4 & & 75,4 & 75,4 & 75,4 & 75,4 & & & & & \\
\hline Power $(\mathrm{kW})$ & 4,67 & & 4,34 & 4,51 & 4,24 & 4,51 & & & & & \\
\hline Ciclone pressure, PSI & 5,5 & & 5,5 & 3 & 6 & 6 & & & & & \\
\hline Ball Mill Fresh Feed, $t / h$ & 1,73 & & 1,75 & 2,09 & 3,10 & 2,21 & & & & & \\
\hline
\end{tabular}

No Load Power: 4,766 kW. _ Prony Brake: Net Power $=$ Gross Power $x$ 0,863 - 2,1604 (70\% Vc).

PO - Partly Open
FO - Fully Open 